\title{
Guidelines
}

\section{Interventional Techniques: Evidence-based Practice Guidelines in the Management of Chronic Spinal Pain}

Mark V. Boswell, MD, PhD, Andrea M. Trescot, MD, Sukdeb Datta, MD, David M. Schultz, MD, Hans C. Hansen, MD, Salahadin Abdi, MD, PhD, Nalini Sehgal, MD, Rinoo V. Shah, MD, Vijay Singh, MD, Ramsin M. Benyamin, MD, Vikram B. Patel, MD, Ricardo M. Buenaventura, MD, James D. Colson, MD, Harold J. Cordner, MD, Richard S. Epter, MD, Joseph F. Jasper, MD, Elmer E. Dunbar, MD, Sairam L. Atluri, MD, Richard C. Bowman, MD, PhD, Timothy R. Deer, MD, John R. Swicegood, MD, Peter S. Staats, MD, Howard S. Smith, MD, PhD, Allen W. Burton, MD, David S. Kloth, MD, James Giordano, PhD, and Laxmaiah Manchikanti, MD

Background: The evidence-based practice guidelines for the management of chronic spinal pain with interventional techniques were developed to provide recommendations to clinicians in the United States.

Objective: To develop evidence-based clinical practice guidelines for interventional techniques in the diagnosis and treatment of chronic spinal pain, utilizing all types of evidence and to apply an evidence-based approach, with broad representation by specialists from academic and clinical practices.

Design: Study design consisted of formulation of essentials of guidelines and a series of potential evidence linkages representing conclusions and statements about relationships between clinical interventions and outcomes.

Methods: The elements of the guideline preparation process included literature searches, literature synthesis, systematic review, consensus evaluation, open forum presentation, and blinded peer review. Methodologic quality evaluation criteria utilized included the Agency for Healthcare Research and Quality (AHRQ) criteria, Quality Assessment of Diagnostic Accuracy Studies (QUADAS) criteria, and Cochrane review criteria. The designation of levels of evidence was from Level I (conclusive), Level II (strong), Level III (moderate), Level IV (limited), to Level V (indeterminate).

Results: Among the diagnostic interventions, the accuracy of facet joint nerve blocks is strong in the diagnosis of lumbar and cervical facet joint pain, whereas, it is moderate in the diagnosis of thoracic facet joint pain. The evidence is strong for lumbar discography, whereas, the evidence is limited for cervical and thoracic discography. The evidence for transforaminal epidural injections or selective nerve root blocks in the preoperative evaluation of patients with negative or inconclusive imaging studies is moderate. The evidence for diagnostic sacroiliac joint injections is limited.

The evidence for therapeutic lumbar intraarticular facet injections is moderate for short-term and long-term improvement, whereas, it is limited for cervical facet joint injections. The evidence for lumbar and cervical medial branch blocks is moderate. The evidence for medial branch neurotomy is moderate.

The evidence for caudal epidural steroid injections is strong for short-term relief and moderate for long-term relief in managing chronic low back and radicular pain, and limited in managing pain of postlumbar laminectomy syndrome. The evidence for interlaminar epidural steroid injections is strong for short-term relief and limited for long-term relief in managing lumbar radiculopathy, whereas,

From: American Society of Interventional Pain Physicians.

Address Correspondence: ASIPP,

81 Lakeview Drive Paducah, KY 42001 E-mail: asipp@asipp.org Funding: None.

Conflict of Interest: None. Author affiliation information is listed in alphabetical order on pages 74 and 75.

Free Full manuscript: www.painphysicianjournal.com for cervical radiculopathy the evidence is moderate. The evidence for transforaminal epidural steroid injections is strong for short-term and moderate for long-term improvement in managing lumbar nerve root pain, whereas, it is moderate for cervical nerve root pain and limited in managing pain secondary to lumbar post laminectomy syndrome and spinal stenosis.

The evidence for percutaneous epidural adhesiolysis is strong. For spinal endoscopic adhesiolysis, the evidence is strong for short-term relief and moderate for long-term relief.

For sacroiliac intraarticular injections, the evidence is limited. The evidence for radiofrequency neurotomy for sacroiliac joint pain is limited.

The evidence for intradiscal electrothermal therapy is moderate in managing chronic discogenic low back pain, whereas for annuloplasty the evidence is limited. 
Among the various techniques utilized for percutaneous disc decompression, the evidence is moderate for short-term and limited for long-term relief for automated percutaneous lumbar discectomy, and percutaneous laser discectomy, whereas it is limited for nucleoplasty and for DeKompressor technology.

For vertebral augmentation procedures, the evidence is moderate for both vertebroplasty and kyphoplasty.

The evidence for spinal cord stimulation in failed back surgery syndrome and complex regional pain syndrome is strong for shortterm relief and moderate for long-term relief. The evidence for implantable intrathecal infusion systems is strong for short-term relief and moderate for long-term relief.

Conclusion: These guidelines include the evaluation of evidence for diagnostic and therapeutic procedures in managing chronic spinal pain and recommendations for managing spinal pain. However, these guidelines do not constitute inflexible treatment recommendations. These guidelines also do not represent a "standard of care."

Key words: Interventional techniques, chronic spinal pain, diagnostic blocks, therapeutic interventions, facet joint interventions, epidural injections, epidural adhesiolysis, discography, radiofrequency, disc decompression, vertebroplasty, kyphoplasty, spinal cord stimulation, intrathecal implantable systems

\section{Contents}

\subsection{Introduction}

1.1 Purpose

1.2 Rationale

1.3 Importance

1.4 Population and Preferences

1.5 Implementation and Review

1.6 Application

1.7 Focus

1.8 Technology

1.9 Methodology

\subsection{Chronic Pain}

2.1 Definitions

2.2 Prevalence

2.3 Spinal Pain

2.4 Chronicity

2.5 Health and Economic Impact

\subsection{Structural Basis}

3.1 Facet or Zygapophysial Joints

3.2 Intervertebral Disc

3.3 Dorsal Root Ganglion

3.4 Sacroiliac Joint

3.5 Postlaminectomy Syndrome

3.6 Spinal Stenosis

\subsection{Interventional Techniques}

4.1 Mechanism of Action

5.0 Diagnostic Interventional Techniques

5.1 Facet or Zygapophysial Joint Blocks
5.2 Provocation Discography

5.3 Transforaminal Epidural Injections

or Selective Nerve Root Blocks

5.4 Sacroiliac Joint Blocks

\subsection{Therapeutic Interventional Techniques}

6.1 Facet Joint Interventions

6.2 Epidural Injections

6.3 Epidural Adhesiolysis

6.4 Sacroiliac Joint Interventions

6.5 Intradiscal Therapies

6.6 Percutaneous Disc Decompression

6.7 Vertebral Augmentation Procedures

6.8 Implantable Therapies

\subsection{Evaluation and Management}

7.1 Evaluation

7.2 Medical Necessity Management

8.0 Delivery of Interventional Technology

8.1 Facet Joint Injections and Medial Branch Blocks

8.2 Medial Branch Neurotomy

8.3 Epidural Injections

8.4 Percutaneous Adhesiolysis

8.5 Spinal Endoscopic Adhesiolysis

8.6 Sacroiliac Joint Injections

8.7 Sacroiliac Joint Radiofrequency Neurotomy

\subsection{An Algorithmic Approach}

10.0 Conclusion 


\subsection{InTRODUCTION}

\subsection{Purpose}

Evidence-based clinical practice guidelines for interventional techniques in the management of chronic spinal pain are statements developed to improve quality of care, patient access, treatment outcomes, appropriateness of care, efficiency and effectiveness, and achieve cost containment by improving the costbenefit ratio (1-4).

\subsection{Rationale}

Interventional pain management is an emerging specialty. Consequently, the problems faced by this specialty may be disproportionate compared to established specialties. Interventional pain management is also faced with increased utilization. The data for interventional techniques in the Medicare population shows that from 1998 to 2005, overall growth in interventional techniques has been $179 \%$, increasing from 1,406,417 procedures in 1998 to 3,925,467 procedures in $2005(5,6)$. Extrapolation of the Medicare statistics suggests that 4 times as many procedures are performed in the general U.S. population.

Available evidence documents a wide degree of variance in the definition and the practice of interventional pain management (1-6). Application of interventional techniques by multiple specialties is highly variable for even the most commonly performed procedures and treated condition(s) (6).

National Uniform Claims Committee (NUCC) (7) defined interventional pain management as the discipline of medicine devoted to the diagnosis and treatment of pain and related disorders by the application of interventional techniques in the management of subacute, chronic, persistent, and intractable pain, independently or in conjunction with other modalities of treatments.

Medicare Payment Advisory Commission (MedPAC) (8) described interventional techniques as minimally invasive procedures including percutaneous precision needle placement, with placement of drugs in targeted areas or ablation of targeted nerves; and some surgical techniques such as laser or endoscopic discectomy, intrathecal infusion pumps and spinal cord stimulators, for the diagnosis and management of chronic, persistent or intractable pain.

\subsection{Importance}

Many of the causes of spinal pain and other chronic pain conditions are considered as either acute recurrent problems that are characterized by periods of quiescence punctuated by flare-ups, or chronic diseases, like diabetes or hypertension, requiring long-term treatment with ongoing care. On the basis of advances in imaging, neural anatomic findings, new discoveries in chemical mediation, the development of precision diagnostic and therapeutic injection techniques, and reported non-operative treatment successes, the importance of interventional techniques in managing chronic spinal pain has been defined.

Many guidelines, systematic reviews, Cochrane Reviews, and other articles pertaining to interventional pain management have been published (1-4,9-82). Neither cancer pain nor spine surgery guidelines may be applied to manage chronic spinal pain. The debated quality of the systematic reviews, guidelines, and policies, along with non-applicability across the populations, bias, with alleged major shortcomings, resulting in potentially harmful healthcare implications for patients in the United States have been highlighted (1-4,9-97). Consequently, the American Society of Interventional Pain Physicians (ASIPP) has developed an ongoing process of evidence synthesis and guideline preparation and appropriate updating since 1999 (1-4). The interventional techniques guidelines and opioid guidelines developed by the American Society of Interventional Pain Physicians have been listed on the AHRQ/NGC website $(98,99)$. ASIPP guidelines have been developed with rigorous quantitative and qualitative methodology with literature review and synthesis.

This is the fourth revision and update of guidelines to address the issues of systematic evaluation and ongoing care of chronic or persistent pain. Primarily, these guidelines provide information about the scientific basis of recommended procedures. The guidelines, properly applied, should increase compliance, dispel misconceptions, contribute to appropriate patient expectations, and facilitate the relationship between patients, physicians, and the payers.

\subsection{Population and Preferences}

The population covered by these guidelines includes all patients suffering with chronic spinal pain eligible to undergo commonly utilized and effective interventional technique(s). A treatment plan must be established taking into consideration the evidence, patient preferences, and risk-benefit ratio. 


\subsection{Implementation and Review}

The dates for implementation and review were established:

- Effective date - February 1, 2007

- Expiration date - January 31, 2009

- Scheduled review - April 1, 2008

\subsection{Application}

These guidelines are intended for use by interventional pain physicians and other physicians trained in interventional pain management. However, these guidelines do not constitute inflexible treatment recommendations. It is expected that a provider will establish a plan of care on a case-by-case basis, taking into account an individual patient's medical condition, personal needs, and preferences, and the physician's experience. Based on an individual patient's needs, treatment different from that outlined here could be warranted. These guidelines do not represent a "standard of care."

The goal of these guidelines is to provide practitioners and payors information to determine whether the available evidence supports the notion of a "standard" for interventional techniques. "Standard" refers to what is applicable to the majority of patients, with a preference for patient convenience and ease of administration without compromising the treatment efficacy or morbidity (100). It is essential to recognize the difference between "standard" and "standard of care," as utilized by a legal definition.

\subsection{Focus}

These updated and revised guidelines focus on a range of interventions that are the essential elements of effective management of chronic spinal pain. It is recognized that management of chronic spinal pain takes place in a wide context of healthcare settings, involving multiple specialists, and multiple techniques which also include non-interventional techniques. Consequently, the decision to implement a particular management approach should be based on a comprehensive assessment of the patient's overall health status, medical requirements, and patient preferences.

\subsection{Technology}

These guidelines describe multiple interventional techniques available in the management of chronic spinal pain, both diagnostic and therapeutic.

The diagnostic interventional techniques include facet joint blocks, provocative discography, sacroiliac joint blocks, and transforaminal epidural injections or selective nerve root blocks.

Therapeutic interventional techniques include facet joint interventions which encompass intraarticular injections, medial branch blocks, and medial branch neurotomy; sacroiliac joint interventions, including sacroiliac joint blocks, and radiofrequency neurotomy; epidural injections including caudal epidural injections, interlaminar epidural injections, and transforaminal epidural injections; epidural adhesiolysis including percutaneous adhesiolysis, and spinal endoscopic adhesiolysis; intradiscal therapies including intradiscal electrothermal therapy (IDET) and radiofrequency posterior annuloplasty; percutaneous disc decompression with automated percutaneous lumbar discectomy, percutaneous laser discectomy, nucleoplasty and decompression utilizing mechanical high RPM device or DeKompressor technology; vertebral augmentation techniques including vertebroplasty and kyphoplasty; and implantable therapies, which include spinal cord stimulation and intrathecal drug administration systems.

These guidelines also describe evaluation and management services, delivery of interventional technology, and an algorithmic approach to diagnosis and management of chronic spinal pain.

\subsection{Methodology}

In developing these guidelines, all types of evidence are utilized. The methodology utilized was the best scientific approach available with comprehensive evidence synthesis. Further, if an evidencebased approach failed to provide adequate levels of evidence, consensus and expert opinions have been utilized. Those approaches have been described in separate publications $(86,87,93,101-118)$. These guidelines include both patient and physician focus to understand the issues and the guidelines easily, so that appropriate care may be provided and the guidelines may be followed in an overall management plan.

While an evidence-based approach may seem to enhance the scientific rigor of guideline development, recommendations may not always meet the highest scientific standards. Evidence-based medicine is defined as the conscientious, explicit, and judicious use of current best evidence in making decisions about the care of individual patients (103). 


\subsubsection{Practice of Evidence-Based Medicine}

The practice of evidence-based medicine requires the integration of individual clinical expertise with the best available external evidence from systematic research. Decisions that affect the care of patients should be made with due weight accorded to all valid, relevant information. This includes valid and relevant clinical evidence derived from randomized, controlled trials, and all types of evidence, patient preferences, and resources. Thus, it is emphasized that no one sort of evidence should necessarily be the determining factor in decision-making. All implies that there should be an active search for all that is valid, relevant information and that an assessment should be made of the accuracy of information and the applicability of the evidence to the decision in question $(85,86,87,112)$.

\subsubsection{Guidelines}

Clinical practice guidelines present statements of best practice based on a thorough evaluation of the evidence from published studies on the outcomes of treatment. In these guidelines, multiple methods used for collecting and evaluating evidence are applied for a wide range of clinical interventions and disciplines to a wide range of interventional procedures, both diagnostic and therapeutic.

The guidelines are based on the practice of evidencebased medicine which is based on four basic contingencies originally defined evidence-based practice (112).

- First, the recognition of the patient's problem and the construction of a structured clinical question.

- Second, the ability to efficiently and effectively search the medical literature to retrieve the best available evidence to answer the clinical question.

- Third, critical appraisal of the evidence.

- Fourth, integration of the evidence with all aspects of individual patient decision making to determine the best clinical care of the patient.

\subsubsection{Development of Guidelines}

In the development of these clinical practice guidelines, multiple resources were utilized to create principles for developing guidelines. Of particular importance are the National Health and Medical Research Council criteria (113) with 9 basic principles as follows:

- Outcomes (survival rates to quality-of-life attributes)

- Best available evidence (according to its quality, relevance and strength)

- Appropriate systems to synthesize the available evidence (judgment, experience and good sense)
- Multidisciplinary process of development

- Flexibility and adaptability

- Cost-effectiveness of treatments

- Appropriate dissemination

- Evaluation of implementation and impact of guidelines

- Appropriate revision of the guidelines on a regular basis

As recommended by the National Health and Medical Research Council (113) and Shaneyfelt et al (93), the present guidelines include the following:

1. Documentation of the purpose of the guidelines

2. Description of the natural history of chronic spinal pain and treatments and various interventional techniques that are available

3. Identification of various conditions where recommendations might not apply

4. Detailed description of the probable outcomes

5. Maintenance of flexibility and comprehensive nature of the guidelines

6. Description of the support services required for each potential treatment

7. Inclusion of the information for consumers and clinicians, on all special clinical training or equipment that is needed

8. Cost-effectiveness and cost comparisons of various options

9. Reference to the type and strength of evidence on which recommendations are based

10. Documentation of certainty or uncertainty of any conclusions

11. Documentation of the economic appraisals used in formulating the guidelines

12. Acknowledgment of consensus-based recommendations whenever applied

\subsubsection{Mechanism of Development of Guidelines}

A policy committee, with broad representation, consisting of academic and clinical practitioners recognized as experts in one or more interventional techniques of concern and representing a variety of practices and geographic areas, were included and convened. This committee formalized the essentials of guidelines. This was followed by formulation of a series of potential evidence linkages, representing conclusions and statements about relationships between clinical interventions and outcomes. The elements of the guideline preparation process included literature searches, literature syntheses, systematic review, consensus evaluation, open forum presentations, and blinded peer review.

Descriptions of evidence synthesis and guideline 
preparation are described in multiple documents $(84,86,87,101-118)$. In addition, multiple systematic, narrative, and/or best evidence synthesis reviews pertaining to interventional techniques have been considered and included. In synthesizing the evidence, systematic reviews, randomized clinical trials, observational studies, and diagnostic accuracy studies were evaluated utilizing reporting criteria and quality evaluation criteria. For a particular technique, if at least 10 randomized trials were not available, nonrandomized or observational studies were also included.

\subsubsection{Level of Evidence}

Systems for grading the strength of a body of evidence are much less uniform and consistent than those for rating study quality. Consequently, the guideline committee designed levels of evidence from Level I through Level $\mathrm{V}$, modified from various publications (Table 1) $(86,87,104-108,114,116$ 118).

\subsection{Chronic Pain}

\subsection{Definitions}

Chronic pain is a complex phenomenon. Consequently, it is difficult to define. A combination of definitions is utilized (1-4):

- Pain that persists beyond the usual course of an acute disease or a reasonable time for any injury to heal that is associated with chronic pathologic processes that cause continuous pain or pain at intervals for months or years

- Persistent pain that is not amenable to routine pain control methods

- Pain where healing may never occur

\subsection{Prevalence}

The prevalence of chronic pain in the adult population ranges from $2 \%$ to $40 \%$, with a median point prevalence of $15 \%$ (119). Persistent pain has been reported with an overall prevalence of $20 \%$ of primary care patients, with approximately $48 \%$ reporting

Table 1. Designation of levels of evidence

\begin{tabular}{|l|l||}
\hline Level I & $\begin{array}{l}\text { Conclusive: Research-based evidence with multiple relevant and high-quality scientific studies or consistent reviews of meta- } \\
\text { analyses. }\end{array}$ \\
\hline Level II & $\begin{array}{l}\text { Strong: Research-based evidence from at least 1 properly designed randomized, controlled trial; or research-based evidence } \\
\text { from multiple properly designed studies of smaller size; or multiple low quality trials. }\end{array}$ \\
\hline Level III & $\begin{array}{l}\text { Moderate: } \\
\text { a) Evidence obtained from well-designed pseudorandomized controlled trials (alternate allocation or some other method); } \\
\text { b) evidence obtained from comparative studies with concurrent controls and allocation not randomized (cohort studies, } \\
\text { case-controlled studies, or interrupted time series with a control group); } \\
\text { c) evidence obtained from comparative studies with historical control, two or more single-arm studies, or interrupted time } \\
\text { series without a parallel control group. }\end{array}$ \\
\hline Level IV & $\begin{array}{l}\text { Limited: Evidence from well-designed nonexperimental studies from more than 1 center or research group; or conflicting } \\
\text { evidence with inconsistent findings in multiple trials. }\end{array}$ \\
\hline Level V & $\begin{array}{l}\text { Indeterminate: Opinions of respected authorities, based on clinical evidence, descriptive studies, or reports of expert } \\
\text { committees. }\end{array}$ \\
\hline
\end{tabular}


back pain (120). The literature also has consistently described the high prevalence of chronic pain in children, adults and the elderly with associated functional disability (119-126). In an evaluation of the prevalence and determinants of pain and pain-related disability in urban and rural setting in Southeastern Ontario, 76\% reported some pain over the past 6 months (127). High pain intensity with low pain interference was seen in 26\% (Grade II) and high pain intensity with high pain interference was seen in $17 \%$ (Grades III and IV). Of those reporting pain, $49 \%$ reported chronic pain (i.e., pain for a minimum of 90 days over the past 6 months) which represented $37 \%$ of the sample. In children it was shown that the prevalence of any pain within the previous 6 months was $70 \%$, while chronic pain was reported by $14 \%$, and $7 \%$ of the children suffered with Grade III or Grade IV pain with high intensity associated with moderate to severe disability (126).

Chronic pain with the involvement of multiple regions is a common occurrence in more than $60 \%$ of patients $(123,128-130)$.

\subsection{Spinal Pain}

Among chronic pain disorders, pain arising from various structures of the spine constitutes the majority of problems. The lifetime prevalence of spinal pain has been reported as $54 \%$ to $80 \%(1-4,119,122,125,131-$ 137). Annual prevalence of chronic low back pain ranges from $15 \%$ to $45 \%$, with a point prevalence of $30 \%(124,125,131,133)$. Studies of the prevalence of low back pain and neck pain $(131,133)$ and its impact on general health showed $25 \%$ of patients reporting grade II to IV low back pain (high pain intensity with disability) vs $14 \%$ with neck pain. The studies evaluating chronic low back pain estimated the average age related prevalence of persistent low back pain in approximately $15 \%$ in children, adolescents, and adults, and $27 \%$ in the elderly $(119,124-127)$. Historically, even though back pain research has primarily focused on younger, working adults, there is clear evidence that back pain is one of the most frequent complaints in older persons $(119,124,138)$, and is an independent correlate of functional limitations $(124,139)$, perceived difficulty in performing daily life activities (140), and a risk factor for future disability.

\subsection{Chronicity}

Conventional beliefs are that most episodes of low back pain will be short-lived, with $80 \%$ to $90 \%$ of attacks resolving in about 6 weeks irrespective of the administration or type of treatment, with only $5 \%$ to $10 \%$ of patients developing persistent back pain. However, this concept has been questioned, as the condition tends to relapse, so that most patients will experience recurrent episodes. Modern evidence has shown that chronic persistent low back pain and neck pain in children, adults, and elderly are seen in $25 \%$ $60 \%$ of patients, one year or longer after the initial episode (141-167).

\subsection{Health and Economic Impact}

Spinal pain is associated with significant economic, societal, and health impact (168-200). Estimates and patterns of direct healthcare expenditures among individuals with back pain in the United States have reached $\$ 90.7$ billion for the year 1998 (184). On average, individuals with back pain incurred healthcare expenditures about $60 \%$ higher than individuals without back pain $(\$ 3,498$ versus $\$ 2,178)$. In the United States, it was estimated that the cost of treatment in the first year after failed back surgery for pain was approximately \$18,883 in 1997 (193). Further, annual healthcare cost incurred by chronic pain patients, excluding cost for surgical procedures, may range from $\$ 500$ to as high as $\$ 35,400$, with the average ranging from $\$ 12,900$ to $\$ 18,883$ annually $(193,194)$. However, the majority of these costs are associated with disability compensation, lost productivity, and lost tax revenue. Disability secondary to spinal pain is enormous $(179,184,186,196-197)$. In the United Kingdom, low back pain was the largest single cause of absence from work in 1988 and 1989 and accounting for $12.5 \%$ of all sick days and over $\mathrm{f} 11$ billion in direct and indirect costs in 2000 (195).

Among the various factors contributing to costs in the United States, workers functional impairment, activity limitations, reduced quality of life, disability, underemployment, reduced work productivity and direct medical costs have been described (180). Among the United States workers, back pain exacerbations and lost productive time (LPT) costs evaluation showed back pain in workers between 40 to 65 years of age costs employers an estimated $\$ 7.4$ billion per year. Workers with back pain exacerbations accounted for $71.6 \%$ of this cost. It was also estimated that back pain related LPT in workers 18 to 65 years of age costs employers $\$ 19.8$ billion per year (180). Moreover, $50 \%$ of the annual cost of the back pain-related LPT in these workers was associated with pain exacerbation (179). However, these estimates do not capture other 
costs associated with the work force "ripple effect," such as the potential hiring and training of replacement workers, impact of coworkers' productivity, and forfeiture of leisure time (179).

Frequent use of opioids in managing chronic noncancer pain has been a major strain on US health care $(99,177,178,181,199-208)$. With the majority of patients receiving opioids for chronic pain combined with increased production of opioids, costs of opioid use have been much higher even when patients were not abusing. Evaluation of direct costs of opioid abuse in the insured population in the United States showed prescription drug claims for opioids of approximately $20 \%$, whereas opioid abusers had drug claims of almost $60 \%$ $(99,201)$. Mean annual direct healthcare costs of the total prescription bill for opioid abusers were more than 8 times higher than for non-abusers with $\$ 15,884$ for abusers versus $\$ 1,830$ for non-abusers.

Costs of abuse and addiction are enormous (204). Multiple investigators (204) have shown a prevalence of drug abuse in $18 \%$ to $41 \%$ of patients receiving opioids for chronic pain. Between 1992 and 2002, the population of the United States increased by $13 \%$. The number of prescriptions written for non-controlled drugs increased by $57 \%$ and the number of prescriptions filled for controlled drugs increased by 154\% $(200,201,206)$. In addition, there was a $90 \%$ increase in the number of people who admitted to abusing controlled prescription drugs during the same period.

Comorbidities among patients with spinal pain are substantial (206). Opioid abusers, compared with non-abusers, had significantly higher prevalence rates for a number of specific comorbidities including nonopioid poisoning, hepatitis, psychiatric illness, and pancreatitis, which were approximately 78, 36, 9, and 21 times higher, respectively, than that of non-abusers (206).

Psychological and physical comorbidities and risk factors are common in spinal pain. There is extensive evidence associating chronic pain and psychopathology (199, 209-216). Consequently, unrecognized and untreated psychopathology can interfere with the successful management of chronic pain and patient rehabilitation, can be predictive of poor surgical outcomes, and may increase pain intensity and disability, thus serving to increase pain related dysfunction, disability, and costs (209). A multitude of physical elements also lead to increased morbidity and mortality along with increased costs in spinal pain patients. These include lack of fitness, poor health, obesity, smoking, drug dependence, and other comorbidities such as heart disease, diabetes, thyroid disease, etc. $(177,197-200,217)$. The prevalence of comorbidities, analgesic use, and healthcare service use, varied by the number of back pain episodes with the highest in patients with more than 6 episodes of back pain. Diabetes, rheumatoid arthritis, anxiety, psychotic illness, depression, and use of opiates and nonsteroidal anti-inflammatory agents were associated with significant incremental increases in costs. In a study of cardiovascular risk factors for physician-diagnosed lumbar disc herniation (197), cardiovascular risk factors significantly and independently were associated with symptomatic lumbar disc herniation. Thus, physical and psychological comorbidities and measures of analgesic use are associated with chronicity, increased healthcare utilization, and costs. Given the association of comorbidities and exploding costs for patients with spinal pain, specifically low back pain, management approaches that are effective across chronic illnesses may prove to be beneficial.

\subsection{Structural Basis}

Chronic spinal pain is a multifactorial disorder with many possible etiologies. The biopsychosocial model, which emerged in the 1980s, views chronic spinal pain as a biopsychosocial phenomenon, in which biological, psychological and social factors dynamically interact with each other. In the 1990s, the biopsychosocial approach dominated chronic spinal pain management, at least among academicians, with the introduction of "psychosocial" approaches. Medically unexplained pain is the subject of controversy with numerous publications in the medical literature (218).

Modern technology, including magnetic resonance imaging (MRI), computed tomographic axial scanning (CT), neurophysiologic testing, and comprehensive physical examination with psychological evaluation, can identify the cause of low back pain in only $15 \%$ of patients in the absence of disc herniation and neurological deficit (1-4, 219-227).

The majority of painful conditions include various types of pain originating from the spine with pain in the neck, upper back, mid back, low back, and upper or lower extremities. It was postulated that, for any structure to be deemed a cause of back pain (224):

- The structure should have a nerve supply

- The structure should be capable of causing pain similar to that seen clinically, ideally demonstrated in normal volunteers 
- The structure should be susceptible to diseases or injuries that are known to be painful

- The structure should have been shown to be a source of pain in patients, using diagnostic techniques of known reliability and validity.

Kuslich et al (228) identified intervertebral discs, facet joints, ligaments, fascia, muscles, and nerve root dura as tissues capable of transmitting pain in the low back. Facet joint pain, discogenic pain, and sacroiliac joint pain also have been proven to be common causes of pain with proven diagnostic techniques (1$4,23,32-36,46,48-50,128,129,229,230)$. In contrast, vertebrae, muscles, and ligaments have not been proven to be common sources of spinal pain with proven diagnostic techniques. In one prospective evaluation (229), consecutive adult patients with intractable low back pain (who had failed conservative therapy) of undetermined etiology (by medical history, physical examination, x-ray, CT, MRI, EMG/NCV) had pain from facet joint(s) in $24 \%$, combined lumbar nerve root and facet disease in $24 \%$, combined facet(s) and sacroiliac joint(s) in $4 \%$, lumbar nerve root irritation in $20 \%$, internal disc disorder in $7 \%$, sacroiliac joint in $6 \%$, and sympathetic dystrophy in $2 \%$. In a second study (230), the relative contributions of various structures in patients with chronic low back pain who failed to respond to conservative modalities of treatments (physical therapy, chiropractic and drug therapy), with lack of radiological evidence to indicate disc protrusion or radiculopathy, were evaluated utilizing controlled, comparative, double diagnostic blocks. In this study, $40 \%$ of the patients were shown to have facet joint pain, $26 \%$ discogenic pain, $2 \%$ sacroiliac joint pain, and possibly $13 \%$ segmental dural/nerve root pain. No cause was identified in 13\% (229) and 19\% (230) of the patients.

\subsection{Facet or Zygapophysial Joints}

The facet or zygapophysial joints are paired diarthrodial articulations between posterior elements of adjacent vertebrae (231). Spinal facet joints have been shown to be a source of pain in the neck and referred pain in the head and upper extremities (232-236); upper back, mid back and referred pain in chest wall $(237,238)$; as well as the low back and referred pain in the lower extremity (239-244) in normal volunteers.

Facet joints are well innervated by the medial branches of the dorsal rami (245-264). Neuroanatomic studies have demonstrated free and encapsulated nerve endings in facet joints, as well as nerves contain- ing substance $\mathrm{P}$ and calcitonin gene-related peptide (264-279).

Neurophysiologic studies have shown that facet joint capsules contain low-threshold mechanoreceptors, mechanically sensitive nociceptors and silent nociceptors (264-283). Inflammation leads to decreased thresholds of nerve endings in facet capsules as well as elevated baseline discharge rates $(264,277-279$, 284-286). Biomechanical studies have shown that lumbar and cervical facet joint capsules can undergo high strains during spine-loading (264,287-298).

Based on controlled diagnostic blocks of facet joints, in accordance with the criteria established by the International Association for the Study of Pain (IASP) (299), facet joints have been implicated as responsible for spinal pain in $15 \%$ to $45 \%$ of patients with low back pain $(128,129,230,300-308), 36 \%$ to $67 \%$ of patients with neck pain $(128,129,309-312)$, and $34 \%$ to $48 \%$ of patients with thoracic pain $(128,129,313)$.

\subsection{Intervertebral Disc}

The human intervertebral disc (IVD) is a unique structure, composed of two major regions - the outer ring, called the annulus fibrosus (AF), and the inner part, called the nucleus pulposus (NP), with a transitional zone that merges these two regions together (314-316). Even though it is controversial whether or not the lumbar intervertebral discs receive innervation, early studies failed to demonstrate nerve fibers or nerve endings within the discs (317-320). Consequently, it has been concluded that the lumbar discs lack innervation (317,321-323). In subsequent studies, it was reported that in a normal intervertebral disc, the nucleus pulposus is devoid of nerve fibers, whereas the outer annulus fibrosus contains an extensive network of sensory nerve fibers $(243,317,324-330)$. Since then, it has also been demonstrated that a variety of free and complex nerve endings were present in the outer third of the annulus (315,317,331-344). Nerve endings in degenerated discs have been found in the deeper layers of the annulus fibrosus; in some studies, nerve endings have been found extending even into the nucleus pulposus (314,334-337). The nerve fibers have been found both in anterior and posterior parts of the disc specimens following a vascularized zone of granulation tissue (334). The ingrowth of nerve endings has been suggested to be the pathoanatomic correlate to the dull chronic ache, which is exacerbated by the mechanical loading of the spine that is experienced by patients with chronic low back pain and which is often 
referred to as discogenic pain (314). In a quantitative analysis of the innervation of the intervertebral disc in a sheep model, there was no significant difference between endplate and annulus innervation densities (344). The endplate innervation was concentrated centrally adjoining the nucleus. The richest area of innervation was in the periannular connective tissue. Consequently, these authors (344) concluded that in the sheep, the lumbar intervertebral disc has a meager innervation, which is concentrated in the periannular connective tissue and the central endplate. However, they also stated that receptor threshold is more closely related to nociceptive function than innervation density. This innervation also has been demonstrated to cervical and thoracic intervertebral discs, synonymous to lumbar discs. However, these have not been studied well $(325,327,330,331,333,338-351)$. These nerve fibers transmit both nociceptive and non-nociceptive information $\quad(243,246,325,330,331,333,338,339,348,352-$ 354). In addition, many of these nerve fibers, identifiable by immunochemistry, are accompanied by blood vessels; this process of neovascularization is associated with inflammation. Neural structures that express substance $\mathrm{P}$ and have the morphology of nociceptive nerve terminals are found in the nucleus of painful discs; this may distinguish painful versus painless disc degeneration (349).

Degeneration of the intervertebral disc is associated with the development of fissures in the outer annular fibrosus, which may be ingrown by vascular tissue and nerve endings $(315,345,355)$. Disc cells are capable of producing a complex mixture of neurotransmitters, cytokines, and other inflammatory mediators that may stimulate free nerve endings (356-358). While neurotransmission pathways for discogenic pain remain poorly understood, nociceptive neuropeptides, which are present within the nerve fibers in the outer annulus and dorsal root ganglion, may likely play a role in discogenic pain transmission (315,346,359-361).

Clinically, the intervertebral disc (IVD), depending on location, can produce pain in the neck, upper extremities, posterior thorax, chest wall, abdominal wall, low back, and lower extremities (228,362-378). IVD-related pain can be caused by structural abnormalities, such as disc degeneration or disc herniation; correspondingly, biochemical effects, such as inflammation, and neurobiological processes may play a role. Nerve growth factor (NGF) dependent neurons are the main neuronal subgroup within the dorsal root ganglion (DRG), that transmit and modulate pain in response to inflammation. This subgroup is responsible for sensitizing the DRG to NGF and is present in the painful IVD. NGF may play an important role in discogenic back pain $(350,371-374)$. The nucleus pulposus is a biologically active tissue that can respond to pro-inflammatory stimuli (374).

The first to create widespread interest in the disc as a source of pain in American literature were Mixter and Barr (364) with their 1934 hallmark description of the herniated nucleus pulposus. However, soon after, Mixter and Ayers (370) in 1935 demonstrated that radicular pain can occur without disc herniation. Subsequently, numerous investigators $(229,230,367,352-$ 354,375-377) have described pain syndromes emanating from the lumbar intervertebral disc without mechanically compressing neural structures. Consequently, the pathophysiology of spinal radicular pain is a subject of ongoing research and controversy and discogenic pain has assumed a major role as a cause of nonspecific low back pain, beyond the more specific disc herniation. Thus, in addition to the mechanical component, inflammation of the compressed nerve root is an important factor in the pathophysiology of radicular and discogenic pain (377-385). Other proposed etiologies include neural compression with dysfunction and vascular compromise (386-390). While neurotoxicity has been attributed to many agents including phospholipase $A_{2}\left(P L A_{2}\right)$, metalloproteinases, and interleukin-6, both prostaglandin $\mathrm{E}_{2}(353,380-$ 384,391-396) and tumor necrosis factor (TNF $\alpha$ ) have been shown to have an essential role in intervertebral disc-induced nerve root damage (397-400).

Cartilage oligomeric matrix protein (COMP) (401) may play a role in maintaining the normal structure of the intervertebral disc. The course of macroscopic degeneration in the human lumbar intervertebral disc was described to start in the nucleus. The temporal sequence suggests a strong correlation of cleft and tears formation starting with the formation of clefts in the second decade (402). It was also shown that in rats, by creating static and dynamic posterior instability of the cervical spine, rapid intervertebral disc degeneration starts, which is characterized by increased apoptosis and local inflammation (403). TFN $\alpha$, also has been shown to contribute to the degenerative changes that occur in the disc disease (404) as well as producing endplate abnormalities related to inflammation and axon growth (405).

The etiology of discogenic pain is unclear (225,360-406). Internal disc disruption (IDD) is a con- 
dition in which the internal architecture of the disc is disrupted, but its external appearance remains essentially normal (407). IDD can be experimentally induced by endplate damage (408). Likewise, experimentally induced annular tears can lead to adverse and progressive mechanical changes in the disc. Annular degeneration has been shown to appear at an early age in lumbar discs and is clearly related to back pain (409). Disrupted discs may not exhibit either bulging or herniation. These features with a normal or near normal contour of discs producing back pain, but with no evidence of herniation or prolapse were described by Crock (407) in 1976 as internal disc disruption. It has been suggested that endplate damage would precede disc degeneration $(405,410)$. Further, diminution of blood supply in the endplate initiates tissue breakdown, first in the endplate and thereafter in the nucleus, starting in the first half of the second decade of life $(402,411)$, with visible tears in the nucleus in the 11 to 16 year age group. The removal of proteoglycans from the endplate, which regulates the movement of solutes into and out of the disc, accelerates the loss of proteoglycans from the nucleus (412). It also has been shown that reduced lumbar artery blood flow may diminish nutrition through the endplates, leading to an increased incidence of disc degeneration $(197,413)$. Discs with internal disc disruption are rendered painful by either chemical nociception or mechanical stimulation. Explanted discs, obtained during posterior lumbar interbody fusion in patients with lumbar discogenic pain, demonstrated a vascularized strip lesion extending from the NP to the $\mathrm{AF}$; this lesion was accompanied by extensive innervation in the posterior disc (414).

In a controlled study, the prevalence of pain due to internal disc disruption was reported as $39 \%$ in patients suffering with chronic low back pain (367). Primary discogenic pain was reported in $7 \%$ (229) to $26 \%$ (230) when no other cause was suspected. The prevalence of cervical discogenic pain in patients with chronic neck pain of traumatic origin in informal studies was estimated to be $20 \%$ (415). Discogenic and radicular pain syndromes continue to pose challenges to patients, physicians, and the society at large.

\subsection{Dorsal Root Ganglion}

The dorsal root ganglion (DRG) plays an important role in the mechanism of spinal pain. This holds true, when the DRG itself is injured or when other spinal structures are injured. Experiments have sug- gested that edema in the dorsal root ganglion is the basis of the production of nerve root pain in patients with disc herniation $(350,356,357,371,416-434)$. Mechano- and chemosensitivity of the dorsal root ganglia have been described $(393,394,419-421)$. Experimentally applied nucleus pulposus from both healthy and degenerative discs reduces nerve root conduction velocity, suggesting a pathomechanism of neural injury (422-428). The NP can induce excitatory changes, rising endoneurial pressures-compartment syndrome, and cause intraneural thrombi in the DRG or the nerve roots $(394,397,423)$. Anti-inflammatory agents, such as tumor-necrosis factor alpha inhibitors, may protect against NP-induced DRG and nerve root injury (393).

\subsection{Sacroiliac Joint}

The sacroiliac joint is a diarthrodial, synovial joint (435-440). However, the innervation of the sacroiliac joint remains a subject of much debate. The lateral branches of the $L 4$ to $S 3$ dorsal rami are cited by some experts as comprising of the major innervation to the posterior SI joint $(437,441)$. Other investigators claim that $\mathrm{L} 3$ and $\mathrm{S} 4$ contribute to the posterior nerve supply $(437,442,443)$. The innervation of the anterior joint is also controversial. The early literature asserted that the anterior sacroiliac joint is supplied by the obturator nerve, superior gluteal nerve, and the lumbosacral trunk $(437,443)$. However, more recent literature suggests the anterior joint is innervated by $L 2$ through $S 2$ $(437,444)$, L4 through S2 $(445)$, and the L5 to S2 ventral rami (446). In addition, some authors have suggested that the anterior sacroiliac joint is devoid of nervous tissue $(437,442,445)$. Neurophysiologic studies conducted showed mechanosensitive afferent units $(437,447-450)$. However, it has been postulated that pain sensitivity of the sacroiliac joints may be lower than that of lumbar facet joints but higher than the anterior portions of the lumbar discs $(437,449,450)$. In summary the sacroiliac joint is well innervated, receiving myelinated and unmyelinated axons capable of nociception (436-456).

Referral patterns of sacroiliac joint provocation or irritation have been published by multiple authors (457-460). Sacroiliac joints have been shown to be capable of producing pain in the low back, buttocks, thigh, lower extremity, groin and occasionally abdomen. Since sacroiliac joints have been shown to have innervation and produce pain in normal volunteers, the prevalence of sacroiliac joint pain has also been determined. Utilizing single diagnostic blocks, 
the prevalence of sacroiliac pain would appear to be at least $13 \%$ and perhaps as high as $30 \%$ in the United States (460) and $10 \%$ in Taiwan (229). Utilizing controlled, comparative local anesthetic blocks in patients with low back pain in whom there was a high index of suspicion for pathology, frequency of sacroiliac joint dysfunction was established as $18.5 \%$ (461), $10 \%(230)$, or $26.6 \%$ (462) in suspected patients. High prevalence may be seen in patients with post-lumbar fusion pain (463-465). In a prospective series of 40 patients with persistent low back pain after a technically successful fusion, with single diagnostic blocks, a 35\% prevalence was demonstrated (465).

\subsection{Postlaminectomy Syndrome}

Postlaminectomy syndrome and other synonyms, such as failed back surgery syndrome, represent a cluster of syndromes following spine surgery wherein the expectations of the patient and spine surgeon are not met (466-471). Persistent pain following spine surgery is common (466-489). Since discectomies, decompressions, and spinal fusions and more recently, minimally invasive surgical and interventional therapies, represent the largest portion of the US spine market (with expenditures of $\$ 2.5$ billion in the United States in 2003 of the estimated $\$ 3$ billion for the worldwide spine market), one may reasonably anticipate that the costs of persistent pain following spine surgery will increase substantially (471). In the year 2002, more than 1 million spinal procedures were performed in the USA. Six hundred thousand cases were not instrumented, but 400,000 were instrumented $(472-476,482)$. The estimated yearly growth rate of uninstrumented cases ranged from $3 \%$ to $5 \%$; in contrast, the growth rate of instrumented cases ranged from $6 \%$ to $8 \%$ (477). The "spine market" may compound as much as $22 \%$ annually (485). Lieberman (471) cautioned that all parties involved in the spine market must be vigilant in not letting the spine market turn into a "cancer," or even worse, allowing the "disc bulge bubble" to burst. A surgeon's assessment of adverse post-operative outcomes may seriously underreport a patient's self-assessment of surgical outcomes (478).

In fact, Weinstein et al (476) in a study of the United States' trends and regional variations in lumbar spine surgery from 1992 to 2003 showed that lumbar fusion rates have increased steadily since 1992 from 0.3 per 1,000 enrollees in 1992 to 1.1 per 1,000 enrollees in 2003. They also showed that Medicare spending for inpatient back surgery more than doubled over the decade, with increase for lumbar fusion of $500 \%$, from $\$ 75$ million to $\$ 482$ million. In 1992, lumbar fusion represented $14 \%$ of total spending for back surgery; by 2003 , lumbar fusion accounted for $47 \%$ of spending.

Animal models of post laminectomy syndrome demonstrate paraspinous muscle spasms, tail contractures, behavioral pain behaviors, tactile allodynia, epidural and perineural scarring, and nerve root adherence to the underlying disc and pedicle (490496). Speculated causes of postlaminectomy syndrome include acquired stenosis, adjacent segment degeneration, internal disc disruption, recurrent disc herniation, retained disc fragment, spondylolisthesis, epidural or intraneural fibrosis, degenerative disc disease, radiculopathy, radicular pain, deconditioning, facet joint pain, sacroiliac joint pain, discitis, arachnoiditis, pseudoarthrosis, segmental instability, and others $(308,463-470,478-481,485,489,497-500)$. Among these, etiologies such as epidural fibrosis, facet joint dysfunction, sacroiliac dysfunction, internal disc disruption, recurrent disc herniation, and spinal stenosis can be treated by interventional pain techniques $(23,32-36,39,40,46,48-50,308,463-$ $470,489,497-500)$. Ultimately, many of these etiologies are interrelated. Facet joint involvement in chronic pain following lumbar surgery has been shown to be present in approximately $8 \%$ to $16 \%$ of the patients (308). Prevalence of sacroiliac joint pain following lumbar fusion has been demonstrated in a study with a single block to be $35 \%$ (465).

Epidural fibrosis may occur following an annular tear, disc herniation, hematoma, infection, surgical trauma, vascular abnormalities, or intrathecal contrast media (490-496,499-509). Epidural fibrosis may account for as much as $20 \%$ to $36 \%$ of all cases of failed back surgery syndrome (FBSS) $(479,480,510-512)$. Alternatively, there may be a final common pathway with all these etiologies, which results in peripheral and central facilitation potentiated by inflammatory and nerve injury mechanisms (490-496). Paraspinal muscles may also become denervated and involved in the pathogenesis of FBSS (513).

\subsection{Spinal Stenosis}

Spinal stenosis can be defined as a narrowing of the spinal canal, resulting in symptoms and signs caused by entrapment and compression of the intraspinal vascular and nervous structures $(514,515)$. Disc bulging, protrusion, and herniation in the cervical, as 
well as lumbar area, combined with osteophytes and arthritic changes of the facet joints can cause narrowing of the spinal canal, encroachment on the contents of the dural sac, or localized nerve root canal stenosis (514-520).

The pain and disability associated with lumbar spinal stenosis can interfere with a patient's lifestyle (521). Treatment options for low back pain and neurogenic claudication related to lumbar spinal stenosis include surgery, but also nonoperative modalities including conservative treatment and interventional techniques.

\subsection{Interventional Techniques}

Various types of injection techniques have been described with multiple benefits including pain relief that outlasts by days, weeks, or months the relatively short duration of pharmacologic action of the local anesthetics and other agents used. No clear-cut explanations for these prolonged improvements are currently available.

\subsection{Mechanism of Action}

Neural blockade has been postulated to alter or interrupt nociceptive input, reflex mechanisms of the afferent limb, self-sustaining activity of neuron pools and neuraxis, and the pattern of central neuronal activities (522). Improvements may be explained in part based on the pharmacological and physical actions of local anesthetics, corticosteroids, and other agents. Local anesthetics interrupt the pain-spasm cycle and reverberating nociceptor transmission, whereas corticosteroids reduce inflammation either by inhibiting the synthesis or release of a number of pro-inflammatory substances and by causing a reversible local anesthetic effect $(419,523-536)$.

Various modes of action of corticosteroids include membrane stabilization; inhibition of neural peptide synthesis or action; blockade of phospholipase A2 activity; prolonged suppression of ongoing neuronal discharge; and suppression of sensitization of dorsal horn neurons. Local anesthetics have been shown to produce prolonged dampening of Cfiber activity. Physical effects include clearing adhesions or inflammatory exudates from the vicinity of the nerve root sleeve. The scientific basis of some of these concepts, at least in part, is proven for spinal pain management with epidural injections of betamethasone and intravenous methylprednisolone (419,529-535).
Various mechanisms of benefits for longer periods of time than the duration of the anesthetics used have been described (537-540). Among the several theories listed include the influence on sympathetic nervous system (541); temporary abolition of spontaneous ectopic discharges, resulting in suppression of dynamically maintained central hyperexcitability, as well as reinforcing endogenous G-protein-couple receptor inhibition of $\mathrm{N}$-type voltage-sensitive calcium channels (538,541); and glial inactivation (540).

\subsection{Diagnostic Interventional TECHNIQUES}

It has been postulated that for any structure to be deemed a cause of back pain, the structure should have been shown to be a source of pain in patients, using diagnostic techniques of known reliability and validity (224). The diagnostic blockade of a structure with a nerve supply with the ability to generate pain can be performed to test the hypothesis that the target structure is a source of a patient's pain. Evidencebased interventional diagnostic techniques include facet joint blocks, discography, sacroiliac joint injections, and transforaminal epidurals or selective nerve root blocks.

\subsubsection{Rationale}

The popularity of neural blockade as a diagnostic tool in painful conditions is due to multiple challenging clinical situations, which include the purely subjective nature of spinal pain and undetermined and uncertain pathophysiology in most painful spinal conditions. Precision diagnostic blocks are used to clarify these challenging clinical situations, in order to determine the pathophysiology of clinical pain, the site of nociception and the pathway of afferent neural signals. Precise anatomical diagnosis in low back pain has been described not only as elusive, but also the diagnostic evaluation is often frustrating for both physicians and patients (1-4,219-227,542-544). History, physical examination, and imaging provide limited information.

\subsubsection{Reliability and Validity}

Clinical studies of precision diagnostic techniques are variable in sensitivity, specificity, accuracy and quality. False-positive rate (how often patients without a condition will nonetheless have a positive test), false-negative rate (how often a patient with disease will have a negative test), and placebo response are crucial. Since none of the tests available in clinical medicine are ideal, there is a degree of uncertainty 
regarding the accuracy of each and every diagnostic test as applied to an individual clinical case.

The accuracy of a diagnostic test is best determined by comparing it to an appropriate reference standard (gold standard) such as biopsy, surgery, autopsy, or long-term follow-up. Tissue confirmation of the presence or absence of a disease at surgery, with a biopsy, or autopsy, which has served as the accepted gold standard across multiple medical disciplines, is not applicable to interventional pain management. Consequently, most pain provocative or relieving tests used to diagnose painful conditions of the spine are more closely related to the physical examination than to a laboratory test (38). Stability of the diagnosis over a long period of time with long-term follow-up may also be used as a gold standard. These facts are especially true in the diagnosis of facet joint pain, discogenic pain, and sacroiliac joint pain.

In interventional pain management, a diagnostic blockade of a structure with a nerve supply that can generate pain is performed to test the hypothesis that the target structure is the source of a patient's pain. Pain provocation in any structure is an unreliable criterion, except in provocative discography (1-4,23,32-36,39,40,46,48-50,219,220,542-546). In an ideal world, all controlled blocks would include placebo injections of normal saline. However, in practical terms, it may be neither logistical, nor ethical to use a placebo injections of normal saline in conventional practice. It would be necessary to perform three diagnostic blocks of the same structure with application of placebo. Consequently, the use of two local anesthetics with different durations of action, on two separate occasions, has been proposed and validated (547-550). The use of comparative local anesthetic blocks with facet joint injections has been validated against challenge with placebo $(549,550)$. Even then, the validity and relevance of diagnostic nerve blocks has been questioned (551-555). Cohen et al (556) also evaluated the causes of false-positive diagnostic facet joint blocks.

\subsubsection{Environment}

The requirements for safe use of diagnostic interventional techniques include a sterile operating room or procedure room, appropriate monitoring equipment, radiological equipment, sterile preparation, resuscitative equipment, needles, gowns, injectable drugs, intravenous fluids, anxiolytic medications, and trained personnel for preparation and monitoring of patients. Minimum requirements include history and physical examination, informed consent, and appropriate documentation of the procedure.

\subsubsection{Contraindications}

Contraindications include ongoing bacterial infection, possible pregnancy, bleeding diathesis, and anticoagulant therapy. Precautions are warranted in patients with antiplatelet or anticoagulant therapy, diabetes mellitus and artificial heart valves (557-559).

\subsection{Facet or Zygapophysial Joint Blocks}

Diagnostic blocks of a facet or zygapophysial joint can be performed by anesthetizing the joint by injections of local anesthetic intraarticularly or on the medial branches of the dorsal rami that innervate the target joint, to test whether the joint is the source of pain. Valid information is only obtained by performing controlled blocks, either in the form of placebo injections of normal saline or comparative local anesthetic blocks, in which on two separate occasions, the same joint is anesthetized using local anesthetics with different durations of action.

The rationale for using facet joint blocks for diagnosis is based on the fact that facet joints are capable of causing pain and they have a nerve supply (245264). They have been shown to be a source of pain in patients using diagnostic techniques of known reliability and validity $(4-20,128,129,230,300-313)$. However, there are no specific markers of facet joint pain. Conventional clinical and radiologic techniques are unreliable in diagnosing facet or zygapophysial joint pain. Various patterns of referred pain described for facet joints in the spine are similar to other structures such as discs. Further, most maneuvers used in physical examination are likely to stress several structures simultaneously, especially the discs, muscles, and facet joints, thus, failing to provide any reasonable diagnostic criteria. The value, validity and clinical effectiveness of diagnostic facet joint nerve blocks was also illustrated by application of therapeutic modalities based on the diagnosis with controlled comparative local anesthetic blocks $(30,34,50)$. The response was much better and longer lasting in patients after the diagnosis was made with controlled comparative local anesthetic blocks than single blocks $(13,20,21,30,51,56)$. The evidence thus far on physical examination and diagnosis has been controversial; demographic features, pain characteristics, and other signs and symptoms may not correlate and are unreliable; and medical imaging provides little useful information with radiographic investigations, including magnetic resonance imaging 
(MRI), revealing only some conditions with certainty (1-4,34-36,50,128, 129,300-311,544,545,560-577).

\subsubsection{Validity}

Controlled diagnostic blocks with two local anesthetics (or placebo-controlled) are the only means of confirming the diagnosis of facet joint pain. The face validity of medial branch blocks has been established by injecting small volumes of local anesthetic and contrast material onto the target points for these structures and by determining the spread of contrast medium in posteroanterior and lateral radiographs $(34-36,50,250,252,253)$. Construct validity of facet joint blocks is important to eliminate placebo effect as the source of confounding results and to secure truepositive results $(544,549,550)$. The hypothesis that testing a patient first with lidocaine and subsequently with bupivacaine provides a means of identifying the placebo response has been tested and proven (544,547-550).

The specificity of the effect of cervical and lumbar facet joint blocks was demonstrated in controlled trials $(250,252,253)$. Provocation response was shown to be unreliable in one study (545). The false-negative rate of diagnostic facet joint blocks was shown to be $8 \%$ due to unrecognized intravascular injection of local anesthetic (252). False-positive rates were evaluated in multiple investigations $(128,129,230,303-$ $308,311,312,578-580)$.

The validity of comparative local anesthetic blocks was determined not only by short-term relief with controlled diagnostic blocks, and ability to perform movements which were painful prior to the blocks, but also with application of another appropriate reference standard (long-term follow-up) as described in the literature (580). Utilizing the criteria established by the International Association for the Study of Pain (299), false-positive rates varying from $27 \%$ to $63 \%$ in the cervical spine, $42 \%$ to $58 \%$ in the thoracic spine, and $17 \%$ to $50 \%$ in the lumbar spine were demonstrated. Minimal effect of sedation (581-583) in cervical and lumbar spine, and lack of influence of psychological factors on the validity of controlled diagnostic local anesthetic blocks of facet joints in the lumbar spine was demonstrated (584). Other variables were also evaluated $(585,586)$.

\subsubsection{Prevalence}

Based on numerous evaluations utilizing controlled diagnostic blocks, facet or zygapophysial joints have been implicated as the source of chronic spinal pain in $15 \%$ to $45 \%$ of heterogenous groups of patients with chronic low back pain $(128,129$, $230,300-308), 34 \%$ to $48 \%$ of the patients with thoracic pain $(128,129,313)$, and $36 \%$ to $67 \%$ of the patients with chronic neck pain $(128,129,309-312)$. The data of prevalence with controlled diagnostic blocks and false-positive rates in cervical, thoracic and lumbar regions are illustrated in Tables 2, 3 and 4 respectively.

\subsubsection{Intraarticular or Medial Branch Blocks}

Facet joints are blocked by either injection into the joint or by blocking the nerves that innervate the joint. Intraarticular injections require intraarticular placement of a needle into the target joint under fluoroscopic control. Contrast medium is injected to obtain an arthrogram and verify intraarticular placement. Medial branch or L5 dorsal ramus blocks, in contrast, require anesthetizing both of the medial branches that innervate the target joint. Medial branch blocks are also performed under fluoroscopic visualization.

The choice between intraarticular blocks and medial branch blocks is to some extent preference and training of the physician. However, various considerations apply in choosing either intraarticular injection or medial branch blocks (544). Intraarticular injections are more difficult and time consuming than nerve blocks because they require accurate placement of the needle within the joint cavity with care not to over distent the joint. In contrast, medial branch blocks are expeditious and carry no risk of over distention. Furthermore, at times joint entry may be impossible because of the severe age related changes or post traumatic arthropathy; no such processes affect access to the nerves (544). Significant leakage of intraarticular injected fluid into epidural space and spillage over to the nerve roots has been described. With appropriate care this is minimal with medial branch blocks. Finally, intraarticular blocks are appropriate if intraarticular therapy is proposed but if radiofrequency therapy is proposed, medial branch blocks become the diagnostic procedure of choice. In addition, in the past only intraarticular injections were considered as therapeutic. However, recent evidence has shown that medial branch blocks have better evidence for the therapeutic effectiveness than intraarticular blocks $(30,51)$. An additional advantage is that if the patient fails to respond to medial branch blocks one may proceed with denervation procedures. Furthermore, the requirements for steroids is much lower or none with medial branch blocks compared to intraarticular injections 
Pain Physician: January 2007:10:7-111

Table 2. Data of prevalence with controlled diagnostic blocks and false-positive rates in cervical region

\begin{tabular}{|c|c|c|c|c|c|c|}
\hline \multirow{2}{*}{ Study } & \multicolumn{2}{|c|}{ Quality Scoring } & \multirow{2}{*}{$\begin{array}{c}\text { \# of } \\
\text { Subjects }\end{array}$} & \multirow{2}{*}{ Type } & \multirow{2}{*}{ Prevalence } & \multirow{2}{*}{ False-Positive Rate } \\
\hline & AHRQ & QUADAS & & & & \\
\hline Barnsley et al (309) 1995 & $4 / 5$ & $13 / 14$ & 50 & $\mathrm{P}, \mathrm{DB}$ & $54 \%(95 \%$ CI $40 \%-68 \%)$ & NA \\
\hline Barnsley et al (579) 1993 & $4 / 5$ & $13 / 14$ & 55 & RCT & NA & $\begin{array}{l}27 \%(95 \% \text { CI } 15 \%- \\
38 \%)\end{array}$ \\
\hline Lord et al (310) 1996 & $4 / 5$ & $13 / 14$ & 68 & $\begin{array}{l}\text { RCT, } \\
\text { DB, PC }\end{array}$ & $60 \%(95 \%$ CI $46 \%-73 \%)$ & NA \\
\hline Manchikanti et al (311) 2002 & $3 / 5$ & $10 / 14$ & 106 & $\mathrm{P}$ & $60 \%(95 \%$ CI $50 \%-70 \%)$ & $\begin{array}{l}40 \%(95 \% \text { CI } 25 \%- \\
56 \%)\end{array}$ \\
\hline Manchikanti et al (307) 2002 & $3 / 5$ & $10 / 14$ & 120 & $\mathrm{P}$ & $67 \%(95 \%$ CI 58\%-75\%) & $\begin{array}{l}\text { 63\% (95\% CI 48\%- } \\
78 \%)\end{array}$ \\
\hline Manchikanti et al (128) 2004 & $3 / 5$ & $11 / 14$ & $\begin{array}{c}255 \text { of } 500 \\
\text { patients }\end{array}$ & $\mathrm{P}$ & $55 \%(95 \%$ CI 49\%-61\%) & $\begin{array}{l}63 \%(95 \% \text { CI } 54 \%- \\
72 \%)\end{array}$ \\
\hline Manchukonda et al (129) 2007 & $3 / 5$ & $9 / 14$ & $\begin{array}{l}251 \text { of } 500 \\
\text { patients }\end{array}$ & $\mathrm{R}$ & $39 \%(95 \%$ CI $32 \%-45 \%)$ & $\begin{array}{l}45 \%(95 \% \text { CI, } 37 \% \\
-52 \%)\end{array}$ \\
\hline Speldewinde et al (312) 2001 & $3 / 5$ & $7 / 14$ & 97 & $\mathrm{R}$ & $36 \%(95 \%$ CI $27 \%-45 \%)$ & NA \\
\hline
\end{tabular}

$R C T=$ randomized, controlled trial; $P=$ prospective; $R=$ retrospective; $P C=$ placebo controlled; $D B=$ double blind; $N A=$ not available

Table 3. Data of prevalence with controlled diagnostic blocks and false-positive rates in thoracic region

\begin{tabular}{|c|c|c|c|c|c|c|}
\hline \multirow{2}{*}{ Study } & \multicolumn{2}{|c|}{ Quality Scoring } & \multirow{2}{*}{$\begin{array}{c}\text { \# of } \\
\text { Subjects }\end{array}$} & \multirow{2}{*}{ Type } & \multirow{2}{*}{ Prevalence } & \multirow{2}{*}{ False-Positive Rate } \\
\hline & AHRQ & QUADAS & & & & \\
\hline Manchikanti et al (128) 2004 & $3 / 5$ & $11 / 14$ & $\begin{array}{c}72 \text { of } 500 \\
\text { patients }\end{array}$ & $\mathrm{P}$ & $42 \%(95 \%$ CI 30\%-53\%) & $55 \%$ (95\% CI 39\%-78\%) \\
\hline Manchikanti et al (313) 2002 & $3 / 5$ & $10 / 14$ & 46 & $\mathrm{P}$ & $48 \%(95 \%$ CI 34\%-62\%) & $58 \%(95 \%$ CI 38\%-78\%) \\
\hline Manchukonda et al (129) 2007 & $3 / 5$ & $9 / 14$ & $\begin{array}{c}65 \text { of } 500 \\
\text { patients }\end{array}$ & $\mathrm{R}$ & $34 \%(95 \%$ CI $22 \%-47 \%)$ & $42 \%(95 \%$ CI $26 \%-59 \%)$ \\
\hline
\end{tabular}

$P=$ prospective $R=$ retrospective

$(30,51)$. However, if intraarticular inflammation is the proven and sole source of pain, intraarticular injection with steroid may be beneficial.

\subsubsection{Cost Effectiveness}

Diagnostic facet joint nerve blocks were not evaluated for cost effectiveness systematically. However, multiple authors $(229,230,587-589)$ described the feasibility and cost-effectiveness of appropriately performed controlled comparative local anesthetic blocks.

\subsubsection{Evidence}

The accuracy of facet joint nerve blocks is strong in the diagnosis of lumbar and cervical facet joint pain, whereas it is moderate in the diagnosis of thoracic facet joint pain.

\subsubsection{Safety and Complications}

Safety of facet joint interventions with intraarticular injections and medial branch blocks has been demonstrated. Though rare and minor, the common reported 
Interventional Techniques: Evidence-based Guidelines

Table 4. Data of prevalence with controlled diagnostic blocks and false-positive rates in lumbar region

\begin{tabular}{|c|c|c|c|c|c|c|}
\hline \multirow{2}{*}{ Study } & \multicolumn{2}{|c|}{ Quality Scoring } & \multirow{2}{*}{ \# of Subjects } & \multirow{2}{*}{ Type } & \multirow{2}{*}{ Prevalence } & \multirow[t]{2}{*}{ False-Positive Rate } \\
\hline & AHRQ & QUADAS & & & & \\
\hline $\begin{array}{l}\text { Schwarzer et al (300) } \\
1994\end{array}$ & $4 / 5$ & $12 / 14$ & 176 & $\mathrm{P}$ & $15 \%$ (95\% CI 10\%-20\%) & NA \\
\hline $\begin{array}{l}\text { Schwarzer et al (578) } \\
1994\end{array}$ & $4 / 5$ & $12 / 14$ & 176 & $\begin{array}{l}\text { Subjects } \\
\text { from } \\
\text { previous } \\
\text { study }\end{array}$ & $15 \%$ & $38 \%$ (95\% CI 30\%-46\%) \\
\hline $\begin{array}{l}\text { Schwarzer et al (302) } \\
1995\end{array}$ & $1 / 4$ & $12 / 14$ & 63 & $\mathrm{P}, \mathrm{SB}$ & $40 \%$ (95\% CI 27\%-53\%) & NA \\
\hline $\begin{array}{l}\text { Manchikanti et al } \\
\text { (303) } 1999\end{array}$ & $3 / 5$ & $8 / 14$ & 120 & $\mathrm{P}$ & $45 \%$ (95\% CI 36\%-54\%) & $41 \%$ (95\% CI 29\%-53\%) \\
\hline $\begin{array}{l}\text { Manchikanti et al } \\
\text { (305) } 2000\end{array}$ & $3 / 5$ & $11 / 14$ & 200 & $\mathrm{P}$ & $42 \%$ (95\% CI 35\%-49\%) & $37 \%$ (95\% CI $28 \%-46 \%)$ \\
\hline $\begin{array}{l}\text { Manchikanti et al } \\
\text { (304) } 2000\end{array}$ & $3 / 5$ & $10 / 14$ & 180 & $\mathrm{P}$ & $\begin{array}{l}\text { Average } 36 \% \text { I: } 38 \% \text { (CI } \\
26 \%-50 \% \text { ) II: } 32 \% \text { (CI } \\
20 \%-44 \% \text { ) III: } 38 \% \text { (CI } \\
26 \%-50 \%)\end{array}$ & $\begin{array}{l}\text { Average 25\% I: 22\% (CI } \\
\text { 9\%-35\%) II: } 27 \% \text { (CI } \\
\text { 13\%-41\%) III: } 27 \% \text { (CI } \\
13 \%-41 \%)\end{array}$ \\
\hline $\begin{array}{l}\text { Manchikanti et al } \\
\text { (230) } 2001\end{array}$ & $4 / 5$ & $10 / 14$ & 120 & $\mathrm{P}$ & $\begin{array}{l}40 \% \text { (95\% CI } 31 \% \text {, } \\
49 \%)\end{array}$ & $47 \%$ (95\% CI 35\%, 59\%) \\
\hline $\begin{array}{l}\text { Manchikanti et al } \\
\text { (586) } 2001\end{array}$ & $3 / 5$ & $8 / 14$ & $\begin{array}{c}\text { Gp I }(<65 \\
\text { years })=50 \text { Gp II } \\
(>65 \text { years })=50\end{array}$ & $\mathrm{P}$ & $\begin{array}{l}\text { I: } 30 \% \text { CI } 17 \%-43 \%) \text { II: } \\
52 \% \text { CI } 38 \%-66 \%)\end{array}$ & $\begin{array}{l}\text { I: } 26 \% \text { CI } 11 \%-40 \%) \text { II: } \\
33 \% \text { CI } 14 \%-35 \%)\end{array}$ \\
\hline $\begin{array}{l}\text { Manchikanti et al } \\
\text { (498) } 2001\end{array}$ & $3 / 5$ & $7 / 14$ & $\begin{array}{c}\text { Gp I (no prior } \\
\text { surgery)=50 Gp II } \\
\text { (prior surgery) }=50\end{array}$ & $\mathrm{P}$ & $\begin{array}{l}\text { I: } 44 \% \text { ( } 95 \% \text { CI } 31 \%- \\
49 \%) \text { II: } 32 \% \text { ( } 95 \% \text { CI } \\
19 \%-45 \%)\end{array}$ & $\begin{array}{l}\text { I: } 36 \% \text { (95\% CI 18\%- } \\
54 \%) \text { II: } 24 \% \text { ( } 95 \% \text { CI } \\
9 \%-38 \%)\end{array}$ \\
\hline $\begin{array}{l}\text { Manchikanti et al } \\
\text { (809) } 2001\end{array}$ & $3 / 5$ & $7 / 14$ & $\begin{array}{c}\mathrm{Gp} \text { I }(\mathrm{BMI}<30)=50 \\
\mathrm{Gp} \mathrm{II}(\mathrm{BMI} \\
>30)=50\end{array}$ & $\mathrm{P}$ & $\begin{array}{l}\text { I: } 36 \% \text { ( } 95 \% \text { CI } 22 \%- \\
50 \%) \text { II: } 40 \% \text { ( } 95 \% \text { CI } \\
26 \%-54 \%)\end{array}$ & $\begin{array}{l}\text { I: } 44 \% \text { (95\% CI } 26 \%- \\
61 \%) \text { II: } 33 \% \text { ( } 95 \% \text { CI } \\
16 \%-51 \%)\end{array}$ \\
\hline $\begin{array}{l}\text { Manchikanti et al } \\
\text { (307) } 2002\end{array}$ & $3 / 5$ & $8 / 14$ & 120 & $\mathrm{P}$ & $40 \%$ (95\% CI 31\%-49\%) & $30 \%$ (95\% CI $20 \%-40 \%)$ \\
\hline $\begin{array}{l}\text { Manchikanti et al } \\
\text { (306) } 2003\end{array}$ & $4 / 5$ & $9 / 14$ & $\begin{array}{l}\text { GI: Single region } \\
=150 \text { GII: multiple } \\
\text { regions }=150\end{array}$ & $\mathrm{P}$ & $\begin{array}{l}\text { I: } 21 \%(95 \% \text { CI } 14 \%- \\
27 \%) \text { II : } 41 \%(95 \% \text { CI } \\
33 \%-49 \%)\end{array}$ & $\begin{array}{l}\text { I: } 17 \%(95 \% \text { CI } 10 \%- \\
24 \%) \text { II : } 27 \%(95 \% \text { CI } \\
18 \%-36 \%)\end{array}$ \\
\hline $\begin{array}{l}\text { Manchikanti et al } \\
\text { (128) } 2004\end{array}$ & $3 / 5$ & $11 / 14$ & 397 of 500 patients & $\mathrm{P}$ & $31 \%$ (95\% CI 27\%-36\%) & $27 \%$ (95\% CI $22 \%-32 \%)$ \\
\hline $\begin{array}{l}\text { Manchukonda et al } \\
\text { (129) } 2007\end{array}$ & $3 / 5$ & $9 / 14$ & 303 of 500 patients & $\mathrm{R}$ & $27 \%$ (95\% CI $22 \%-33 \%)$ & $45 \%$ (95\% CI 36\%-53\%) \\
\hline $\begin{array}{l}\text { Manchikanti et al } \\
\text { (308) } 2007\end{array}$ & $4 / 5$ & $12 / 14$ & 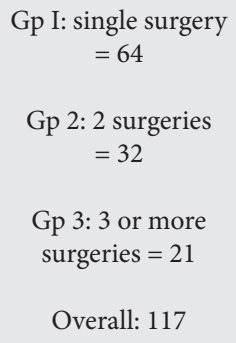 & $\mathrm{P}$ & $\begin{array}{l}14 \%(95 \% \text { CI 5\%-23\%) } \\
19 \%(95 \% \text { CI 5\%-33\%) } \\
19 \%(95 \% \text { CI 2\%-36\%) } \\
\text { Overall: } 16 \%(95 \% \text { CI } \\
9 \%-23 \%)\end{array}$ & $\begin{array}{l}49 \% \text { (95\% CI 36\%-63\%) } \\
50 \% \text { (95\% CI 30\%-70\%) } \\
\text { 47\% (95\% CI 23\%-71\%) } \\
\text { Overall: 49\% (95\% CI } \\
39 \%-59 \%)\end{array}$ \\
\hline
\end{tabular}

$P=$ prospective $S B=$ single blind $R=$ retrospective 
complications of facet joint injections or nerve blocks are related to needle placement and drug administration. These complications include hemorrhage, dural puncture, spinal cord trauma, infection, intraarterial or intravenous injection, chemical meningitis, neural trauma, paralysis, pneumothorax, radiation exposure, facet capsule rupture, hematoma formation, steroid side effects, and epidural, subdural or subarachnoid spread $(1-4,30,34-36,50,51,559,590-610)$.

\subsection{Provocation Discography}

Discography is a procedure that is used to characterize the pathoanatomy/architecture of the intervertebral disc and to determine if the IVD is a source of chronic spinal pain. Implicitly, discography is an invasive diagnostic test that should only be applied to those chronic spinal pain patients in whom one suspects a discogenic etiology. Discography literally means the opacification of the nucleus pulposus of an intervertebral disc to render it visible under radiographs (546). The commonly practiced technical and evaluative components of discography include: sterile needle placement into the center of the IVD (nucleus pulposus), radiopaque contrast instillation to provoke pain, radiological assessment of disc morphology, and clinical assessment of the intensity and concordancy of evoked pain in relation to baseline pain. Discography has been used extensively in the study of lumbar discs, somewhat less so in cervical discs, and infrequently in thoracic discs.

\subsubsection{Rationale}

Formal studies have shown that the discs are innervated and can be a source of pain that has pathomorphologic correlates (243,317-415). Even though the specific neurobiological events involved in how discography causes pain have not been elucidated, sound anatomic, histopathological, radiological, and biomechanical evidence suggests that lumbar discography may help to identify symptomatic and pathological IVDs $(32,39,49,546)$. However, the cervical and thoracic discs differ from lumbar discs and do not appear to suffer the same pathology (546,611-613).

Discography was performed in asymptomatic volunteers without spinal pain in the cervical spine (611), thoracic spine (612), and lumbar spine (613). It was shown that discographically normal discs were never painful in either symptomatic or asymptomatic groups.

The rationale is well established for lumbar discography $(32,39,49,546)$. Discography is helpful in patients with low back or lower extremity pain to acquire information about the structure and sensitivity of their lumbar intervertebral discs and to make informed decisions about treatment and modifications of activity. Although the clinical exam may demonstrate a favorable correlation with discography or disc-related pain (563,570,614-617), this information may not be sufficient to guide invasive treatment for discogenic pain. There is a significant overlap in evoked pain patterns among discs (618).

\subsubsection{Validity}

Examinations of cadaver discs typically confirm the presence of annular tears and disc degeneration, as revealed by discograms (619-623). Multiple authors also have investigated the accuracy of discographic and CT/discographic findings based on the ability to demonstrate accurate pathology confirmed at the time of surgery. There is a high inter- and intra-observer agreement in assessing discographic morphology, i.e., the Adam's classification (624,625). It was reported that the exact reproduction of pain was more likely in ruptured or fissured discs and less likely in degenerative discs; based on the Adam's Classification (625), the sensitivity and specificity of intervertebral disc morphology was $81 \%$ and $64 \%$ respectively for pain. While many authors (626-631) demonstrated significant correlation with confirmation of reliability of provocative discography, some $(632,633)$ have demonstrated poor correlation. CT scanning post-discography provided minimal additional information (625). The validity of cervical discography was questioned by Holt in 1964 (634). He reported false-positive discograms in a large number of asymptomatic prison population. While multiple experiments were conducted to refute the data of Holt in lumbar spine, no such experiments were conducted in the cervical spine. Thus, the value of cervical discography still warrants further investigations.

Discography was compared with myelography, CT, $\mathrm{MRI}$, and results of surgical and conservative management. CT discography was reported to be more accurate than myelography $(611,619,627,628,633,635-640)$. On similar grounds, discography was shown to be superior to plain computed tomography $(636,639-642)$. While comparing the results of discography with MRI, some found discography to be as good as MRI, even though MRI was preferable as it was non-invasive and allowed assessment of more levels with one test, with minimal risk of complications and minimal discomfort $(643,644)$. However, others have identified advantages of discography with pain provocation, when MRIs 
were normal or equivocal $(611,612,645-648)$. Strong correlation was demonstrated between MR/discography and CT/discography in assessing annular tears and degeneration $(642,649,650)$. In the cervical spine, an MRI may have a false-positive rate of $51 \%$ and a false negative rate of $27 \%$ in predicting which cervical spine levels to fuse, as compared to discography (651). The role of discography in a normal MRI is of questionable value and the routine performance of discography in this setting is not advised.

A good correlation between MRI, discography, and the high intensity zone (HIZ) has been established by some $(649,650,652-658)$, while others have reported poor correlation and limited value of discography (658-660). Finally, the relationship of discography to outcomes, including conservative management, minimally invasive surgery, and open procedures remains controversial $(32,39,49)$.

While the accuracy of discography as an imaging test is high, with high specificity and sensitivity for the diagnosis of disc degeneration, the key question with discography is whether this test is accurate for the diagnosis of discogenic pain. An integral part of the problem is the lack of an adequate reference or gold standard. Surgical exposure can confirm the presence of disc degeneration or disruption, but it cannot definitely confirm the presence or absence of discogenic pain. However, the results from both surgical and minimally invasive treatment of discogenic pain in patients whose diagnosis was confirmed by discography should provide a reference standard for discogenic pain.

The face validity of discography has been established by injecting small volumes of contrast into the disc and determining concordant pain, with spread of the contrast medium in posteroanterior and lateral radiographs and/or computed tomography. This "face" validity can be challenged, since clinicians are relying on the transduction of a non-painful stimulus, pressure, into a painful stimulus. Nonetheless, discography may correlate with the use of frankly noxious intradiscal stimuli. Sixty-eight percent of patients undergoing intradiscal electrothermal therapy reported exact reproduction of their pain in quality and location; none reported unfamiliar pain (362).

Construct validity of the discograms is also equally important to avoid a false-positive result and obtain a true-positive response. Consequently, for a response to be considered positive, concordant pain must be produced; and for the test to be valid, there must be at least one disc (preferably two) that do not elicit pain upon injection, thereby serving as a control disc $(32,39,49,661-663)$.

The validity of cervical discography has been established in asymptomatic patients. However, there are no modern normative data that establish that cervical discography is a specific test for cervical discogenic pain $(32,49,546,664,665)$. There is evidence indicating that up to $40 \%$ of the positive cervical discograms may be false-positive (415). However, others (664) have concluded that cervical discography is a safe and valuable technique.

With thoracic discography, unfamiliar or disconcordant pain may be produced in Schmorl's nodes, in lifelong asymptomatic individuals (612). However, thoracic discography may demonstrate disc pathology that is not seen on MRI (612). The value of thoracic discography is preliminary.

The validity of lumbar discography has been studied extensively, yet the controversy remains $(32,39,546,663,666,667)$. While there are substantial number of proponents of discography $(32,39,49,54,67,663)$, multiple other investigators have questioned the reliability of patients' reports of concordant pain (668-673). In the modern era, the opponents of discography (674-683), as well as proponents (684-688) have published numerous articles against and in support of discography.

Carragee et al (676) performed a prospective controlled study on patients without low back pain who had undergone lumbar discography. They also reported a prospective, controlled, longitudinal study on 50 subjects without low back pain who had undergone lumbar discography as well as patients with mild persistent low back pain (677); performed discography in patients with and without low back pain following laminotomy and discectomy (678); performed discography in 8 patients without history of low back pain, all of whom underwent iliac crest harvesting for non-lumbar procedures (679); prospectively performed lumbar discography on 26 individuals, who had no history of low back pain (674); performed a prospective, observational study of patients with and without low back pain to investigate the relevance of the high intensity zone to discography pain provocation (683); performed a prospective, longitudinal study of 100 subjects with high risk factors for serious low back pain as determined by structural and psychosocial characteristics (680); retrospectively reviewed the data of positive disc injections at low pressures among 69 subjects with and without chronic low 
back pain (681); and attempted to test the hypothesis that positive discography accurately identifies the low back pain illness due to a primary discogenic lesion as determined by clinical cure with successful arthrodesis in a best case clinical setting (682). In summary, Carragee et al (674-683) state that their findings continue to offer support for the conclusion that subjects with neither low back pain, a chronic pain state, nor previous surgery have a low risk for low-pressure painful injections. However their studies were extensively criticized by others. Despite their conclusions, their data suggests that truly asymptomatic patients and discs are at a negligible risk for discography-induced pain, at low pressure. In contrast, proponents have shown a different picture with reliability of discography when it is performed appropriately (684-688).

Derby et al (684) concluded that patients with "chemically sensitized" discs had significantly better outcomes following interbody/combined fusion versus posterolateral fusions. "Chemically sensitized" referred to those discs where in the static pressure, above opening static pressure, provoked familiar pain at least at less than $15 \mathrm{lbs}$. per square inch (PSI). They speculated that these discs present pathological discs that have undergone inflammatory sensitization of their annular nociceptors. Derby et al also performed pressure-controlled discography in 13 asymptomatic volunteers evaluating 43 discs (686); performed pressure-controlled discography in 16 volunteers without low back evaluating 55 discs and in 90 chronic low back pain patients evaluating 282 discs (687); and performed pressure-controlled discography in 86 chronic low back pain patients evaluating 279 discs (688). O'Neill and Kurgansky (685) also evaluated subgroups of patients with positive discography.

In 1968, Holt (666) reported false-positive discograms in $37 \%$ of an asymptomatic prison population in the lumbar spine. Simmons et al (667) reassessed Holt's data (666) and pointed out that discography as performed by Holt, although appropriate for its time, was quite different from discography as performed in 1988. Walsh et al (613), in a carefully controlled series of disc injections in asymptomatic volunteers, showed a $0 \%$ false-positive rate, refuting the findings of Holt (666).

It is noteworthy that provocative discography provided similar results in patients with or without somatization or combinations of the psychological triad of somatization disorder, depression, and generalized anxiety disorder (689). Over a three year period, Co- hen et al (690) in a retrospective review of patients with chronic low back pain, showed that prevalence of discogenic pain was $65 \%$ irrespective of whether the patients had prior back surgery or not. They also showed that needle insertion site does not affect the percentage of positive discogram results.

Calhoun et al (691) determined that lumbar discography has a sensitivity of $90.3 \%$ and false-negative rate of $9.7 \%$, when surgical outcomes are used as the criterion standard. Pain provocation is most common with posterior annular tears. Outcome was $89 \%$ in those patients selected for provocative discography compared to those $52 \%$ for those selected by non-invasive imaging.

\subsubsection{Indications}

Much of the controversy about discography has arisen because the results of discography have been used to help decide whether a certain patient should or should not have surgery, even though patients have usually undergone other diagnostic tests, the results of which were either equivocal or non-diagnostic. Thus, discography should be performed only if the patient has failed to respond to adequate attempts at non-operative care, and if diagnostic tests such as MRI have not provided sufficient diagnostic information. Generally, discography should be viewed as an invasive test to be used to seek abnormalities when results from other tests are equivocal or inconsistent, in a patient with symptoms severe enough to require further evaluation $(32,39,49)$. Thus, specific uses for discography include, but are not limited to:

- Further evaluation of demonstrably abnormal discs to help assess the extent of abnormality or correlation of the abnormality with clinical symptoms (in case of recurrent pain from a previously operated disc and a lateral disc herniation);

- Patients with persistent, severe symptoms in whom other diagnostic tests have failed to reveal clear confirmation of a suspected disc as the source of pain;

- Assessment of patients who have failed to respond to surgical procedures to determine if there is painful pseudoarthrosis or a symptomatic disc in a posteriorly fused segment, or to evaluate possible recurrent disc herniation;

- Assessment of discs before fusion to determine if the discs within the proposed fusion segment are symptomatic and to determine if discs adjacent to this segment are normal; and

- Assessment of minimally invasive surgical candi- 
dates to confirm a contained disc herniation or to investigate contrast distribution pattern before intradiscal procedures.

Overall, discography is a useful imaging tool. Intradiscal pathology may be missed by other studies. A post-discography CT scan may provide useful, additional information, particularly to differentiate annular tears from annular disruption. Based on the present literature, discography can produce pain in patients with mild or chronic low back pain, with a chronic pain disorder, or with no pain at all. However, discography rarely provokes pain in morphologically normal discs. Annular tears, particularly those extending to the outer annulus, are often associated with discographically provoked pain. However, degenerative disc changes are not necessarily associated with pain provocation, whereas, progressive degeneration is associated with dissimilar and similar pain provocation.

Discography cannot predict future back pain problems or disability in asymptomatic patients. Discography should not be used as a screening test for employment. Patients with persistent back pain may have emotional and psychological problems which can influence future outcomes and response to therapy and the development of disability due to chronic back pain. In subjecting a patient to discography, false-positives may be reduced during discography, if only patients with normal psychomatic profiles and without other chronic pain syndromes or prior lumbar spine surgery are selected. However, in chronic pain this could be a major and difficult issue.

\subsubsection{Prevalence}

Prevalence of pain due to internal disc disruption was reported as $39 \%$ of patients suffering with chronic low back pain (367) in the United States and 7\% (229) in Taiwan. In contrast, primary discogenic pain was reported in $26 \%$ of patients suffering with chronic low back pain in the United States (230). The prevalence of cervical discogenic pain in patients with chronic neck pain of traumatic origin in informal studies was estimated to be $20 \%$ (415). Prevalence of thoracic discogenic pain has not been studied.

\subsubsection{Cost Effectiveness}

There are no cost effectiveness studies of provocative discography available in the literature.

\subsubsection{Evidence}

The evidence for cervical and thoracic discography is limited. The evidence for lumbar discography is strong for discogenic pain provided that lumbar discography is performed based on the history, physical examination, imaging data, and analysis of other precision diagnostic techniques. There is no evidence to support discography without other non-invasive or less invasive modalities of treatments or other precision diagnostic injections.

\subsubsection{Safety and Complications}

Complications related to discography include discitis, subdural abscess, spinal cord injury, vascular injury, epidural and prevertebral abscess (665,692706). Complications are less frequent with lumbar discography compared to cervical discography. Lack of permanent effects from discography has been reported (700-702). A review of lumbar discography and prophylactic antibiotics (703) concluded that with lumbar discography using a two-needle technique without prophylactic antibiotics, the risk of post discography discitis is minimal, and there is not enough support from the literature to justify the routine use of prophylactic antibiotics. They reported an overall incidence of $0.24 \%$ per patient and $0.091 \%$ per disc. However, other studies have shown effective prevention of discitis with intravenous cefazolin or vancomycin (704), and the combination of cefoperazone and sulbactam (705). The administration of intradiscal antibiotics accidentally into the intrathecal space can have significant complications (706).

\subsection{Transforaminal Epidural Injections or Se- lective Nerve Root Blocks}

Transforaminal epidural injection (modern nomenclature) or a selective nerve root block (old nomenclature) consists of injection of contrast, local anesthetic, or other substances around spinal nerves under fluoroscopy $(1-4,33,46)$. Purists insist on describing them as 2 separate and distinct techniques. However, over the years authors have used them interchangeably. Consequently, we considered transforaminal epidural and selective nerve root blocks as the same procedure. Both the provocative response and analgesic response provide clinically useful information (707-709). The validity of provocative and analgesic spinal injections was recognized as early as 1938 (707). In 1971, the value of diagnostic, selective nerve root blocks in the preoperative evaluation of patients with negative or inconclusive imaging studies and clinical findings of root irritation was reported (708). Nerve blocks were utilized to diagnose the source of radicular pain when imaging studies suggested possible com- 
pression of several nerve roots $(708,710-732)$. The relief of usual symptoms following the injection of local anesthetic, $1 \mathrm{~mL}$ of $2 \%$ lidocaine, was the main determinant. Numerous authors (710-714,721732) described results of diagnostic transforaminal epidural injections or selective nerve root blocks. The pattern of provoked symptoms from mechanical stimulation of nerve roots during selective nerve root blocks was described $(713,722,724)$. The literature on diagnostic selective nerve root blocks in the evaluation of low back pain was analyzed with the conclusion that selective nerve root blocks provide important prognostic information about surgical outcomes (726).

\subsubsection{Rationale}

Diagnostic selective nerve block is typically performed in a patient with persistent pain when history, examination, imaging, and other precision diagnostic injections and electrophysiologic testing do not identify the pain generator.

\subsubsection{Validity}

The reported sensitivity of a diagnostic selective nerve root block ranges from $45 \%$ to $100 \%(554,71$ $0,711,714,718,725,727)$. The face validity of selective nerve root blocks may be accomplished by providing the blockade under fluoroscopic visualization utilizing contrast and small volume of local anesthetic with provocative and analgesic response. However, thus far, there are no means to eliminate false-positives and establish construct validity for selective nerve root blocks. North et al (554), examined the specificity and sensitivity of a battery of local anesthetic blocks. They evaluated lumbosacral nerve root blocks, medial branch blocks, sciatic nerve blocks, and compared to lumbar subcutaneous injection of an identical volume of $3 \mathrm{~mL}$ of $0.5 \%$ bupivacaine. They showed that falsepositive results were common and specificity was low. They concluded that there was only a limited role for uncontrolled local anesthetic blocks in the diagnostic evaluation of sciatica and referred pain syndromes in general.

The construct validity of selective nerve root blocks has not been established. As for facet joint block or sacroiliac joint blocks, and provocative discography, no standards have been established to eliminate false-positive responses with transforaminal epidural injections. However, true-positive responses may be secured by performing controlled blocks with placebo injections of normal saline.
Comparative local anesthetic blocks that have been shown to be valid in the diagnosis of facet joint pain have not been studied for transforaminal usage. The only study that compared a short-acting local anesthetic (lidocaine) with a long-acting local anesthetic (bupivacaine) in selective nerve root blocks used 2 test blocks in a random order to test the validity of the block response (725). However, no differences in effect were found between lidocaine and bupivacaine. Significant false-positive rates have been described with multiple other diagnostic interventional techniques involving facet joints, intervertebral discs, and sacroiliac joints. However, at present, there are no false-positive with selective nerve root blocks if properly performed; the only outcome is either negative or positive. Further, multiple confounding factors of psychological issues and sedation have not been studied for selective nerve root blocks.

Thus, properly performed, controlled diagnostic selective nerve root blocks can be an effective technique in evaluating patients with multilevel pathology to help identify the pain generator. Similarly, they are useful when the location of symptoms seems to conflict with abnormalities identified with imaging findings $(719,732)$ or when no other cause was found based on evaluation and application of precision diagnostic techniques.

\subsubsection{Cost Effectiveness}

Cost effectiveness of diagnostic transforaminal epidural injections or selective nerve root blocks has not been evaluated. However, the feasibility and costeffectiveness of appropriately performed controlled comparative local anesthetic blocks has been described (229,587-589).

\subsubsection{Evidence}

The evidence is moderate for selective nerve root blocks in the preoperative evaluation of patients with negative or inconclusive imaging studies and clinical findings of nerve root irritation.

\subsubsection{Safety and Complications}

Complications are infrequent. However, the most common and worrisome complications of transforaminal epidural injections are related to dural puncture, infection, intravascular injection, air embolism, vascular trauma, particulate embolism, cerebral thrombosis, epidural hematoma, neural or spinal cord damage, and complications related to administration of steroids (733-760). Recent reports of paraplegia, vertebral artery dissection, neurological disorders, and death are concerning. 


\subsection{Sacroiliac Joint Blocks}

The sacroiliac joint is accepted as a potential source of low back and/or buttock pain with or without lower extremity pain (436-456). Diagnostic blocks of a sacroiliac joint can be performed to determine whether the sacroiliac joint is the source of the patient's pain $(229,230,460-465)$. The sacroiliac joint can be anesthetized with intraarticular injection of local anesthetic.

\subsubsection{Rationale}

The rationale for sacroiliac joint blocks for diagnosis is based upon the fact that sacroiliac joints are innervated and have been shown capable of being a source of low back pain and referred pain in the lower extremity (436-456). There are no definite historical, physical, or radiological features to provide accurate diagnosis of sacroiliac joint pain $(229,230,436-440,460,461,465,562,761-786)$. Nevertheless, many authors $(563,763-765,777-786)$ have advocated provocative maneuvers, which may enter into the differential diagnosis of sacroiliac joint pain. Multiple publications by Laslett et al $(562,777,778)$ extensively evaluated the value of provocations tests, and they believed that multiple tests can provide appropriate diagnosis of sacroiliac joint pain or more importantly can rule it out. Various tests described by others and a systematic methodological review has been skeptical $(786,787)$. In a study utilizing comparative, local anesthetic diagnostic intraarticular sacroiliac joint blocks to identify positive responders with chronic low back pain due to SI joint pain from non-responders, it was shown that there were no significant differences between responders and non-responders with regard to pain referral areas, while major differences between two groups were found using intensity maps; however, this study also showed correlation between the positive outcome of three or more provocational tests and the positive outcomes to the comparative local anesthetic blocks $(781,783)$. In contrast, a review by Berthelot et al $(785)$ assessed the literature on both provocative $\mathrm{SI}$ joint maneuvers as well as comparative local anesthetic intraarticular SI joint blocks, and concluded that both are unreliable for diagnosing pain originating from the SI joint. Many studies have evaluated the accuracy of plain films (766), computed tomography (767), single photon emission computed tomography (768), bone scans $(769,770)$, nuclear imaging (771-774), and magnetic resonance imaging $(775,776)$ with variable results.

\subsubsection{Validity}

The face validity of sacroiliac joint block has been established by injecting small volumes of local anesthetic with contrast into the joint and determining contrast spread in posterior, anterior and lateral radiographs. Construct validity of sacroiliac joint blocks has been established by determining the false-positive rate of single, uncontrolled, sacroiliac joint injections of $20 \%$ and $22 \%(230,461)$. False-positive responses may occur with extravasation of anesthetic agent out of the joint due to defects in the joint capsule (785). False-negative results may occur from faulty needle placement, intravascular injection or inability of the local anesthetic to reach the painful portion of the joint due to loculations $(23,48,436-440,788-791)$.

\subsubsection{Prevalence}

Several authors have shown the sacroiliac joint to be a source of pain in $10 \%$ to $30 \%$ of cases by a single block $(229,460)$ and $10 \%$ to $26.6 \%$ by a double block paradigm $(230,461,462)$. In post fusion patients the prevalence was demonstrated to be $35 \%$ with single local anesthetic blocks (465). Table 5 shows description of prevalence studies of sacroiliac joint pain with a controlled design.

\subsubsection{Cost Effectiveness}

There are no studies evaluating the cost effectiveness of diagnostic sacroiliac joint blocks.

\subsubsection{Evidence}

The evidence for the accuracy of sacroiliac joint diagnostic injections is moderate for the diagnosis of sacroiliac joint pain.

\subsubsection{Safety and Complications}

Complications of sacroiliac joint injection include infection, trauma to the sciatic nerve, embolic phenomena, and complications related to drug administration.

\subsection{Therapeutic Interventional TECHNiques}

Therapeutic interventional techniques in the management of chronic spinal pain include various types of neural blockade and minimally invasive surgical procedures. These include epidural injections, facet joint injections, neuroablation techniques, intradiscal therapies, percutaneous disc decompression, vertebral augmentation and implantables.

\subsubsection{Rationale}

The rationale for therapeutic interventional techniques in the spine is based upon the following considerations: 
Table 5. Characteristics of reported prospective diagnostic studies evaluating prevalence of sacroiliac joint pain.

\begin{tabular}{|c|c|c|c|c|}
\hline Study & Participants & Objective(s) & Interventions(s) & Result(s) \\
\hline $\begin{array}{l}\text { Maigne et al (461) } \\
\text { AHRQ Score } \\
3 / 5 \\
\text { QUADAS Score } \\
10 / 14\end{array}$ & $\begin{array}{l}54 \text { patients aged } \\
18-75 \text { with chronic } \\
\text { unilateral LBP with } \\
\text { or without radiation } \\
\text { to the posterior thigh } \\
\text { for }>50 \text { days (median } \\
4.2 \text { months). Patients } \\
\text { had failed epidural } \\
\text { or lumbar facet } \\
\text { injections. }\end{array}$ & $\begin{array}{l}\text { To determine } \\
\text { the prevalence of } \\
\text { sacroiliac joint pain in } \\
\text { a selected population } \\
\text { of patients with } \\
\text { low back pain and } \\
\text { assess certain pain } \\
\text { provocation tests. }\end{array}$ & $\begin{array}{l}\text { Successful blockade of the sacroiliac } \\
\text { joint in } 54 \text { patients. A screening block } \\
\text { was done with } 2 \% \text { lidocaine and a } \\
\text { confirmatory block was performed } \\
\text { with bupivacaine } 0.5 \% \text {. Greater than } \\
75 \% \text { relief was considered a positive } \\
\text { block. }\end{array}$ & $\begin{array}{l}\text { Prevalence }=18.5 \% \\
\text { False-positive rate } \\
=20 \%\end{array}$ \\
\hline $\begin{array}{l}\text { Manchikanti et } \\
\text { al (230) } \\
\text { AHRQ Score } \\
4 / 5 \\
\text { QUADAS Score } \\
11 / 14\end{array}$ & $\begin{array}{l}120 \text { patients (age } \\
18-90 \text { ) presenting to } \\
\text { the clinic with }>6 \\
\text { months of low back } \\
\text { pain and no structural } \\
\text { basis for the pain by } \\
\text { radiographic imaging. } \\
20 \text { patients were } \\
\text { evaluated for SI joint } \\
\text { pain. }\end{array}$ & $\begin{array}{l}\text { To determine the } \\
\text { frequency of various } \\
\text { structures responsible } \\
\text { for low back pain. }\end{array}$ & $\begin{array}{l}\text { All patients had facet blocks. } \\
\text { Nonresponders who fit criteria had } \\
\text { double injection SIJ blocks. The } \\
\text { screening block was done with } 2 \% \\
\text { lidocaine and the confirmatory } \\
\text { block was performed using } 0.5 \% \\
\text { bupivacaine. }\end{array}$ & $\begin{array}{l}\text { The incidence of } \\
\text { SIJ pain was } 2 \% \text { of } \\
\text { the overall sample } \\
\text { and } 10 \% \text { of those } \\
\text { suspected to have } \\
\text { SIJ pain. The false- } \\
\text { positive rate was } \\
22 \% \text {. }\end{array}$ \\
\hline $\begin{array}{l}\text { Irwin et al (462) } \\
\text { AHRQ Score } \\
3 / 5 \\
\text { QUADAS Score } \\
7 / 14\end{array}$ & $\begin{array}{l}158 \text { patients } \\
\text { underwent sacroiliac } \\
\text { joint injections with } \\
\text { average symptoms } \\
\text { duration of } 34 \\
\text { months. Patients } \\
\text { failed conservative } \\
\text { modalities prior to } \\
\text { injection therapy. }\end{array}$ & $\begin{array}{l}\text { To evaluate prevalence } \\
\text { and correlation } \\
\text { between age, gender, } \\
\text { and body mass index } \\
\text { by dual comparative } \\
\text { local anesthetic } \\
\text { blocks. }\end{array}$ & $\begin{array}{l}\text { The fluoroscopically guided } \\
\text { contrast-enhanced sacroiliac joint } \\
\text { injections were performed initially } \\
\text { with } 2 \mathrm{~mL} \text { of } 2 \% \text { lidocaine for the } \\
\text { first injection, followed by } 2 \mathrm{~mL} \text { of } \\
0.25 \% \text { bupivacaine, a local anesthetic, } \\
\text { for the confirmatory injection. A } \\
\text { patient was required to have at least } \\
70 \% \text { reduction of familiar painful } \\
\text { symptoms after the initial injection } \\
\text { for } 3 \text { or } 4 \text { hours for positive response. }\end{array}$ & $\begin{array}{l}26.6 \% \text { were found } \\
\text { to have sacroiliac } \\
\text { joint pain by dual } \\
\text { injections. }\end{array}$ \\
\hline
\end{tabular}

- Chronic spinal pain is a complex problem (1-4,921,52-56,209-227).

- Cardinal source(s) of chronic spinal pain, particularly discs and joints, are accessible to neural blockade (1-4,11-42,46-51).

- Removal or correction of structural abnormalities of the spine may fail to cure and may worsen painful spinal conditions (1-4,41-44,64,227,463-489).

- Degenerative processes of the spine and the origin of spinal pain are complex without correlation of radiographic changes to clinical picture and prognosis (1-4,41-44,300-311,362-365,370,375,377,463$489,521,544,545,560-577,791-808)$.

- The effectiveness of a large variety of therapeutic interventions used to manage chronic spinal pain has not been demonstrated conclusively (1-4,10$12,14,16,17,26,29,41-44,57-97,200-208,227,463-$ 489,791-795).

- There is increasing evidence supporting use of interventional techniques in managing spinal pain $(1-4,13,22-25,29-31,41,42,47,48,51,56)$.

\subsubsection{Environment}

The requirements for safe use of therapeutic interventions include a sterile operating room or a procedure room, appropriate monitoring equipment, radiological equipment, special instruments based on technique, sterile preparation with all the resuscitative equipment, needles, gowns, injectable drugs, intravenous fluids, anxiolytic medications, and trained personnel for preparation and monitoring of the 
patients. Minimum requirements include history and physical examination, informed consent, and appropriate documentation of the procedure.

\subsubsection{Contraindications}

Contraindications include ongoing bacterial infection, possible pregnancy, bleeding diathesis, and anticoagulant therapy. Precautions are warranted in patients with anticoagulant or antiplatelet therapy, diabetes mellitus and artificial heart valves (557-559).

\subsection{Facet Joint Interventions}

A preponderance of the evidence supports the existence of facet joint pain $(15,30,34-36,50,51,128$, $129,232-313,808-820)$, although there are a few detractors $(221-226,821,822)$. Based on a detailed review of the literature, the general consensus appears to be that facet joint pain can be diagnosed with reasonable certainty only on the basis of controlled diagnostic local anesthetic blocks (21,34-36,823-825). Therefore, assessment of the efficacy of interventional procedures for the treatment of facet joint pain requires that studies only employ controlled diagnostic medial branch blocks or intraarticular injections as selection criteria for such studies.

Facet joint pain may be managed by intraarticular injections, medial branch blocks, or neurolysis of medial branches (12-15,30,51).

Relief with intraarticular injections or medial branch blocks was considered as short-term if documented for less than 6 weeks, and long-term, if documented for 6 weeks or longer. Relief with medial branch neurotomy was considered short-term if it was less than 3 months, and long-term if it was 3 months or longer.

\subsubsection{Intraarticular Blocks}

Therapeutic benefit has been reported with the injection of corticosteroids, local anesthetics, or normal saline into the facet joints. The literature describing the effectiveness of these interventions is abundant. European guidelines for the management of chronic non-specific low back pain (56) described intraarticular facet joint injections as ineffective, reviewing the literature from January 1995 to November 2002. Boswell et al (30) concluded that intraarticular injections were ineffective on a long-term basis. Slipman et al (15) in a critical review determined that the evidence for the treatment of lumbar zygapophysial joint syndrome with intraarticular injections should be rated as level III (moderate) to IV (limited). Bogduk (823) in a narrative review suggested that intraarticular facet joint injections were no better than placebo for chronic lumbar spine pain.

Six randomized clinical trials offer data on the use of intraarticular injections in the spine (826-831). Open, controlled and uncontrolled clinical studies that evaluated the long-term relief from intraarticular facet joint injections are abundant $(803,831-840)$. Table 6 illustrates published results.

The effectiveness of intraarticular corticosteroid lumbar facet joint injections $(824,826,828-831)$ and cervical facet joint injections (827) was studied comparing the results to those of a similar group not receiving intraarticular steroids. Of these, 3 randomized trials, 1 by Carette et al (826) involving lumbar facet joint injections, a second study by Fuchs et al (831) and the third one by Barnsley et al (827) involving cervical facet joint injections were included. Even then, Carette et al (826) failed to exclude placebo responders, which may account for the relatively high incidence of patients in their study with presumed facet joint pain $(58 \%)$, diluting the findings of true responses, making detection of differences between the study and control groups more difficult.

Fuchs et al (831) investigated the efficacy and safety of intraarticular sodium hyaluronate $(\mathrm{SH})$ compared with intraarticular glucocorticoids (triamcinolone acetonide; TA) in the treatment of chronic nonradicular lumbar pain. They included 60 patients in this randomized, controlled, blind-observer clinical study and randomly assigned to 2 groups to receive $10 \mathrm{mg}$ of SH or $10 \mathrm{mg}$ TA per facet joint. The facet joints on both sides at level L3-4, L4-5, and L5-S1 were treated once per week under computed tomographic guidance. They used outcome parameters with visual analog scale, Roland Morris Questionnaire, Oswestry Disability Questionnaire, the Low Back Outcome Score, and the Short Form 36 questionnaire. The results showed significant pain relief, improved function and quality of life with both treatments; however, this study also showed intraarticular hyaluronic acid was not inferior to intraarticular glucocorticoid injections. The follow-up was carried out at 3 and 6 months after completion of treatment; thus, this was considered as a positive study for both hyaluronic acid and glucocorticoid injections. The drawbacks of this study include lack of diagnosis of facet joint pain by controlled local anesthetic blocks which may have increased the probability of inclusion of patients without facet joint pain.

Barnsley et al (827) included a small number of patients, a total of 41 , whose origin of neck pain 
Table 6. Results of published reports of effectiveness of intraarticular injections of cervical and lumbar facet joints

\begin{tabular}{|c|c|c|c|c|c|c|c|c|c|}
\hline \multirow[b]{2}{*}{ Study } & \multirow{2}{*}{$\begin{array}{c}\text { Study } \\
\text { Characteristics }\end{array}$} & \multicolumn{2}{|c|}{$\begin{array}{l}\text { Methodological } \\
\text { Quality Score(s) }\end{array}$} & \multirow{2}{*}{$\begin{array}{l}\text { No. of } \\
\text { Patients }\end{array}$} & \multirow{2}{*}{$\begin{array}{c}\text { Initial } \\
\text { Relief } \\
\\
<6 \\
\text { weeks }\end{array}$} & \multicolumn{2}{|c|}{ Long-term Relief } & \multicolumn{2}{|c|}{ Results } \\
\hline & & $\begin{array}{c}\text { AHRQ } \\
\text { Score(s) }\end{array}$ & $\begin{array}{l}\text { Cochrane } \\
\text { Score(s) }\end{array}$ & & & 3 months & $\begin{array}{c}6 \\
\text { months }\end{array}$ & $\begin{array}{c}\text { Short- } \\
\text { term } \\
<6 \\
\text { weeks }\end{array}$ & $\begin{array}{c}\text { Long- } \\
\text { term } \\
\text { relief } \geq \\
6 \text { weeks }\end{array}$ \\
\hline \multicolumn{10}{|l|}{ Lumbar Spine } \\
\hline Carette et al (826) & PC, RA, DB & $10 / 10$ & $10 / 10$ & $\begin{array}{l}\mathrm{C}=50 \\
\mathrm{~T}=51\end{array}$ & $\begin{array}{c}33 \% \text { vs } \\
42 \%\end{array}$ & NA & $\begin{array}{c}15 \% \text { vs } \\
42 \%\end{array}$ & $\mathrm{~N}$ & $\mathrm{~N}$ \\
\hline Fuchs et al (831) & $\mathrm{RA}, \mathrm{DB}$ & $9 / 10$ & $9 / 10$ & 60 & SI & SI & SI & $\mathbf{P}$ & $\mathbf{P}$ \\
\hline Schulte et al (834) & $p$ & $6 / 8$ & --- & 39 & $62 \%$ & $41 \%$ & $36 \%$ & 9 & $\mathrm{~N}$ \\
\hline $\begin{array}{l}\text { Lynch and Taylor } \\
\text { (838) }\end{array}$ & $p$ & $6 / 8$ & --- & $\begin{array}{l}\text { Extraarti. }=15 \\
\text { Intraarti. }=35\end{array}$ & $\begin{array}{c}53 \% \text { vs } \\
89 \%\end{array}$ & $62 \%$ & $56 \%$ & $\mathbf{P}$ & $\mathbf{P}$ \\
\hline Murtagh (803) & $p$ & $6 / 8$ & --- & 100 & NA & $54 \%$ & $54 \%$ & $\mathbf{P}$ & $\mathbf{P}$ \\
\hline Desoutet et al (837) & $p$ & $6 / 8$ & --- & 54 & $54 \%$ & $38 \%$ & $38 \%$ & $\mathbf{P}$ & $\mathrm{N}$ \\
\hline Lippitt (839) & $\mathrm{R}$ & $5 / 8$ & --- & 99 & $42 \%$ & $51 \%$ & $14 \%$ & $\mathrm{~N}$ & $\mathrm{~N}$ \\
\hline Lau et al (840) & $\mathrm{R}$ & $6 / 8$ & --- & 34 & $56 \%$ & $44 \%$ & $35 \%$ & $\mathbf{P}$ & $\mathrm{N}$ \\
\hline \multicolumn{10}{|l|}{ Cervical Spine } \\
\hline Barnsley et al (827) & RA, DB & $10 / 10$ & $9 / 10$ & 41 & $50 \%$ & NA & NA & $\mathrm{N}$ & $\mathrm{N}$ \\
\hline Kim et al (835) & $p$ & $4 / 8$ & --- & 60 & SI & SI & SI & $\mathbf{P}$ & $\mathbf{P}$ \\
\hline Folman et al (836) & $p$ & $4 / 8$ & --- & 30 & SI & SI & NA & $\mathbf{P}$ & $\mathbf{P}$ \\
\hline
\end{tabular}

$R=$ Retrospective $P=$ prospective $; R A=$ randomized $P C=$ placebo controlled $; D B=$ double blind $; C=$ control $; T=$ treatment;

$N A=$ not available $; S I=$ significant improvement $; \mathbf{P}=$ positive,$N=$ negative

was posttraumatic following whiplash. Consequently, these results, although from randomized trials, may not be applied across a heterogenous population.

Among the other 3 randomized trials, Marks et al (828) and Nash (829) compared the effects of intraarticular injections with medial branch blocks with a single injection, with only short-term evaluation. Lilius et al (830) used overly broad criteria for inclusion without confirming the diagnosis by controlled diagnostic blocks, and used excessive injectate volumes ( $3 \mathrm{~mL}$ to $8 \mathrm{~mL}$ ) of active agents.
Both well-controlled trials of Carette et al (826) and Fuchs et al (831) were included in the lumbar evaluation. Carette et al (826) showed that $42 \%$ of the methylprednisolone group (20 patients), versus 33\% of the saline group (16 patients) achieved significant relief at the 1-month follow-up. However, at 6-month follow-up, $46 \%$ of the patients in the methylprednisolone group compared to $15 \%$ of the patients in the saline group continued to experience marked pain relief, with a statistically significant difference. Fuchs et al (831) showed positive results both with intraarticular hyaluronic acid and glucocorticoid injections with in- 
jections performed under fluoroscopy with excellent outcome parameters. The only drawback was the lack of diagnostic blocks and exclusion of patients with false-positive pain.

Barnsley et al (827) showed that the time to return to $50 \%$ of baseline pain was 3 days in the steroid group and 3.5 days in the local anesthetic group. Less than half of the patients reported relief of pain for more than 1 week, and fewer than 1 in 5 patients reported relief for more than 1 month, regardless of whether the injection was with steroids or local anesthetic.

Among the non-randomized trials, multiple observational studies were evaluated for inclusion. Among these, 6 prospective studies $(803,834-838)$ and 2 retrospective evaluations $(839,840)$ were included in evidence synthesis. Schulte et al (834) evaluated 39 patients with lumbar facet syndrome using a standarized protocol with injection of steroid, lidocaine and $5 \%$ phenol under fluoroscopic control, and evaluated on follow-up based on a specially designed questionnaire, which included McNab criteria, visual analogue scale, and pain disability index. They reported pain relief up to 6 months after treatment. The outcome was assessed excellent or good by $62 \%$ (24 patients) of the patients after one month, by $41 \%$ (16 patients) after 3 months, and by $36 \%$ (14 patients) after 6 months. They concluded that facet joint injection therapy using a standardized protocol is safe, effective, and easy to perform. Multiple disadvantages of this study include lack of appropriate diagnosis of facet joint pain by controlled local anesthetic blocks, including many false-positive patients and the injection of phenol along with steroid. Combinations of phenol and steroid have not been recommended since phenol is injected to induce inflammation whereas prednisolone suppresses the inflammation. However, the results were positive with $62 \%$ of the patients reporting excellent or good pain relief after 1 month with a single block which extended to $36 \%$ of the patients after 6 months. Lynch and Taylor (838) reported initial pain relief in 31 of 35 patients receiving intraarticular steroids, whereas 8 of 15 patients receiving extraarticular steroids reported initial pain relief. Long-term pain relief was reported in $62 \%$ at 3 months, and $56 \%$ at 6 months. Destouet et al (837) reported significant pain relief for 1 to 3 months in $54 \%$ of the patients and 3 to 6 months in $38 \%$ of the 54 patients. Murtagh (803) reported long-term relief of up to 6 months in 54\% of the 100 patients. Among the retrospective evalu- ations, Lippitt (839) reported greater than $50 \%$ relief initially in $42 \%$ of patients, which declined to $14 \%$ at 6 months and $8 \%$ at 12 months in 99 patients. Lau et al (840) also reported initial relief in $56 \%$ of the patients, which declined to $44 \%$ at 3 months, and $35 \%$ at 6 to 12 months. Thus, all the observational studies showed positive results.

Kim et al (835) classified patients with zygapophysial joint pain of $C 5 / 6$ and $C 6 / 7$ treated with therapeutic cervical zygapophysial joint injections with a mixture of $0.5 \mathrm{~mL}$ of $1 \%$ lidocaine with $5 \mathrm{mg}$ of triamcinolone under fluoroscopy. The therapeutic effects were compared with reduction of numeric rating scale (NRS) of pain before and immediately after blockade and symptom-free periods after 12 months. The NRS scores decreased immediately after blockade and the symptom-free duration after blockade lasted longer in the herniated nucleus pulposus group with $11.3 \pm$ 1.7 months than the other two groups; the myofascial pain syndrome group had relief for $3.2 \pm 0.9$ months, while the whiplash-associated disorders group had relief lasting for $3.0 \pm 0.8$ months. While it is difficult to understand the philosophy behind the longer and better response in the herniated nucleus pulposus group overall results showed that it was effective in all groups longer than 6 weeks.

Folman et al (836) prospectively evaluated the effectiveness of facet joint injections on chronic cervical pain. Their follow-up was limited to only 3 months. They reported relief of approximately 12 to 13 weeks in patients with chronic pain which was superior to the relief of 3 days as reported in patients similarly treated following whiplash neck injury. The study was excluded from the analysis as it failed to include falsepositive patients and failed to exclude outcome parameters and had only limited follow-up periods.

Among the observational studies Gorbach et al (833) and Shih et al (832) were excluded. Gorbach et al (833) performed the injections under fluoroscopy and reported good pain relief with a single injection however, they failed to exclude false-positive patients and failed to include outcome parameters with a short-term follow-up. Basically they demonstrated that there was a positive immediate effect in $74 \%$ and a positive medium-term effect in $33 \%$ of the patients. They also postulated that outcome depended on clinical, not on morphologic or imaging findings. Shih et al (832) evaluated a large number of patients (277 patients) and included bilateral injections in 117 patients. They performed procedures under fluoros- 
copy with arthrography and provided follow-up at 1 , 3,6 and 12 weeks. They reported excellent or good response in $73.6 \%$ of the patients in the treatment group, while the control group showed improvement in only $26.4 \%$ of the patients. However the relief declined from $72.1 \%$ after 3 weeks in the study group to $40.7 \%$ after 6 weeks, and $31.4 \%$ after 12 weeks. They also showed synovial cysts in $9 \%$ of the patients of whom $92 \%$ responded well. Three of the patients had contrast medium extravasating into the epidural space during injection. The study was excluded due to shortterm follow-up and lack of exclusion of false-positives and lack of functional assessment parameters.

\subsubsection{Cost Effectiveness}

No studies were performed evaluating cost effectiveness of therapeutic intraarticular facet joint injections.

\subsubsection{Evidence}

For intraarticular injections of local anesthetics and steroids, there is moderate evidence for short and long-term improvement in managing low back pain and the evidence is limited for short and long-term relief in the management of neck pain.

\subsubsection{Medial Branch Blocks}

Therapeutic benefit has been reported with medial branch blocks with local anesthetic and local anesthetic and steroids. The literature describing the effectiveness of medial branch blocks as a therapeutic intervention is scarce. A single systematic review (30) and evidence-based guidelines $(1,2)$ evaluated the effectiveness of medial branch blocks in the management of chronic spinal pain as a therapeutic entity. The European guidelines for the management of chronic non-specific low back pain by Airaksinen et al (56) showed no significant effectiveness of medial branch blocks; however, the literature search was limited from January 1995 through November 2002, even though guidelines were published in 2006 .

The therapeutic role of medial branch blocks was evaluated in 6 randomized clinical trials $(828,829,841$ $844)$ and 2 prospective controlled trials $(845,846)$. Table 7 shows details of the included studies.

Among the randomized trials, Marks et al (828) and Nash (829) compared the effectiveness of intraarticular injections and medial branch blocks with one injection, without any long-term follow-up. Manchikanti et al (842) compared the effect of Sarapin on various types of nerve blocks including epidurals and medial branch blocks in a random manner. However, this was not a specific study of effectiveness of medial branch blocks. Thus, $3(828,829,842)$ of 6 studies were excluded. The three remaining studies met inclusion criteria $(841,843,844)$.

Manchikanti et al (841) evaluated 73 patients for lumbar facet joint pain by means of controlled, comparative local anesthetic blocks. They randomly allocated patients into 2 groups, either receiving therapeutic medial branch blocks with a local anesthetic and Sarapin or with a mixture of local anesthetic, Sarapin and methylprednisolone. Significant improvement was documented in both groups in various parameters of pain relief, functional status, opioid intake, return to work, and psychological status. Significant pain relief was seen with 1 to 3 injections in $100 \%$ of the patients up to 1 to 3 months, $82 \%$ of the patients for 4 to 6 months, and $21 \%$ for 7 to 12 months. The mean relief was $6.5 \pm 0.76$ months.

Manchikanti et al (843) evaluated effectiveness of therapeutic medial branch blocks in managing chronic neck pain in a preliminary report of a double-blind, randomized controlled trial. They reported data from a total of 60 patients, with 15 patients in each of the 4 groups. Thirty patients were in a non-steroid group and an additional 30 patients were in a steroid group. All of the patients met the diagnostic criteria of cervical facet joint pain by means of comparative, controlled diagnostic blocks. Four types of interventions were included. Group I served as control, receiving medial branch blocks using bupivacaine. Group II consisted of cervical medial branch blocks with bupivacaine and Sarapin. Group III consisted of cervical medial branch blocks with bupivacaine and betamethasone. Group IV consisted of cervical medial branch blocks with bupivacaine, Sarapin and betamethasone. Significant pain relief was defined as $50 \%$ or greater improvement in pain, and functional status improvement was evaluated by Neck Pain Disability Index, which improved significantly at 3 months, 6 months and 12 months in $80 \%-87 \%, 80 \%-93 \%$, and $87 \%-93 \%$ of patients respectively. The average number of treatments for one year was $3.8 \pm 0.7$ in the non-steroid group and $3.4 \pm 1.0$ in the steroid group. Duration of average pain relief with each procedure was $13.4 \pm$ 3.5 weeks in the non-steroid group, and it was $15.9 \pm$ 8.0 weeks in the steroid group with no significant difference among the groups. Clinically significant return-towork was seen, which was statistically insignificant. This study showed that therapeutic cervical medial branch nerve blocks, with or without Sarapin or steroids, may provide effective management for chronic neck pain of facet joint origin. 
Manchikanti et al (844) evaluated effectiveness of therapeutic lumbar facet joint nerve blocks in managing chronic low back pain in a preliminary report of a prospective, randomized, double-blind trial. They reported data from a total of 60 patients, with 15 patients in each of the 4 groups. Thirty patients were in a non-steroid group and additional 30 patients were in a steroid group. All of the patients met the diagnostic criteria of lumbar facet joint pain by means of comparative, controlled diagnostic blocks. Four types of interventions were included. Group I served as control, receiving lumbar facet joint nerve blocks using bupivacaine. Group II consisted of lumbar facet joint nerve blocks with bupivacaine and Sarapin. Group III consisted of lumbar facet joint nerve blocks with bupivacaine and betamethasone. Group IV consisted of lumbar facet joint nerve blocks with bupivacaine, Sarapin and betamethasone. Significant pain relief was defined as $50 \%$ or greater decrease in pain and functional status improvement was evaluated by Oswestry Disability Index, which improved significantly at 3 months, 6 months and 12 months in $73 \%-87 \%, 87 \%-93 \%$, and $73 \%-93 \%$ of patients respectively. The average number of treat- ments for one year was 3.7 with no significant differences among the groups. Duration of average pain relief with each procedure was $14.8 \pm 7.9$ weeks in the non-steroid group, and it was $12.5 \pm 3.3$ weeks in the steroid group with no significant difference among the groups. Clinically significant return-towork was seen, which was statistically insignificant. This study showed that therapeutic lumbar medial branch nerve blocks, with or without Sarapin or steroids, may provide effective management for chronic low back pain of facet joint origin.

Manchikanti et al (845) evaluated the therapeutic effectiveness of cervical facet joint nerve blocks in chronic neck pain in a prospective outcome study. They evaluated 100 consecutive patients meeting the diagnostic criteria of facet joint pain by means of comparative, controlled diagnostic blocks. There were significant differences in numeric pain scores and pain relief (> 50\%) at 3 months (92\%), 6 months (82\%), and 12 months (56\%) compared to baseline measurements. There was significant improvement in functional status, psychological status and employment among patients eligible for employment (employed and unemployed) from baseline to 12 months.

Table 7. Results of published reports of effectiveness of cervical, thoracic and lumbar medial branch blocks

\begin{tabular}{|c|c|c|c|c|c|c|c|c|c|}
\hline \multirow[b]{2}{*}{ Study } & \multirow[b]{2}{*}{$\begin{array}{c}\text { Study } \\
\text { Characteristics }\end{array}$} & \multicolumn{2}{|c|}{$\begin{array}{l}\text { Methodological } \\
\text { Quality Score(s) }\end{array}$} & \multirow[b]{2}{*}{$\begin{array}{l}\text { No. of } \\
\text { Patients }\end{array}$} & \multirow{2}{*}{$\begin{array}{c}\text { Initial } \\
\text { Relief }\end{array}$} & \multicolumn{2}{|c|}{ Long-term Relief } & \multicolumn{2}{|c|}{ Results } \\
\hline & & $\begin{array}{c}\text { AHRQ } \\
\text { Score(s) }\end{array}$ & $\begin{array}{l}\text { Cochrane } \\
\text { Score }(s)\end{array}$ & & & $\begin{array}{c}3 \\
\text { months }\end{array}$ & $\begin{array}{c}6 \\
\text { months }\end{array}$ & $\begin{array}{c}\text { Short- } \\
\text { term } \\
\text { relief } \\
<6 \\
\text { weeks }\end{array}$ & $\begin{array}{c}\text { Long- } \\
\text { term } \\
\text { relief } \\
\geq 6 \\
\text { weeks }\end{array}$ \\
\hline \multicolumn{10}{|l|}{ CERVICAL } \\
\hline Manchikanti et al (843) & RA, DB & $7 / 10$ & $10 / 10$ & 60 & $\begin{array}{l}80 \%- \\
87 \%\end{array}$ & $\begin{array}{l}80 \%- \\
87 \%\end{array}$ & $\begin{array}{l}80 \%- \\
93 \%\end{array}$ & $\mathbf{P}$ & $\mathbf{P}$ \\
\hline Manchikanti et al (845) & $P$ & $8 / 8$ & --- & 100 & $92 \%$ & $92 \%$ & $82 \%$ & $\mathbf{P}$ & $\mathbf{P}$ \\
\hline \multicolumn{10}{|l|}{ THORACIC } \\
\hline Manchikanti et al (846) & $P$ & $8 / 10$ & --- & 55 & $71 \%$ & $71 \%$ & $71 \%$ & $\mathbf{P}$ & $\mathbf{P}$ \\
\hline \multicolumn{10}{|l|}{ LUMBAR } \\
\hline Manchikanti et al (844) & RA, DB & $8 / 10$ & $8 / 10$ & 60 & $\begin{array}{l}73 \%- \\
87 \%\end{array}$ & $\begin{array}{l}73 \%- \\
87 \%\end{array}$ & $\begin{array}{c}87 \%- \\
93 \%\end{array}$ & $\mathbf{P}$ & $\mathbf{P}$ \\
\hline Manchikanti et al (841) & RA & $8 / 10$ & $6 / 10$ & 73 & $100 \%$ & 100 & $82 \%$ & $\mathbf{P}$ & $\mathbf{P}$ \\
\hline
\end{tabular}

$P=$ prospective $; R A=$ randomized $; D B=$ Double-blind $; \mathbf{P}=$ positive 
Manchikanti et al (846) in a prospective outcome study with minimum of one-year follow-up, evaluated therapeutic role of thoracic medial branch blocks in managing chronic thoracic pain. Fifty-five consecutive patients meeting the diagnostic criteria of thoracic facet joint pain by means of comparative, controlled diagnostic blocks were included. Medial branch blocks were performed with local anesthetic with or without steroids. The results showed significant differences in numeric pain scores and significant pain relief $(>50 \%)$ in $71 \%$ of the patient at 3 months and 6 months, $76 \%$ at 12 months, $71 \%$ at 24 months and $69 \%$ at 36 months, compared to baseline measurements. Functional improvement was demonstrated at 1 year, 2 years and 3 years from baseline. There was significant improvement with increase in employment among the patients eligible for employment from baseline to 1 year, 2 years, and 3 years in conjunction with improved psychological function.

\subsubsection{Cost Effectiveness}

The cost effectiveness of lumbar facet joint nerve blocks was evaluated by Manchikanti et al (841) with 1 -year improvement of quality of life at $\$ 3,461$. The cost of one-year improvement was similar to various investigations with neural blockade, but also was significantly better than the cost effectiveness with intrathecal morphine delivery or lumbar laminectomy, with or without instrumented fusion.

\subsubsection{Evidence}

The evidence for lumbar, cervical, and thoracic medial branch blocks in managing chronic low back, neck, mid back and upper back pain is moderate for short-term and long-term pain relief.

\subsubsection{Medial Branch Neurotomy}

Percutaneous neurotomy of medial branches is a procedure that offers pain relief by denervation of the nerves that innervate a painful joint. The denervation may be performed by radiofrequency thermoneurolysis utilizing a thermal or pulsed mode, cryoneurolysis, or laser denervation.

There have been 5 systematic reviews of medial branch radiofrequency neurotomy $(12-15,30)$ and there also have been multiple guidelines $(3,4,56)$. However, there have not been any significant publications or systematic reviews with pulsed radiofrequency, cryoneurolysis, and laser neurotomy.

Geurts et al (12) concluded that there was moderate evidence that radiofrequency lumbar facet denervation was more effective for chronic low back pain than placebo, and there was only limited evidence ex- istent for effectiveness of radiofrequency neurotomy for chronic cervical zygapophysial joint pain after flexion/extension injury. Manchikanti et al (13) concluded that there was strong evidence for short-term relief and moderate evidence for long-term relief of facet joint pain. Niemesto et al (14), within the framework of the Cochrane Collaboration Back Review Group, concluded that there was limited evidence that radiofrequency denervation had a positive short-term effect on chronic cervical zygapophysial joint pain, and a conflicting short-term effect on chronic low back pain. In the European Guidelines for the management of chronic non-specific low back pain (56), utilizing the literature through 2002, published in 2006, they concluded that there is conflicting evidence that radiofrequency denervation of the facet joints is more successful than placebo for eliciting short-term or long-term improvements in pain or functional disability in mechanical chronic low back pain (Level $\mathrm{C}$ evidence). However they also concluded that there is limited evidence that intraarticular denervation of the facet joints is more effective than extra-articular denervation. Further, they concluded that proper selection of patients with successful diagnostic blocks and an optimal technique may be important to achieve better results; however, they also denied the recommendation of radiofrequency facet denervation for patients with non-specific chronic low back pain. In a health technology assessment by Canadian Agency for Drugs and Technologies in Health by Murtagh and Foerster (62) in an evaluation of radiofrequency neurotomy for lumbar pain, utilizing the modern evidence, concluded that the procedure continues to be an emerging technology, with some studies suggesting it is efficacious, but procedural and other methodological shortcomings rendering much of this research inconclusive. They also added that the most rigorous assessment to date suggests that meticulous attention to diagnosis and treatment may generate positive results. Slipman et al (15) concluded that current studies failed to give more than sparse evidence to support the use of interventional techniques in the treatment of lumbar zygapophysial joint pain and the evidence for radiofrequency denervation was at Level 3 or moderate.

The systematic reviews by Manchikanti et al (13) and Boswell et al (30) evaluated the effectiveness of facet joint neurotomy utilizing the criteria established by Agency for Health Care Research and Quality (AHRQ) for evaluation of randomized and non-ran- 
domized trials and Cochrane Musculoskeletal Review Group for randomized trials. They concluded that the evidence for pain relief with radiofrequency neurotomy of medial branch nerves was moderate to strong in cervical and lumbar spine. Slipman et al (15) utilized the criteria by AHRQ. Thus, the systematic reviews by Manchikanti et al (13), Slipman et al (15), and Boswell et al (30) met inclusion criteria.

Due to several deficiencies, 2 systematic reviews $(12,14)$ were excluded from evidence synthesis.

The therapeutic role of medial branch neurotomy was evaluated in 8 randomized trials (847-854), and in 18 observational studies (855-872). Two randomized trials $(847,848)$ and 15 observational studies (855-869) were included in evidence synthesis. Six of 8 randomized trials were excluded because of inappropriate inclusion criteria, inappropriate diagnostic evaluation, inappropriate interventions, or inadequate follow-up. Fifteen of 18 observational studies were included in evidence synthesis. Results of various studies included in evidence synthesis are illustrated in Table 8 showing the results of cervical medial branch neurotomy, in Table 9 showing the results of lumbar medial branch neurotomy and Table 10 showing thoracic medial branch neurotomy.

Lord et al (847) evaluated percutaneous radiofrequency neurotomy in patients with cervical facet joint pain with controlled local anesthetic blocks, in a double-blind, placebo-controlled trial. The results showed that the median time that elapsed before the pain returned to at least $50 \%$ of the preoperative level was 263 days in the active treatment group and 8 days in the control group. The authors concluded that in patients with chronic cervical facet joint pain, percutaneous radiofrequency neurotomy with multiple lesions of target nerves can provide long-lasting relief. In the second study, Van Kleef et al (848) showed that after 3,6 , and 12 months, the number of successes in the lesion and sham groups was 9 and 4, 7 and 3, and 7 and 2, respectively. These results demonstrated that radiofrequency denervation of the lumbar facet joints can be effective for pain reduction in patients with lumbar facet joint pain.

Haspeslagh et al (853) in a randomized controlled trial of cervical radiofrequency lesions as a treatment for cervicogenic headache evaluated 30 patients with cervicogenic headache according to Sjaastad diagnostic criteria, with 15 patients receiving a sequence of radiofrequency treatments with cervical facet joint denervation followed by cervical dorsal root ganglion lesions when necessary, and other 15 patients undergoing local injections with steroid and anesthetic at the greater occipital nerve, followed by transcutaneous electrical nerve stimulation when necessary. There were no statistically significant differences between the two treatment groups at any time point in the trial. They concluded that they did not find evidence that radiofrequency treatment of cervical facet joints and upper dorsal root ganglions is a better treatment than infiltration of the greater occipital nerve, followed by TENS for patients fulfilling the clinical criteria of cervicogenic headache. This study was totally flawed not only in the diagnosis but also in the application of technique. Authors claim that they developed a sequence of various cervical radiofrequency neurotomies that proved successful in a prospective pilot trial with 15 chronic headache patients. Their diagnosis was not established by controlled diagnostic blocks; in addition, the treatments were targeting 2 different structures, namely cervical facet joints and dorsal root ganglion compared to occipital nerves. Thus, this study was excluded from evidence synthesis.

Van Wijk et al (854) in a study which sounds elegant and technically competent, described radiofrequency denervation of lumbar facet joints in the treatment of chronic low back pain: a randomized, double-blind, sham lesion-controlled trial evaluated a total of 81 out of 462 patients randomly assigned to radiofrequency denervation or sham treatment. Multiple outcome measures were used. They concluded that the combined outcome measure and VAS showed no difference between radiofrequency and sham, though in both groups, significant VAS improvements occurred. However, the global perceived effect was in favor of radiofrequency. They also concluded that in selected patients, radiofrequency facet denervation appears to be more effective than sham treatment. This study has numerous deficiencies, such as criteria for inclusion which consisted of a single diagnostic block and only $50 \%$ relief on visual analog scale reduction from the diagnostic block, which will not eliminate falsepositives. There also has been criticism regarding technical aspects of this procedure $(873,874)$. It has been compared with a study by Dreyfuss et al (865) which was meticulously performed. Other randomized trials were also excluded as they failed to meet inclusion or methodological criteria. The study by Leclaire et al (851), on the surface appeared to be an elegant, well-performed, double-blind, placebo- 
controlled trial, similar to the one by Van Wijk et al (854). However this study had numerous deficiencies, as it failed to define the study population using appropriate diagnostic criteria which was a fatal error. Patients were evaluated with a single diagnostic block. These authors considered any pain relief of 1 day duration during a 7-day period following a single diagnostic block. This type of pain relief may be as a result of many, many factors including natural sequence; consequently, any results or conclusions based on this study would be erroneous $(875,876)$. Thus, it was excluded from the analysis. A study by Gallagher et al (849) was not included because it used the invalidated Shealy technique, and failed to describe appropriate diagnostic techniques and outcome analysis. It is also unclear whether these interventions were performed with or without fluoroscopy. Two other studies were excluded from inclusion and evidence synthesis: one study used intraarticular facet joint denervation (850), which is not medial branch neurotomy and is of unclear clin- ical relevance, while another study (852) compared reproducibility of lesion size of 2 current radiofrequency techniques.

Multiple non-randomized evaluations were included in the evidence synthesis. Staender et al (858) performed a computerized tomography-guided cryoneurolysis in 76 patients with lumbar facet joint syndrome. In this prospective evaluation a diagnosis was established after 3 positive CT-guided medial branch nerve blocks. Outcome measurements which included visual analog score, use of medication, ability to work and physical conditions was evaluated at 3 days, 3 months and every 3 months thereafter, with a median follow-up period of 22.5 months ranging from 6 to 43 months. They reported significant reductions in the VAS at 3 months and 6 months postoperatively. In $40 \%$ of patients pain was reduced for 12 months or longer, 18 patients underwent a second, 7 a third, and 1 a fourth kryorhizotomy. Birkenmaier et al (857) evaluated cryoneurolysis for lumbar facet pain diagnosed with positive medial branch local anesthetic

Table 8. Characteristics of results of studies of cervical medial branch neurotomy

\begin{tabular}{|c|c|c|c|c|c|c|c|c|c|}
\hline \multirow[b]{2}{*}{ Study } & \multirow{2}{*}{$\begin{array}{c}\text { Study } \\
\text { Characteristics }\end{array}$} & \multicolumn{2}{|c|}{$\begin{array}{l}\text { Methodological } \\
\text { Quality Score(s) }\end{array}$} & \multirow{2}{*}{$\begin{array}{c}\text { No. of } \\
\text { Patients }\end{array}$} & \multirow{2}{*}{$\begin{array}{c}\text { Initial } \\
\text { Relief }<3 \\
\text { months }\end{array}$} & \multicolumn{2}{|c|}{ Long-term Relief } & \multicolumn{2}{|c|}{ Results } \\
\hline & & $\begin{array}{c}\text { AHRQ } \\
\text { Score(s) }\end{array}$ & $\begin{array}{c}\text { Cochrane } \\
\text { Score(s) }\end{array}$ & & & 6 mos. & $12 \mathrm{mos}$ & $\begin{array}{c}\text { Short- } \\
\text { term } \\
\text { relief }<3 \\
\text { months }\end{array}$ & $\begin{array}{c}\text { Long- } \\
\text { term } \\
\text { relief } \geq 3 \\
\text { months }\end{array}$ \\
\hline Lord et al (847) & PC, RA, DB & $9 / 10$ & $9 / 10$ & $\begin{array}{c}\mathrm{LA}=12 \\
\mathrm{RFTN}=12\end{array}$ & $\begin{array}{c}50 \% \text { vs } \\
67 \%\end{array}$ & $\begin{array}{c}8 \% \text { vs } \\
58 \%\end{array}$ & $\begin{array}{l}8 \% \text { vs } \\
58 \%\end{array}$ & $\mathrm{P}$ & $\mathrm{P}$ \\
\hline Barnsley (855) & $\mathrm{P}$ & $7 / 8$ & --- & 35 & $74 \%$ & $74 \%$ & $74 \%$ & $P$ & $P$ \\
\hline $\begin{array}{l}\text { McDonald et al } \\
(862)\end{array}$ & $\mathrm{P}$ & $7 / 8$ & --- & 28 & $71 \%$ & $71 \%$ & $71 \%$ & $\mathrm{P}$ & $\mathrm{P}$ \\
\hline $\begin{array}{l}\text { Sapir and Gorup } \\
(861)\end{array}$ & $\mathrm{P}$ & $7 / 8$ & --- & 46 & NA & NA & NA & $\mathrm{P}$ & $\mathrm{P}$ \\
\hline Shin et al (856) & $\mathrm{P}$ & $7 / 8$ & --- & 28 & $68 \%$ & $68 \%$ & $68 \%$ & $\mathrm{P}$ & $\mathrm{P}$ \\
\hline Schaerer (864) & $\mathrm{R}$ & $5 / 8$ & --- & 117 & NA & NA & $68 \%$ & $\mathrm{~N}$ & $\mathrm{~N}$ \\
\hline $\begin{array}{l}\text { Tzaan and Tasker } \\
\text { (863) }\end{array}$ & $\mathrm{R}$ & $5 / 8$ & --- & 90 & NA & $41 \%$ & NA & $\mathrm{N}$ & $\mathrm{N}$ \\
\hline
\end{tabular}

$R=$ Retrospective; $P=$ prospective $; R A=$ randomized $P C=$ placebo controlled; $D B=$ double blind; $L A=$ local anesthetic; $R F T N=$ radiofrequency thermoneurolysis; $N A=$ not available $P=$ positive $;=$ negative 
Table 9. Characteristics of results of studies of lumbar medial branch neurotomy

\begin{tabular}{|c|c|c|c|c|c|c|c|c|c|}
\hline \multirow[b]{3}{*}{ Study } & \multirow[b]{3}{*}{$\begin{array}{c}\text { Study } \\
\text { Characteristics }\end{array}$} & \multicolumn{2}{|c|}{$\begin{array}{l}\text { Methodological } \\
\text { Quality Score(s) }\end{array}$} & \multirow[b]{3}{*}{$\begin{array}{c}\text { No. of } \\
\text { Patients }\end{array}$} & \multirow[b]{3}{*}{$\begin{array}{c}\text { Initial } \\
\text { Relief< } \\
3 \text { mos. }\end{array}$} & \multirow{2}{*}{\multicolumn{2}{|c|}{$\begin{array}{l}\text { Long-term } \\
\text { Relief }\end{array}$}} & \multirow{2}{*}{\multicolumn{2}{|c|}{ Results }} \\
\hline & & & & & & & & & \\
\hline & & $\begin{array}{c}\text { AHRQ } \\
\text { Score(s) }\end{array}$ & $\begin{array}{l}\text { Cochrane } \\
\text { Score(s) }\end{array}$ & & & 6 mos. & $\begin{array}{c}12 \\
\text { mos. }\end{array}$ & $\begin{array}{c}\text { Short- } \\
\text { term } \\
\text { relief }<3 \\
\text { mos. }\end{array}$ & $\begin{array}{c}\text { Long- } \\
\text { term } \\
\text { relief } \geq 3 \\
\text { months }\end{array}$ \\
\hline Van Kleef et al (848) & PC, RA, DB & $9 / 10$ & $7 / 10$ & $\mathrm{C}=16 \mathrm{~T}=15$ & $\begin{array}{c}38 \% \text { vs } \\
67 \%\end{array}$ & $\begin{array}{c}19 \% \text { vs } \\
47 \%\end{array}$ & $\begin{array}{c}13 \% \text { vs } \\
47 \%\end{array}$ & $\mathbf{P}$ & $\mathbf{P}$ \\
\hline Dreyfuss et al (865) & $P$ & $8 / 8$ & --- & 15 & $93 \%$ & $87 \%$ & $87 \%$ & $\mathbf{P}$ & $\mathbf{P}$ \\
\hline Mogalles et al (859) & $P$ & $6 / 8$ & --- & 15 & $93 \%$ & $93 \%$ & $93 \%$ & $\mathbf{P}$ & $\mathbf{P}$ \\
\hline Vad et al (867) & $P$ & $8 / 8$ & --- & 12 & $83 \%$ & $83 \%$ & $83 \%$ & $\mathbf{P}$ & $\mathbf{P}$ \\
\hline $\begin{array}{l}\text { Schofferman and Kine } \\
\text { (866) }\end{array}$ & $\mathrm{R}$ & $5 / 8$ & --- & 20 & $85 \%$ & $85 \%$ & $85 \%$ & $\mathbf{P}$ & $\mathbf{P}$ \\
\hline Schaerer (864) & $\mathrm{R}$ & $5 / 8$ & --- & 117 & NA & NA & $68 \%$ & $\mathrm{~N}$ & $\mathrm{~N}$ \\
\hline Tzaan and Tasker (863) & $\mathrm{R}$ & $5 / 8$ & --- & 90 & NA & $41 \%$ & NA & $\mathrm{N}$ & $\mathrm{N}$ \\
\hline North et al (868) & $\mathrm{R}$ & $6 / 8$ & --- & 42 & $45 \%$ & $45 \%$ & $45 \%$ & $\mathrm{~N}$ & $\mathrm{~N}$ \\
\hline Birkenmaier et al (857) & $P$ & $5 / 8$ & --- & 46 & $72 \%$ & $57 \%$ & $57 \%$ & $\mathbf{P}$ & $\mathbf{P}$ \\
\hline Staender et al (858) & $P$ & $5 / 8$ & --- & 76 & $40 \%$ & $40 \%$ & $40 \%$ & $\mathbf{P}$ & $\mathbf{P}$ \\
\hline $\begin{array}{l}\text { Martinez-Suarez et al } \\
(860)\end{array}$ & $\mathrm{R}$ & $4 / 8$ & --- & 252 & $75 \%$ & $75 \%$ & $75 \%$ & $\mathbf{P}$ & $\mathbf{P}$ \\
\hline
\end{tabular}

$R=$ Retrospective $; P=$ prospective $; R A=$ randomized $; P C=$ placebo controlled $; D B=$ double blind $; N A=$ not available $; \mathbf{P}=$ positive $; N=$ negative

Table 10. Characteristics of results of studies of thoracic medial branch neurotomy

\begin{tabular}{|c|c|c|c|c|c|c|c|c|}
\hline \multirow[b]{2}{*}{ Study } & \multirow[b]{2}{*}{$\begin{array}{c}\text { Study } \\
\text { Characteristics }\end{array}$} & \multirow[b]{2}{*}{$\begin{array}{c}\text { AHRQ } \\
\text { Methodological } \\
\text { Quality Score(s) }\end{array}$} & \multirow[b]{2}{*}{$\begin{array}{l}\text { No. of } \\
\text { Patients }\end{array}$} & \multirow[b]{2}{*}{$\begin{aligned} & \text { Initial } \\
& \text { Relief } \\
< & 3 \text { month }\end{aligned}$} & \multicolumn{2}{|c|}{ Long-term Relief } & \multicolumn{2}{|c|}{ Results } \\
\hline & & & & & $\begin{array}{c}6 \\
\text { months }\end{array}$ & $\begin{array}{c}12 \\
\text { months }\end{array}$ & $\begin{array}{c}\text { Short- } \\
\text { term } \\
\text { relief } \\
<3 \\
\text { months }\end{array}$ & $\begin{array}{c}\text { Long- } \\
\text { term } \\
\text { relief } \\
\geq 3 \\
\text { months }\end{array}$ \\
\hline Stolker et al (869) & $P$ & $5 / 8$ & 40 & $83 \%$ & $83 \%$ & $83 \%$ & $\mathbf{P}$ & $\mathbf{P}$ \\
\hline $\begin{array}{l}\text { Tzaan and Tasker } \\
(863)\end{array}$ & $\mathrm{R}$ & $5 / 8$ & 90 & NA & $41 \%$ & NA & $\mathrm{N}$ & $\mathrm{N}$ \\
\hline
\end{tabular}

$R=$ Retrospective $;=$ prospective $; A=$ not available $\mathbf{P}=$ positive $; N=$ negative 
blocks. In this prospective evaluation, the outcome parameters were low back pain improvement, improved activity and overall satisfaction, with determination of outcomes at 6 weeks, 3, 6, and 12 months. They reported significant improvement in low back pain (>50\%) achieved in $72 \%$ of patients at 6 weeks; $70 \%$ at 3 months, and $57 \%$ at 12 months. Thus, only one study (857) evaluating cryoneurolysis has shown positive results. This was only a prospective study and there have not been any randomized studies evaluating cryoneurolysis thus far. Further, this was evaluated only in the lumbar spine.

Mogalles et al (859) evaluated percutaneous laser denervation of the zygapophysial joints in the facet pain syndrome. This prospective evaluation included percutaneous laser denervation in 15 patients in whom the facet joint pain was confirmed by 2 diagnostic blocks. Of the 15 patients undergoing laser denervation, 8 experienced complete relief and 6 experienced more than $50 \%$ pain relief. They concluded laser denervation is an effective treatment; however this appears to be the first published study on laser denervation in a prospective study. Though selection criteria was appropriate, there were no appropriate outcome parameters and the results have not been substantiated in a randomized double-blind trial.

Barnsley (855) evaluated the results of radiofrequency for cervical facet joint pain as applied in usual clinical practice. He included the diagnosis of cervical facet joint pain made with comparative local anesthetic blocks. The primary outcome was duration of complete pain relief for all consecutive procedures performed over a 2-year period. Of the 35 patients included in the study, $60 \%$ of patients obtained complete pain relief for a duration in excess of 35 weeks. McDonald et al (862) determined the long-term efficacy of percutaneous radiofrequency medial branch neurotomy in the treatment of chronic neck pain in 28 patients diagnosed as having cervical zygapophysial joint pain, on the basis of controlled diagnostic blocks. They reported complete relief of pain in $71 \%$ of patients after an initial procedure. The median duration of relief after a first procedure was 219 days when failures were included, but 422 days when only the successes were considered. Dreyfuss et al (865) described lumbar facet joint radiofrequency neurotomy in 15 patients utilizing strict criteria and procedural considerations, and noted $60 \%$ of the patients were improved at 1 year. Sapir and Gorup (861) studied 46 patients reporting overall reduction in cervical whip- lash symptoms and visual analog pain scores in a significant proportion of patients at 1 year in both litigant and non-litigant patients. Vad et al (867) described the role of lumbar radiofrequency denervation in baseball pitchers. They reported a median pain relief of 1.3 years (range: 1 to 2.1 years) and improved function in $83 \%$, or 10 of 12 patients. Stolker et al (869) studied thoracic facet joint neurolysis in 40 patients and reported positive results, with $47.5 \%$ of the patients being pain-free and an additional 35\% having relief greater than $50 \%$ at 2-months follow-up. After a follow-up of 18 to 54 months, they reported $83 \%$ of the patients with greater than $50 \%$ pain relief.

A prospective study by Shin et al (856) evaluated the role of radiofrequency neurotomy of cervical medial branches for chronic cervicobrachialgia, radiating in typical facet joint patterns to the neck and shoulder. Twenty-eight patients with facet joint pain were identified with comparative local anesthetic blocks and subsequently underwent radiofrequency neurolysis. The primary outcome was pain relief at 1, 2, 3, 6, 9, and 12 months. Sixty-eight percent of patients had a successful outcome (> 50\% pain relief) after 6 months of follow-up; $29 \%$ reported complete pain relief.

Among the retrospective evaluations, MartinezSuarez et al (860) evaluated 252 patients with diagnosis of lumbar facet joint pain. They reported effectiveness in $74.7 \%$ of cases. Schofferman and Kine (866), in a chart review of 20 patients, reported 10.5 months of mean relief (range: 4-9 months) following lumbar radiofrequency neurotomy. Tzaan and Tasker (863) evaluated 118 consecutive percutaneous radiofrequency facet rhizotomies performed on 90 patients. They reported that with the first procedure, $41 \%$ of patients had greater than $50 \%$ subjective reduction of pain. The study included cervical, thoracic and lumbosacral facets. North et al (868) evaluated radiofrequency lumbar facet denervation with long-term outcome assessment by a disinterested third party interview. Forty-five percent of patients undergoing denervation reported at least $50 \%$ relief of pain at long-term follow-up. Schaerer (864) evaluated radiofrequency facet rhizotomy in 117 consecutive patients with chronic neck and low back pain and reported that overall results were fair to excellent in $68 \%$ of patients, with an average follow-up of 13.7 months.

The effectiveness of pulsed radiofrequency was evaluated in 2 studies $(870,871)$. Mikeladze et al (870) retrospectively evaluated 114 patients with clinical signs of facet joint involvement and a favorable re- 
sponse to a diagnostic medial branch block utilizing local anesthetic. With application of pulsed radiofrequency they reported that of 114 patients with positive response to diagnostic block, 46 patients did not response favorably to pulsed radiofrequency application. They reported success in 68 patients, with average relief lasting $3.93 \pm 1.86$ months. Eighteen patients also had the procedure repeated with the same duration of pain relief that was achieved initially. Previous surgery, duration of pain, sex, spinal levels (either cervical or lumbar), and stimulation levels did not influence outcomes. This study is not only preliminary but also had many flaws. They applied a single diagnostic block, which is subject to multiple falsepositives. In a sense, 46 patients who did not respond may represent the false-positives themselves. Further, appropriate outcome parameters were not applied. Lindner et al (871) also evaluated pulsed radiofrequency treatment of the lumbar medial branch for facet pain, the results of which were reported in 48 patients. Authors offered the pulsed radiofrequency treatment to patients who did not respond with conventional radiofrequency heat lesioning. They defined a successful outcome as a greater than $60 \%$ improvement on the numeric rating scale at 4-month followup. The successful outcome was established in 21 of 29 non-operative patients and 5 of 19 operative patients. In the unsuccessful patients who were subsequently treated with heat lesions, the success rate was 1 of 6. While this study did not compared heat lesioning directly to pulsed radiofrequency, it appears that patients failed to response to heat lesioning when they failed to respond to pulsed radiofrequency. This may confirm a proposed neuropathic component in facet joint pain, with patients responding better to medial branch nerve blocks (albeit for a shorter period) than radiofrequency. Overall the evidence for pulsed radiofrequency is very preliminary and indeterminate.

\subsubsection{Cost Effectiveness}

No cost effectiveness evaluations were performed with medial branch neurotomy.

\subsubsection{Evidence}

Evidence for radiofrequency neurotomy of medial branch of cervical spine utilizing the techniques described by Lord et al (847), McDonald et al (862), and Barnsley (855) with multiple lesioning and strict criteria of $100 \%$ pain relief with diagnostic blocks, a tedious and time-consuming procedure as described by Bogduk (877), is strong for short- and long-term relief of cervical facet joint pain.
Utilizing traditional radiofrequency neurotomy techniques as practiced in the United States in the cervical and lumbar region, the evidence for radiofrequency neurotomy of medial branches is strong for short-term and moderate for long-term relief. Evidence for cryo denervation and pulsed radiofrequency is indeterminate.

\subsubsection{Safety and Complications}

Complications are rare. Among them, the most common and worrisome complications of facet joint interventions are related to needle placement, drug administration, and neurolysis (1-4,30,34-36,50,51,590$610,699,878-885)$. Complications include dural puncture, spinal cord trauma, infection, intraarterial or intravenous injection, spinal anesthesia, chemical meningitis, neural trauma, pneumothorax, radiation exposure, facet capsule rupture, hematoma formation, and steroid side effects. In addition, potential side effects with radiofrequency denervation include painful cutaneous dysesthesias, increased pain due to neuritis or neurogenic inflammation, anesthesia dolorosa, cutaneous hyperesthesia, pneumothorax and deafferentation pain.

\subsection{Epidural Injections}

Several approaches are available to access the lumbar epidural space: caudal, interlaminar, and transforaminal $(1-4,24,25,45,886)$. There are substantial differences between the 3 approaches. The interlaminar entry is directed more closely to the assumed site of pathology, requiring less volume than the caudal route. The caudal entry is relatively easily achieved, with minimal risk of inadvertent dural puncture. The transforaminal approach is target specific with smallest volume, fulfilling the aim of reaching the primary site of pathology; the ventrolateral epidural space.

Due to the inherent variations, differences, advantages, and disadvantages applicable to each technique (including the effectiveness and outcomes), caudal epidural injections; interlaminar epidural injections (cervical, thoracic, and lumbar epidural injections); and transforaminal epidural injections (cervical, thoracic, and lumbosacral) are considered as separate entities within epidural injections and are discussed as such below.

In this evaluation, we considered all relevant quality systematic reviews $(11,24-26,28,886-888)$ along with randomized, and non-randomized trials for each category, including caudal, interlaminar, and transfo- 
raminal epidural injections. Short-term effect was defined as a significant relief of less than 6 weeks and long-term effect was defined as 6 weeks or longer relief.

Of particular importance are the European guidelines for the management of chronic non-specific low back pain (56). They included 4 high quality systematic reviews $(11,26,887,888)$; however, they included studies only through 2002 even though the guidelines were published in 2006. They did, however, include a 2004 systematic review. Based on the available literature at the time and also not separating the types of epidurals (caudal, interlaminar and transforaminal), they summarized the evidence as no evidence for the effectiveness of epidural corticosteroids in patients with non-radicular, non-specific low back pain. However, they also concluded the epidural corticosteroid injections should only be considered for radicular pain, if a contained disc prolapse is the cause of the pain and if the corticosteroid is injected close to the target. Further, they added that the injection should be fluoroscopically guided and should aim at the ventral part of the epidural space, meaning a transforaminal approach. They also concluded that there was conflicting evidence that conventional epidural steroids without fluoroscopic guidance are effective in radicular pain. The general consensus from the systematic reviews $(11,26,28,887,888)$ is that there is conflicting evidence for the effectiveness of epidural and perineural corticosteroid injections for radicular pain (Level C) (56). However, Abdi et al (24), Boswell et al (25) and Bogduk et al (886), utilizing separate though more stringent criteria, separating interlaminar, caudal and transforaminal injections, have arrived at different conclusions. These reviewers demonstrated the effectiveness of transforaminal and caudal epidural injections and ineffectiveness of interlaminar epidural injections in managing lumbar pain. Boswell et al (25) and Abdi et al (24) have shown moderate effectiveness of cervical interlaminar epidural injections.

\subsubsection{Caudal Epidural Injections}

Several systematic reviews have evaluated the effectiveness of epidural steroids in general and interlaminar epidural steroids in particular $(11,24-$ $26,28,886-888$ ). While all the reviews included caudal epidural steroid injections, some failed to separate caudal and interlaminar techniques, arriving at erroneous conclusions $(11,28,887,888)$. Of importance are systematic reviews performed by Nelemans et al (11),
Koes et al (26), Van Tulder et al (28), and guidelines by Airaksinen et al (56). All these studies included essentially the same criteria as well as the same studies, uniformly arriving at inaccurate conclusions. In contrast, Abdi et al (24) and Boswell et al (25) in a systematic review and Bogduk et al (886) in a comprehensive review, evaluated caudal epidural steroid injections as a separate procedure, reaching opposite conclusions. They concluded that the effectiveness of caudal epidural injections in managing lumbar radiculopathy was moderate.

Among the multitude of trials, there were 11 randomized trials (889-899), 5 prospective evaluations (900-904), and many retrospective evaluations $(886,905-907)$. The results of published reports of the randomized trials and prospective trials of caudal epidurals utilized in evidence synthesis and guideline preparation are shown in Table 11.

Of the 11 randomized trials, 3 studies were excluded $(897,898,890)$ from evidence synthesis, due to non-availability of analyzable information (898), due to lack of data at 3 months (897), and due to lack of appropriate data and nonuse of fluoroscopy in 2005 (890). Of the 8 randomized trials, 6 trials evaluated predominantly patients with disc herniation or radiculitis $(889,891,894-896,899), 2$ trials evaluated post surgery syndrome $(892,893), 1$ study (899) evaluated a mixed population with $50 \%$ with post surgery syndrome and the other $50 \%$ with sciatica, and 1 study (891) evaluated similarities between interlaminar and caudal. Four of the 6 trials of disc herniation or radicular pain were positive for long-term relief $(889,894,896,899)$, whereas, only one of the 2 trials (892) for post surgery syndrome was positive for short-term relief. The study of a mixed population (899) was positive for longterm relief. Thus, overall 4 of 6 studies were positive for pain of disc herniation and radiculopathy, and 1 of 2 were positive for post surgery syndrome pain.

Among the 5 prospective evaluations (900-904), the role of caudal epidural steroids was evaluated in 2 studies in patients with radiculopathy or sciatica $(902,903)$, in 2 studies in patients with chronic low back pain $(900,901)$, and in 1 study (904) with spinal stenosis. All showed positive results for short-term and long-term pain relief.

Only 1 study was performed with fluoroscopic visualization (889). In this study, caudal steroid epidural was compared with targeted steroid placement during spinal endoscopy for chronic sciatica in a prospective, randomized, double-blind trial. In this 
Table 11. Results of published reports on caudal epidural steroid injections

\begin{tabular}{|c|c|c|c|c|c|c|c|c|c|}
\hline \multirow[b]{2}{*}{ Study } & \multirow[b]{2}{*}{$\begin{array}{c}\text { Study } \\
\text { Characteristics }\end{array}$} & \multicolumn{2}{|c|}{$\begin{array}{l}\text { Methodological } \\
\text { Quality Score(s) }\end{array}$} & \multirow[b]{2}{*}{ No. of Patients } & \multirow{2}{*}{$\begin{array}{c}\text { Initial } \\
\text { Relief }\end{array}$} & \multicolumn{2}{|c|}{$\begin{array}{l}\text { Long-term } \\
\text { Relief }\end{array}$} & \multicolumn{2}{|c|}{ Results } \\
\hline & & $\begin{array}{c}\text { AHRQ } \\
\operatorname{Score}(\mathbf{s})\end{array}$ & $\begin{array}{l}\text { Cochrane } \\
\text { Score(s) }\end{array}$ & & & $3 \mathrm{mos}$ & $6 \mathrm{mos}$ & $\begin{array}{c}\text { Short- } \\
\text { term } \\
\text { relief } \\
<6 \\
\text { weeks }\end{array}$ & $\begin{array}{c}\text { Long- } \\
\text { term } \\
\text { relief } \\
\geq 6 \\
\text { weeks }\end{array}$ \\
\hline $\begin{array}{l}\text { Dashfield et al } \\
\text { (889) }\end{array}$ & RA, DB & $9 / 10$ & $8 / 10$ & $\begin{array}{c}\text { Caudal }=30 \\
\text { Endoscopy }=30\end{array}$ & SI & SI & SI & $\mathbf{P}$ & $\mathbf{P}$ \\
\hline Breivik et al (894) & RA, DB & $8 / 10$ & $7 / 10$ & $\mathrm{C}=19 \mathrm{~T}=16$ & $\begin{array}{c}25 \% \\
\text { vs. } 63 \% \\
\end{array}$ & $\begin{array}{c}20 \% \text { vs } \\
50 \%\end{array}$ & $\begin{array}{c}20 \% \text { vs. } \\
50 \%\end{array}$ & $\mathbf{P}$ & $\mathbf{P}$ \\
\hline $\begin{array}{l}\text { Bush and Hillier } \\
\text { (895) }\end{array}$ & RA, DB & $8 / 10$ & $8 / 10$ & $\mathrm{C}=11 \mathrm{~T}=12$ & $100 \%$ & NA & $\begin{array}{l}64 \% \text { vs } \\
83 \%\end{array}$ & $\mathbf{P}$ & $\mathrm{N}$ \\
\hline $\begin{array}{l}\text { Matthews et al } \\
\text { (896) }\end{array}$ & RA, DB & $8 / 10$ & $7 / 10$ & $\mathrm{C}=34 \mathrm{~T}=23$ & $\begin{array}{c}56 \% \\
\text { vs } 67 \%\end{array}$ & SI & NA & $\mathrm{N}$ & $\mathbf{P}$ \\
\hline $\begin{array}{l}\text { Helsa and Breivik } \\
(899)\end{array}$ & RA, DB & $7 / 10$ & $7 / 10$ & 69 crossover & NA & NA & $\begin{array}{c}59 \% \text { vs } \\
25 \% \\
\end{array}$ & $\mathbf{P}$ & $\mathbf{P}$ \\
\hline Revel et al (892) & RA & $7 / 10$ & $6 / 10$ & $\begin{array}{c}\text { Forceful injection }=29 \\
\quad \text { Regular }=31\end{array}$ & NA & NA & $\begin{array}{c}49 \% \text { vs } \\
19 \%\end{array}$ & $\mathbf{P}$ & $\mathrm{N}$ \\
\hline $\begin{array}{l}\text { Meadeb et al } \\
(893)\end{array}$ & RA & $6 / 10$ & $6 / 10$ & $\begin{array}{c}D=16 \\
D \pm G=15 \\
G=16\end{array}$ & NA & NA & NA & $\mathrm{N}$ & $\mathrm{N}$ \\
\hline $\begin{array}{l}\text { McGregor et al } \\
(891)\end{array}$ & RA & $6 / 10$ & $5 / 10$ & $\begin{array}{c}\text { Caudal=14 } \\
\text { Interlaminar }=16\end{array}$ & NA & NA & NA & $\mathrm{N}$ & $\mathrm{N}$ \\
\hline $\begin{array}{l}\text { Manchikanti et al } \\
(901)\end{array}$ & $\mathrm{P}$ & $5 / 8$ & --- & $\begin{array}{l}\mathrm{ND}=45 \\
\mathrm{PD}=17\end{array}$ & $\begin{array}{c}71 \% \\
\text { vs } 65 \%\end{array}$ & $\begin{array}{c}67 \% \text { vs } \\
65 \%\end{array}$ & $\begin{array}{c}47 \% \text { vs } \\
41 \%\end{array}$ & $\mathbf{P}$ & $\mathbf{P}$ \\
\hline Yates (902) & $\mathrm{P}$ & $5 / 8$ & --- & 20 & NA & NA & NA & $\mathbf{P}$ & $\mathbf{P}$ \\
\hline Waldman (903) & $\mathrm{P}$ & $5 / 8$ & --- & 53 & $63 \%$ & $67 \%$ & $71 \%$ & $\mathbf{P}$ & $\mathbf{P}$ \\
\hline Ciocon et al (904) & $\mathrm{P}$ & $5 / 8$ & --- & 30 & SI & SI & SI & $\mathbf{P}$ & $\mathbf{P}$ \\
\hline $\begin{array}{l}\text { Manchikanti et al } \\
(900)\end{array}$ & $\mathrm{P}$ & $5 / 8$ & --- & $\begin{array}{l}\mathrm{G} 1=15 \\
\mathrm{G} 2=22 \\
\mathrm{G} 3=33\end{array}$ & $\begin{array}{c}0 \% \\
100 \% \\
97 \%\end{array}$ & $\begin{array}{c}0 \% \\
59 \% \\
55 \%\end{array}$ & $\begin{array}{c}0 \% \\
19 \% \\
15 \%\end{array}$ & $\mathbf{P}$ & $\mathbf{P}$ \\
\hline
\end{tabular}

$P=$ prospective $; R A=$ randomized $; D B=$ double blind $; C=$ control $; T=$ treatment $; N A=$ not available $; S I=$ significant improvement $;$ vs = versus; $\mathbf{P}=$ positive $;=$ negative $; N D=$ negative discography; $P D=$ positive discography $D=$ disruption, $G=$ Glucocorticoid

study, for the caudal group significant improvements were found for descriptive pain at 6 months, as well as visual analog scale at 6 weeks, 3 months, and 6 months. This study also showed present pain intensity improvements at 3 months and 6 months along with improvements in anxiety at 6 weeks, 3 months and 6 months and depression at 6 months only. The authors concluded that the targeted placement of epidural steroid onto the affected nerve root causing sciatica does not significantly reduce pain intensity and anxiety and depression compared with untargeted caudal epidural steroid injection. However, both techniques 
benefited the patients.

\subsubsection{Cost Effectiveness}

The cost effectiveness of fluoroscopically directed caudal epidural steroids was $\$ 3,635$ and that of transforaminal steroids was $\$ 2,927$ per year (905). In a prospective evaluation, the cost for 1-year improvement for quality of life was $\$ 2,550$ in patients treated with caudal epidurals using local anesthetic and Sarapin or steroids under fluoroscopy (900).

\subsubsection{Evidence}

The evidence for caudal epidural steroid injections is strong for short-term relief and moderate for long-term relief, in managing chronic low back and radicular pain. The evidence in post-lumbar laminectomy syndrome and spinal stenosis is limited.

\subsubsection{Interlaminar Epidural Injections}

Multiple systematic reviews provided conflicting opinions $(11,24-26,28,886-888)$. Further, most of the systematic reviews $(11,26,28)$ utilized combined caudal and interlaminar epidural steroid injections. Consequently, no reasonable definitive conclusions may be drawn from these systematic reviews, and their conclusions may not be applied in clinical practice settings. Thus far, all the systematic reviews concluded that interlaminar epidural steroid injections lacked long-term effectiveness. Multiple guidelines $(1-4,56)$ also showed no significant evidence for long-term relief. Two systematic reviews $(24,25)$ separately analyzed caudal and interlaminar epidurals. However, they also concluded that there was strong evidence for short-term relief with only limited evidence for long-term relief of greater than 6 weeks. European guidelines for the management of chronic non-specific low back pain (56) evaluated the literature from January 1995 through November 2002. In addition, they also used evidence from 4 high quality systematic reviews $(11,26,887,888)$. But, they combined transforaminal, caudal and interlaminar epidural injections in the management of chronic low back pain. They concluded that epidural corticosteroid injections could only be considered for radicular pain and the evidence was conflicting with regards to conventional epidural steroids without fluoroscopy even in radicular pain. They also concluded that there is no evidence for the effectiveness of epidural corticosteroids in patients with non-radicular, non-specific low back pain.

Twenty-three randomized trials (891,908-929), 9 prospective evaluations (930-938), and numerous retrospective studies (939-949) were identified. Among the 23 randomized trials, 13 met inclusion criteria and were utilized for evidence synthesis with exclusion of 10 studies $(908,912,917-919,923-925,927,928)$. Since 11 randomized trials (over 10) were available in evidence synthesis for interlaminar epidural steroid injections in the lumbar spine, no prospective or other observational evaluations were utilized in the evidence synthesis.

Of the 13 randomized trials included in the evidence synthesis, 11 of them evaluated the effectiveness of interlaminar epidural steroid injections, either on disc herniation, sciatica, or radiculopathy in the lumbar spine $(891,909,910,912-916,920,921,929)$, whereas, 2 randomized evaluations included cervical disc herniation with radiculitis or brachialgia $(922,926)$. One study resulted in 2 publications $(910,911)$. None of the randomized evaluations were performed to manage axial low back pain. Results of the included studies are illustrated in Table 12. Of the 11 randomized trials evaluating lumbar radiculitis, 6 were positive for short-term relief $(909,910,912,913,920,921$, 929), whereas only one study was positive for longterm relief (916). Among the negative studies, Cuckler et al (915) included patients suffering with post surgery syndrome.

For evaluation of cervical pain and radiculopathy, 2 randomized trials $(922,926), 1$ prospective trial (930), and multiple retrospective evaluations (938-949) were available. In the evaluation of cervical interlaminar epidural steroids in managing cervical radiculopathy, both randomized trials were positive $(922,926)$. None of the randomized evaluations were performed to evaluate the management of axial neck pain.

Results of included studies are illustrated in Table 13. Among the retrospective evaluations (938$947,949)$, the majority demonstrated favorable results. In the one prospective study of the cervical spine (930), patients received cervical interlaminar epidural steroid injections for cervical radiculopathy and cervical transforaminal epidural steroid injections if they failed to respond to the interlaminar epidural steroid injections.

\subsubsection{Cost Effectiveness}

In the evaluation of cost effectiveness, Manchikanti et al (905) and Price et al (911) concluded that interlaminar epidural steroid injections were not cost effective.

\subsubsection{Evidence}

The evidence of interlaminar epidural steroid injections in managing lumbar radiculopathy is strong for short-term relief and limited for long-term relief. In managing cervical radiculopathy, the evidence is 
Table 12. Results of published reports of lumbar interlaminar epidural steroid injections

\begin{tabular}{|c|c|c|c|c|c|c|c|c|c|}
\hline \multirow[b]{2}{*}{ Study } & \multirow[b]{2}{*}{$\begin{array}{c}\text { Study } \\
\text { Characteristics }\end{array}$} & \multicolumn{2}{|c|}{$\begin{array}{r}\text { Methodological } \\
\text { Quality Score(s) } \\
\end{array}$} & \multirow[b]{2}{*}{$\begin{array}{c}\text { No. of } \\
\text { Patients }\end{array}$} & \multirow{2}{*}{$\begin{array}{c}\begin{array}{c}\text { Initial } \\
\text { Relief }\end{array} \\
<6 \\
\text { weeks }\end{array}$} & \multicolumn{2}{|c|}{$\begin{array}{l}\text { Long-term } \\
\text { Relief }\end{array}$} & \multicolumn{2}{|c|}{ Results } \\
\hline & & $\begin{array}{c}\text { AHRQ } \\
\operatorname{Score}(\mathrm{s})\end{array}$ & $\begin{array}{l}\text { Cochrane } \\
\text { Score(s) }\end{array}$ & & & $\begin{array}{c}3 \\
\text { mos }\end{array}$ & $6 \mathrm{mos}$ & $\begin{array}{c}\text { Short- } \\
\text { term } \\
\text { relief } \\
<6 \\
\text { weeks }\end{array}$ & $\begin{array}{c}\text { Long- } \\
\text { term } \\
\text { relief } \\
>6 \\
\text { weeks }\end{array}$ \\
\hline $\begin{array}{l}\text { Arden et al } \\
(910)\end{array}$ & RA, DB, PC & $10 / 10$ & $9 / 10$ & 228 & $75 \%$ & NSD & NSD & $P$ & $N$ \\
\hline $\begin{array}{l}\text { Carette et al } \\
(913)\end{array}$ & RA, DB, PC & $10 / 10$ & $10 / 10$ & $\begin{array}{l}\mathrm{C}=80 \\
\mathrm{~T}=78\end{array}$ & SIT & NSD & NSD & $P$ & $N$ \\
\hline $\begin{array}{l}\text { Cuckler et al } \\
\text { (915) }\end{array}$ & $\mathrm{RA}, \mathrm{DB}$ & $9 / 10$ & $9 / 10$ & $\begin{array}{l}\mathrm{C}=31 \\
\mathrm{~T}=42\end{array}$ & NSD & NSD & NSD & $N$ & $N$ \\
\hline $\begin{array}{l}\text { Rogers et al } \\
(921)\end{array}$ & RA, SB & $6 / 10$ & $5 / 10$ & $\begin{array}{l}\mathrm{C}=15 \\
\mathrm{~T}=15\end{array}$ & SI & NSD & NSD & $P$ & $N$ \\
\hline $\begin{array}{l}\text { Wilson- } \\
\text { McDonald et al } \\
\text { (909) }\end{array}$ & RA & $10 / 10$ & $7 / 10$ & 93 & SI & NSD & NSD & $P$ & $N$ \\
\hline $\begin{array}{l}\text { Snoek et al } \\
(914)\end{array}$ & RA & $7 / 10$ & $6 / 10$ & $\begin{array}{l}\mathrm{C}=24 \\
\mathrm{~T}=27\end{array}$ & NSD & NSD & NSD & $N$ & $N$ \\
\hline Dilke et al (916) & RA & $7 / 10$ & $7 / 10$ & $\begin{array}{l}\mathrm{C}=48 \\
\mathrm{~T}=51\end{array}$ & $\begin{array}{c}31 \% \text { vs } \\
60 \%\end{array}$ & SI & NA & $P$ & $P$ \\
\hline $\begin{array}{l}\text { Ridley et al } \\
(920)\end{array}$ & RA & $9 / 10$ & $8 / 10$ & $\begin{array}{l}\mathrm{C}=16 \\
\mathrm{~T}=19\end{array}$ & $\begin{array}{c}19 \% \text { vs } \\
90 \%\end{array}$ & $\begin{array}{c}19 \% \\
\text { vs } \\
90 \%\end{array}$ & NA & $P$ & $N$ \\
\hline $\begin{array}{l}\text { Kraemer et al } \\
(929)\end{array}$ & RA & $6 / 10$ & $5 / 10$ & $\begin{array}{l}\mathrm{C}=46 \\
\mathrm{~T}=40\end{array}$ & SI & NA & NA & $P$ & $N$ \\
\hline $\begin{array}{l}\text { Pirbudak et al } \\
\text { (912) }\end{array}$ & RA & $6 / 10$ & $6 / 10$ & $\begin{array}{c}\text { steroid }=46 \\
\text { steroid } \pm \\
\text { amitriptyline } \\
\quad=40\end{array}$ & $\begin{array}{c}\text { SI } \\
(\mathrm{AM})\end{array}$ & $\begin{array}{c}\text { SI } \\
(\mathrm{AM})\end{array}$ & $\begin{array}{c}\text { SI } \\
(\mathrm{AM})\end{array}$ & $P$ & $P$ \\
\hline $\begin{array}{l}\text { McGregor et al } \\
\text { (891) }\end{array}$ & RA & $6 / 10$ & $5 / 10$ & $\begin{array}{c}14=\text { caudal } \\
16=\text { interlaminar }\end{array}$ & NSD & NSD & NA & $N$ & $N$ \\
\hline
\end{tabular}

$R A=$ randomized $; S B=$ single blind $; D B=$ double blind $; P C=$ placebo controlled $; N A=$ not available $; S I=$ significant improvement $; S I T=$ significant improvement in treatment group; $A M=$ amitriptyline; $N S D=$ no significant difference; $v$ s $=$ versus, $C=$ control, $T=$ treatment; $P=$ positive; $N$ = negative

moderate for short-term and long-term relief. The evidence is indeterminate in the management of neck pain, low back pain, and lumbar spinal stenosis.

\subsubsection{Transforaminal Epidural Injections}

Transforaminal epidural injections have emerged as a target-specific modality for the treatment for management of spinal pain. Review of the literature showed 4 systematic reviews $(18,24,25,56)$.

Two systematic reviews $(24,25)$ showed the evidence of lumbar transforaminal epidural steroid in- jections for lumbar nerve root pain was strong for short-term and moderate for long-term improvement. The evidence for cervical transforaminal epidural steroid injections for cervical nerve root pain was moderate. The evidence was limited for lumbar radicular pain in post surgery syndrome. DePalma et al (18) performed a critical appraisal of the evidence for selective nerve root injection in the treatment of lumbosacral radiculopathy and showed there was moderate evidence in support of these mini- 
Pain Physician: January 2007:10:7-111

Table 13. Results of published reports of cervical interlaminar epidural steroid injections

\begin{tabular}{|c|c|c|c|c|c|c|c|c|c|}
\hline \multirow[b]{2}{*}{ Study } & \multirow{2}{*}{$\begin{array}{c}\text { Study } \\
\text { Characteristics }\end{array}$} & \multicolumn{2}{|c|}{$\begin{array}{r}\text { Methodological } \\
\text { Quality Score(s) } \\
\end{array}$} & \multirow{2}{*}{$\begin{array}{l}\text { No. of } \\
\text { Patients }\end{array}$} & \multirow{2}{*}{$\begin{array}{c}\text { Initial } \\
\text { Relief } \\
\\
<6 \\
\text { weeks }\end{array}$} & \multicolumn{2}{|c|}{$\begin{array}{l}\text { Long-term } \\
\text { Relief }\end{array}$} & \multicolumn{2}{|c|}{ Results } \\
\hline & & $\begin{array}{c}\text { AHRQ } \\
\text { Score(s) }\end{array}$ & $\begin{array}{l}\text { Cochrane } \\
\text { Score(s) }\end{array}$ & & & $\begin{array}{c}3 \\
\text { mos. }\end{array}$ & $6 \mathrm{mos}$ & $\begin{array}{c}\begin{array}{c}\text { Short- } \\
\text { term } \\
\text { relief }<6 \\
\text { weeks }\end{array} \\
\text { a }\end{array}$ & $\begin{array}{l}\text { Long- } \\
\text { term } \\
\text { relief } \geq 6 \\
\text { weeks }\end{array}$ \\
\hline $\begin{array}{l}\text { Castagnera et al } \\
(922)\end{array}$ & RA & $7 / 10$ & $6 / 10$ & $\begin{array}{c}\text { Local } \\
\text { anesthetic } \pm \\
\text { steroids }=14 \\
\text { Local } \\
\text { anesthetic } \pm \\
\text { steroids } \pm \\
\text { Morphine }=10\end{array}$ & $\begin{array}{l}75 \% \text { vs } \\
96 \%\end{array}$ & $79 \%$ & $79 \%$ & $\mathrm{P}$ & $\mathrm{P}$ \\
\hline Stav et al (926) & RA & $6 / 10$ & $5 / 10$ & $\begin{array}{l}\mathrm{C}=17 \\
\mathrm{~T}=25\end{array}$ & $\begin{array}{c}36 \% \text { vs } \\
76 \%\end{array}$ & $\begin{array}{c}12 \% \text { vs } \\
68 \%\end{array}$ & $\begin{array}{c}12 \% \text { vs } \\
68 \%\end{array}$ & $\mathrm{P}$ & $\mathrm{P}$ \\
\hline
\end{tabular}

$R A=$ randomized $;$ vs $=$ versus,$C=$ control,$T=$ treatment $; P=$ positive

mally invasive and safe procedures in treating painful radicular symptoms. European guidelines for the management of chronic non-specific low back pain (56) also provided a favorable level of evidence for transforaminal epidural steroid injections. Following the review of the literature from January 1995 to November 2002, they concluded that epidural corticosteroid injections should only be considered for radicular pain if a contained disc prolapse is the cause of the pain and if the corticosteroid is injected close to the target through a transforaminal approach under fluoroscopic guidance (56). Favorable evidence was also provided in other guidelines (1-4).

The evaluation for evidence synthesis led to identification of 12 randomized controlled trials (950-961), 15 observational reports (930,962-976), and multiple retrospective evaluations (905,977998). Of the 12 randomized controlled trials (950961), 7 trials were included in evidence synthesis $(950,952,953,955,956,958-961)$, whereas of 15 prospective evaluations $(930,962-976), 7$ were included $(930,965,968,973-975,977)$. A summary of reported studies is listed in Tables 14 and 15.

Among the 7 randomized trials included in the evidence synthesis meeting inclusion criteria, 6 of them evaluated effectiveness in lumbar disc herniation and radiculopathy $(950,952,955,956,958,961)$, showing positive results in 4 of the 6 , both in short-term and long-term with 2 negative studies $(951,958)$. The seventh trial (953) studied effectiveness in post surgery syndrome and yielded negative results.
Among the 7 prospective evaluations included for evaluation, 2 studies evaluated the effectiveness of cervical transforaminal epidurals $(930,975)$, showing positive results. The remaining 5 studies $(965,973-$ $975,977)$ evaluated lumbar transforaminal epidural steroid injections. One study (975) compared effectiveness of transforaminal epidural steroid injections in lumbar spine with discectomy. One evaluation reported the effect on spinal stenosis (977). Multiple retrospective evaluations also showed positive results.

The results of the included studies are described in Tables 14 and 15. Riew et al (961) performed a study with a minimum 5-year follow-up to evaluate nerve root blocks in the treatment of lumbar radicular pain. This was a continuation of a previous randomized double-blind controlled study evaluating the effect of nerve root blocks on the need for operative treatment of lumbar radicular pain (950). All of the patients in both studies $(950,961)$ were considered to be operative candidates by the treating surgeon and all had initially requested operative intervention. They had been then randomized to be treated with a selective nerve-root block with either bupivacaine or bupivacaine and betamethasone. Both the treating physician and the patient were blinded to the type of medication. Of the 55 randomized patients, 29 avoided an operation in the original study; 21 of those 29 patients were reevaluated with a follow-up questionnaire at a minimum of 5 years after the initial block, and 17 of 21 patients still had not had operative intervention. There was no difference between the 
group treated with bupivacaine alone and the group treated with bupivacaine and betamethasone with regard to the avoidance of surgery for 5 years. At the 5-year follow-up evaluation, all of the patients who had avoided operative treatment had significant decrease in neurological symptoms and back pain compared with baseline values. Authors concluded that the majority of patients with lumbar radicular pain who avoid an operation for at least one year after receiving a nerve root injection with bupivacaine alone or in combination with betamethasone will continue to avoid operative intervention for a minimum of 5 years. $\mathrm{Ng}$ et al (958) studied periradicular infiltration of nerve roots (synonymous with transforaminal or selective nerve root injections) with local anesthetic and steroid versus local anesthetic alone. They evaluated 86 patients with unilateral leg pain and an MRI showing a lumbar herniated disc or foraminal stenosis at a level compatible with the symptoms. All the patients received a single level injection under fluoroscopy with $2 \mathrm{~mL}$ of $0.25 \%$ bupivacaine with $40 \mathrm{mg}$ of methylprednisolone in one group, while the second group received bupivacaine alone. The results showed no significant difference between the groups. In both the groups there was only a modest decrease in VAS at 3 months. Criticism of this study is that only one injection was offered. Yang et al (960) evaluated the effect of transforaminal epidural steroids on candidates for discectomy in 21 patients. They reported that $63 \%$ of the patients had significant pain relief lasting through 24-month follow-up, avoiding surgery, with the transforaminal epidural resulting in significant relief of leg pain and improvement in activities of daily living. However, there was no improvement in the low back pain. Kolstad et al (959) studied cervical transforaminal epidural steroids on 21 patients awaiting cervical disc surgery. Patients were given 2 epidural injections 2 weeks apart and followed for 4 months. They used 2 outcome assessment measures including visual analog scale for neck and radicular pain and Odom's criteria. Outcomes were measured at baseline, 6 weeks and 4 months. Five of the 21 patients canceled their surgery due to improvement in pain, and overall there was a significant decrease in radicular pain at 6 weeks and 4 months. Neck pain was also improved, and patients with spondylosis responded as well as patients with disc herniations.

There was one new retrospective evaluation for cervical disc herniation and radiculopathy (949). Lin et al (949) evaluated cervical epidural steroid injections for symptomatic disc herniation in 70 patients; $63 \%$ or 44 had significant relief of their symptoms and did not wish to proceed with surgical treatment with an average of 13-month follow-up. In addition, 75\% would attempt cervical epidural steroid injections again in the future. They concluded that cervical epidural injections are a reasonable part of the non-operative treatment of patients with symptomatic cervical disc herniations. They also concluded that a large percentage of the patients may obtain relief from radicular symptoms and avoid surgery for the follow-up period up to one year. In addition, patients older than 50 years and those who received the injection earlier, less than 100 days from diagnosis, seemed to have a more favorable outcome.

\subsubsection{Cost Effectiveness}

In the management of chronic low back pain, cost per 1 year improvement of quality of life was $\$ 2,927$ per year with transforaminal epidural steroid injections (905). Furthermore, in patients treated with transforaminal steroids, operations were avoided for contained herniations, costing $\$ 12,666$ less per responder in the steroid group (952). Cost effectiveness was also demonstrated by others by avoiding surgical intervention $(949,950,959,961)$.

\subsubsection{Evidence}

The evidence for lumbar transforaminal epidural steroid injections in managing lumbar nerve root pain is strong for short-term and moderate for long-term improvement. The evidence for cervical transforaminal epidural steroid injections in managing cervical nerve root pain is moderate for short-term and long-term improvement. The evidence is limited in managing lumbar radicular pain in postlumbar laminectomy syndrome. The evidence is indeterminate in managing axial low back pain, axial neck pain, and lumbar disc extrusions.

\subsubsection{Safety and Complications}

Complications of caudal, interlaminar, and transforaminal epidural injections are predominantly of two types: those related to needle placement and those related to drug administration (556-558,601603,735-760,877,878,882,886,996-1035). Reported complications include dural puncture, spinal cord trauma, infection, hematoma formation, abscess formation, subdural injection, intracranial air injection, epidural lipomatosis, pneumothorax, nerve damage, headache, death, brain damage, increased intracranial pressure, intravascular injection, vascular injury, cerebral vascular or pulmonary embolus and effects of steroids. Spinal cord trauma and spi- 
Pain Physician: January 2007:10:7-111

Table 14. Results of published reports on lumbar transforaminal epidural injections

\begin{tabular}{|c|c|c|c|c|c|c|c|c|c|}
\hline \multirow[b]{2}{*}{ Study } & \multirow{2}{*}{$\begin{array}{c}\text { Study } \\
\text { Characteristics }\end{array}$} & \multicolumn{2}{|c|}{$\begin{array}{l}\text { Methodological } \\
\text { Quality Score(s) }\end{array}$} & \multirow{2}{*}{$\begin{array}{c}\text { No. of } \\
\text { Patients }\end{array}$} & \multirow{2}{*}{$\begin{array}{c}\text { Initial } \\
\text { Relief } \\
<6 \\
\text { weeks }\end{array}$} & \multicolumn{2}{|c|}{ Long-term Relief } & \multicolumn{2}{|c|}{ Results } \\
\hline & & $\begin{array}{c}\text { AHRQ } \\
\text { Score(s) }\end{array}$ & $\begin{array}{l}\text { Cochrane } \\
\text { Score(s) }\end{array}$ & & & $\begin{array}{c}3 \\
\text { months }\end{array}$ & $\begin{array}{c}6 \\
\text { months }\end{array}$ & $\begin{array}{c}\text { Short- } \\
\text { term <6 } \\
\text { weeks }\end{array}$ & $\begin{array}{c}\text { Long- } \\
\text { term } \\
\geq 6 \\
\text { weeks }\end{array}$ \\
\hline $\begin{array}{l}\text { Karppinen et al (951, } \\
952)\end{array}$ & $\mathrm{RA}, \mathrm{DB}, \mathrm{PC}$ & $9 / 10$ & $8 / 10$ & $\begin{array}{l}\mathrm{C}=80 \\
\mathrm{~T}=80\end{array}$ & NA & NA & NA & $\mathrm{N}$ & $\mathrm{N}$ \\
\hline Riew et al (961) & P, RA, DB & $8 / 10$ & $7 / 10$ & 55 & $\begin{array}{c}33 \% \text { vs } \\
77 \%\end{array}$ & $\begin{array}{c}33 \% \text { vs } \\
77 \%\end{array}$ & $\begin{array}{c}33 \% \text { vs } \\
77 \%\end{array}$ & $\mathbf{P}$ & $\mathbf{P}$ \\
\hline Riew et al (950) & RA, DB & $8 / 10$ & $7 / 10$ & $\begin{array}{c}\mathrm{LA}=27 \\
\mathrm{LA} \pm \mathrm{S}=28\end{array}$ & $\begin{array}{c}33 \% \text { vs } \\
77 \%\end{array}$ & $\begin{array}{c}33 \% \text { vs } \\
77 \%\end{array}$ & $\begin{array}{c}33 \% \text { vs } \\
77 \%\end{array}$ & $\mathbf{P}$ & $\mathbf{P}$ \\
\hline Ng et al (958) & RA, DB & $8 / 10$ & $8 / 10$ & $\begin{array}{c}\mathrm{LA}=43 \\
\mathrm{LA} \pm \mathrm{S}=43\end{array}$ & $\begin{array}{c}42 \% \text { vs } \\
48 \%\end{array}$ & $\begin{array}{c}42 \% \text { vs } \\
48 \%\end{array}$ & NSI & $\mathrm{N}$ & $\mathrm{N}$ \\
\hline Devulder et al (953) & RA & $6 / 10$ & $5 / 10$ & 60 & NSI & NSI & NSI & $\mathrm{N}$ & $\mathrm{N}$ \\
\hline Vad et al (955) & RA & $7 / 10$ & $7 / 10$ & 48 & $\begin{array}{c}48 \% \text { vs } \\
84 \%\end{array}$ & $\begin{array}{l}8 \% \text { vs } \\
84 \%\end{array}$ & $\begin{array}{l}8 \% \text { vs } \\
84 \%\end{array}$ & $\mathbf{P}$ & $\mathbf{P}$ \\
\hline Thomas et al (956) & RA & $6 / 10$ & $5 / 10$ & $\begin{array}{l}\mathrm{C}=15 \\
\mathrm{~T}=16\end{array}$ & SI & SI & SI & $\mathbf{P}$ & $\mathbf{P}$ \\
\hline Yang et al (960) & $\mathrm{P}$ & $4 / 8$ & --- & 21 & $63 \%$ & $63 \%$ & $63 \%$ & $\mathbf{P}$ & $\mathbf{P}$ \\
\hline Lutz et al (965) & $\mathrm{P}$ & $4 / 8$ & --- & 69 & $75 \%$ & $75 \%$ & $75 \%$ & $\mathbf{P}$ & $\mathbf{P}$ \\
\hline Butterman (973) & $\mathrm{P}$ & $4 / 8$ & --- & 232 & SI & SI & SI & $\mathbf{P}$ & $\mathrm{N}$ \\
\hline Buttermann (974) & $\mathrm{P}$ & $4 / 8$ & --- & 169 & NA & NA & $\begin{array}{l}42 \%- \\
56 \%\end{array}$ & $\mathbf{P}$ & $\mathbf{P}$ \\
\hline Botwin et al (977) & $\mathrm{P}$ & $4 / 8$ & --- & 34 & $75 \%$ & $75 \%$ & $75 \%$ & $\mathbf{P}$ & $\mathbf{P}$ \\
\hline
\end{tabular}

$P=$ prospective $; R A=$ randomized $; D B=$ double blind $; P C=$ placebo controlled $; L A=$ local anesthetic $L A \pm S=$ Local anesthetic \pm steroid $; N A$

$=$ not available; $S I=$ significant improvement $; S I T=$ significant improvement in treatment group; $A M=$ amitriptyline; NSI = no significant improvement; vs = versus, $C=$ control, $T=$ treatment $; \mathbf{P}=$ positive; $N=$ negative

nal cord or epidural hematoma formation are catastrophic complications, but rarely seen following epidural injections.

\subsection{Epidural Adhesiolysis}

Percutaneous epidural adhesiolysis or lysis of epidural adhesions or epidural adhesiolysis with a spinal endoscope (myeloscope or epiduroscope) are interventional pain management techniques that play an active role in managing chronic intractable low back pain $(1-4,31,65,499,500,1036)$.

The purpose of percutaneous epidural lysis of adhesions is to minimize the deleterious effects of epidural scarring, which can physically prevent direct application of drugs to nerves and other spinal tissues and to treat chronic back pain. Epidural lysis of adhesions and direct deposition of corticosteroids in the spinal canal can also be achieved with a 3-dimensional view provided by epiduroscopy or spinal endoscopy.

Duration of relief of less than 3 months was considered as short-term and longer than 3 months was considered as long-term.

\subsubsection{Percutaneous Adhesiolysis}

Clinical effectiveness of percutaneous adhesiolysis was evaluated in 1 systematic review (31), 
Table 15. Results of published reports on cervical transforaminal epidural injections

\begin{tabular}{|c|c|c|c|c|c|c|c|c|}
\hline \multirow[b]{2}{*}{ Study } & \multirow[b]{2}{*}{$\begin{array}{c}\text { Study } \\
\text { Characteristics }\end{array}$} & \multirow[b]{2}{*}{$\begin{array}{c}\text { AHRQ } \\
\text { Methodological } \\
\text { Quality Score(s) }\end{array}$} & \multirow[b]{2}{*}{$\begin{array}{l}\text { No. of } \\
\text { Patients }\end{array}$} & \multirow{2}{*}{$\begin{array}{c}\text { Initial } \\
\text { Relief }\end{array}$} & \multicolumn{2}{|c|}{ Long-term Relief } & \multicolumn{2}{|c|}{ Results } \\
\hline & & & & & $\begin{array}{c}3 \\
\text { months }\end{array}$ & $\begin{array}{c}6 \\
\text { months }\end{array}$ & $\begin{array}{l}\text { Short- } \\
\text { term } \\
<6 \\
\text { weeks }\end{array}$ & $\begin{array}{c}\text { Long- } \\
\text { term } \\
\geq 6 \\
\text { weeks }\end{array}$ \\
\hline $\begin{array}{l}\text { Bush and Hillier } \\
(930)\end{array}$ & $\mathrm{P}$ & $4 / 8$ & 68 & $93 \%$ & $93 \%$ & $93 \%$ & $\mathrm{P}$ & $\mathrm{P}$ \\
\hline Kolstad et al (959) & $P$ & $4 / 8$ & 21 & SI & SI & SI & $\mathrm{P}$ & $\mathrm{P}$ \\
\hline Cyteval et al (975) & $\mathrm{P}$ & $4 / 8$ & 30 & $60 \%$ & $60 \%$ & $60 \%$ & $\mathrm{P}$ & $\mathrm{P}$ \\
\hline Lin et al (949) & $\mathrm{R}$ & $4 / 8$ & 70 & $63 \%$ & $63 \%$ & $63 \%$ & $\mathrm{P}$ & $\mathrm{P}$ \\
\hline
\end{tabular}

$P=$ prospective $; R=$ retrospective $; S I=$ significant improvement $; P=$ positive

and 1 health technology assessment (65). Chopra et al (31) concluded that there was strong evidence to indicate effectiveness of percutaneous epidural adhesiolysis with administration of epidural steroids for short-term and long-term in chronic, refractory low back pain and radicular pain. There was moderate evidence of effectiveness of the addition of hypertonic saline. The evidence of effectiveness of hyaluronidase was negative. In preparation of European guidelines for the management of chronic non-specific low back pain, Airaksinen et al (56) evaluated percutaneous adhesiolysis as part of epidural corticosteroid injections. They concluded that epidural corticosteroid injections should only be considered for radicular pain if a contained disc prolapse is the cause of the pain and if the corticosteroid is injected close to the target. Further, they also concluded that the injection should be fluoroscopically guided and should aim at the ventral part of the epidural space, near the spinal nerve root, indirectly improving targeted delivery after adhesiolysis of epidural steroid injections. In the technology assessment of epidural adhesiolysis for the treatment of back pain (65) from the Office of the Medical Director, Washington State Department of Labor and Industries, randomized, prospective, and retrospective studies were evaluated. They concluded that the number of prospec- tive studies on epidural adhesiolysis was small and adhesiolysis may provide benefit by eliminating scar tissue, thereby allowing application of drugs to the nerves for the treatment of low back pain.

Of the 14 relevant articles identified, 5 randomized trials (1037-1041), 2 prospective evaluations $(1042,1043)$, and 3 retrospective evaluations (10441046) were included in the analysis. The remaining studies failed to meet inclusion criteria and were excluded from the evidence synthesis (1047-1050).

Three randomized trials $(1037,1039,1040)$ and one of the 2 retrospective studies (1044) included patients with and without previous surgery. One study (1045) included only post surgical patients. All the studies included patients with chronic, refractory low back pain and lower extremity pain. Among the 3 recent studies, one was randomized (1041) and 2 were prospective $(1042,1043)$, and included patients with radiculitis secondary to disc herniation and also post surgery syndrome.

Of the 4 randomized trials included in evidence synthesis $(1037,1039-1041)$, all were positive for shortterm and long-term pain relief. Of the 2 prospective evaluations $(1042,1043)$ both were positive for shortterm relief, whereas only one study (1043) was positive for long-term relief of 6 months. Among the two retrospective evaluations $(1044,1045)$, both were positive for short-term relief. However, only one study (1045) was positive for long-term relief. The summary of the 
Pain Physician: January 2007:10:7-111

Table 16. Results of published reports of percutaneous lysis of lumbar epidural adhesions and hypertonic saline neurolysis

\begin{tabular}{|c|c|c|c|c|c|c|c|c|c|c|}
\hline \multirow{2}{*}{ Study } & \multirow{2}{*}{$\begin{array}{c}\text { Study } \\
\text { Characteristics }\end{array}$} & \multicolumn{2}{|c|}{$\begin{array}{l}\text { Methodological } \\
\text { Quality Score(s) }\end{array}$} & \multirow{2}{*}{$\begin{array}{c}\text { No. of } \\
\text { Patients }\end{array}$} & \multirow{2}{*}{$\begin{array}{c}\text { Initial } \\
\text { Relief }\end{array}$} & \multicolumn{3}{|c|}{ Long-term Relief } & \multicolumn{2}{|c|}{ Results } \\
\hline & & $\begin{array}{c}\text { AHRQ } \\
\operatorname{Score}(\mathbf{s})\end{array}$ & $\begin{array}{c}\text { Cochrane } \\
\text { Score(s) }\end{array}$ & & & $\begin{array}{c}3 \\
\text { mos. }\end{array}$ & $\begin{array}{c}6 \\
\text { mos. }\end{array}$ & $\begin{array}{c}12 \\
\text { mos. }\end{array}$ & $\begin{array}{c}\text { Short- } \\
\text { term } \\
\text { <3 mos }\end{array}$ & 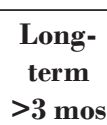 \\
\hline $\begin{array}{l}\text { Manchikanti et al } \\
\text { (1039) }\end{array}$ & $\mathrm{RA}, \mathrm{DB}$ & $10 / 10$ & $10 / 10$ & $\begin{array}{l}\mathrm{G} 1=25 \\
\mathrm{G} 2=25 \\
\mathrm{G} 3=25\end{array}$ & $\begin{array}{l}33 \% \\
64 \% \\
72 \%\end{array}$ & $\begin{array}{l}0 \% \\
64 \% \\
72 \%\end{array}$ & $\begin{array}{l}0 \% \\
60 \% \\
72 \%\end{array}$ & $\begin{array}{l}0 \% \\
60 \% \\
72 \%\end{array}$ & $\mathrm{P}$ & $\mathrm{P}$ \\
\hline Heavner et al (1037) & RA, DB & $7 / 10$ & $7 / 10$ & 59 & $83 \%$ & $49 \%$ & $43 \%$ & $49 \%$ & $\mathrm{P}$ & $\mathrm{P}$ \\
\hline $\begin{array}{l}\text { Manchikanti et al } \\
\text { (1040) }\end{array}$ & RA & $5 / 10$ & $6 / 10$ & $\begin{array}{l}C=15 \\
T x=30\end{array}$ & $\begin{array}{l}\text { NSI } \\
97 \%\end{array}$ & $\begin{array}{l}\text { NSI } \\
97 \%\end{array}$ & $\begin{array}{l}\text { NSI } \\
93 \%\end{array}$ & $\begin{array}{l}\text { NSI } \\
47 \%\end{array}$ & $\mathrm{P}$ & $\mathrm{P}$ \\
\hline $\begin{array}{l}\text { Veihelmann et al } \\
\text { (1041) }\end{array}$ & RA & $6 / 10$ & $5 / 10$ & 99 & SI & SI & SI & SI & $\mathrm{P}$ & $\mathrm{P}$ \\
\hline $\begin{array}{l}\text { Gerdesmeyer et al } \\
(1042)\end{array}$ & $\mathrm{P}$ & $5 / 8$ & --- & 25 & SI & SI & SI & SI & $\mathrm{P}$ & $\mathrm{P}$ \\
\hline $\begin{array}{l}\text { Gerdesmeyer et al } \\
\text { (1043) }\end{array}$ & $\mathrm{P}$ & $5 / 8$ & --- & 61 & SI & SI & SI & SI & $\mathrm{P}$ & $\mathrm{P}$ \\
\hline $\begin{array}{l}\text { Manchikanti et al } \\
\text { (1044) }\end{array}$ & $\mathrm{R}$ & $4 / 8$ & --- & 129 & $79 \%$ & $68 \%$ & $36 \%$ & $13 \%$ & $\mathrm{P}$ & $\mathrm{N}$ \\
\hline $\begin{array}{l}\text { Manchikanti et al } \\
\text { (1045) }\end{array}$ & $\mathrm{R}$ & $4 / 8$ & --- & 60 & $100 \%$ & $90 \%$ & $72 \%$ & $52 \%$ & $\mathrm{P}$ & $\mathrm{P}$ \\
\hline
\end{tabular}

$R A=$ randomized $; D B=$ double blind; $R=$ retrospective; $C=$ control; $T=$ treatment $; A=$ not available; $S I=$ significant improvement; NSI=no significant improvement; $P=$ positive; $N=$ negative

studies included in the evidence synthesis is described in Table 16.

\subsubsection{Cost Effectiveness}

Cost effectiveness for 1-year of improvement in the quality of life varied from $\$ 2,028$ to $\$ 5,564$ $(1040,1044,1045)$.

\subsubsection{Evidence}

The evidence is strong in managing chronic low back and lower extremity pain in post surgery syndrome. The evidence is moderate in managing low back and lower extremity pain secondary to disc herniation producing radiculopathy. The evidence is limited in managing back and/or lower extremity pain secondary to spinal stenosis.

\subsubsection{Endoscopic Adhesiolysis}

Spinal endoscopic adhesiolysis and target delivery of steroids (1051) were evaluated in 1 systematic review (31), and 1 health technology assessment (65).

The systematic review by Chopra et al (31) concluded that there was strong evidence to indicate effectiveness of spinal endoscopic adhesiolysis and epidural steroid administration for short-term improvement, and moderate evidence for long-term improvement in managing chronic, refractory low back and lower extremity pain. The technology assessment (65) concluded that the number of studies was too small.

There were 3 reports, one prelimary report (1052), and 2 randomized double-blind trials $(889,1053)$; however, only one study met inclusion criteria (1053). The study by Dashfield et al (889) studied endoscopic delivery of steroids or caudal epidural steroid injection in patients without adhesions. The primary purpose of spinal endoscopy is adhesiolysis; thus, since there was no adhesiolysis, the study failed to meet inclusion criteria. In addition, 3 prospective evaluations $(1054-1056)$, and $2(1056,1057)$ of the 3 retrospective evaluations were included (1056-1058). One randomized trial (1053) included in the analysis showed significant short-term and long-term improvement. Among the 3 prospective, observational studies, one study (1058) evaluated the effectiveness of spinal endoscopic adhesiolysis in lumbar spinal stenosis, showing good short-term and long-term improvement in patients with low back pain; however, 
long-term improvement of leg pain was seen only in the mono-segmental group. The other 2 prospective evaluations $(1054,1056)$ also showed positive results. Both the retrospective evaluations $(1045,1046)$ showed positive short-term and long-term relief. Table 17 illustrates the results of various studies of spinal endoscopy. The majority of the studies included a heterogenous group of patients, most with post surgery syndrome or epidural fibrosis.

\subsubsection{Cost Effectiveness}

The cost effectiveness of spinal endoscopy in patients failing to respond to all conservative modalities of treatments, including percutaneous adhesiolysis with a spring-guided catheter, was shown to be $\$ 7,020$ to $\$ 8,127(1045,1057)$.

\subsubsection{Evidence}

Evidence for spinal endoscopy is strong for shortterm relief and moderate for long-term relief, in managing chronic refractory low back and lower extremity pain secondary to post-lumbar surgery syndrome.

\subsubsection{Complications}

Complications were typically minor: mild back pain and recognized dural puncture. However, severe complications, following adhesiolysis and spinal endoscopy, have been reported (1059-1073). These include spinal cord compression, catheter shearing, excessive intra- spinal and intracranial pressures, epidural hematoma, bleeding, infection, elevated intraocular pressures with resultant visual deficiencies, and even blindness. Steroids, hypertonic saline, hyaluronidase, instrumention with endoscope, and administration of high volumes of fluids may cause elevated epidural hydrostatic pressures (556,557,878, 1009-1011,1014,1015, 1018, 1024-1036), and consequently, spinal cord compression. Unintended access of the subarachnoid or subdural space is possible. If recognized early, injection of local anesthetic or hypertonic saline may be avoided; hypertonic saline injected into the subarachnoid space has been reported to cause cardiac arrhythmias, myelopathy, paralysis, and loss of sphincter control.

\subsection{Sacroiliac Joint Interventions}

The sacroiliac joint is a diarthrodial synovial joint with abundant innervation and capability of being a source of low back pain and referred pain in the lower extremity (435-465). The sacroiliac joint has been shown to be a source of pain in $10 \%$ to $26.6 \%$ of the suspected cases $(230,461,462)$.

Sacroiliac joint pain may be managed by intraarticular injections or neurolysis of the sacroiliac joint. Relief with intraarticular injections was considered short-term if less than 6 weeks and long-term if

Table 17. Results of published reports of spinal endoscopy

\begin{tabular}{|c|c|c|c|c|c|c|c|c|c|c|}
\hline \multirow{2}{*}{ Study } & \multirow{2}{*}{$\begin{array}{c}\text { Study } \\
\text { Characteristics }\end{array}$} & \multicolumn{2}{|c|}{$\begin{array}{c}\text { Methodological } \\
\text { Quality Score(s) }\end{array}$} & \multirow{2}{*}{$\begin{array}{c}\text { No. of } \\
\text { Patients }\end{array}$} & \multirow{2}{*}{$\begin{array}{l}\begin{array}{l}\text { Initial } \\
\text { Relief }\end{array} \\
\text { < } 6 \text { wks }\end{array}$} & \multicolumn{3}{|c|}{ Long-term Relief } & \multicolumn{2}{|c|}{ Results } \\
\hline & & $\begin{array}{c}\text { AHRQ } \\
\operatorname{Score}(s)\end{array}$ & $\begin{array}{l}\text { Cochrane } \\
\text { Score(s) }\end{array}$ & & & $3 \mathrm{mos}$ & $6 \mathrm{mos}$ & $\begin{array}{c}12 \\
\text { mos }\end{array}$ & $\begin{array}{c}\text { Short- } \\
\text { term } \\
<6 \text { wks }\end{array}$ & $\begin{array}{c}\text { Long- } \\
\text { term } \\
\geq 6 \mathrm{wks}\end{array}$ \\
\hline $\begin{array}{l}\text { Manchikanti et al } \\
\text { (1053) }\end{array}$ & RA, DB & $10 / 10$ & $10 / 10$ & $\begin{array}{l}C=33 \\
T x=50\end{array}$ & $\begin{array}{c}33 \% \text { vs } \\
90 \%\end{array}$ & $\begin{array}{l}0 \% \text { vs } \\
80 \%\end{array}$ & $\begin{array}{c}0 \% \text { vs } \\
56 \%\end{array}$ & $\begin{array}{c}0 \% \text { vs } \\
48 \%\end{array}$ & $\mathbf{P}$ & $\mathbf{P}$ \\
\hline $\begin{array}{l}\text { Igarashi et al } \\
\text { (1055) }\end{array}$ & $\mathrm{P}$ & $5 / 8$ & & $\begin{array}{l}\text { Mono }=34 \\
\text { Multi }=24\end{array}$ & SI & SI & $\begin{array}{l}\text { SI in } \\
\text { mono }\end{array}$ & $\begin{array}{l}\text { SI in } \\
\text { mono }\end{array}$ & $\mathbf{P}$ & $\mathbf{P}$ \\
\hline $\begin{array}{l}\text { Geurts et al } \\
(1054)\end{array}$ & $\mathrm{P}$ & $6 / 8$ & & 20 & $55 \%$ & $55 \%$ & $40 \%$ & $35 \%$ & $\mathbf{P}$ & $\mathbf{P}$ \\
\hline $\begin{array}{l}\text { Richardson et al } \\
\text { (1056) }\end{array}$ & $\mathrm{P}$ & $4 / 8$ & & 34 & SI & SI & SI & SI & $\mathbf{P}$ & $\mathbf{P}$ \\
\hline $\begin{array}{l}\text { Manchikanti et al } \\
\text { (1045) }\end{array}$ & $\mathrm{R}$ & $4 / 8$ & & 60 & $100 \%$ & $75 \%$ & $40 \%$ & $22 \%$ & $\mathbf{P}$ & $\mathbf{P}$ \\
\hline $\begin{array}{l}\text { Manchikanti et al } \\
\text { (1057) }\end{array}$ & $\mathrm{R}$ & $4 / 8$ & & 85 & $100 \%$ & $77 \%$ & $52 \%$ & $21 \%$ & $\mathbf{P}$ & $\mathbf{P}$ \\
\hline
\end{tabular}

$P=$ prospective $; R=$ retrospective $; R A=$ randomized $; D B=$ double blind $;$ vs=versus; $S I=$ s ignificant improvement $;$ Mono = monosegmental $;$ Multi $=$ multisegmental $; \mathbf{P}=$ positive 
Pain Physician: January 2007:10:7-111

Table 18. Results of published reports on therapeutic intraarticular sacroiliac joint injections.

\begin{tabular}{|c|c|c|c|c|c|c|c|c|c|}
\hline \multirow{3}{*}{ Study } & \multirow{3}{*}{$\begin{array}{c}\text { Study } \\
\text { Characteristics }\end{array}$} & \multicolumn{2}{|c|}{$\begin{array}{l}\text { Methodological } \\
\text { Quality Score(s) }\end{array}$} & \multirow{3}{*}{$\begin{array}{l}\text { No. of } \\
\text { Patients }\end{array}$} & \multirow{3}{*}{$\begin{array}{l}\text { Initial } \\
\text { Relief }\end{array}$} & \multirow{2}{*}{\multicolumn{2}{|c|}{$\begin{array}{l}\text { Long-term } \\
\text { Relief }\end{array}$}} & \multirow{2}{*}{\multicolumn{2}{|c|}{ Results }} \\
\hline & & \multirow[b]{2}{*}{$\begin{array}{c}\text { AHRQ } \\
\operatorname{Score}(s)\end{array}$} & \multirow[b]{2}{*}{$\begin{array}{l}\text { Cochrane } \\
\operatorname{Score}(\mathrm{s})\end{array}$} & & & & & & \\
\hline & & & & & & $\begin{array}{c}3 \\
\text { mos }\end{array}$ & $\begin{array}{c}6 \\
\text { mos. }\end{array}$ & $\begin{array}{l}\text { Short-term } \\
<6 \text { wks }\end{array}$ & $\begin{array}{c}\text { Long- } \\
\text { term } \geq 6 \\
\text { wks }\end{array}$ \\
\hline Maugars et al (1075) & RA & $6 / 10$ & $6 / 10$ & $\begin{array}{c}10 \\
6 \text { joints } \\
\text { - steroids } \\
7 \text { joints } \\
\text { - placebo }\end{array}$ & $70 \%$ & $62 \%$ & $58 \%$ & $\mathbf{P}$ & $\mathbf{P}$ \\
\hline Pereira et al (1085) & $\mathrm{P}$ & $5 / 8$ & --- & 10 & $80 \%$ & $80 \%$ & $80 \%$ & $\mathbf{P}$ & $\mathbf{P}$ \\
\hline $\begin{array}{l}\text { Chakravarty and } \\
\text { Dias (1089) }\end{array}$ & $\mathrm{R}$ & $4 / 8$ & --- & 33 & $50 \%$ & NSI & NSI & $\mathrm{N}$ & $\mathrm{N}$ \\
\hline Slipman et al (1088) & $\mathrm{R}$ & $6 / 8$ & --- & 31 & SI & SI & SI & $\mathbf{P}$ & $\mathbf{P}$ \\
\hline
\end{tabular}

$P=$ prospective $; R=$ retrospective $; R A=$ randomized $; S I=$ significant improvement $; N S I=$ no significant improvement $; N=$ negative $; \mathbf{P}=$ positive

6 weeks or longer. Relief with radiofrequency neurotomy was considered short-term if less than 3 months, and long-term 3 months or longer.

\subsection{Intraarticular Injections}

The effectiveness of intraarticular sacroiliac joint injections was evaluated in a systematic review (23) and was also mentioned in European Guidelines for the management of chronic non-specific low back pain (56). McKenzie-Brown et al (23) in the systematic review concluded that the evidence for the therapeutic intraarticular sacroiliac joint injections was limited to moderate. Airaksinen et al (56) showed that there was limited evidence for injection of the sacroiliac joint with corticosteroids to relieve sacroiliac pain of unknown origin for a short time, thus Level C evidence. However, they added that a sacroiliac joint injection is not recommended for the treatment of non-specific chronic low back pain.

Four randomized trials (1074-1077), 9 prospective evaluations (1078-1086), and 4 retrospective evaluations $(463,1087-1089)$ were identified. However, only 1 randomized trial (1075), 1 prospective evaluation (1085), and 2 retrospective evaluation $(1088,1089)$ met the inclusion criteria (Table 18).

Maugars et al (1075), in a double-blind study of 10 patients suffering with painful sacroiliitis, reported improvement in 5 of the 6 sacroiliac joints injected with corticosteroid with $70 \%$ relief at 1 -month, with none of the 7 of the placebo joint injections reporting any significant relief. There was significant improvement in $62 \%$ of the patients at 3 months and $58 \%$ of the patients at 6 months. Slipman et al (1088) in a retrospective study with independent clinical review of 31 patients receiving an average of 2.1 therapeutic injections concluded that fluoroscopically guided therapeutic sacroiliac joint injections are a clinically effective intervention in the treatment of patients with sacroiliac joint syndrome.

Pereira et al (1085) in a prospective observational study evaluated 10 patients with sacroiliitis of which 9 of them had bilateral sacroiliitis. They treated 21 joints with corticosteroid without local anesthetic. The results showed good to excellent pain relief in 8 of 10 patients lasting a mean of 13.5 months. The 2 non-responders suffered from fibromyalgia and reactive depression. They used MRI to guide the injections. They also showed that subchondral marrow edema resolved on follow-up MRI, minimally in 3 patients, partially in 3 patients, and completely in 3 patients.

Chakravarty and Dias (1089) in an audit of conservative management of chronic low back pain in a secondary care setting, evaluated the results of intraarticular sacroiliac joint injections with corticosteroid in 33 patients, averaging 40 years of age with a range of 70 to 74 years. They reported $50 \%$ pain 
relief for the duration of local anesthetic only. There was a $50 \%$ global subject to improvement 1 day to 4 weeks after the injection, $9 \%$ improvement 4 weeks to 3 months later, and only $1 \%$ at 3 to 6 months.

Slipman et al (1088) in a retrospective evaluation with independent clinical review, reported a significant reduction in Oswestry Disability scores, visual analogue pain scores, and work status.

\subsubsection{Cost Effectiveness}

No studies were performed evaluating the cost effectiveness of therapeutic sacroiliac joint injections.

6.4.1.2 Evidence

The evidence for intraarticular sacroiliac joint injections is limited for short- and long-term relief.

\subsubsection{Radiofrequency Neurotomy}

Percutaneous radiofrequency neurotomy of sacroiliac joints has been reported to provide long-term relief (453,454, 1090-1094).

Of all the evaluations performed on radiofrequency neurotomy in managing sacroiliac joint pain, 4 reports were prospective $(454,1091,1093,1094)$ and 3 were retrospective $(453,1090,1092,1093)$. However, 2 prospective evaluations $(1091,1093)$ only had 3-months follow-up and consequently failed to meet inclusion criteria. Two prospective evaluations $(454,1094)$ were included.

Burnham and Yasui (1094) published the results of an alternate method of radiofrequency neurotomy of the sacroiliac joint in a pilot study. They evaluated 9 subjects with sacroiliac joint pain confirmed by a local anesthetic joint block. They were treated with a series of radiofrequency strip lesions performed adjacent to the lateral dorsal foraminal aperture plus conventional monopolar lesions at the L5 dorsal ramus. The followup was at 1, 3, 6, 9, and 12 months after the procedure. After the procedure, significant reductions of back and leg pain frequency and severity, analgesic intake, and dissatisfaction with their current level of pain occurred. Complications were minimal. Overall, 8 of the 9 subjects were satisfied with the procedure. The median improvement in pain intensity was 4.1 NRS and reduction of disability was 17.8 (Oswestry Disability Scale). Overall satisfaction was $67 \%$ at 12 -month follow-up.

Vallejo et al (454) from a total of 126 patients with presumptive sacroiliac joint dysfunction based on history and physical examination, performed arthrographically confirmed steroid/local anesthetic sacroiliac joint injections, and selected 22 patients to undergo pulsed radiofrequency when they failed to respond to physical therapy, repeated sacroiliac joint injections, and analgesics. The pulsed radiofrequency denervation of the medial branch of the L4, posterior primary rami of L5, and lateral branches S1 and S2 were carried out. Outcome measures included visual analogue score and quality of life assessments. Sixteen patients or $73 \%$ experienced excellent or good pain relief following pulsed radiofrequency denervation.

All 3 retrospective evaluations were included in the evidence synthesis (Table 19). Among the retrospective reports, Ferrante et al (1090) evaluated the effectiveness of sacroiliac joint radiofrequency denervations in 33 patients. They reported that only $36 \%$ of the patients met the criteria for successful denervation at 6 months. Yin et al (453) in a retrospective evaluation of 14 patients reported that $64 \%$ of the patients experienced a successful outcome. Finally, Cohen and Abdi (1092) evaluated radiofrequency lesioning on 9 patients and reported that $89 \%$ obtained $>50 \%$ pain relief from this procedure that persisted at the 9-month follow-up. In addition to the thermal radiofrequency Vallejo et al (454) evaluated the effectiveness of pulsed radiofrequency however, there has not been any significant literature on utilization of pulsed radiofrequency; not only in the sacroiliac joints but other areas also. Thus, it was not included in evidence synthesis.

\subsubsection{Cost Effectiveness}

No cost effectiveness evaluations were performed with radiofrequency neurotomy of sacroiliac joint innervation.

\subsubsection{Evidence}

The evidence for thermal and pulsed radiofrequency neurotomy in managing sacroiliac joint pain is limited.

\subsubsection{Safety and Complications}

No complications have been reported in any of the studies included in this review. However, expected complications include infection, hematoma formation, neural damage, trauma to the sciatic nerve, potential gas and vascular particulate embolism, leakage of the drug from the joint, and other complications related to drug administration.

\subsection{Intradiscal Therapies}

The pathologic basis for some forms of low back pain may lie in internally disrupted intervertebral discs and in particular, sensitized annular tears (229, 230,367,375-377,407,1095). Multiple treatments described to manage internal disc disruption and discogenic pain include surgical intervention with total disc excision and arthrodesis or conservative measures 
Pain Physician: January 2007:10:7-111

Table 19. Results of published reports of sacroiliac joint radiofrequency thermoneurolysis

\begin{tabular}{|c|c|c|c|c|c|c|c|c|c|}
\hline \multirow[b]{2}{*}{ Study } & \multirow[b]{2}{*}{$\begin{array}{c}\text { Study } \\
\text { Characteristics }\end{array}$} & \multirow{2}{*}{$\begin{array}{c}\text { Methodological } \\
\text { Quality } \\
\text { CriteriaAHRQ } \\
\text { Score }\end{array}$} & \multirow[b]{2}{*}{$\begin{array}{c}\text { No. of } \\
\text { Patients }\end{array}$} & \multirow{2}{*}{$\begin{array}{l}\text { Initial } \\
\text { Relief } \\
<3 \mathrm{mos}\end{array}$} & \multicolumn{3}{|c|}{ Long-term Relief } & \multicolumn{2}{|c|}{ Results } \\
\hline & & & & & $3 \mathrm{mos}$ & $6 \mathrm{mos}$ & $\begin{array}{c}1 \\
\text { year }\end{array}$ & $\begin{array}{c}\text { Short- } \\
\text { term } \\
\text { relief }<3 \\
\text { mos }\end{array}$ & $\begin{array}{c}\text { Long-term } \\
\text { relief } \geq \mathbf{3} \\
\text { mos }\end{array}$ \\
\hline $\begin{array}{l}\text { Burnham and } \\
\text { Yasui (1094) }\end{array}$ & $\mathrm{P}$ & $6 / 8$ & 9 & $89 \%$ & $89 \%$ & $89 \%$ & $89 \%$ & $\mathbf{P}$ & $\mathbf{P}$ \\
\hline $\begin{array}{l}\text { Vallejo et al } \\
(454)\end{array}$ & $\mathrm{P}$ & $6 / 8$ & 22 & $56 \%$ & $41 \%$ & $32 \%$ & NA & $\mathbf{P}$ & $\mathrm{N}$ \\
\hline Yin et al (453) & $\mathrm{R}$ & $4 / 8$ & 14 & $64 \%$ & $64 \%$ & $64 \%$ & $64 \%$ & $\mathbf{P}$ & $\mathbf{P}$ \\
\hline $\begin{array}{l}\text { Ferrante et al } \\
(1090)\end{array}$ & $\mathrm{R}$ & $4 / 8$ & 33 & $35 \%$ & $35 \%$ & $35 \%$ & NA & $\mathrm{N}$ & $\mathrm{N}$ \\
\hline $\begin{array}{l}\text { Cohen and } \\
\text { Abdi (1092) }\end{array}$ & $\mathrm{R}$ & $4 / 8$ & 9 & $89 \%$ & $89 \%$ & $89 \%$ & NA & $\mathbf{P}$ & $\mathbf{P}$ \\
\hline
\end{tabular}

$R=$ retrospective $; P=$ prospective $; N A=$ not available $; \mathbf{P}=$ positive $; N=$ negative

such as intradiscal steroid, chemonucleolysis, intradiscal glycerol, and the use of intradiscal laser devices.

Two minimally invasive procedures have been promoted as alternatives to major surgical intervention. Both involve the introduction of a flexible electrode into the painful disc, with the aim of coagulating the posterior annulus (1096). The first technique is described as intradiscal electrothermal therapy or IDET and the second technique was named radiofrequency posterior annuloplasty or RFA.

For this evaluation, relief of less than 6 months was considered as short-term and relief of 6 months or longer was considered as long-term.

\subsubsection{Intradiscal Electrothermal Therapy.}

Intradiscal electrothermal therapy (IDET), as originally described, did not require placement of the electrode explicitly in the annulus fibrosus (1097). The electrode is a flexible, thermal resistive coil which coagulates the adjacent tissue with radiant heat. However, the mechanism of action of IDET has not been established. It has been proposed that heating the annulus may serve to strengthen the collagen fibers, seal fissures, denature inflammatory exudates, or coagulate nociceptors (1098).

The evidence for intradiscal electrothermal therapy includes 3 systematic reviews (41-43), a technology assessment update (64), critical appraisal of the evidence (57) and other multiple reviews. Evidence for
IDET was also reviewed in multiple guideline preparations $(1,2,56)$.

Appleby et al (42) in a systematic review reviewed the literature from all the available studies and concluded that there was compelling evidence for the relative efficacy and safety of intradiscal electrothermal therapy. From 1998 to March 2005, authors selected a total of 17 published reports and included them in the review. This metaanalysis showed an overall mean improvement in pain intensity of 2.9 points, physical function of 21.1 points as measured by SF-36 and disability of 7.0 points as measured by the Oswestry Disability Index. Andersson et al (41) performed a systematic review of spinal fusion and intradiscal electrothermal therapy in the treatment of intractable discogenic low back pain. They concluded that the majority of patients reported improvement in symptoms following both spinal fusion and IDET procedure. However, the IDET procedure appeared to offer sufficiently similar symptom amelioration to spinal fusion without attendant complications. Gibson and Waddell (43) concluded that the preliminary results of 3 similar trials of intradiscal electrotherapy suggests it is ineffective, except possibly in highly selected patients.

Freeman (57) performed a critical appraisal of the evidence of IDET and concluded that the evidence for the efficacy of IDET remains weak and has not passed the standard of scientific proof. European Guidelines 
for the Treatment of Chronic Non-specific Low Back Pain (56) concluded that there is conflicting evidence that IDET, in patients with discogenic low back pain, is not more effective than sham treatment (Level C). Interventional Pain Management Guidelines by Boswell et al (1) and Manchikanti et al (2) concluded that the evidence for intradiscal electrothermal therapy was strong for short-term relief and moderate for long-term relief in managing chronic discogenic low back pain.

A technology assessment update (64) evaluating all the available studies concluded that initial results from the studies are promising. However, the majority of data comes from small case series studies. This assessment considered IDET as a controversial and investigational therapy until more randomized controlled trials with long-term follow-up were conducted and showed the effectiveness of IDET.

The relevant studies identified included 2 randomized controlled trials $(1099,1100), 2$ non-randomized controlled trials (1101,1102), 12 prospective evaluations (1097,1103-1113), and multiple case series (1114-1120). Of the 12 prospective evaluations, 2 nonrandomized controlled trials reported outcomes on the same patient population with different lengths of follow-up $(1101,1102)$. Of the remaining 10 prospective trials, 5 reported outcomes on the same patient population with different lengths of follow-up (109 $7,1104,1105,1107,1108)$. Table 20 summarizes demographic and study characteristics of studies included in the evidence synthesis.

Two randomized controlled trials $(1099,1100)$ of percutaneous intradiscal electrothermal therapy for chronic discogenic low back pain were double-blind and placebo-controlled. Pauza et al (1099) in evaluation of the effectiveness of intradiscal electrothermal therapy for the treatment of discogenic low back pain in a randomized, placebo-controlled trial reported significant improvements in pain, disability and depression in the group treated with IDET. However, only $40 \%$ of patients treated with IDET achieved greater than $50 \%$ relief of pain at 6 months. Freeman et al (1100), in a prospective randomized, double-blind, placebocontrolled trial with crossover offered to the placebo subjects when unblinding occurred at 6 months, with a total of 57 subjects, randomized 38 patients to IDET and 19 patients to placebo (sham) treatment. The results showed no benefit from IDET over placebo.

Karasek and Bogduk (1101) and Bogduk and Karasek (1102) studied 53 patients with back pain and followed them for 2 years. They concluded that in carefully selected cases, IDET can eliminate or dramatically reduce the pain of internal disc disruption in a substantial proportion of patients and appears to be superior to conventional conservative care for internal disc disruption. At 24 months, 54\% of the patients had achieved at least $50 \%$ relief with functional improvement.

Saal and Saal $(1097,1104,1108)$ reported results of their experience over a period of 6 months, 1 year, and 2 years, with overall improvement in $71 \%$ of the patients. They reported a VAS change for the entire group of 3.2 with a mean change on the SF-36 physical function subscale of 20 , and the mean change on the SF-36 bodily pain subscale of 17.8 .

Derby et al (1103) reported that $63 \%$ of the 32 patients had a favorable outcome, with no change in outcome measures at the 6-month and 12-month follow-ups. Bryce et al (1113) evaluated 51 patients, at 6 months follow-up, they demonstrated statistically significant improvement was measured by a mean change of over 20 points from the pretreatment score on the Roland Morris Disability Questionnaire. At one year, data remained with significant improvement in the 33 patients who had achieved this time point.

Kapural et al (1096) evaluated 21 patients with electrothermal therapy and an additional 21 patients with radiofrequency annuloplasty. From the third to twelth month after the procedure, the intradiscal electrothermal therapy group had significantly lower mean pain scores with an average VAS pain score decrease of $7.4 \pm 1.9$. There was also improvement in pain disability index.

The present evidence summarizes 1 positive randomized trial, 1 negative randomized trial, 7 positive prospective evaluations $(1096,1101,1103,1107,1108$, $1110,1112)$, with 2 negative reports $(1109,1116)$.

\subsubsection{Cost Effectiveness}

Cost effectiveness of intradiscal electrothermal annuloplasty has not been evaluated. Andersson et al (41) in their systematic review of intractable low back pain treatment with IDET versus spinal fusion surgery concluded that more than half of patients treated with IDET can avoid surgery and therefore spare the cost of surgery and its complications.

\subsubsection{Evidence}

The evidence for intradiscal electrothermal therapy (IDET) is moderate in managing chronic discogenic low back pain.

\subsubsection{Complications}

Complications include catheter breakage, nerve 
Table 20. Results of published reports of IDET

\begin{tabular}{|c|c|c|c|c|c|c|c|c|c|}
\hline \multirow[b]{2}{*}{ Study } & \multirow{2}{*}{$\begin{array}{c}\text { Study } \\
\text { Characteristics }\end{array}$} & \multicolumn{2}{|c|}{$\begin{array}{l}\text { Methodological } \\
\text { Quality Score(s) }\end{array}$} & \multirow{2}{*}{$\begin{array}{c}\text { No. of } \\
\text { Patients }\end{array}$} & \multirow{2}{*}{$\begin{array}{c}\text { Initial } \\
\text { Relief } \\
<6 \\
\text { mos }\end{array}$} & \multicolumn{2}{|c|}{$\begin{array}{l}\text { Long-term } \\
\text { Relief }\end{array}$} & \multicolumn{2}{|c|}{ Results } \\
\hline & & $\begin{array}{c}\text { AHRQ } \\
\operatorname{Score}(s)\end{array}$ & $\begin{array}{l}\text { Cochrane } \\
\text { Score }(s)\end{array}$ & & & $\begin{array}{c}6 \\
\operatorname{mos}\end{array}$ & $\begin{array}{c}1 \\
\text { year }\end{array}$ & $\begin{array}{c}\text { Short- } \\
\text { term } \\
\text { relief <6 } \\
\text { mos }\end{array}$ & $\begin{array}{c}\text { Long-term } \\
\text { relief } \geq \mathbf{6} \\
\text { mos }\end{array}$ \\
\hline Pauza et al (1099) & $\mathrm{RA}, \mathrm{DB}, \mathrm{PC}$ & $10 / 10$ & $10 / 10$ & $\begin{array}{l}\mathrm{C}=27 \\
\mathrm{~T}=37\end{array}$ & Equal & $\begin{array}{l}50 \% \\
\text { Treat }\end{array}$ & NA & $\mathbf{P}$ & $\mathrm{N}$ \\
\hline $\begin{array}{l}\text { Freeman et al } \\
(1100)\end{array}$ & $\mathrm{RA}, \mathrm{DB}, \mathrm{PC}$ & $10 / 10$ & $10 / 10$ & $\begin{array}{l}\mathrm{C}=19 \\
\mathrm{~T}=38\end{array}$ & $0 \%$ & $0 \%$ & $0 \%$ & $\mathrm{~N}$ & $\mathrm{~N}$ \\
\hline Kapural et al (1096) & $\mathrm{P}$ & $5 / 8$ & --- & 21 & SI & SI & SI & $\mathbf{P}$ & $\mathrm{P}$ \\
\hline $\begin{array}{l}\text { Karasek \& Bogduk } \\
(1101,1102)\end{array}$ & $\mathrm{P}$ & $5 / 8$ & --- & $\begin{array}{l}\mathrm{C}=17 \\
\mathrm{~T}=35\end{array}$ & $\begin{array}{c}6 \% \text { vs } \\
70 \%\end{array}$ & $53 \%$ & $53 \%$ & $\mathbf{P}$ & $\mathbf{P}$ \\
\hline $\begin{array}{l}\text { Saal and Saal (1097, } \\
1104,1108)\end{array}$ & $\mathrm{P}$ & $5 / 8$ & --- & 58 & SI & SI & SI & $\mathbf{P}$ & $\mathbf{P}$ \\
\hline $\begin{array}{l}\text { Gerszten et al } \\
(1107)\end{array}$ & $\mathrm{P}$ & $5 / 8$ & --- & 27 & $75 \%$ & $75 \%$ & $75 \%$ & $\mathbf{P}$ & $\mathbf{P}$ \\
\hline $\begin{array}{l}\text { Mekhail and } \\
\text { Kapural (1112) }\end{array}$ & $\mathrm{P}$ & $5 / 8$ & --- & 32 & SI & SI & SI & $\mathbf{P}$ & $\mathbf{P}$ \\
\hline Lutz et al (1110) & $\mathrm{P}$ & $5 / 8$ & --- & 33 & SI & SI & SI & $\mathbf{P}$ & $\mathbf{P}$ \\
\hline $\begin{array}{l}\text { Freedman et al } \\
(1116)\end{array}$ & $\mathrm{P}$ & $5 / 8$ & --- & 36 & NA & $47 \%$ & $16 \%$ & $\mathrm{~N}$ & $\mathrm{~N}$ \\
\hline $\begin{array}{l}\text { Spruit and Jacobs } \\
(1109)\end{array}$ & $\mathrm{P}$ & $4 / 8$ & --- & 20 & NSI & NSI & NSI & $\mathrm{N}$ & $\mathrm{N}$ \\
\hline Derby et al (1103) & $\mathrm{R}$ & $4 / 8$ & --- & 99 & $64 \%$ & $64 \%$ & $64 \%$ & $\mathbf{P}$ & $\mathbf{P}$ \\
\hline Bryce et al (1113) & $\mathrm{P}$ & $4 / 8$ & --- & 51 & SI & SI & $64 \%$ & $\mathbf{P}$ & $\mathbf{P}$ \\
\hline
\end{tabular}

$P=$ prospective $; P C=$ placebo controlled $; R A=$ randomized $; R=$ retrospective $; C=$ control $; T=$ treatment $; S I=$ significant improvement $;$ NSI $=$ No significant improvement; $N A=$ not available; $\mathbf{P}=$ positive; $N=$ negative

root injuries, post-IDET disc herniation, cauda equina syndrome, infection, epidural abscess, and spinal cord damage (1121-1130). Appleby et al (42) tabulated all the complications included in their meta-analysis. Complications included burning sensation, paresthesias and numbness, foot drop, increasing low back pain, increase in radicular pain, headache, increase in the size of the herniation, cerebral spinal fluid leak, inability to thread the catheters through scar tissue, nerve root injury and decreased sphincter control, discitis, and anterolisthesis.

\subsubsection{Radiofrequency Posterior Annuloplasty}

Radiofrequency posterior annuloplasty (RFA) is also commonly known by the name of the device used to place the lesion (discTRODE). The electrode is a semirigid, radiofrequency probe, which does not, by itself, generate heat. However, the electrode focuses an alternating, radiofrequency current onto surrounding tissues, whose component molecules are isolated and thereby heated. The electrode also serves to monitor the temperature generated in those tissues. There is far less literature on this procedure than there is for IDET (1096).

There are no systematic reviews performed on radiofrequency posterior annuloplasty. The relevant studies identified on intradiscal radiofrequency ablation included 2 prospective evaluations $(1096,1131)$.

Finch et al (1131) studied 31 patients by heating of their annular tears with a flexible radiofrequency electrode placed across the posterior annulus and 
compared 15 patients with conservative management. The visual analog scale decreased significantly after the radiofrequency treatment and this decrease persisted at 12 months follow-up. The VAS did not change over 12 months in untreated controlled subjects. The Oswestry Disability Index also decreased in treated patients but not in controlled subjects.

Kapural et al (1096) performed a prospective matched controlled trial of intradiscal thermal annuloplasty versus intradiscal radiofrequency ablation for treatment of discogenic pain. They matched 42 patients with 21 having IDET and 21 having radiofrequency annuloplasty. They reported the IDET group had significantly lower mean pain scores than the radiofrequency annuloplasty group; however, there was improvement noted in both groups. VAS pain scores decreased from $6.6 \pm 2.0$ before to $4.4 \pm 2.4$ at one year after radiofrequency annuloplasty, whereas in IDET group the average VAS pain score decreased from $7.4 \pm 1.9$ before IDET to $1.4 \pm 1.9$ at 1 -year follow-up. Similarly, pain disability index scores in the IDET group had a significantly larger improvement than those for patients who received radiofrequency annuloplasty.

\subsubsection{Cost Effectiveness}

Cost effectiveness of radiofrequency annuloplasty has not been performed.

\subsubsection{Evidence}

The evidence for radiofrequency posterior annuloplasty was limited for short-term improvement, and indeterminate for long-term improvement in managing chronic discogenic low back pain.

\subsubsection{Complications}

Complications are similar to IDET with catheter breakage, nerve root injuries, discitis, disc herniation, cauda equina syndrome, infection, epidural abscess, and spinal cord damage $(42,1121-1130)$.

\subsection{Percutaneous Disc Decompression}

A herniated intervertebral lumbar disc results from a protrusion of the nucleus pulposus. A ruptured annulus fibrosus causes an extruded disc while an intact but stretched annulus fibrosus results in a contained disc prolapse which may compress one or more nerve roots (63).

The primary goal of surgical treatment of a disc prolapse, protrusion or extrusion is the relief of nerve root compression by removing the herniated nuclear material. The primary modality of treatment has been open discectomy. However, several alternative techniques include microdiscectomy, chemonucleolysis, automated percutaneous discectomy, laser discectomy, radiofrequency Coblation or plasma discectomy known as nucleoplasty, mechanical disc decompression with a high rotation per minute device for nuclear extraction also known as DeKompressor, and manual percutaneous lumbar discectomy. Claims have been made from the literature that all of these alternative procedures can produce satisfactory results with small wounds and fewer serious complications; however, these claims remain controversial.

The subject of the guidelines in this section is of percutaneous discectomy, which is a class of minimally invasive surgical procedures that specifically treat contained, herniated discs. Manual percutaneous lumbar discectomy, microdiscectomy, and chemonucleolysis are not included in this review.

6.6.1 Automated Percutaneous Lumbar Discectomy

Automated percutaneous lumbar discectomy or APLD is performed with a pneumatically driven, suction-cutting probe in a cannula with a $2.8 \mathrm{~mm}$ outer diameter. Most of the disc removal occurs $1 \mathrm{~cm}$ anterior to the herniation removing approximately 1 to 3 grams of disc material to reduce intradiscal pressure and decompress the nerve roots (1132-1134).

Waddell et al (1135), in a systematic review based on Cochrane Collaboration Review and meta-analysis of surgical interventions in the lumbar spine (44), identified 3 trials comparing automated percutaneous discectomy with other surgical techniques and concluded there was limited and contradictory evidence (Strength of Evidence C) that automated percutaneous discectomy gives poorer clinical results than alternative surgical techniques with which it has been compared.

The technology assessment performed for the Department of Labor and Industries, Washington State on Percutaneous Discectomy (63) evaluated the literature until 2004. Published studies included 5 randomized trials $(1133,1136-1139)$ of which Haines et al had 2 publications from one study $(1138,1139)$. Revel et al (1133) and Krugluger and Knahr(1136) performed randomized trials of APLD and chemonucleolysis, whereas Chatterjee et al $(1137)$ and Haines et al $(1138,1139)$ performed trials comparing APLD with microdiscectomy. Multiple prospective and case series studies were also reported (1140-1147). Other studies included predictive factors, side effects and complications (1148-1151). Evidence from 4 of the 4 randomized published studies were shown to be negative, while all observational studies were positive. 
Among the published randomized trials, 2 trials $(1133,1136)$ compared APLD and chemonucleolysis. Revel et al (1133) randomized patients with sciatica caused by a disc herniation to undergo as an APLD or chemonucleolysis. The study measured outcomes with visual analog scale to measure sciatica and low back pain, a straight leg test, the Schoebert Test, neurologic status, self-assessment, disc height and herniation size. Patients were followed at 1 month, 3 months, and 6 months. The trial included 72 chemonucleolysis and 69 APLD patients of which $43 \%$ of chemonucleolysis patients and $26 \%$ of APLD patients were considered sedentary subjects, and the disc appeared degenerated more often in the chemonucleolysis group (92\%) than in the APLD group (76\%). The study had 32 patients withdrawing during trial as therapeutic failures. They described that there were no significant differences between the two groups in most of the demographic data, clinical and radiographic variables between the two groups. They concluded that the results of both chemonucleolysis and APLD were generally disappointing, because $48 \%$ of the overall population entering the study considered treatment a failure and $20 \%$ submitted to open laminectomy within 6 months. They further described that while the failure rate of chemonucleolysis was similar to that observed in various controlled studies, the results observed in the APLD group were strikingly different from most reported previous uncontrolled series. They also postulated that APLD success rate in this study approached that observed in the placebo groups in the chemonucleolysis trials. At one-year follow-up, overall success rates were $66 \%$ in the chemonucleolysis group and $37 \%$ in the APLD group.

Many aspects of the Revel et al's study (1133), such as patient selection criteria, which led to poor results have been criticized. The size of the disc herniation was an issue because for APLD it should not occupy more than $30 \%$ of the spinal canal, whereas in Revel et al's study (1133) in 59\% of APLD and $64 \%$ of chemonucleolysis patients the disc herniation covered between $25 \%$ and $50 \%$ of the spinal canal. Further, in $71 \%$ of the APLD patients and $79 \%$ of chemonucleolysis patients, the disc herniation had migrated up to $5 \mathrm{~mm}$ cranially or caudally to the endplate levels, considered a contraindication of APLD. Other factors included that at discography, 39\% of the tested discs showed epidural leakage, $76 \%$ of the discs were severely degenerated (APLD is not effective in diffuse annular bulging), $9 \%$ had marked disc space narrowing, and $21 \%$ of patients had severe back pain, but no correlation to leg pain was made.

Krugluger and Knahr (1136) also conducted a study comparing APLD with chemonucleolysis. The study initially selected 29 patients with symptomatic disc lesion confirmed by discography, however, due to epidural leakage of contrast material, 7 patients were excluded with 22 patient randomized to either chemonucleolysis or APLD. The results showed that at 6 weeks, both groups showed significant improvement in neurological deficits and Oswestry score. However, the differences between groups were not statistically significant at the 12-month follow-up.

Randomized trials of APLD and microdiscectomy included Chatterjee et al (1137) and Haines et al $(1138,1139)$. Chatterjee et al (1137) compared APLD to microdiscectomy in the treatment of contained lumbar disc herniation in a randomized study with blind assessment. The study included 71 patients with radicular pain as their dominant symptom after failure of conservative therapy for at least 6 weeks and with MRI demonstration of contained disc herniation at a single level with a disc bulge of less than $30 \%$ of the canal size. The study excluded patients with dominant symptoms of low back pain, disc extrusion, sequestration, subarticular or foraminal stenosis, or multiple levels of herniation. The results showed satisfactory outcomes in $29 \%$ of the patients in APLD group and $80 \%$ of the microdiscectomy group. They concluded that APLD was ineffective as a method of treatment for small, contained lumbar disc herniations. Authors were criticized in that they failed to utilize CT discography.

Haines et al (1138) conducted a randomized study comparing APLD to conventional discectomy as a first line treatment for herniated lumbar discs. The study measured outcomes with physical signs related to the severity of low back pain and sciatica, but used a modified Roland Scale for disability assessment, and the SF-36 for general health status. The primary endpoint was the patients' outcome ratings 12 months after surgery. The study included patients with unilateral leg pain or paresthesia with no history of lumbar spinal surgery, whereas exclusions included moderate or advanced lumbar spondylosis, spondylolisthesis, lateral restenosis, herniated disc fragment occupying more than $30 \%$ of the AP diameter of the spinal canal, herniated disc fragment migrating more than $1 \mathrm{~mm}$ above or below the disc space, calcified disc herniation, lateral disc herniation, or posterior disc space height less than $3 \mathrm{~mm}$. Success rate of the 
2 procedures was identified as APLD $41 \%$ compared to conventional discectomy $40 \%$. However they concluded that the study did not have power to identify clinically important differences because of insufficient patient enrollment.

Among the prospective evaluations and case series studies $(1142,1147)$, all of them reported positive results in greater than $50 \%$ of patients in a large population.

Delamarter et al (1132) described the predictive factors and concluded that it is difficult to predict the clinical outcome in percutaneous discectomy. Dullerud et al (1149) in a prospective study concluded that patients with normal or slightly narrow disc space experienced better results compared to patients with a larger degree of disc space narrowing.

\subsubsection{Complications}

A retrospective review of 243 patients with treatment at 271 disc levels showed a technical failure rate of $2.6 \%$, clinical and radiological changes consistent with discitis in 2 patients, mild spasm in the extensor muscles in $9 \%$ of the patients, $25 \%$ of the patient with mild to moderate sensation on instability and 1 patient developing functional paresis of lower limbs one month after treatment (1149). In another case report of a 24-year-old who underwent APLD at L5/S1 for relief of low back pain, it was reported that the patient developed acute right lumbar radicular syndrome, with MRI showing far lateral extraforaminal disc herniation at L5/S1 with compression of the right nerve root, which corresponded to the nucleotomy site of the probe (1150). In a multicenter analysis of percutaneous discectomy, two psoas muscle hematomas and one transient radicular deficit was reported (1151).

\subsubsection{Cost Effectiveness}

No cost effectiveness studies were conducted in the United States. However, Stevenson et al (1152) conducted a prospective cost evaluation including socioeconomic data comparing APLD to microdiscectomy. Average cost of treatment and follow-up surgery was $\$ 2,317$ per APLD patient compared to $\$ 1,567$ per microdiscectomy patient. Further, the average cost per APLD successful outcome was $\$ 3,264$ compared to $\$ 1,958$ for microdiscectomy successful outcome.

\subsubsection{Evidence}

The evidence is moderate for short-term and limited for long-term relief.

\subsubsection{Percutaneous Laser Discectomy}

Percutaneous laser discectomy or PLD is an alter- native to the standard open discectomy treatment. Laser energy is used to reduce pressure by vaporizing a small volume of the nucleus pulposus. It is hypothesized that the change in pressure between the nucleus pulposus and the peridiscal tissue causes retraction of the herniation away from the nerve root (1153-1168). Laser discectomy may be performed with or without endoscopy. The majority of the studies were without endoscopy.

Based on the systematic review by Waddell et al (1135) there is no acceptable evidence (Strength of Evidence D) for laser discectomy. Relevant studies evaluating the effectiveness of laser disc decompression included 14 studies (1154-1158,1160-1168) meeting inclusion criteria. There were no randomized trials.

Table 21 illustrates results of percutaneous disc decompression with laser-assisted disc removal. All the studies showed positive results (1154-1158,11601168). Results varied from satisfactory improvement in $57 \%$ of the patients to $93 \%$ of the patients. In the 14 reports included in the evidence synthesis, 2,181 patients were studied with positive outcome in 1,600 patients.

\subsubsection{Complications}

Complications of percutaneous discectomy laser can be divided into intraoperative and postoperative categories (1169-1171). The general complications are often due to patient positioning, anesthesia or allergic reaction. The intraoperative complications may be correlated to the surgical technique or instrumentation. Postoperative complications refer to bleeding or infection and general postoperative complications associated with the procedure itself such as cardiovascular problems.

Ohnmeiss et al (1157) in a series of 164 laser discectomies, reported the tip of the instrument bent in one case, 12 patients complained of postoperative dermatomal dysesthesia, which resolved in 5 cases, and 2 patients had signs of reflex sympathetic dystrophy.

Mayer et al (1169) in a retrospective analysis of 658 cases treated at 9 different centers observed $1.1 \%$ intraoperative complications and $1.5 \%$ postoperative complications. They reported for radicular deficits in 4 patients $(0.5 \%)$, L5 nerve root injury in 3 cases, vascular injuries in 2 cases, sigmoid artery injury in 1 patient, anomalous iliolumbar artery injury in 1 patient, and transverse process injury in 1 patient.

In a report of 10 cases, complications were present 
Table 21. Results of percutaneous disc decompression with laser assisted disc removal

\begin{tabular}{|l|c|c|c|c|}
\hline \multirow{2}{*}{ Study } & \multirow{2}{*}{$\begin{array}{c}\text { No. of } \\
\text { patients }\end{array}$} & \multicolumn{2}{|c|}{ 1 year relief } & \\
\cline { 3 - 5 } & & Percent & $\begin{array}{c}\text { Number } \\
\text { of } \\
\text { Patients }\end{array}$ & \\
\hline $\begin{array}{l}\text { Siebert et al } \\
(1156)\end{array}$ & 180 & $73 \%$ & 131 & Positive \\
\hline $\begin{array}{l}\text { Ohnmeiss et al } \\
(1157)\end{array}$ & 164 & $71 \%$ & 116 & Positive \\
\hline $\begin{array}{l}\text { Leibler (1158) } \\
\text { Bosacco et al } \\
(1154)\end{array}$ & 117 & $70 \%$ & 82 & Positive \\
\hline Choy (1155) & 518 & $75 \%$ & 389 & Positive \\
\hline Senel et al (1160) & 102 & $57 \%$ & 58 & Positive \\
\hline $\begin{array}{l}\text { Knight and } \\
\text { Goswami (1161) }\end{array}$ & 388 & $73 \%$ & 283 & Positive \\
\hline $\begin{array}{l}\text { Groemeyer et al } \\
(1162)\end{array}$ & 200 & $73 \%$ & 126 & Positive \\
\hline Tassi (1163) & 92 & $83 \%$ & 76 & Positive \\
\hline Zhao et al (1164) & 173 & $82 \%$ & 142 & Positive \\
\hline Lee et al (1165) & 60 & $93 \%$ & 56 & Positive \\
\hline $\begin{array}{l}\text { Tonami et al } \\
(1166)\end{array}$ & 26 & $65 \%$ & 17 & Positive \\
\hline $\begin{array}{l}\text { Nerubay et al } \\
(1167)\end{array}$ & 50 & $74 \%$ & 37 & Positive \\
\hline $\begin{array}{l}\text { Simons et al } \\
(1168)\end{array}$ & 50 & $86 \%$ & 43 & Positive \\
\hline Total & $\mathbf{2 1 8 1}$ & $\mathbf{7 3 \%}$ & $\mathbf{1 6 0 0}$ & Positive \\
\hline
\end{tabular}

in $1.5 \%$ of the total number of cases, which reported to have spondylodiscitis (1170). In another report, after PLAD a patient developed a subacute cauda equina syndrome (1171).

\subsubsection{Cost Effectiveness}

In 1996 the average hospital cost for percutaneous laser discectomy was $\$ 3,720$ (1153). This was 35\% of the average hospital cost for the open discectomy of $\$ 10,600$.

\subsubsection{Evidence}

The evidence is moderate for short-term and limited to long-term relief.

\subsubsection{Nucleoplasty}

Percutaneous disc decompression (PDD) with nucleoplasty (coblation technology) is performed with
RF energy to dissolve nuclear material through molecular dissociation. Bipolar RF coagulation denatures proteoglycans, changing the internal environment of the affected nucleus pulposus with reduction in intradiscal pressure (1172-1174). The proposed advantage of the coblation technology is that the procedure provides for a controlled and highly localized ablation, resulting in minimal thermal damage to surrounding tissues. The bi-products of this non-heat driven process are elementary molecules and low-molecular weight inert gases, which escape from the disc via the needle $(1172,1175,1176)$.

There were no systematic reviews evaluating the effectiveness of nucleoplasty thus far in the literature. However, the literature was synthesized in preparation of the guidelines and limited evidence was provided $(1,2)$. The effectiveness of nucleoplasty has been reported in 6 prospective $(1174,1175,1177-1180)$ evaluations.

Sharps and Isaac (1175) evaluated 49 patients with low back pain with or without radicular pain. The study excluded patients due to sequestered herniation, contained herniation larger than one-third of the sagittal diameter of the spinal canal or stenosis. The study evaluated pain on visual analog scale at 1 month, 3 months, 6 months and 1 year. Success was defined as a 2-point reduction on the VAS, patient satisfaction, no use of narcotics, and return to work. Results showed significant improvement in visual analog scale at 1-month, 3 months, 6 months and 12 months; however, follow-up of the reported patients declined to 41 at 3 months, 24 at 6 months, and 13 at 12 months.

Among 3 studies published by Singh et al $(1174,1177,1178)$, initially they (1174) published a prospective study of 67 patients with back and leg pain, with $80 \%$ of the patients reporting statistically significant improvement in numeric pain scores at 1-year. Singh et al (1178) also published results of 80 patients with back and leg pain followed for 1-year with similar findings as in first study (1174). Singh et al (1177) evaluated 47 patients presenting with predominantly back pain and undergoing treatment with nucleoplasty procedure using coblation technology. The proportion of patients who reported $>50 \%$ pain relief was $80 \%, 74 \%, 63 \%$, and $53 \%$ at the 1-month, 3-month, 6-month, and 12-month follow-up time periods, respectively. Functional improvements were also reported by $46 \%$ of patients for sitting ability, $41 \%$ for standing ability, and $49 \%$ for walking ability at 12 months. 
Marin (1179) published results of 64 patients with contained disc herniation undergoing radiofrequency coblation to treat low back pain and/or leg pain. The average duration of pain before treatment with coblation was 18 months. The results demonstrated improvement in pain scores in $75 \%$ as very good and in $5 \%$ as good at the 6 - to 12 -month follow-up. Fifteen percent of the patients showed some improvement however it was not good, and $5 \%$ of the patients showed no improvement at all.

Gerszten et al (1180) in a prospective, non-randomized, longitudinal cohort study evaluated 67 patients with primarily radicular pain due to contained disc herniation. They measured quality of life outcomes at 3 months and 6 months of the 34 patients in whom a 3-month follow-up was available, VAS scores were significantly improved. However, at 6 months following nucleoplasty, there was no longer a difference in VAS pain score in 23 patients compared with preoperative pain levels. Table 22 illustrates results of published trials meeting inclusion criteria.

\subsubsection{Complications}

The side effects and complications after percutaneous disc decompression using coblation technology have been reported (1181). From a total of 53 patients, the most common side effects at 24 hours post procedure was soreness at the needle insertion site (76\%), new numbness and tingling (26\%), increased intensity of preprocedure back pain (15\%) and new areas of back pain (15\%). However, all the other complications reported with electrothermal therapy are also potential complications with nucleoplasty.

Table 22 illustrates the results of published evaluations of nucleoplasty. All of them were prospective evaluations with no randomized trials. Further, all of them had less than 100 patients in the study. However, 5 of 6 showed positive results.

\subsubsection{Cost Effectiveness}

Cost effectiveness of percutaneous disc decompression with coblation nucleoplasty has not been evaluated.

\subsubsection{Evidence}

The evidence of nucleoplasty is limited for shortand long-term relief.

\subsubsection{Mechanical High RPM Device}

The DeKompressor probe is a mechanical high rotation per minute device designed to extract the nuclear material through an introducer cannula using an auger-like device that rotates at high speeds.

The DeKompressor is one of the new methods that extract the nuclear material of the disc using a high RPM spiral tip instrument.

There have been no systematic evaluations of percutaneous disc decompression utilizing the DeKompressor. There also have not been any guidelines describing this technology.

Table 22. Results of published evaluations of nucleoplasty

\begin{tabular}{|c|c|c|c|c|c|c|c|c|}
\hline \multirow[b]{2}{*}{ Study } & \multirow{2}{*}{$\begin{array}{c}\text { Study } \\
\text { Characteristics }\end{array}$} & \multirow{2}{*}{$\begin{array}{c}\text { Methodological } \\
\text { Quality Score } \\
\text { AHRQ Score }\end{array}$} & \multirow{2}{*}{$\begin{array}{l}\text { No. of } \\
\text { patients }\end{array}$} & \multirow{2}{*}{$\begin{array}{c}\text { Initial } \\
\text { relief }\end{array}$} & \multicolumn{2}{|c|}{$\begin{array}{l}\text { Long-term } \\
\text { relief }\end{array}$} & \multicolumn{2}{|c|}{ Results } \\
\hline & & & & & $6 \mathrm{mos}$ & 1 year & $\begin{array}{l}\text { Short- } \\
\text { term } \\
\text { relief }<6 \\
\text { mos }\end{array}$ & $\begin{array}{l}\text { Long- } \\
\text { term } \\
\text { relief } \\
\geq 6 \mathrm{mos}\end{array}$ \\
\hline $\begin{array}{l}\text { Sharps and Isaac } \\
\text { (1175) }\end{array}$ & $\mathrm{P}$ & $5 / 8$ & 49 & SI & SI & SI & $\mathbf{P}$ & $\mathbf{P}$ \\
\hline Singh et al (1174) & $\mathrm{P}$ & $5 / 8$ & 67 & $79 \%$ & $59 \%$ & $56 \%$ & $\mathbf{P}$ & $\mathbf{P}$ \\
\hline Singh et al (1177) & $\mathrm{P}$ & $5 / 8$ & 80 & $73 \%$ & $60 \%$ & $54 \%$ & $\mathbf{P}$ & $\mathbf{P}$ \\
\hline Singh et al (1178) & $\mathrm{P}$ & $5 / 8$ & 80 & $79 \%$ & $76 \%$ & $77 \%$ & $\mathbf{P}$ & $\mathbf{P}$ \\
\hline Marin (1179) & $\mathrm{P}$ & $5 / 8$ & 64 & $80 \%$ & $80 \%$ & $80 \%$ & $\mathbf{P}$ & $\mathbf{P}$ \\
\hline Gerszten et al (1180) & $\mathrm{P}$ & $5 / 8$ & 67 & $50 \%$ & NSD & NSD & $\mathrm{N}$ & $\mathrm{N}$ \\
\hline
\end{tabular}

$P=$ prospective $; S I=$ significant improvement $; N S D=$ No significant difference $; \mathbf{P}=$ positive $; N=$ negative 
Relevant literature included 2 publications from 1 prospective clinical trial $(1182,1183)$ and 1 case series report (1184). Both reports showed positive results.

Alo et al $(1182,1183)$ published the findings on the outcome of disc herniations treated with the DeKompressor in 2 publications from 1 study. Clinical response in an initial cohort of 50 consecutive patients with chronic radicular pain was evaluated in a randomized prospective clinical trial. Data was collected on the 6-month outcomes. Their inclusion criteria were radicular pain with contained herniation $<=6 \mathrm{~mm}$., correlating history and physical findings, pain for $>6$ months, failure of conservative therapies, good to excellent short-term relief ( $<2$ weeks) after a fluoroscopically guided transforaminal injection, confirmatory selective segmental spinal nerve block with $0.5-1.5 \mathrm{~mL}$ of anesthetic providing $>80 \%$ relief lasting at least the duration of the local anesthetic and preservation of disc height (less than $50 \%$ loss). They excluded patients with progressive neurological deficits, more than 2 symptomatic levels, previous open surgery at the proposed treatment level, spine instability, fracture or tumor; pain drawing inconsistent with clinical diagnosis and significant coexisting medical or psychological condition. They assessed the outcome using VAS score, analgesic usage; self reported functional improvement and overall satisfaction. It may have been more objective had they utilized some form of functional improvement measure. After 6 months, 74\% patients reported reducing their analgesic intake, $90 \%$ reported improvement in functional status and overall satisfaction with the therapy was $80 \%$. After 1-year follow-up, the data was published on 42 patients (54 levels). They noted an average reduction in pre-operative pain score (VAS) of $65 \%$. Also noted was a reduction in the analgesic intake in $79 \%$ and functional improvement in $91 \%$ of patients.

Amoretti et al (1184) published results of a clinical follow-up of 50 patients treated by percutaneous lumbar discectomy using the DeKompressor. Although it is not a blinded and randomized study, the data collection was thought to be good. The inclusion and exclusion criteria were clearly defined. They included patients with "lumbar sciatica of disco-lumbar origin" secondary to a herniated disc documented by an MRI. Patients had undergone medical therapies such as "CT-guided infiltration" which one assumes to be a corticosteroid injection. There was no change in disc height and the discs possessed satisfactory hydration as documented by a T2 signal on MRI. They excluded patients with extruded herniations and inconsistency between MRI and clinical findings as well as other common exclusions like infection and coagulopathy. Patients were also being medically treated with morphine and anti-inflammatory drugs pre-operatively. Using a DeKompressor instrument under CT or fluoroscopic guidance, they performed disc decompression on mainly L4-5 and L5-S1 discs with some L3-4 discs. They found that 11 patients did not respond satisfactorily to the treatment, but 39 patient were either able to suspend their medications (31 patients) or definitely reduce their medications ( 8 patients). The reduction in pain was found to be stabilized after about 7 days in most patients. Of the ones who responded favorably, 2536 out of 50 showed $>70 \%$ relief. More importantly they noted $>70 \%$ improvement in $79 \%$ patients with postero-lateral hernias versus $50 \%$ of patients with postero-medial hernias.

\subsubsection{Complications}

A critical failure of the DeKompressor probe was reported. The complication (1185) happened while performing a discectomy at $L 4 / 5$ level using a percutaneous DeKompressor probe on a 54-year-old patient. After operating the instrument for 1 to 2 minutes, the probe was removed and it was found to be broken. The remaining 4-inch tip was removed surgically, and patient recovered without any major complication. Similar instances have been reported by 2 other authors in the past. One of the instances was thought to have happened because of a bent cannula which may have contributed to the break of the device.

\subsubsection{Cost Effectiveness}

There were no cost effectiveness studies of percutaneous disc decompression utilizing DeKompressor available in the literature.

\subsubsection{Evidence}

The evidence for percutaneous disc decompression utilizing DeKompressor is limited for short- and long-term relief.

\subsection{Vertebral Augmentation Procedures}

Vertebral compression fractures (VCFs) constitute a major healthcare problem in the United States, not only because of high incidence of these lesions, but also due to their direct and indirect negative consequences for patient health-related quality of life and the costs to the healthcare system $(75,76,1186-1188)$. Vertebral fractures may result in pain about the fracture site, loss of height caused by vertebral collapse, 
spinal instability, and in many cases kyphotic deformity $(76,1189)$. Regardless of their etiology, the mainstay of management for symptomatic vertebral compression fractures has been medical therapy that may include analgesics, bedrest, external fixation, and rehabilitation $(75,1190,1191)$. However, such treatments are only partially effective in addressing symptoms and about one-third of patients have been reported to suffer from persistent pain and progressive functional limitation and loss of mobility (1192). The surgical treatment for vertebral compression fractures, refractory to medical therapy, that addressed deformity has been decompression and stabilization of the fractured vertebra with different kinds of metal implants (1193). However, surgical fixation often fails because of poor quality of osteoporotic bone (1194). Further, the procedures have generally been limited to cases where there is concurrent spinal instability or neurological deficit, due to the risks of open surgery in often elderly, frail patients $(75,1194,1195)$.

Vertebroplasty and balloon kyphoplasty are 2 minimally invasive surgical approaches developed for the management of symptoms of vertebral compression fractures (76,1196-1204). Galibert et al (1196) first reported vertebroplasty in 1987 for the minimally invasive of hemangiomas, which, since then has been adapted for use in the treatment of intractable, focal, intense pain localized to a vertebral fracture. Kyphoplasty was introduced in 1998 to restore vertebral body height and help realign the spine, using an inflatable balloon to reduce the fracture before the injection of cement $(1197,1198)$. Currently, vertebroplasty and kyphoplasty have been gaining popularity to stabilize vertebral fractures mainly caused by osteoporosis but also including malignant involvement of the spinal column, hemangioma, and vertebral osteonecrosis $(75,76,1199)$.

\subsubsection{Vertebroplasty}

Vertebroplasty involves a percutaneous injection of polymethylmethacrylate (PMMA) into the fractured vertebral body.

A number of reviews of literature and commentaries have promoted the use of vertebroplasty in patients with symptomatic vertebral compression fractures from osteoporotic or neoplastic etiology $(75,76,1192,1198,1200-1210)$. Of these, 2 systematic reviews $(75,76)$ of effectiveness and safety published in 2006 concluded that there is level 3 evidence to support vertebroplasty as effective therapy in the management of patients with symptomatic osteo- porotic vertebral compression fractures refractory to conventional medical therapy (75). However, it was also concluded that there was no definite evidence to state that vertebroplasty is a safe and effective procedure due to lack of comparative, blinded, randomized clinical trials.

Relevant studies evaluating vertebroplasty included multiple systematic reviews, prospective and comparative studies, as well as case series. Taylor et al (75) identified 2 non-randomized, comparative studies $(1211,1212)$ and 57 case series meeting the inclusion criteria. Hulme et al (76) identified 65 non-controlled, single-group cohort studies for vertebroplasty and kyphoplasty combined.

The evidence was considered short-term for less than 6 months and long-term for 6 months or longer.

Taylor et al (75) showed that 1 prospective study (1211) compared vertebroplasty with conventional medical care and another prospective study compared vertebroplasty and kyphoplasty (1212). Included patients were predominantly women over 65 years who had experienced symptomatic osteoporotic VCF, the remainder had neoplastic lesions. Even though, no difference in pain relief compared with medical therapy was reported in the 1 vertebroplasty study (1212) and improvement in the functional capacity was observed. In the study comparing balloon kyphoplasty and vertebroplasty (1211), both procedures appeared to provide a similar level of pain relief after surgery, although there was insufficient patients with follow-up in order to comment on 1year outcome. In case series, a total of 3,029 patients with 4,861 vertebral fractures were included in 57 case series of vertebroplasty. Sample size varied considerably (75), across the studies as did study duration with up to 55 months of follow-up available following vertebroplasty. Most patients (greater than $80 \%$ ) had experienced painful VCF as the result of primary or secondary osteoporosis (75). Only a small proportion of studies were specifically conducted in patients with neoplastic lesions. Overall the quality of case series studies was poor.

Hulme et al (76) demonstrated that methodological quality of various studies was poor. None of the studies were randomized and only a few studies had an aspect of the study that was blinded (12131218). In addition, confounding factors, bias, and limitations were not consistently reported. There were 12 prospective, 29 retrospective and 6 unreported vertebroplasty studies showing the results 
of 2,958 subjects (in 47 studies), including 1,959 females, 676 males, and 323 unreported with a mean age of 72 years, who underwent 4,456 procedures. Fifty percent of the vertebroplasty procedures were performed within the thoracolumbar regions of the spine including $\mathrm{T} 11$ to $\mathrm{L} 2$.

\subsubsection{Effectiveness}

Hulme et al (76) reported a $16 \%$ to $47 \%$ full-scale improvement in physical function after vertebroplasty in 7 studies using different variants of a 5-point mobility scale $(1215,1219-1224)$. Hulme et al (76) reported that $49 \%$ to $90 \%$ of subjects reported ambulation improvements in 4 studies assessed by qualitative patient response $(1199,1213,1214,1225)$. They also reported results of 3 studies that showed improvements in physical function using a validated health-related outcomes instrument (1226-1228). Vertebral height restoration data was not reported qualitatively, however, $39 \%$ of the patients (512 patients in 8 studies) following vertebroplasty intervention did not result in an appreciable restoration of height or kyphotic angle.

Taylor et al (75) reported that a total of 3,029 with 4,861 vertebral fractures were included in 57 case series of vertebroplasty. There was a significant reduction in the pooled level of pain following vertebroplasty. However, only one vertebroplasty study reported use of a validated outcome tool, Oswestry Disability Index, but failed to report numerical outcomes (1229). Five vertebroplasty studies reported quality of life, 4 using a variety of validated health-related quality of life measures $(1199,1229-1231)$. Of these, 3 reported significant improvement in quality of life following vertebroplasty while 1 study reported no change (1231). Taylor et al (75) also reported that 4 vertebroplasty studies $(1216,1218,1232,1233)$ reported a significant increase in vertebral height and 3 of these studies $(1218,1232,1233)$ reported on a reduction in kyphotic angle. Visual analog pain scores reduced from an average of 8.2 to 3.0.

\subsubsection{Cost Effectiveness}

There were no cost effectiveness studies of vertebroplasty available in the literature.

\subsubsection{Evidence}

The level of evidence for vertebroplasty is moderate.

\subsubsection{Kyphoplasty}

Balloon kyphoplasty is performed by injection of poly methyl methacrylate (PMMA) following insertion of a tamp (balloon) into the vertebral body in order to compress the cancellous bone creating a cavity, and if possible realignment of the endplate of the vertebral body (75). After the removal of the bone tamp the PMMA fixes and stabilizes the fracture.

A number of reviews of literature and commentaries have promoted the use of kyphoplasty in patients with symptomatic vertebral compression fractures from osteoporotic or neoplastic etiology $(75,76,1195,1198,1200-1210)$. Of these, 2 systematic reviews $(75,76)$ of effectiveness and safety published in 2006 concluded that there is level 3 evidence to support balloon kyphoplasty as effective therapy in the management of patients with symptomatic osteoporotic vertebral compression fractures refractory to conventional medical therapy (75). However, it was also concluded that there was no definite evidence to state that kyphoplasty is a safe and effective procedure due to lack of comparative, blinded, randomized clinical trials.

Relevant studies evaluating kyphoplasty have been many. Taylor et al (75) identified 4 non-randomized comparative studies $(1211,1233-1235)$ and multiple case series $(1197,1201,1236-1243)$ that met the inclusion criteria. Of these 1 prospective study and 2 retrospective studies compared balloon kyphoplasty and conventional medical care. One prospective study compared the 2 procedures. Included patients were predominantly women over 65 years who had experienced a symptomatic osteoporotic VCF, the remainder having neoplastic lesions. In 1 study (1234) patients had experienced pain for at least 12 months, whereas, in another study (1235) patients experienced pain for an average of only 34 days. In case series a total of 641 patients with 1,070 vertebral fractures in 13 case series of balloon kyphoplasty were included. The duration of pain was infrequently reported, although rare details were available. The mean duration across balloon kyphoplasty was 7.4 months, indicating that patients were likely to be refractory to conventional medical therapy. Several balloon kyphoplasty studies assessed health-related quality of life utilizing an instrument $(1197,1237,1238)$ with substantial overall improvements.

Hulme et al (76) included 13 prospective, 8 retrospective and 1 unreported study evaluating kyphoplasty showing the results of 1,288 subjects in 22 studies including 829 females, 403 males and 56 unreported with a mean age of 72 years who underwent 1,624 procedures. Sixty percent of kyphoplasty procedures 
were performed within the thoracolumbar region of the spine including T11 to L2.

\subsubsection{Effectiveness}

A large proportion of patients had some pain relief with $92 \%$ of the population involving 447 patients in 7 studies. Visual analog pain scores reduced from an average of 7.5 to 3.4. Two studies showed change in SF-36 scores for kyphoplasty $(75,76)$. Two kyphoplasty studies showed improvements in disability, mean Oswestry Disability Index preoperative $60 \%$ and postoperative $32 \%$ in 77 subjects $(1228,1244)$. Hulme et al (76) also showed mean kyphotic angle restoration was 6.6 degrees in 9 studies; however, not all subjects had a reduction in kyphotic angular restoration of height. A mean of $34 \%$ of kyphoplasty interventions did not result in an appreciable restoration of height or kyphotic angle. Taylor et al (75) showed that compared with medical therapy alone, balloon kyphoplasty significantly improved patients level of pain and functionality based on the studies evaluated. One study (1234) reported statistically significant improvements in both vertebral height and kyphotic angle following balloon kyphoplasty.

\subsubsection{Cost Effectiveness}

No systematic evaluation of cost effectiveness was performed for kyphoplasty.

\subsubsection{Evidence}

The level of evidence for kyphoplasty is moderate.

\subsubsection{Complications}

Immediate complications associated with vertebroplasty and kyphoplasty can be separated into 2 categories, procedural and cement leakage (76). Reported procedural complications include infection $(1222,1245,1246)$, fractures of the transverse process, pedicle, sternum, and ribs $(1199,1212,1216,1219$, $1222,1247)$, and respiratory distress caused by the anesthetic $(1213,1248)$. Cement leakage occurred in $41 \%$ of vertebra during vertebroplasty and $9 \%$ of vertebra during kyphoplasty (76). The distribution of leaks was $32 \%$ and $11 \%$ epidural, $32.5 \%$ and $48 \%$ paraspinal, 30.5 and $38 \%$ intradiscal, $1.7 \%$ and $1.5 \%$ pulmonary, and $3.3 \%$ and $1.5 \%$ foraminal for vertebroplasty and kyphoplasty respectively with 1,081 leakage locations reported in 30 studies and 65 leakage locations reported in 10 studies for vertebroplasty and kyphoplasty respectively. Most leaks were clinically asymptomatic (76). Clinical complications occurred for $2.6 \%$ and $1.3 \%$ of augmented vertebra and $3.9 \%$ and $2.2 \%$ of subjects for vertebroplasty and kyphoplasty respectively. Because pulmonary emboli can cause serious ramifications, asymptomatic emboli were counted as a clinical complication. Pulmonary emboli occurred in $0.6 \%$ and $0.01 \%$ of augmented vertebra for vertebroplasty and kyphoplasty, respectively, while neurologic complications occurred in $0.6 \%$ and $0.03 \%$ of vertebra (76).

Taylor et al (75) reported that rates of adverse events including pulmonary embolism, neurologic complications, and perioperative mortality were low for both procedures although poorly reported across studies. A significantly higher rate of cement leakage was reported for vertebroplasty than balloon kyphoplasty. In addition, no leaks were reported to be symptomatic with balloon kyphoplasty, while some $3 \%$ of leaks with vertebroplasty were reported to be symptomatic. The study of Fourney et al (1211), comparing balloon kyphoplasty and vertebroplasty reported no cement leakages in balloon kyphoplasty patients while 6 of 65 (9.2\%) of patients treated with vertebroplasty reported asymptomatic extravasations.

The systematic review by Hulme et al (76) reported 17 vertebroplasty and 12 kyphoplasty clinical trials that reported new fractures. Of new vertebral fractures using vertebroplasty and kyphoplasty, 60\% and $66 \%$, respectively, were adjacent to the augmented vertebra.

Taylor et al (75) reported incidence of new vertebral fractures, both total and adjacent, was somewhat higher for balloon kyphoplasty than vertebroplasty, although their $95 \%$ confidence intervals overlapped.

\subsection{Implantable Therapies}

Spinal cord stimulation systems and implantable intrathecal devices are frequently used in managing chronic intractable pain $(1,2,22,29,56,67,71,1249$ 1253). Significant improvements of less than one year were considered as short-term, whereas, one year or longer were considered as long-term.

\subsubsection{Spinal Cord Stimulation}

Spinal cord stimulation consists of implanting epidural electrodes transcutaneously and connecting them to a generator which is internalizing during a second procedure if the test stimulation is successful.

In the United States, the primary indications for spinal cord stimulation are failed back surgery syndrome and complex regional pain syndromes type I and type II $(22,29,56,67,1249-1253)$.

Multiple systematic reviews $(22,29,56,67,1250$ 1254), 5 randomized controlled trials (1255-1259), 6 
prospective trials (1260-1265), and multiple case series (1266-1283) were identified.

Three of the 5 randomized trials were included $(1256,1257,1259)$. Two reports by Kemlar et al $(1257,1258)$ and two studies by North et al $(1255,1259)$ were included as one each. Raphael et al (1256) reported positive results of spinal cord stimulation in failed back surgery syndrome. Kemler et al $(1257,1258)$ evaluated the effectiveness in complex regional pain syndrome. Taylor et al $(22,1251,1252,1254)$ in multiple systematic reviews included analysis of spinal cord stimulation (SCS) cost and its use in the back and extremity pain, failed back surgery syndrome (FBSS), and complex regional pain syndrome (CRPS). Their reviews revealed moderate evidence to support SCS in CRPS Type I, FBSS, and chronic low back and lower extremity pain with strong evidence supporting its use in CRPS Type I and moderate evidence to support in use in the other diagnoses listed. Furthermore, they reported evidence to support the long-term cost effectiveness of spinal cord stimulation compared to other standard modalities used for treatment of FBSS with a cost of $\$ 29,123$ in the SCS group and $\$ 38,029$ in the control group (1266). With CRPS, there is an estimated savings of $\$ 60,000$ over lifetime use.

Turner et al (1250) have reported on SCS for low back pain, FBSS, and CRPS in 2 large systematic reviews also evaluated which revealed similar findings in whole to Taylor's conclusions $(29,1250-1253)$.

Cameron's 20-year literature review (1253) included studies totaling 3,679 patients and showed that SCS has a "positive, symptomatic, long-term effect in cases of refractory angina pain..." as well as with PVD, peripheral neuropathic pain, and chronic low back pain. It also concluded that SCS is safe and effective for treatment of chronic neuropathic pain.

Of the 5 randomized controlled studies, 3 that met the criteria for this review, all reported positive findings. Kemler et al (1257) reported on CRPS plus physical therapy (PT) versus PT alone. North et al (1259) evaluated FBSS patients who either underwent repeat spinal surgery or SCS placement and found favorable results with SCS superior to reoperation through three years follow-up. Raphael et al (1256) also revealed positive results for the use of SCS in FBSS patients.

Among the prospective evaluations, 3 studies (1260-1262) evaluated the use of SCS in patients with low back pain. All revealed positive findings for control of back pain and/or lower extremity radicular pain. Two prospective trials $(1263,1264)$ showed improvements in CRPS Type I pain, post-herpetic neuralgia pain and acute herpes zoster pain. Another prospective trial (1265) demonstrated pain relief in patients with interstitial cystitis with average pain score. Change was from 5.8 out of 10 to 1.6 out of 10 at a 14-month average follow-up timeframe. Of the 19 case series included, all showed favorable findings for the use of SCS in neuropathic pain (1266-1276). Three addressed the use of SCS in CRPS (1266-1268). Two reported its use in FBSS $(1269,1270), 2$ in chronic back pain $(1271,1272)$, and 1 with lumbar spinal stenosis (1273). One studied its utility in refractory leg pain, one studied abdominal pain, one reported on SCS and interstitial cystitis, and one evaluated unilateral limb pain conditions. Three studies (1274-1276) revealed the results of large numbers of patients treated with SCS in a variety of neuropathic pain conditions.

\subsubsection{Cost Effectiveness}

Taylor et al (1254) performed a systematic review of the literature. They reviewed 99 abstracts and found 14 studies that met the criteria of the review. They found across a range of health care institutions that the initial healthcare acquisition costs were offset by a reduction in post-implant healthcare resource demand and costs. Costs were $\$ 29,123$ in intervention group, compared to $\$ 38,029$ in the control group for failed back surgery syndrome. In contrast, for CRPS (1254) in the lifetime analysis, spinal cord stimulation per patient was estimated to be $\$ 60,000$ cheaper than control therapy.

\subsubsection{Evidence}

The evidence for spinal cord stimulation in failed back surgery syndrome and complex regional pain syndrome is strong for short-term relief and moderate for long-term relief.

\subsubsection{Complications}

Complications with spinal cord stimulation range from infection, hematoma, nerve damage, lack of appropriate paraesthesia coverage, paralysis, nerve injury, and death $(1271,1277)$.

6.8.2 Implantable Intrathecal Drug Administration Systems

Continuous infusion of intrathecal medication is used for control of chronic, refractory, malignant and non-malignant pain. In an exhaustive review of available literature, Bennett et al (1278) concluded that clinical efficacy in large-scale randomized controlled trials utilizing intrathecal delivery of most compounds has not been demonstrated and variations between study designs make useful comparisons of existing 
studies difficult. In another review, Walker et al (1279) concluded that the evidence for the safety and effectiveness of combination spinal analgesic therapies is moderate in acute pain, whereas, they found limited or no evidence to support the combination analgesics in chronic pain. Turner et al (71) performed a systematic review of effectiveness and complications of programmable intrathecal opioid delivery systems for chronic non-malignant pain. They included six studies in the evidence synthesis and found improvement in pain on average among patients who received a permanent intrathecal drug delivery systems (1280-1285). All of the articles also reported some improvement in physical function. Guidelines also have been published on the drugs used in intrathecal infusion systems (1286).

The literature supporting the use of intrathecal infusion systems includes four randomized trials (1287-1290), multiple prospective trials (1280-1286), and multiple retrospective evaluations (1291-1298).

Among the randomized trials (1287-1290), Siddall et al (1287) compared the effectiveness of intrathecal morphine or clonidine, alone or in combination, in the treatment of neuropathic pain after spinal cord injury. They concluded that the combination of morphine and clonidine produced significantly more pain relief than placebo 4 hours after administration. van Hilten et al (1288) evaluated the use of intrathecal baclofen for the treatment of dystonia in patients with complex regional pain syndrome, in a double-blind, randomized, controlled, crossover trial of bolus intrathecal injections of baclofen in various doses. They concluded that in some patients, the dystonia associated with reflex sympathetic dystrophy responded markedly to intrathecal baclofen. Smith et al (1289) reported significant improvement in patients treated with intrathecal infusion systems when compared to patients treated with conventional aggressive medical management in patients with malignant pain. Staats et al (1290) in a multicenter, double-blind trial, reported that a neuron-specific calcium channel blocker delivered via an implanted intrathecal pump in patients with cancer and AIDS-related pain syndromes significantly decreased pain scores in $51 \%$ of the patients compared to $18 \%$ in the placebo group at the 7 -day follow-up. Thus, all the randomized trials were performed for neuropathic pain utilizing various types of drugs and short-term follow-up.

Among the prospective studies, Hassenbusch et al (1291) reported favorable results in patients with long-standing non-malignant neuropathic pain in a study of 14 patients, $61 \%$ reported good or fair pain control with a mean follow-up duration of 2.4 years. Angel et al (1292) reported good to excellent analgesic response in $73 \%$ of 11 patients. Deer et al (1285) reported the results of the National Outcomes Registry for low back pain collected at 6- and 12-month follow-ups. They reported that in the implant group, numeric pain ratings dropped by more than $47 \%$ for back pain and more than $31 \%$ for leg pain at 12 month follow-up. They also reported improvement in Oswestry scores in $65 \%$ of the patients.

Anderson and Burchiel (1280) in 30 patients implanted with diverse diagnosis including 14 patients with failed back surgery syndrome with a mean age of 58 years showed positive outcomes. Kumar et al $(1281,1283)$, Rainov et al (1282), and Anderson et al (1284) all showed positive outcomes.

Retrospective reports dominate the literature on intrathecal pain management (1294-1298). Among the retrospective evaluations, the reports provided significant improvement at short-term and long-term follow-up.

\subsubsection{Cost Effectiveness}

In post lumbar laminectomy syndrome, it was shown that intrathecal morphine delivery resulted in lower cumulative 60-month costs of $\$ 16,579$ per year and $\$ 1,382$ per month versus medical management at $\$ 17,037$ per year or $\$ 1,420$ per month (1299).

In another study (194), the expected total cost of intrathecal morphine over 60 months was $\$ 82,893$ (an average of $\$ 1382$ per month).

\subsubsection{Evidence}

The evidence for implantable intrathecal infusion systems is strong for short-term improvement in pain of malignancy or neuropathic pain. The evidence is moderate for long-term management of chronic pain.

\subsubsection{Complications}

The complications include post-dural puncture headache, infection, nausea, urinary retention, pruritus, catheter and pump failure, pedal edema, hormonal changes, granuloma formation, and decreased libido.

Turner et al (71) described complications derived from 10 published reports. Non-pharmacological biological complications included wound infection $12 \%$ across in 3 studies, meningitis $2 \%$ in 3 studies, and pump malposition in $17 \%$ in 2 studies. CSF leaks dur- 
ing catheter placement leading to postdural headache were not commonly reported. Among the 10 studies, 7 studies $(1281-1284,1291,1300,1301)$ did not mention this complication at all, $2(1280,1285)$ mentioned, it but did not provide both the number of patients assessed for this complication and the number who had the complication, and 1 (1292) reported that no patients had it. In 1 study, one of 30 patients showed drug-seeking behavior and 1 patient received an overdose of morphine and bupivacaine due to a programming error (1285). The most commonly reported drug side effects were nausea/vomiting. Other side effects mentioned in some articles in the complications review were provocation of asthma, insomnia, dry mouth, nightmares, myoclonic jerk/spasm, dizziness, loss of appetite, diarrhea, and headache $(1281,1301)$.

Hardware complications were reported commonly on average across studies, $12 \%$ of patients with permanent systems had catheter migration or dislodgement, $19 \%$ had a catheter obstruction or occlusion, and $5 \%$ had mechanical failure of the pump or battery, not including normal battery replacement (71). Equipment revision was reported in $27 \%$ of patients and pump removal was reported in $5 \%$ of the patients (71).

There were a number of intrathecal granulomas at the tip of the intrathecal catheter some of which were large enough to cause spinal cord compression and neurologic dysfunction such as urinary incontinence and paraparesis or paraplegia (71). Traumatic syrinx, local erythema and edema in the area of the abdominal wall pocket and lower extremity edema, transverse myelitis due to catheter-tip infection, postdural puncture headache, diplopia, cranial nerve palsy, and intracranial subdural hematoma, dissociative mental state, symptoms of withdrawal, and patient self-draining of morphine have been reported (71).

\subsection{Evaluation and Management}

\subsection{Evaluation}

Appropriate history, physical examination, and medical decision making are essential to provide appropriate documentation and patient care (13021307). There are numerous acceptable medical methods to evaluate a chronic spinal pain patient. These methods vary from physician to physician and textbook to textbook. The guidelines established by the Centers for Medicare and Medicaid Services (CMS) and the American Medical Association's Current Procedural Terminology (CPT) aid the physician in performing a comprehensive and complete evaluation, and assist in complying with regulations. The CMS guidelines define 5 levels of services. The 3 crucial components of evaluation and management services are history, physical examination, and medical decision-making. Other components include counseling, coordination of care, nature of presenting problem, and time.

Suggested algorithm for comprehensive evaluation and management of chronic spinal pain is illustrated in Figure 1.

\subsection{Medical Necessity Management}

The following criteria should be considered carefully in performing interventional techniques:

1. Complete initial evaluation, including history and physical examination.

2. Physiological and functional assessment, as necessary and feasible.

3. Determination of indications and medical necessity:

- Suspected organic problem.

- Nonresponsiveness to less invasive modalities of treatments except in acute situations such as acute disc herniation, herpes zoster and postherpetic neuralgia, reflex sympathetic dystrophy, and intractable pain secondary to carcinoma.

- Pain and disability of moderate-to-severe degree.

- No evidence of contraindications such as severe spinal stenosis resulting in intraspinal obstruction, infection, or predominantly psychogenic pain.

- Responsiveness to prior interventions with improvement in physical and functional status to justify repeat blocks or other interventions.

- Repeating interventions only upon return of pain and deterioration in functional status.

\subsection{Delivery of Interventional TECHNOLOGY}

There is no consensus among the interventional pain management specialists with regards to type, dosage, frequency, total number of injections, or other interventions. Yet significant attention in the literature seems to be focused on the complications attributed to the use of epidural steroids in the entire arena of interventional pain management. Thus, various limitations of interventional techniques, specifically neural blockade, have arisen from basically false impressions. Based on the available literature 
and scientific application, the most commonly used formulations of long-acting steroids, which include methylprednisolone (Depo-Medrol), triamcinolone diacetate (Aristocort), triamcinolone acetonide (Kenalog), and betamethasone acetate and phosphate mixture (Celestone Soluspan), appear to be safe and effective $(882,890,966,1308-1330)$. Based on the present literature, it appears that if repeated within 2 weeks, betamethasone may be the best choice in avoiding side effects; whereas, if treatment is carried out at 6-week intervals or longer, any one of the 4 formulations will be safe and effective. In recent years, there has been substantial attention focused on particulate and non-particulate steroids. Complication rates with epidural steroid injections are typically low and include paresthesia, hematoma, epidural abscess, meningitis, arachnoiditis, and inadvertent subdural or subarachnoid injection. However, in recent years, complications with persistent paraplegia, cerebral infarct, and other multiple central nervous systems sequelae have been reported. Undetected intraarterial injection or arterial trauma have been implicated as possible causes $(743,1025)$. Tiso et al $(1025)$ reported a case of massive cerebellar infarction after uneventful selective cervical transforaminal block, which was attributed to intraarterial injection of corticosteroid. Subsequently, they conducted studies with focus on particulate size of compound versus blood vessel dimension. They proposed a potential role for corticosteroid particulate embolus during unintended intraarterial injection as a potential mechanism. Others $(900,901,950,961,966,1329,1330)$ have evaluated effectiveness of various types of steroids comparing to other types, along with comparing to local anesthetic. There were no significant differences in some studies $(900,901,950,961)$ in the duration of relief whether steroids were used or not. In 1 study (966), compared dexamethasone and triamcinolone for cervical transforaminal injection with results indicating the effectiveness of dexamethasone was slightly less than that of triamcinolone but the difference was neither statistically nor clinically significant. Thus, authors of this study felt that non-particulate agent, namely dexamethasone, theoretically appears to be a valid alternative to particulate agents such as triamcinolone. Noe and Haynsworth (1330) compared Depo-Medrol to a non-depo form of betamethasone in patients with low back pain. The results showed that patients who received epidural methylprednisolone (Depo-medrol) reported significant reduction in pain ratings as well as disability scores after 4 weeks, while patients receiving betamethasone showed no significant difference in pain or disability scores. They concluded that the anti-inflammatory effect of a depo-steroid can be greater than a non-deposteroid even at equally potent doses. Stanczak et al (1329) reviewed the results of 597 patients who received Kenalog or Celestone Soluspan as an epidural injection for treatment of low back pain from 1997 to 2002. The procedures were performed under fluoroscopy. They showed that on days 0 to 3 , on day 17 , and on day 14 response was better with Kenalog than Celestone. On day 14, 54\% of Celestone recipients and $71 \%$ of Kenalog recipients showed improvement in low back pain and improvement in leg or buttock pain. Anwar et al (890) in a prospective, randomized, single-blind study of epidural steroid injection comparing triamcinolone with methylprednisolone acetate used a non-fluoroscopic technique with a caudal approach. Comparing 20 subjects in each group, they showed that there were marked improvements in symptoms with both agents but there were no differences in terms of superiority from one agent to another.

The questions also have been raised with regards to the effectiveness of intraarticular facet joint injections with steroids and medial branch blocks with steroids $(826,828,829,843,844)$.

Frequency and total number of injections or interventions are key issues, although controversial and rarely addressed (1-4,1331-1334). Descriptions of the frequency of various types of interventional techniques are included here. These are based on available evidence and consensus regarding the safety, clinical effectiveness, and cost effectiveness. However, they are not based on evidence synthesis methodology. Descriptions are provided only for commonly used procedures, which frequently require repeat interventions. Medicare, Medicaid and third party payers in each region and state may have rules and regulations different from these guidelines. Interventions permitted per year and per region are also variable.

\subsection{Facet Joint Injections and Medial Branch Blocks}

- In the diagnostic phase, a patient may receive 2 procedures at intervals of no sooner than 1 week or preferably 2 weeks.

- In the therapeutic phase (after the diagnostic phase 
is completed), the suggested frequency would be 2-3 months or longer between injections, provided that $>50 \%$ relief is obtained for 6 weeks.

- If the interventional procedures are applied for different regions, they may be performed at intervals of no sooner than 1 week or preferably 2 weeks for most types of procedures. It is suggested that therapeutic frequency remain at 2 months for each region. It is further suggested that all regions be treated at the same time, provided all procedures can be performed safely.

- In the treatment or therapeutic phase, the inter- ventional procedures should be repeated only as necessary according to the medical necessity criteria, and it is suggested that these be limited to a maximum of 4 to 6 times for local anesthetic and steroid blocks over a period of 1 year, per region.

- Under unusual circumstances with a recurrent injury or cervicogenic headache, procedures may be repeated at intervals of 6 weeks after stabilization in the treatment phase.

\subsection{Medial Branch Neurotomy}

- The suggested frequency would be 3 months or

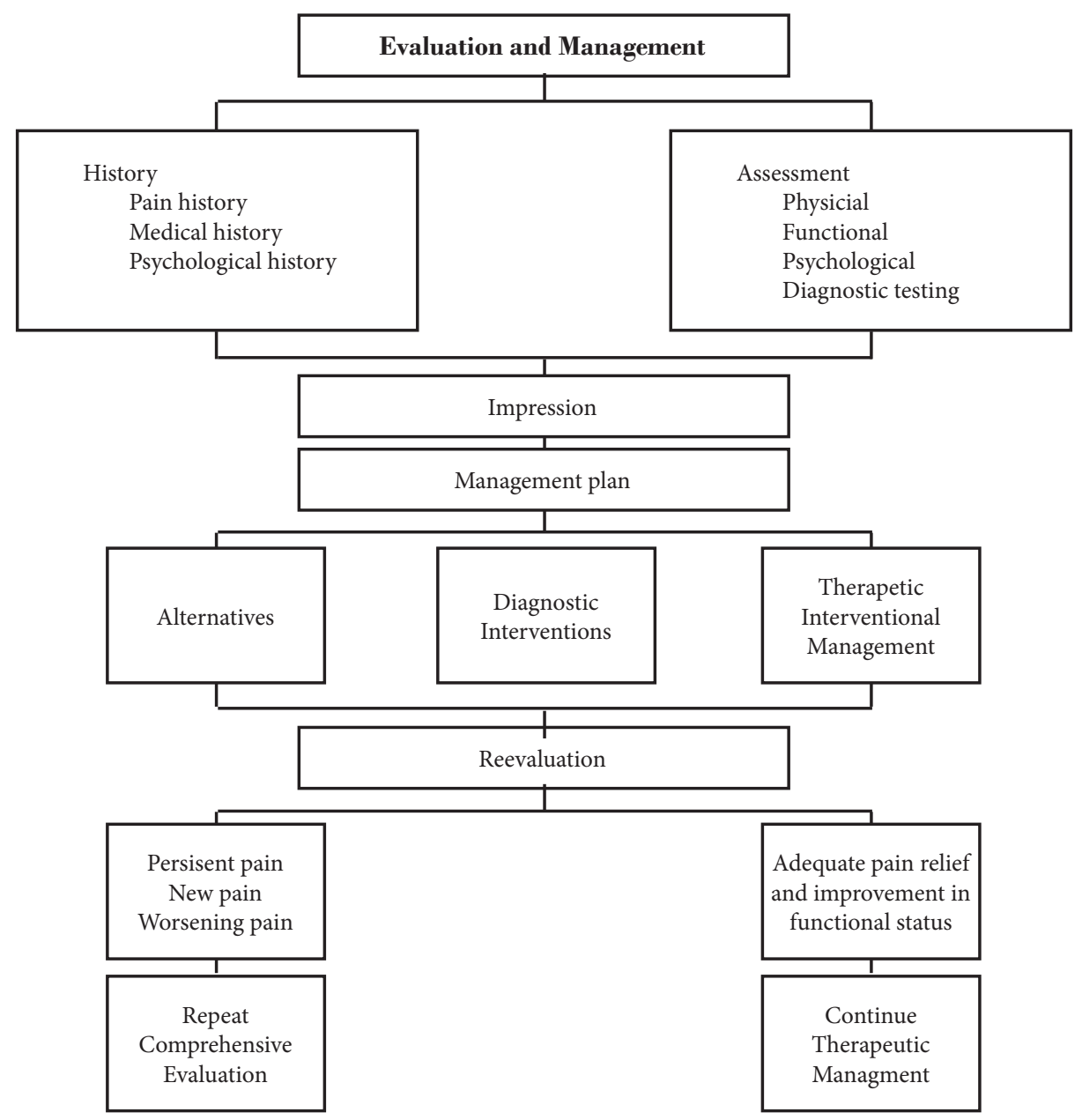

Fig 1. A comprehensive patient evaluation.

Adapted from ref. (2) 
longer (maximum of 3 times per year) between each procedure, provided that $>50 \%$ relief is obtained for 10 to 12 weeks.

- The therapeutic frequency for medial branch neurotomy should remain at intervals of at least 3 months for each region. It is further suggested that all regions be treated at the same time, provided all procedures are performed safely.

\subsection{Epidural Injections}

- Epidural injections include caudal, interlaminar, and transforaminal.

- In the diagnostic phase, a patient may receive 2 procedures at intervals of no sooner than 1 week or preferably 2 weeks except in cancer pain or when a continuous administration of local anesthetic is employed for reflex sympathetic dystrophy.

- In the therapeutic phase (after the diagnostic phase is completed), the suggested frequency of interventional techniques should be 2 months or longer between each injection, provided that $>50 \%$ relief is obtained for 6 to 8 weeks.

- If the neural blockade is applied for different regions, they may be performed at intervals of no sooner than 1 week and preferably 2 weeks for most types of procedures. The therapeutic frequency may remain at intervals of at least 2 months for each region. It is further suggested that all regions be treated at the same time, provided all procedures can be performed safely.

- In the treatment or therapeutic phase, the interventional procedures should be repeated only as necessary according to medical necessity criteria, and it is suggested that these be limited to a maximum of 4-6 times per year.

- Under unusual circumstances with a recurrent injury, carcinoma, or reflex sympathetic dystrophy, blocks may be repeated at intervals of 6 weeks after diagnosis/stabilization in the treatment phase.

\subsection{Percutaneous Adhesiolysis}

- The number of procedures are preferably limited to:

With a 3-day protocol, 2 interventions per year,

With a 1-day protocol, 4 interventions per year.

\subsection{Spinal Endoscopic Adhesiolysis}

- The procedures are preferably limited to a maximum of 2 per year provided the relief was $>50 \%$ for $>4$ months.

\subsection{Sacroiliac Joint Injections}

- In the diagnostic phase, a patient may receive two procedures at intervals of no sooner than 1 week or preferably 2 weeks.

- In the therapeutic phase (after the diagnostic phase is completed), the suggested frequency would be 2 months or longer between injections, provided that $>50 \%$ relief is obtained for 6 weeks.

- If the procedures are done for different joints, they be performed at intervals of no sooner than 1 week or preferably 2 weeks. It is suggested that therapeutic frequency remain at 2 months for each joint. It is further suggested that both joints be treated at the same time, provided the injections can be performed safely.

- In the treatment or therapeutic phase, the interventional procedures should be repeated only as necessary according to the medical necessity criteria, and it is suggested that they be limited to a maximum of 4-6 times for local anesthetic and steroid blocks over a period of 1 year, per region.

- Under unusual circumstances with a recurrent injury, procedures may be repeated at intervals of 6 weeks after stabilization in the treatment phase.

\subsection{Sacroiliac Joint Radiofrequency Neurotomy}

- The suggested frequency is 3 months or longer between each procedure (maximum of 3 times per year), provided that $>50 \%$ relief is obtained for 10 to 12 weeks.

- The therapeutic frequency for neurotomy should remain at intervals of at least 3 months for each region. It is further suggested that all regions be treated at the same time, provided all procedures are performed safely.

\subsection{An Algorithmic Approach}

In the changing paradigm of modern medicine, with its major focus on evidence-based medicine, interventional pain physicians may benefit from the practice of evidence-based interventional pain management. An algorithmic approach, if developed properly, may assist the physician in the clinical practice of interventional pain management. 
An algorithmic approach was developed, based on the structural basis of spinal pain, and incorporated acceptable evidence of diagnostic and therapeutic interventional techniques available in managing chronic spinal pain. Consensus was utilized in the absence of specific evidence. Figure 2 describes a proposed algorithmic approach for the diagnosis of chronic low back pain and Figure 3 describes an algorithmic approach to management of chronic low back pain. Figure 4 describes a proposed algorithmic approach for diagnosis and management of chronic neck pain.

\subsection{Conclusion}

The American Society of Interventional Pain Physicians has developed and updated evidence-based practice guidelines for interventional techniques in the management of chronic spinal pain, as an ongoing process utilizing the best available clinical evidence from systematic research. A policy committee with broad representation, consisting of academic and clinical practitioners recognized as experts in one or more interventional techniques under consideration and representing a variety of practices and geographic areas, assisted in preparation of these guidelines. All types of relevant and published evidence and consensus were utilized. These guidelines are a comprehensive review of interventional techniques for managing chronic spinal pain. It is hoped that these guidelines will assist both physicians and patients in making appropriate health care decisions for the diagnosis and treatment of chronic spinal pain.

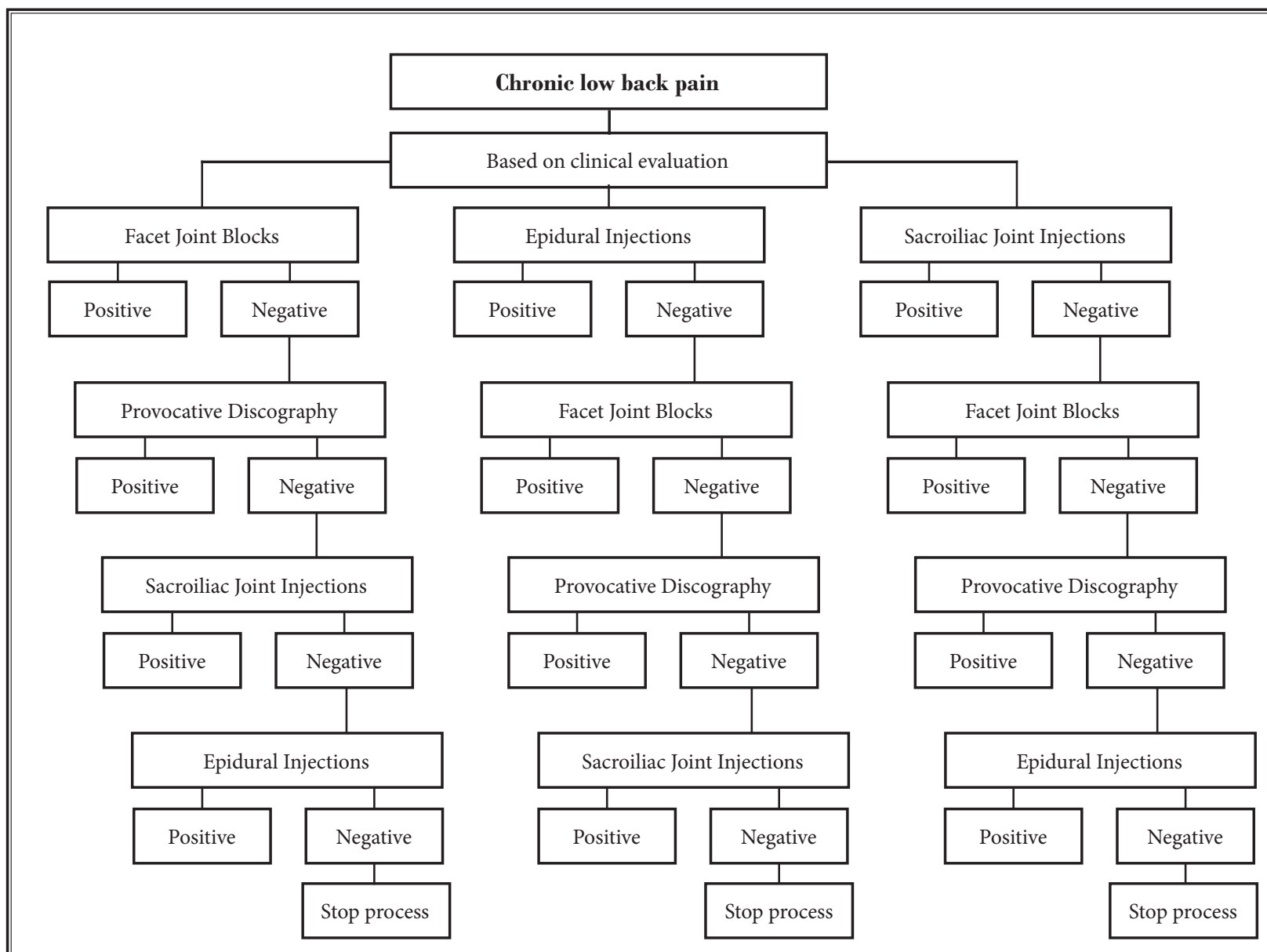

Fig 2. An algorithmic approach to diagnosis of chronic low back pain without disc herniation. 


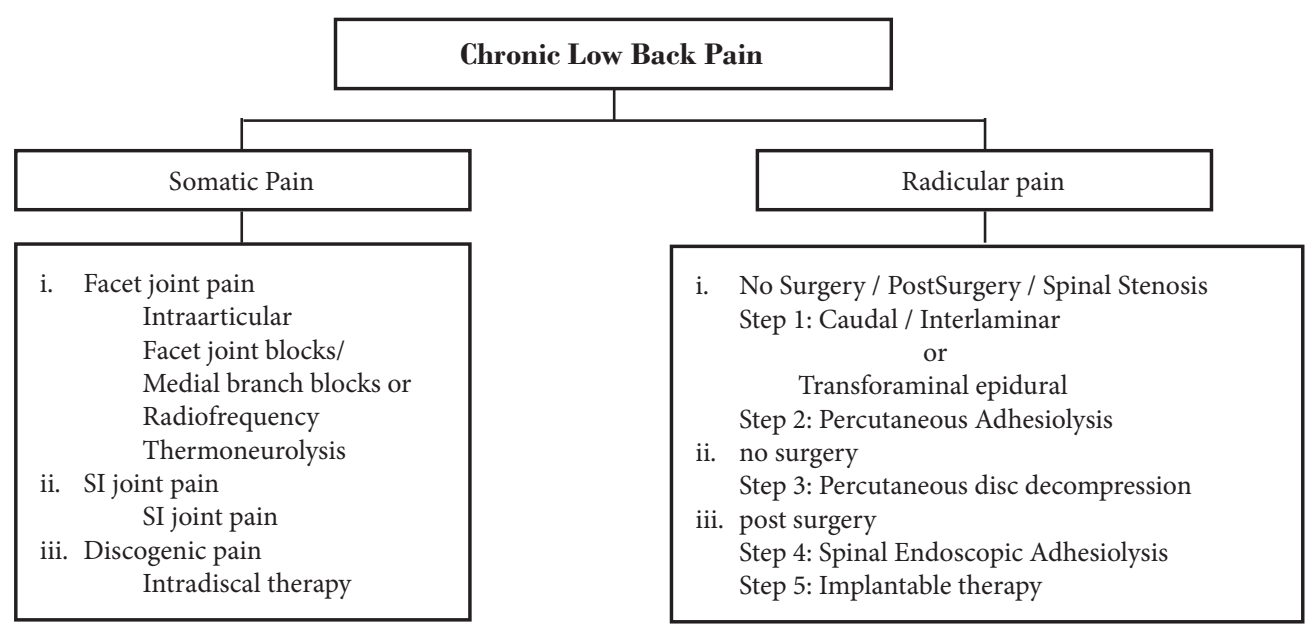

Fig 3. A suggested algorithm for therapeutic interventional techniques in management of chronic low back pain.

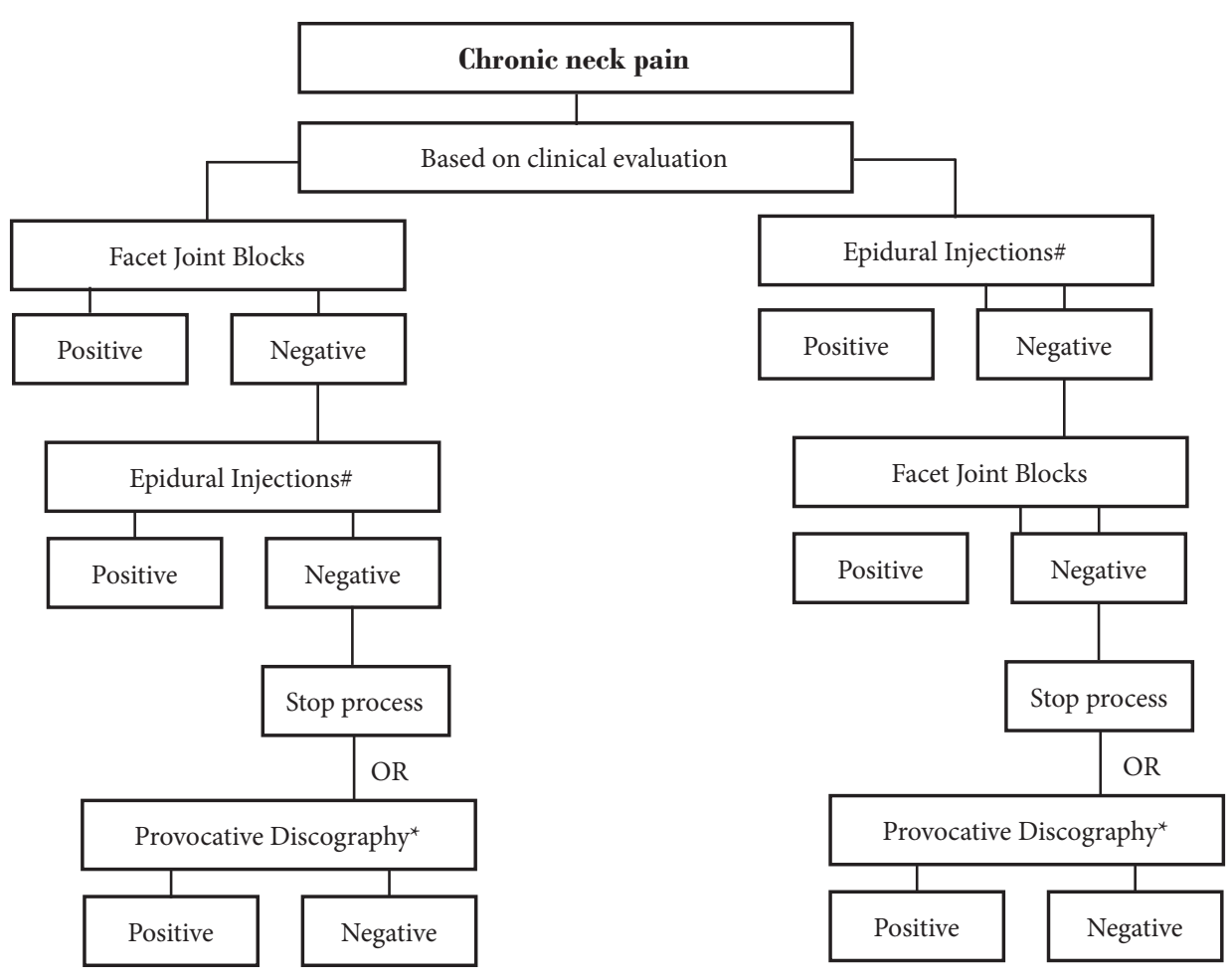

Fig 4. An algorithmic approach to diagnosis of chrnoic neck pain without disc herniation.

\footnotetext{
\# Transforaminal epidural injections have been associated with reports of risk

* Not based on evidence synthesis
} 


\section{Author Affiliation}

\author{
Salahadin Abdi, MD, PhD \\ Professor and Chief, Division of \\ Pain Medicine \\ Department of Anesthesiology, \\ Perioperative Medicine, and Pain \\ Management \\ University of Miami, Miller School \\ of Medicine \\ 1611 NW 12 ${ }^{\text {th }}$ Ave., SW 303 \\ Miami, FL 33136 \\ e-mail: sabdi@med.miami.edu
}

Sairam L. Atluri, MD

Tri State Pain Management Institute

7655 Five Mile Road, Suite 117

Loveland, $\mathrm{OH} 45242$

e-mail: atluri_ps@sprynet.com

Ramsin M. Benyamin, MD

President

Millennium Pain Center

1015 S. Mercer

Bloomington, IL 61701

Clinical Instructor

Department of Surgery

College of Medicine

University of Illinois

Urbana-Champaign, IL

e-mail: ramsinbenyamin@yahoo.com

Mark V. Boswell, MD, PhD

Professor of Anesthesiology

Director, Messer-Racz Pain Center

Department of Anesthesiology

Texas Tech University Health

Sciences Center

3601 4th Street MS 8182

Lubbock, TX 79424

e-mail: mark.boswell@ttuhsc.edu

Richard C. Bowman, MD, PhD

The Center for Pain Relief

400 Court Street, Suite 304

Charleston WV 25301

jaimegbowman@yahoo.com
Ricardo M. Buenaventura, MD

Dayton Pain Med

3490 Far Hills Avenue, Suite 202

Kettering, OH 45429

e-mail: rbuena@yahoo.com

Allen W. Burton, MD
Associate Professor
Section Chief of Cancer Pain
Management
Department of Anesthesiology and
Pain Medicine-Unit 409
1400 Holcombe Blvd.
University of Texas
MD Anderson Cancer Center
Houston, TX 77030-4009
e-mail: awburton@mdanderson.org
James D. Colson, MD
Assistant Professor of Anesthesiology
Pain Medicine Service
Department of Anesthesiology
West Virginia University Hospitals
1 Medical Center Drive
Morgantown, WV26506
e-mail: colsonj@rcbhsc.wvu.edu

Harold J. Cordner, MD

Florida Pain Management Associates 13825 US Highway 1

Sebastian FL 32905

e-mail: gassdoc@aol.com

\section{Sukdeb Datta, MD}

Director

Pain Management Services

VA Tennessee Valley Healthcare

System

1310 24th Avenue South

Nashville, TN 37212

Assistant Professor

Vanderbilt University School of

Medicine

Department of Anesthesiology

Nashville TN 37212

e-mailsukdeb@hotmail.com
Timothy R. Deer, MD

Director,

The Center for Pain Relief and

Clinical Professor, Anesthesiology

West Virginia University

Chairman, Committee on Pain

Medicine

The American Society of

Anesthesiology

400 Court Street, Suite 304

Charleston WV 25301

e-mail: DocTDeer@aol.com

Elmer E. Dunbar, MD

Medical Director

Pain Control Network

6400 Dutchman Parkway, Suite 60

Louisville KY 40205

e-mail: eed@paincontrolnetwork.net

\section{Richard S. Epter, MD}

Augusta Pain Center

P.O. Box 211839

Augusta GA 30917-1839

e-mail: paindoc727@aol.com

James Giordano, PhD

Scholar-in-Residence

Center for Clinical Bioethics

Georgetown University Medical

Center

4000 Reservoir Rd.

Washington, DC 20057

e-mail: jgiordano@neurobioethics.org

Hans C. Hansen, MD

Medical Director

The Pain Relief Centers, PA

1224 Commerce Street SW

Conover, NC 28613

e-mail: hans@hippocrates.org

\section{Joseph F. Jasper, MD}

Medical Director

Advanced Pain Medicine Physicians 1628 South Mildred Street, Suite \#105

Tacoma, WA 98465-1613

e-mail: apmedicine@qwest.net 
David S. Kloth, MD

Medical Director

Connecticut Pain Care, PC

109 Newton Road

Danbury CT 06810

e-mail:dkmd@ctpaincare.com

\section{Laxmaiah Manchikanti, MD \\ CEO, American Society of \\ Interventional Pain Physicians \\ Medical Director \\ Pain Management Center of \\ Paducah \\ 2831 Lone Oak Road \\ Paducah, KY 42003 \\ Associate Clinical Professor of \\ Anesthesiology and Perioperative \\ Medicine \\ University of Louisville, KY 40292 \\ e-mail:drm@apex.net.}

Vikram B. Patel, MD

Associate Professor of Anesthesiology

Director of Pain Fellowship

Program

Dept. of Anesthesiology

Loyola University Medical Center

2160 S. First Avenue

Maywood, IL 60153

e-mail:vikpatel1@hotmail.com
David M. Schultz, MD

Medical Advanced Pain Specialists

Assistant Professor

Department of Anesthesiology

University of Minnesota Medical

School

2104 Northdale Blvd. NW, Suite 220

Minneapolis, MN 55433

e-mail:dschultz@painphysicians.com

\section{Nalini Sehgal, MD}

Associate Professor of

Rehabilitation Medicine

Medical Director of Interventional

Pain Program

University of Wisconsin School of

Medicine and Public Health

Dept. of Orthopedics and Rehabilitation

Madison, WI

e-mail: NSegal@uwhealth.org

Rinoo V. Shah, MD

Assistant Professor

Interventional Pain Management

Department of Anesthesiology

Guthrie Clinic

Sayre, PA

e-mail: rinoo_shah@yahoo.com

Vijay Singh, MD

Medical Director

Pain Diagnostics Associates

1601 Roosevelt Road

Niagara, WI 54151

e-mail: vj@wmpnet.net
Howard S. Smith, MD, PhD

Academic Director of Pain

Management

Professor of Anesthesiology

Albany Medical College

47 New Scotland Avenue

Albany, NY 12208

e-mail: smithh@mail.amc.edu

\section{Peter S. Staats, MD}

Interventional Pain Management

160 Avenue at the Common

Shrewsbury, NJ 07702

e-mail: pstaats@jhmi.edu

John R. Swicegood, MD

Medical Director

Advanced Interventional Pain and

Diagnostics of Western Arkansas

PO Box 10206

Fort Smith, AR 72917

e-mail: aipd@sbcglobalnet

\section{Andrea M. Trescot, MD}

Director, Pain Fellowship Program

University of Florida

Gainesville, FL

The Pain Center

1564 Kingsley Ave

Orange Park, FL 32073

e-mail:amt57@aol.com 


\section{References}

1. Boswell MV, Shah RV, Everett CR, Sehgal N, Mckenzie-Brown AM, Abdi S, Bowman RC, Deer TR, Datta S, Colson JD, Spillane WF, Smith HS, LucasLevin LF, Burton AW, Chopra P, Staats PS, Wasserman RA, Manchikanti L. Interventional techniques in the management of chronic spinal pain: Evidencebased practice guidelines. Pain Physician 2005; 8:1-47.

2. Manchikanti L, Staats PS, Singh V, Schultz DM, Vilims BD, Jasper JF, Kloth DS, Trescot AM, Hansen HC, Falasca TD, Racz GB, Deer T, Burton AW, Helm S, Lou L, Bakhit CE, Dunbar EE, Atluri SL, Calodney AK, Hassenbusch S, Feler CA. Evidence-based practice guidelines for interventional techniques in the management of chronic spinal pain. Pain Physician 2003; 6:3-80.

3. Manchikanti L, Singh V, Kloth DS, Slipman CW, Jasper JF, Trescot AM, Varley KG, Atluri SL, Giron C, Curran MJ, Rivera JJ, Baha A, Bakhit CE, Reuter M. Interventional techniques in the management of chronic pain: Part 2.o. Pain Physician 2001; 4:24-96.

4. Manchikanti L, Singh V, Bakhit CE, Fellows $\mathrm{B}$. Interventional techniques in the management of chronic pain. Part 1.0. Pain Physician 2000; 3:7-42.

5. Manchikanti L. Medicare in interventional pain management: A critical analysis. Pain Physician 2006; 9:171-198.

6. Specialty Utilization data files from CMS: http://www.cms.hhs.gov/physicians/ pfs.

7. The National Uniform Claims Committee. Specialty Designation for Interventional Pain Management- 09.

8. Medicare Payment Advisory Commission Report to the Congress. Paying for Interventional Pain Services in Ambulatory Settings. December 2001.

9. Practice guidelines for chronic pain management. A report by the American Society of Anesthesiologists Task Force on Pain Management, Chronic Pain Section. Anesthesiology 1997; 86:9951004.

10. Sanders SH, Harden RN, Benson SE, Vicente PJ. Clinical practice guidelines for chronic non-malignant pain syndrome patients II: An evidence-based approach. J Back Musc Rehabil 1999; 13:47-58.

11. Nelemans PJ, Debie RA, DeVet HC, Sturmans F. Injection therapy for subacute and chronic benign low back pain. Spine 2001; 26:501-515.

12. Geurts JW, van Wijk RM, Stolker RJ,
Groen GJ. Efficacy of radiofrequency procedures for the treatment of spinal pain: A systematic review of randomized clinical trials. Reg Anesth Pain Med 2001; 26:394-400.

13. Manchikanti L, Singh V, Vilims B, Hansen HC, Schultz DM, Kloth DS. Medial branch neurotomy in management of chronic spinal pain: Systematic review of the evidence. Pain Physician 2002; 5:405-418.

14. Niemisto L, Kalso E, Malmivaara A, Seitsalo S, Hurri H. Cochrane Collaboration Back Review Group. Radiofrequency denervation for neck and back pain: a systematic review within the framework of the Cochrane collaboration back review group. Spine 2003, 28:1877-1888.

15. Slipman CW, Bhat AL, Gilchrist RV, Isaac Z, Chou L, Lenrow DA. A critical review of the evidence for the use of zygapophysial injections and radiofrequency denervation in the treatment of low back pain. Spine J 2003; 3:310-316.

16. Occupational Medicine Practice Guidelines. Evaluation and Management of Common Health Problems and Functional Recovery in Workers. American College of Occupational and Environmental Medicine. 2nd edition, 2004.

17. van Tulder MW, Koes B, Malmivaara A Outcome of non-invasive treatment modalities on back pain: an evidencebased review. Eur Spine J 2006; 15 Suppl 1:S64-S81.

18. DePalma MJ, Bhargava A, Slipman CW. A critical appraisal of the evidence for selective nerve root injection in the treatment of lumbosacral radiculopathy. Arch Phys Med Rehabil 2005; 86:14771483.

19. Bogduk N, Govind J. Medical Management of Acute Lumbar Radicular Pain: An Evidence-Based Approach. Cambridge Press, Newcastle 1999.

20. Bogduk N, McGuirk B. Medical Manage ment of Acute and Chronic Low Back Pain. An Evidence-Based Approach: Pain Research and Clinical Management. Amsterdam: Elsevier Science BV, 2002.

21. Bogduk N, McGuirk B. Management of Acute and Chronic Neck Pain. An Evidence-Based Approach. Elsevier, 2006.

22. Taylor RS, Van Buyten JP, Buchser E. Spinal cord stimulation for chronic back and leg pain and failed back surgery syndrome: A systematic review and analysis of prognostic factors. Spine 2005; 30:152-160.

23. McKenzie-Brown A, Shah RV, Sehgal N, Everett CR. A systematic review of sac roiliac joint interventions. Pain Physician 2005; 8:115-125.

24. Abdi S, Lucas LF, Datta S. Role of epidural steroids in the management of chronic spinal pain: A systematic review of effectiveness and complications Pain Physician 2005; 8:127-143.

25. Boswell M, Hansen H, Trescot A, Hirsch J. Epidural steroids in the management of chronic spinal pain and radiculopathy. Pain Physician 2003; 6:319-334.

26. Koes BW, Scholten RJ, Mens JMA, Bouter LM. Epidural steroid injections for low back pain and sciatica. An updated systematic review of randomized clinical trials. Pain Digest 1999; 9:241-247.

27. Bigos SJ, Boyer OR, Braen GR, Brown $\mathrm{K}$, Deyo R. Acute Low Back Problems in Adults. Clinical Practice Guideline Number 4. AHCPR Publication No. 95-0642. Agency for Health Care Policy and Research, Public Health Service, US Department of Health and Human Services, Rockville, December 1994.

28. van Tulder MWV, Koes BW, Bouter LM. Conservative treatment of acute and chronic nonspecific low back pain. A systematic review of randomized controlled trials of the most common interventions. Spine 1997; 22:2128-2156.

29. Turner J, Loeser J, Deyo R, Sanders SB. Spinal cord stimulation for patients with failed back surgery syndrome or complex regional pain syndrome: A systemic review of effectiveness and complications. Pain 2004; 108:137-147.

30. Boswell MV, Colson JD, Spillane WF. Therapeutic facet joint interventions: A systematic review of their role in chronic spinal pain management and complications. Pain Physician 2005; 8:101114 .

31. Chopra P, Smith HS, Deer TR, Bowman RC. Systematic review of adhesiolysis in managing chronic low back pain. Pain Physician 2005; 8:87-100.

32. Shah RV, Everett CR, McKenzie-Brown AM, Sehgal N. Discography as a diagnostic test for spinal pain: A systematic and narrative review. Pain Physician 2005; 8:187-209.

33. Everett CR, Shah R, Sehgal N, McKenzie-Brown AM. A systematic review of diagnostic utility of selective nerve root blocks. Pain Physician 2005; 8:251255.

34. Bogduk N. International Spinal Injection Society guidelines for the performance of spinal injection procedures. Part 1: Zygapophyseal joint blocks. Clin J Pain 1997; 13:285-302. 
35. Boswell MV, Singh V, Staats PS, Hirsch JA. Accuracy of precision diagnostic blocks in the diagnosis of chronic spinal pain of facet or zygapophysial joint origin. Pain Physician 2003; 6:449-456.

36. Sehgal N, Shah RV, McKenzie-Brown $A M$, Everett CR. Diagnostic utility of facet (zygapophysial) joint injections in chronic spinal pain: A systematic review of evidence. Pain Physician 2005; 8:211-224.

37. American Geriatrics Society. The management of chronic pain in older persons: New guidelines from the American Geriatrics Society. J Am Geriatr Soc 1998; 46:128-150.

38. Saal JS. General principles of diagnostic testing as related to painful lumbar spine disorders. Spine 2002; 27:25382545.

39. Guyer R, Ohnmeiss D. Lumbar discography. Spine J 2003; 3:11S-27S.

40. Cohen SP, Larkin TM, Barna SA, Palmer WE, Hecht AC, Stojanovic MP. Lumbar discography: a comprehensive review of outcome studies, diagnostic accuracy, and principles. Reg Anesth Pain Med 2005; 2:163-183.

41. Andersson GB, Mekhail NA, Block JE. Treatment of intractable discogenic low back pain. A systematic review of spinal fusion and intradiscal electrothermal therapy (IDET). Pain Physician 2006; 9:237-248.

42. Appleby D, Andersson G, Totta M. Metaanalysis of the efficacy and safety of intradiscal electrothermal therapy (IDET). Pain Med 2006; 4:308-316.

43. Gibson JN, Waddell G. Surgery for degenerative lumbar spondylosis: Updated Cochrane Review. Spine 2005; 30:2312-2320.

44. Gibson JN, Grant IC, Waddell G.The Cochrane review of surgery for lumbar disc prolapse and degenerative lumbar spondylosis. Spine 1999; 24:18201832.

45. Abdi S, Datta S, Trescot AM, Schultz DM, Adlaka R, Atluri SL, Smith HS, Manchikanti L. Epidural steroids in the management of chronic spinal pain: A systematic review. Pain Physician 2007; 10:185-212.

46. Datta S, Everett CR, Trescot AM, Schultz DM, Adlaka R, Abdi S, Atluri SL, Smith HS, Shah RV. An updated systematic review of diagnostic utility of selective nerve root blocks. Pain Physician 2007; 10:113-128.

47. Trescot AM, Chopra P, Abdi S, Datta S, Schultz DM. Systematic review of effectiveness and complications of adhe- siolysis in the management of chronic spinal pain: An update. Pain Physician 2007; 10:129-146.

48. Hansen HC, McKenzie-Brown AM, Cohen SP, Swicegood JR, Colson JD, Manchikanti L. Sacroiliac joint interventions: A systematic review. Pain Physician 2007; 10:165-184.

49. Buenaventura RM, Shah RV, Patel V, Benyamin R, Singh V. Systematic review of discography as a diagnostic test for spinal pain: An update. Pain Physician 2007; 10:147-164.

50. Sehgal N, Dunbar EE, Shah RV, Colson JD. Systematic review of diagnostic utility of facet (zygapophysial) joint injections in chronic spinal pain: An update. Pain Physician 2007; 10:213-228.

51. Boswell MV, Colson JD, Sehgal N, Dunbar E, Epter R. A systematic review of therapeutic facet joint interventions in chronic spinal pain. Pain Physician 2007; 10:229-253.

52. Morley S, Eccleston C, Williams A. Systematic review and meta-analysis of randomized controlled trials of cognitive behaviour therapy and behaviour therapy for chronic pain in adults, excluding headache. Pain 1999; 80:1-13.

53. van Tulder MW, Ostelo R, Vlaeyen JW, Linton SJ, Morley SJ, Assendelft WJ. Behavioral treatment for chronic low back pain: a systematic review within the framework of the Cochrane Back Re view Group. Spine 2001; 26:270-281.

54. Rossy LA, Buckelew SP, Dorr N, Hagglund KJ, Thayer JF, McIntosh MJ, Hewett JE, Johnson JC. A meta-analysis of fibromyalgia treatment interventions. Ann Behav Med 1999; 21:180-191.

55. Hayden JA, Van Tulder MW, Tomlinson G. Systematic review: Strategies for using exercise therapy to improve outcomes in chronic low back pain. Ann Intern Med 2005; 142:776-785.

56. Airaksinen O, Brox JI, Cedraschi C, Hildebrandt J, Klaber-Moffett J, Kovacs F, Mannion AF, Reis S, Staal JB, Ursin H , Zanoli G. Chapter 4: European guidelines for the management of chronic nonspecific low back pain. Eur Spine J 2006; 15:S192-S300.

57. Freeman BJC. IDET: A critical appraisal of the evidence. Eur Spine J 2006; 15: S448-457.

58. Eriksen J, Sjogren P, Bruera E, Ekholm O, Rasmussen NK. Critical issues on opioids in chronic non-cancer pain: an epidemiological study. Pain 2006; 125:172179.

59. Schnitzer TJ, Ferraro A, Hunsche E, Kong SX. A comprehensive review of clinical trials on the efficacy and safety of drugs for the treatment of low back pain. $J$ Pain Symptom Manage 2004; 28:7295.

6o. Musculoskeletal Guidelines. Musculoskeletal Imaging Guidelines. MedSolutions, Inc. 2004; pp 3-17.

61. Macario A, Pergolizzi JV. Systematic literature review of spinal decompression via motorized traction for chronic discogenic low back pain. Spine 2006; 6:171178.

62. Murtagh J, Foerster V. Radiofrequency neurotomy for lumbar pain [Issues in emerging health technologies issue 83]. Ottawa: Canadian Agency for Drugs and Technologies in Health; 2006.

63. Percutaneous Discectomy. Washington State Department of Labor and Industries, Office of Medical Director; February 24, 2004.

64. Intradiscal Electrothermal Therapy (IDET). Technology Assessment Update. Washington State Department of Labor and Industries, Office of the Medical Director; September 30, 2003.

65. Belozer M, Wang G. Epidural adhesiolysis for the treatment of back pain. Health Technol Assess 2004; 5:1-19.

66. Khadilkar A, Milne S, Brosseau L, Robinson $V$, Saginur $M$, Shea B, Tugwell P, Wells G. Transcutaneous electrical nerve stimulation (TENS) for chronic low-back pain. Cochrane Database Syst Rev 2005; 3:CDoo3008.

67. Mailis-Gagnon A, Furlan AD, Sandoval JA, Taylor R. Spinal cord stimulation for chronic pain. Cochrane Database Syst Rev 2004; 3:CDo03783.

68. French SD, Cameron M, Walker BF, Reggars JW, Esterman AJ. A Cochrane review of superficial heat or cold for low back pain. Spine 2006; 31:998-1006.

69. Clarke JA, van Tulder MW, Blomberg SE, de Vet HC, van der Heijden GJ, Bronfort G. Traction for low-back pain with or without sciatica. Cochrane Database Syst Rev 2005; 4:CDo03010.

70. Kay TM, Gross A, Goldsmith C, Santaguida PL, Hoving J, Bronfort G, Cervical Overview Group. Exercises for mechanical neck disorders. Cochrane Database Syst Rev 2005; 3:CDo04250.

71. Turner JA, Sears JM, Loeser JD. Programmable intrathecal opioid delivery systems for chronic non-malignant pain: $\mathrm{A}$ systematic review of effectiveness and complications. www.Ini.wa.gov/Claimslns/Files/OMD/pumpReview2006.pdf

72. Assendelft WJ, Morton SC, Yu EI, Suttorp MJ, Shekelle PG. Spinal manipulative therapy for low back pain. Cochrane Da- 
tabase Syst Rev 2004; 1:CDoo04474.

73. Karjalainen K, Malmivaara A, van Tulder $M$, Roine R, Jauhiainen M, Hurri H, Koes B. Multidisciplinary biopsychosocial rehabilitation for neck and shoulder pain among working age adults. Cochrane Database Syst Rev 2003; 2:CDoo2194.

74. Singh K, Ledet E, Carl A. Intradiscal therapy: a review of current treatment modalities. Spine 2005; 30:S20-S26.

75. Taylor RS, Taylor RJ, Fritzell P. Balloon kyphoplasty and vertebroplasty for vertebral compression fractures: A comparative systematic review of efficacy and safety. Spine 2006; 31:2747-2755.

76. Hulme PA, Krebs J, Ferguson SJ, Berlemann U. Vertebroplasty and kyphoplasty: A systematic review of 69 clinical studies. Spine 2006; 31:1983-2001.

77. Bouza C, López T, Magro A, Navalpotro L, Amate JM. Efficacy and safety of balloon kyphoplasty in the treatment of vertebral compression fractures: A systematic review. Eur Spine J 2006; 15:1050-1067.

78. Hollingworth W, Jarvik JG. Evidence on the effectiveness and cost-effectiveness of vertebroplasty: A review of policy makers' responses. Acad Radiol 2006; 13:550-555.

79. Ploeg WT, Veldhuizen AG, The B, Sietsma MS. Percutaneous vertebroplasty as a treatment for osteoporotic vertebral compression fractures: a systematic review. Eur Spine J 2006; 15:1749-1758.

8o. Leonardi M, Pfirrmann CW, Boos N. Injection studies in spinal disorders. Clin Orthop Relat Res 2006; 443:168-182.

81. Waggershauser T, Schwarzkopf S, Reiser M. Facet blockade, peridural and periradicular pain therapy. Radiologe 2006; 46:520-526.

82. Resnick DK, Choudhri TF, Dailey AT, Groff MW, Khoo L, Matz PG, Mummaneni P, Watters WC 3rd, Wang J, Walters BC, Hadley MN; American Association of Neurological Surgeons/Congress of Neurological Surgeons. Guidelines for the performance of fusion procedures for degenerative disease of the lumbar spine. Part 13: injection therapies, lowback pain, and lumbar fusion. J Neurosurg Spine 2005; 2:707-715.

83. Helm SH 2nd. California Workers' Compensation System: Are Occupational Medicine Practice Guidelines sufficient for the treatment of chronic spinal pain or do they require supplementation by guidelines for interventional techniques? Pain Physician 2004; 7:229238.

84. AGREE Collaboration. Development and validation of an international appraisal instrument for assessing the quality of clinical practice guidelines: the AGREE project. Qual Saf Health Care 2003; 12:18-23.

85. Cates JR, Young DN, Bowerman DS, Porter RC. An independent AGREE evaluation of the Occupational Medicine Practice Guidelines. Spine J 2006; 6:72-77.

86. Manchikanti L, Abdi S, Lucas LF. Evidence synthesis and development of guidelines in interventional pain management. Pain Physician 2005; 8:7386.

87. Manchikanti L, Heavner J, Racz GB, Mekhail NA, Schultz DM, Hansen HC, Singh $V$. Methods for evidence synthesis in interventional pain management. Pain Physician 2003; 6:89-111.

88. Moore RA, Derry S, Phillips CJ, McQuay HJ. Nonsteroidal anti-inflammatory drugs (NSAIDs), cyxlooxygenase-2 selective inhibitors (coxibs) and gastrointestinal harm: review of clinical trials and clinical practice. BMC Musculoskelet Disord 2006; 7:79.

89. Fuhrer MJ. Overview of clinical trials in medical rehabilitation: impetuses, challenges, and needed future directions. Am J Phys Med Rehabil 2003; 82:S8-15.

90. Liddle SD, Baxter GD, Gracey JH. Exercise and chronic low back pain: what works? Pain 2004; 107:176-190.

91. Murphy AY, van Teijlingen ER, Gobbi MO. Inconsistent grading of evidence across countries: a review of low back pain guidelines. J Manipulative Physiol Ther 2006; 29:576-581.

92. Arnau JM, Vallano A, Lopez A, Pellise F, Delgado MJ, Prat N. A critical review of guidelines for low back pain treatment. Eur Spine J 2006; 15:543-553.

93. Shaneyfelt TM, Mayo-Smith MF, Rothwangl J. Are guidelines following guidelines? The methodological quality of clinical practice guidelines in the peer reviewed medical literature. JAMA 1999; 281:1900-1905.

94. Bogduk N. In defense of radiofrequency neurotomy. Reg Anesth Pain Med 2002; 27:439-441.

95. Manchikanti L, Jasper J, Singh V. Cochrane Review by Nelemans et al. Spine 2001; 26:2641-2643.

96. Errico TJ, Gatchel RJ, Schofferman J, Benzel EC, Faciszewski T, Eskay-Auerbach $M$, Wang JC. A fair and balanced view of spine fusion surgery. Spine $J$ 2004; 4:129S-142S.

97. Gatchel RJ, McGeary D. Cochrane collaboration-based reviews of healthcare interventions: Are they unequivo- cal and valid scientifically or simply nihilistic? Spine J 2002; 2:315-319.

98. Interventional techniques in the management of chronic spinal pain: evidence-based practice guidelines. American Society of Interventional Pain Physicians - Medical Specialty Society. 2003 (revised 2005). 47 pages. NGC:004173.

99. Opioid guidelines in the management of chronic non-cancer pain. American Society of Interventional Pain Physicians - Medical Specialty Society. 2006. 40 pages. NGC:004853.

100. Wu JS, Wong RK, Lloyd NS, Johnston M, Bezjak A, Whelan T; Supportive Care Guidelines Group of Cancer Care Ontario. Radiotherapy fractionation for the palliation of uncomplicated painful bone metastases - An evidence-based practice guideline. BMC Cancer 2004; 4:71.

101. Shekelle P, Woolf S, Grimshaw J. Clinical guidelines: Developing guidelines. $B M$ J 1999; 318:593-596.

102. Connis R, Nickinovich D, Caplan R, Arens J. The development of evidence-based clinical practice guidelines. Integrating medical science and practice. Int J Technol Assess Health Care 2000; 16:10031012.

103. Sackett D, Richardson WS, Roseberg W, Haynes RB. Evidence Based Medicine. Churchill Livingstone, Philadelphia, 1996.

104. West S, King V, Carey T, Lohr K, McKoy N, Sutton S, Lux L. Systems to rate the strength of scientific evidence. Evidence Report/Technology Assessment No. 47 University of North Carolina: Agency for Healthcare Research and Quality. AHRQ Publication No. 02-E016; April 2002.

105. Tunis SR, Stryer DB, Clancy CM. Practical clinical trials: Increasing the value of clinical research for decision making in clinical and health policy. JAMA 2003; 290:1624-1632.

106. Silagy C, Rubin G, Henderson-Smart D, Gross P. A guide to the development, implementation and evaluation of clinical practice guidelines. National Health and Medical Research Council, Canberra, Commonwealth of Australia, 1998, pp 1-79.

107. O'Brien P, Silagy C, McCallum J, O'Connell, D, Glasziou P, Hill A. How to use the evidence: Assessment and application of scientific evidence. National Health and Medical Research Council, Canberra, Commonwealth of Australia, 2000, pp 1-84.

108. van Tulder M, Assendelft W, Koes B, Bouter LM. Method guidelines for sys- 
tematic reviews in the Cochrane Collaboration Back Review Group for Spinal Disorders. Spine 1997; 22:2323-2330.

109. Eccles M, Mason J. How to develop costconscious guidelines. Health Technol Assess 2001; 5:1-69.

110. Cook DJ, Greengold NL, Ellrodt AG, Weingarten SR. The relation between systematic reviews and practice guidelines. Ann Intern Med 1997; 127:210216.

111. Keffer JH. Guidelines and algorithms: Perceptions of why and when they are successful and how to improve them. Clin Chem 2001; 47:1563-1572.

112. Hatala R, Guyatt G. Evaluating the teaching of evidence-based medicine. JAMA 2002; 288:1110-1112.

113. A guide to the development, implementation and evaluation of clinical practice guidelines. National Health and Medical Research Council, Canberra, Commonwealth of Australia, 1998, pp 1-79.

114. Whiting P, Rutjes A, Reitsma J, Bossuyt P, Kleijnen J. The Development of QUADAS: A tools for the quality assessment of studies of diagnostic accuracy included in systematic reviews. BMC Med Res Methodol 2003; 3:25.

115. http://www.consort-statement.org/ QUOROM.pdf

116. Bossuyt PM, Reitsma JB, Bruns DE, Gatsonis CA, Glasziou PP, Irwig LM, Lijmer JG, Moher D, Rennie D, de Vet HC; Standards for Reporting of Diagnostic Accuracy. Towards complete and accurate reporting of studies of diagnostic accuracy: The STARD initiative. Clin Chem 2003; 49:1-6. http://www.clinchem. org/cgi/content/full/49/1/1

117. Stroup DF, Berlin JA, Morton SC, Olkin I, Williamson GD, Rennie D, Moher D, Becker BJ, Sipe TA, Thacker SB. Metaanalysis of observational studies in epidemiology: A proposal for reporting. JAMA 2000; 283:2008-2012.

118. Moher D, Schulz KF, Altman D, for the CONSORT Group. The CONSORT statement: revised recommendations for improving the quality of report of parallel-group randomized trials. JAMA 2001; 285:1987-1991.

119. Verhaak PF, Kerssens JJ, Dekker J, Sorbi MJ, Bensing JM. Prevalence of chronic benign pain disorder among adults: A review of the literature. Pain 1998; 77:231-239.

120. Gureje O, Von Korff M, Simon GE, Gater R. Persistent pain and well-being: a World Health Organization Study in Primary Care. JAMA 1998; 280:147-151.

121. Blyth FM, March LM, Brnabic AJ, Jorm LR, Williamson M, Cousins MJ. Chron- ic pain in Australia: A prevalence study. Pain 2001; 89:127-134.

122. Elliott $A M$, Smith BH, Hannaford PC, Smith WC, Chambers WA. The course of chronic pain in the community: Results of a 4-year follow-up study. Pain 2002; 99:299-307.

123. Yeung SS, Genaidy A, Deddens J, Alhe$\operatorname{mood} A$, Leung PC. Prevalence of musculoskeletal symptoms in single and multiple body regions and effects of perceived risk of injury among manual handling workers. Spine 2002; 27:21662172.

124. Bressler HB, Keyes WJ, Rochon PA, Badley $E$. The prevalence of low back pain in the elderly. A systemic review of the literature. Spine 1999; 24:1813-1819.

125. Lawrence RC, Helmick CG, Arnett FC. Estimates of the prevalence of arthritis and selected musculoskeletal disorders in the United States. Arthritis Rheum 1998; 41:778-799.

126. Mallen C, Peat G, Thomas E, Croft P. Severely disabling chronic pain in young adults: prevalence from a populationbased postal survey in North Staffordshire. BMC Musculoskelet Disord 2005; 6:42.

127. Tripp DA, Vandenkerkhof EG, McAlister $M$. Prevalence and determinants of pain and pain-related disability in urban and rural settings in southeastern Ontario. Pain Res Manag 2006; 11:225-233.

128. Manchikanti L, Boswell MV, Singh V, Pampati V, Damron KS, Beyer CD. Prevalence of facet joint pain in chronic spinal pain of cervical, thoracic, and lumbar regions. BMC Musculoskelet Disord 2004; 5:15.

129. Manchukonda R, Manchikanti KN, Cash KA, Pampati V, Manchikanti L. Facet joint pain in chronic spinal pain: an evaluation of prevalence and false positive rate of diagnostic blocks. 2007; in press.

130. Jacob T, Zeev A. Are localized low back pain and generalized back pain similar entities? Results of a longitudinal community based study. Disabil Rehabil 2006; 28:369-377.

131. Cassidy JD, Carroll LJ, Cotê P. The Saskatchewan Health and Back Pain Survey. The prevalence of low back pain and related disability in Saskatchewan Adults. Spine 1998; 23:1860-1867.

132. Guo HR, Tanaka S, Halperin WE, Cameron LL. Back pain prevalence in US industry and estimates of lost workdays. Am J Public Health 1999; 89:1029-1035.

133. Côté P, Cassidy JD, Carroll L. The Saskatchewan Health and Back Pain Sur- vey. The prevalence of neck pain and related disability in Saskatchewan adults. Spine 1998; 23:1689-1698.

134. Linton SJ, Hellsing AL, Hallden K. A population based study of spinal pain among 35-45-year old individuals. Spine 1998, 23:1457-1463.

135. Miemelainen R, Videman T, Battie MC. Prevalence and characteristics of upper or mid-back pain in Finnish men. Spine 2006; 31:1846-1849.

136. Walker BF, Muller R, Grant WD. Low back pain in Australian adults: prevalence and associated disability. J Manipulative Physiol Ther 2004; 27:238-244.

137. Bot SD, van der Waal JM, Terwee CB, van der Windt DA, Schellevis FG, Bouter LM, Dekker J. Incidence and prevalence of complaints of the neck and upper extremity in general practice. Ann Rheum Dis 2005; 64:118-123.

138. Cecchi F, Debolini P, Lova RM, Macchi C, Bandinelli S, Bartali B, Lauretani F, Benvenuti E, Hicks G, Ferrucci L. Epidemiology of back pain in a representative cohort of Italian persons 65 years of age and older: the InCHIANTI study. Spine 2006; 31:1149-1155.

139. Edmond SL, Felson DT. Function and back symptoms in older adults. / Am Geriatr Soc 2003; 51:1702-1709.

140. Leveille SG, Guralnik JM, Hochberg M, Hirsch R, Ferrucci L, Langlois J, Rantanen T, Ling S. Low back pain and disability in older women: independent association with difficulty but not inability to perform daily living activities. I Gerontol A Biol Sci Med Sci 1999; 54: M487-493.

141. Cassidy JD, Côté P, Carroll LJ, Kristman V. Incidence and course of low back pain episodes in the general population. Spine 2005; 30:2817-2823.

142. Hestbaek L, Leboeuf-Yde C, Manniche C. Low back pain: what is the long-term course? A review of studies of general patient populations. Eur Spine J 2003; 12:149-165.

143. Croft PR, Lewis M, Papageorgiou AC, Thomas E, Jayson MI, Macfarlane GJ, Silman AJ. Risk factors for neck pain: A longitudinal study in the general population. Pain 2001; 93:317-325.

144. Côté P, Cassidy JD, Carroll LJ, Kristman $V$. The annual incidence and course of neck pain in the general population: a population-based cohort study. Pain 2004; 112:267-273.

145. Enthoven P, Skargren E, Oberg B. Clinical course in patients seeking primary care for back or neck pain: A prospective 5-year follow-up of outcome and 
health care consumption with subgroup analysis. Spine 2004; 29:2458-2465.

146. Elder LA, Burdorf A. Prevalence, incidence, and recurrence of low back pain in scaffolders during a 3-year follow-up study. Spine 2004; 29:E101-E106.

147. Croft PR, Papageorgiou AC, Thomas E, Macfarlane GJ, Silman AJ. Short-term physical risk factors for new episodes of low back pain. Prospective evidence from the South Manchester Back Pain Study. Spine 1999; 24:1556-1561.

148. Miedema HS, Chorus AM, Wevers CW, van der Linden S. Chronicity of back problems during working life. Spine 1998; 23:2021-2028.

149. Thomas E, Silman AJ, Croft PR, Papageorgiou AC, Jayson MI, Macfarlane GJ. Predicting who develops chronic low back pain in primary care. A prospective study. Brit Med J. 1999; 318:1662-1667.

150. Mortimer M, Pernold G, Wiktorin C. Low back pain in a general population. Natural course and influence of physical exercise - A 5-year follow-up of the Musculoskeletal Intervention Center-Norrtalje Study. Spine 2006; 31:3045-3051.

151. Jackson JL, Passamonti M. The outcomes among patients presenting in primary care with a physical symptom at 5 years. J Gen Intern Med 2005;20:10321037.

152. Jones GT, Johnson RE, Wiles NJ, Chaddock C, Potter RG, Roberts C, Symmons DP, Macfarlane GJ. Predicting persistent disabling low back pain in general practice: a prospective cohort study. $\mathrm{Br} J$ Gen Pract 2006; 56:334-341.

153. Kaaria S, Luukkonen R, Riihimaki H, Kirjonen J, Leino-Arjas P. Persistence of low back pain reporting among a cohort of employees in a metal corporation: A study with 5-, 10-, and 28-year followups. Pain 2006; 120:131-137.

154. Leboeuf-Yde C, Gronstvedt A, Borge JA, Lothe J, Magnesen E, Nilsson O, Rosok G, Stig LC, Larsen K. The Nordic back pain subpopulation program: A 1-year prospective multicenter study of outcomes of persistent low-back pain in chiropractic patients. / Manipulative Physiol Ther 2005; 28:90-96.

155. Sjolie AN. Persistence and change in nonspecific low back pain among adolescents: A 3-year prospective study. Spine 2004; 29:2452-2457.

156. Jacob T, Baras M, Zeev A, Epstein L. A longitudinal, community-based study of low back pain outcomes. Spine 2004; 29:1810-1817.

157. Hill J, Lewis M, Papageorgiou AC, Dziedzic K, Croft P. Predicting persistent neck pain: a 1-year follow-up of a population cohort. Spine 2004; 29:16481654 .

158. Hestbaek L, Leboeuf-Yde C, Engberg M, Lauritzen T, Bruun NH, Manniche C. The course of low back pain in a general population. Results from a 5 -year prospective study. I Manipulative Physiol Ther 2003; 26:213-219.

159. Szpalski M, Gunzburg R, Balague F, Nor$\operatorname{din} \mathrm{M}$, Melot C. A 2-year prospective longitudinal study on low back pain in primary school children. Eur Spine J 2002; 11:459-464.

160. Waxman R, Tennant A, Helliwell P. A prospective follow-up study of low back pain in the community. Spine 2000; 25:2085-2090.

161. Eriksen J, Ekholm O, Sjogren P, Rasmussen NK. Development of and recovery from long-term pain. A 6-year followup study of a cross-section of the adult Danish population. Pain 2004; 108:154162.

162. Borghouts JA, Koes BW, Bouter LM. The clinical course and prognostic factors of non-specific neck pain: A systematic review. Pain 1998; 77:1-13.

163. Papageorgiou AC, Silman AJ, Macfarlane GJ. Chronic widespread pain in the population: a seven year follow up study. Ann Rheum Dis 2002; 61:10711074 .

164. Kadam UT, Thomas E, Croft PR. Is chronic widespread pain a predictor of allcause morbidity? A 3 year prospective population based study in family practice. J Rheumatol. 2005; 32:1341-1348.

165. Kovacs FM, Fernández C, Cordero A, Muriel A, Gonzalez-Lujan L, Gil del Real MT; Spanish Back Pain Research Network. Non-specific low back pain in primary care in the Spanish National Health Service: A prospective study on clinical outcomes and determinants of management. BMC Health Serv Res 2006; 6:57.

166. Holmberg SA, Thelin AG. Primary care consultation, hospital admission, sick leave and disability pension owing to neck and low back pain: A 12-year prospective cohort study in a rural population. BMC Musculoskelet Disord 2006; 7:66.

167. Smith BH, Elliott AM, Hannaford PC, Chambers WA, Smith WC. Factors related to the onset and persistence of chronic back pain in the community: results from a general population followup study. Spine 2004; 29:1032-1040.

168. Saastamoinen P, Leino-Arjas P, Laaksonen M, Lahelma E. Socio-economic differences in the prevalence of acute, chronic and disabling chronic pain among ageing employees. Pain 2005; 114:364-371.

169. Bunketorp L, Stener-Victorin E, Carlsson J. Neck pain and disability following motor vehicle accidents - a cohort study. Eur Spine J 2005; 14:84-89.

170. Frank AO, De Souza LH, Frank CA. Neck pain and disability: a cross-sectional survey of the demographic and clinical characteristics of neck pain seen in a rheumatology clinic. Int I Clin Pract 2005; 59:173-182.

171. Hartvigsen J, Frederiksen H, Christensen K. Physical and mental function and incident low back pain in seniors: A population-based two-year prospective study of 1387 Danish twins aged 70 to 100 years. Spine 2006; 31:1628-1632.

172. Jacob T. Low back pain incident episodes: A community-based study. Spine J 2006; 6:306-310.

173. Takahashi N, Kikuchi S, Konno S, Morita S, Suzukamo Y, Green J, Fukuhara S. Discrepancy between disability and the severity of low back pain: demographic, psychologic, and employment-related factors. Spine 2006; 31:931-939.

174. Hestbaek L, Leboeuf-Yde C, Kyvik KO. Is comorbidity in adolescence a predictor for adult low back pain? A prospective study of a young population. BMC Musculoskelet Disord 2006; 7:29.

175. Weiner DK, Kim YS, Bonino P, Wang T. Low back pain in older adults: are we utilizing healthcare resources wisely? Pain Med 2006; 7:143-150.

176. Ekman M, Jönhagen S, Hunsche E, Jonsson $L$. Burden of illness of chronic low back pain in Sweden: A cross-sectional, retrospective study in primary care setting. Spine 2005; 30:1777-1785.

177. Ritzwoller DP, Crounse L, Shetterly S, Rublee D. The association of comorbidities, utilization and costs for patients identified with low back pain. BMC Musculoskelet Disord 2006; 7:72.

178. Vogt MT, Kwoh CK, Cope DK, Osial TA, Culyba M, Starz TW. Analgesic usage for low back pain: impact on health care costs and service use. Spine 2005; 30:1075-1081.

179. Ricci JA, Stewart WF, Chee E, Leotta C, Foley K, Hochberg MC. Back pain exacerbations and lost productive time costs in United States workers. Spine 2006; 31:3052-3060.

180. Stewart WF, Ricci JA, Chee E, Morganstein D, Lipton R. Lost productive time and cost due to common pain conditions in the US workforce. JAMA 2003; 290:2443-2454. 
181. White AG, Birnbaum HG, Mareva MN, Daher M, Vallow S, Schein J, Katz N. Direct costs of opioid abuse in an insured population in the United States. J Manag Care Pharm 2005; 11:469-479.

182. Daffner SD, Hilibrand AS, Hanscom BS, Brislin BT, Vaccaro AR, Albert TJ. Impact of neck and arm pain on overall health status. Spine 2003; 28:2030-2035.

183. Dionne CE, Chenard M. Back-related functional limitations among fulltime homemakers: a comparison with women employed full-time outside the home. Spine 2004; 29:1375-1382.

184. Luo X, Pietrobon R, Sun SX, Liu GG, Hey L. Estimates and patterns of direct health care expenditures among individuals with back pain in the United States. Spine 2004; 29:79-86.

185. Reyes-Gibby CC, Aday L, Cleeland C. Impact of pain on self-rated health in the community-dwelling older adults. Pain 2002; 95:75-82.

186. Leigh JP, Markowitz SB, Fahs M, Shin C, Landrigan PJ. Occupational injury and illness in the United States. Estimates of costs, morbidity, and mortality. Arch Intern Med 1997; 157:1557-1568.

187. Freedman VA, Martin LG, Schoeni RF. Recent trends in disability and functioning among older adults in the United States. JAMA 2002; 288:3137-3146.

188. Ohayon MM, Schatzberg AF. Using chronic pain to predict depressive morbidity in the general population. Arch Gen Psychiatry 2003; 60:39-47.

189. Hurwitz EL, Morgenstern H, Yu F. Crosssectional and longitudinal associations of low-back pain and related disability with psychological distress among patients enrolled in the UCLA LowBack Pain Study. J Clin Epidemiol 2003; 56:463-471.

190. Turner JA, Franklin G, Heagerty PJ, Wu R, Egan K, Fulton-Kehoe D, Gluck JV, Wickizer TM. The association between pain and disability. Pain 2004; 112:307-314.

191. Pai S, Sundaram LJ. The economic burden of low back pain: A review of studies published between 1996 and 2001. Orthop Clin North Am 2004; 35:1-5.

192. Maetzel A, Li L. The economic burden of low back pain: A review of studies published between 1996 and 2001. Best Pract Res Clin Rheumatol 2002; 16:2330.

193. Bell G, Kidd D, North R. Cost-effectiveness analysis of spinal cord stimulation in treatment of failed back surgery syndrome. J Pain Symp Manage 1997; 13:286-295.

194. de Lissovoy G, Brown RE, Halpern M,
Hassenbusch SJ, Ross E. Cost-effectiveness of long-term intrathecal morphine therapy for pain associated with failed back surgery syndrome. Clin Ther 1997; 19:96-112.

195. Maniadakis N, Gray A. The economic burden of back pain in the UK. Pain 2000; 84:95-103.

196. Walker BF, Muller R, Grant WD. Low back pain in Australian adults: the economic burden. Asia Pac J Public Health 2003; $15: 79-87$.

197. Jhawar BS, Fuchs CS, Colditz GA, Stampfer MJ. Cardiovascular risk factors for physician-diagnosed lumbar disc herniation. Spine J 2006; 6:684-691.

198. Carroll LJ, Cassidy JD, Côté P. Frequency, timing, and course of depressive symptomatology after whiplash. Spine 2006; 31:E551-E556.

199. Dersh J, Gatchel RJ, Mayer T, Polatin P, Temple OR. Prevalence of psychiatric disorders in patients with chronic disabling occupational spinal disorders. Spine 2006; 31:1156-1162.

200. Paulozzi LJ, Budnitz DS, Yongli X. Increasing deaths from opioid analgesics in the United States. Pharmacoepidemiol Drug Saf 2006; 15:618-627.

201. Birnbaum HG, White AG, Reynolds JL, Greenberg PE, Zhang M, Vallow S, Schein JR, Katz NP. Estimated costs of prescription opioid analgesic abuse in the United States in 2001: A societal perspective. Clin J Pain 2006; 22:667676.

202. Hatten AL, Gatchel RJ, Polatin PB, Stowell AW. A cost-utility analysis of chronic spinal pain treatment outcomes: converting SF-36 data into quality-adjusted life years. Clin J Pain 2006; 22:700-711.

203. Feder J, Rowland D, Holahan J, Heslam D. The Medicaid Cost Explosion: Causes and Consequences. Henry J. Kaiser Family Foundation. Menlo Park, CA, 1993, pp 18-22.

204. Manchikanti L. Prescription drug abuse: What is being done to address this new drug epidemic? Testimony before the Subcommittee on Criminal Justice, Drug Policy and Human Resources. Pain Physician 2006; 9:287-321.

205. Kentucky All Schedule Prescription Electronic Reporting (KASPER). A Comprehensive Report on Kentucky's Prescription Monitoring Program Prepared by the Cabinet for Health and Family Services Office of the Inspector General, Version $1-3 / 29 / 2006$. chfs.ky.gov/ $\mathrm{NR} /$ rdonlyres/2D 46AB2E-FAE8-43DC 9CE6-6BB4B419918F/o/AComprehensiveSummaryofKASPERDraft.pdf
206. Sikirica V, Vallow S, Schein J, Doshi D, Katz N, White A, Stang P. Prevalence, comorbidities, and utilization of services of opioid abusers in a managed care plan. Abstract Presented at the AAPM Annual Meeting. Pain Med 2005; 6:190.

207. Manchikanti L, Whitfield E, Pallone F. Evolution of the National All Schedules Prescription Electronic Reporting Act (NASPER): A public law for balancing treatment of pain and drug abuse and diversion. Pain Physician 2005; 8:335347.

208. Manchikanti L, Manchukonda R, Damron KS, Brandon D, McManus CD, Cash $\mathrm{KA}$. Does adherence monitoring reduce controlled substance abuse in chronic pain patients? Pain Physician 2006; 9:57-60.

209. Rivera JJ, Singh V, Fellows B, Pampati V, Damron KS, McManus CD. Reliability of psychological evaluation in chronic pain in an interventional pain management setting. Pain Physician 2005; 8:375-383.

210. Rush AJ, Polatin P, Gatchel RJ. Depression and chronic low back pain. Spine 2000; 25:2566-2571.

211. McWilliams LA, Cox BJ, Enns MW. Mood and anxiety disorders associated with chronic pain: an examination in a nationally representative sample. Pain 2003; 106:127-133.

212. Polatin PB, Kinney RK, Gatchel RJ, Lillo E, Mayer TG. Psychiatric illness and chronic low back pain: The mind and the spine - which goes first? Spine 1993; 18:66-71.

213. Manchikanti L, Pampati VS, Fellows B, Beyer CD, Damron KS, Barnhill RC, Burks T. Characteristics of chronic low back pain in patients in an interventional pain management setting: A prospective evaluation. Pain Physician 2001; 4:131-142.

214. Davis PJ, Reeves JL, Hastie BA, GraffRadford SB, Naliboff BD. Depression determines illness conviction and pain impact: A structural equation modeling analysis. Pain Med 2000; 1:238-246.

215. Manchikanti L, Fellows B, Pampati VS, Damron KS, Beyer CD, Barnhill RC. Comparison of psychological status of chronic pain patients with general population. Pain Physician 2002; 5:40-48.

216. Manchikanti L, Pampati VS, Damron KS, Beyer CD, Barnhill RC. Evaluation of psychological status in chronic low back pain: Comparison with general population. Pain Physician 2002; 5:149-155.

217. Vindigni D, Walker BF, Jamison JR, Da Costa C, Parkinson L, Blunden S. Low 
back pain risk factors in a large rural Australian Aboriginal community. An opportunity for managing co-morbidities? Chiropr Osteopat 2005; 13:21.

218. Gagliese L, Katz J. Medically unexplained pain is not caused by psychopathology. Pain Res Manage 2000; 5:251257.

219. Bogduk N, McGuirk B. Causes and sources of chronic low back pain. In Medical Management of Acute and Chronic Low Back Pain. An Evidence-Based Approach: Pain Research and Clinical Management, Vol. 13, Elsevier Science BV, Amsterdam, 2002, pp 115-126.

220. Bogduk N, McGuirk B. An algorithm for precision diagnosis. In Bogduk N, McGuirk B, eds. Medical Management of Acute and Chronic Low Back Pain. An Evidence-Based Approach: Pain Research and Clinical Management. Amsterdam: Elsevier Science BV 2002; 13:177-186.

221. Deyo RA, Weinstein JN. Low back pain. N Engl J Med 2001; 344:363-370.

222. Deyo RA. Fads in the treatment of low back pain. N Engl J Med 1991; 325:10391040.

223. Deyo RA, Rainville J, Kent DL. What can the history and physical examination tell us about low back pain? JAMA 1992; 268: 760-765.

224. Bogduk N. Low back pain. Clinical Anatomy of Lumbar Spine and Sacrum. 4th edition. Churchill Livingstone, New York, 2005, pp 183-216.

225. Carragee EJ. Clinical practice. Persistent low back pain. N Engl J Med 2005; 352:1891-1898.

226. Mooney V. Where is the pain coming from? Spine 1987; 12:754-759.

227. Spitzer WO, LeBlanc FE, Dupuis M. Scientific approach to the assessment and management of activity-related spinal disorders: A monograph for clinicians. Report of Quebec Task Force on Spinal Disorders. Spine 1987; 12:S1-59.

228. Kuslich SD, Ulstrom CL, Michael CJ. The tissue origin of low back pain and sciatica: A report of pain response to tissue stimulation during operation on the lumbar spine using local anesthesia. Orthop Clin North Am 1991; 22:181-187.

229. Pang WW, Mok MS, Lin ML, Chang DP, Hwang MH. Application of spinal pain mapping in the diagnosis of low back pain-analysis of 104 cases. Acta Anaesthesiol Sin 1998; 36:71-74.

230. Manchikanti L, Singh V, Pampati V, Damron K, Barnhill R, Beyer C, Cash K. Evaluation of the relative contributions of various structures in chronic low back pain. Pain Physician 2001; 4:308-316.
231. Bogduk N. The zygapophysial joints. In Clinical Anatomy of the Lumbar Spine and Sacrum, Third edition. Churchill Livingstone, New York, 2005, pp 29-38.

232. Fukui S, Ohseto K, Shiotani M, Ohno K, Karasawa H, Naganuma Y, Yuda Y. Referred pain distribution of the cervical zygapophyseal joints and cervical dorsal rami. Pain 1996; 68:79-83.

233. Dwyer A, Aprill C, Bogduk N. Cervical zygapophyseal joint pain patterns: A study in normal volunteers. Spine 1990; 15:453-457.

234. Aprill C, Dwyer A, Bogduk N. The prevalence of cervical zygapophyseal joint pain patterns II: A clinical evaluation. Spine 1990; 15:458-461.

235. Pawl RP. Headache, cervical spondylosis, and anterior cervical fusion. Surg Ann 1977; 9:391-498.

236. Windsor RE, Nagula D, Storm S. Electrical stimulation induced cervical medial branch referral patterns. Pain Physician 2003; 6:411-418.

237. Dreyfuss P, Tibiletti C, Dreyer SJ. Thoracic zygapophyseal joint pain patterns: A study in normal volunteers. Spine 1994; 19:807-811.

238. Fukui S, Ohseto K, Shiotani M. Patterns of pain induced by distending the thoracic zygapophyseal joints. Reg Anesth 1997; 22:332-336.

239. Mooney V, Robertson J. The facet syndrome. Clin Orthop 1976; 115:149-156.

240. McCall IW, Park WM, O'Brien JP. Induced pain referral from posterior elements in normal subjects. Spine 1979; 4:441446.

241. Marks R. Distribution of pain provoked from lumbar facet joints and related structures during diagnostic spinal infiltration. Pain 1989; 39:37-40.

242. Fukui S, Ohseto K, Shiotani M, Ohno K, Karasawa H, Naganuma Y. Distribution of referral pain from the lumbar zygapophyseal joints and dorsal rami. Clin J Pain 1997; 13:303-307.

243. Hirsch C, Ingelmark BE, Miller M. The anatomical basis for low back pain. Acta Orthop Orthop Scand 1963; 33:1-17.

244. Windsor RE, King FJ, Roman SJ, Tata N, Cone-Sullivan LA, Thampi S, Acebey M, Gilhool JJ, Rao R, Sugar R. Electrical stimulation induced lumbar medial branch referral patterns. Pain Physician 2002; 5:347-353.

245. Bogduk N. The clinical anatomy of the cervical dorsal rami. Spine 1982; 7:319330.

246. Cavanaugh JM, Ozaktay AC, Yamashita T, Avramov A, Getchell TV, King Al.
Mechanisms of low back pain: A neurophysiologic and neuroanatomic study. Clin Orthop 1997; 335:166-180.

247. Bogduk N, Wilson AS, Tynan W. The human lumbar dorsal rami. J Anat 1982; 134:383-397.

248. Ohtori S, Takahashi K, Chiba T, Yamagata M, Sameda H, Moriya H. Sensory innervation of the cervical facet joints in rats. Spine 2001; 26:147-150.

249. Chua WH, Bogduk N. The surgical anatomy of thoracic facet denervation. Acta Neurochir 1995; 136:140-144.

250. Barnsley L, Bogduk N. Medial branch blocks are specific for the diagnosis of cervical zygapophyseal joint pain. Reg Anesth 1993; 18:343-350.

251. Zhang J, Tsuzuki N, Hirabayashi S, Saiki K, Fujita K. Surgical anatomy of the nerves and muscles in the posterior cervical spine. Spine 2003; 1379-1384.

252. Dreyfuss P, Schwarzer AC, Lau P, Bogduk N. Specificity of lumbar medial branch and $\mathrm{L} 5$ dorsal ramus blocks. Spine 1997; 22:895-902.

253. Kaplan M, Dreyfuss P, Halbrook B, Bogduk N. The ability of lumbar medial branch blocks to anesthetize the zygapophysial joint. Spine 1998; 23:18471852.

254. Lau P, Mercer S, Govind J, Bogduk N. The surgical anatomy of lumbar medial branch neurotomy (facet denervation). Pain Med 2004; 5:289-298.

255. Ishikawa T, Miyagi M, Ohtori S, Aoki Y, Ozawa T, Doya H, Saito T, Moriya H, Takahashi K. Characteristics of sensory DRG neurons innervating the lumbar facet joints in rats. Eur Spine J 2005; 14:559-564.

256. Suseki K, Takahashi Y, Takahashi K, Chiba T, Tanaka K, Morinaga T, Nakamura S, Moriya $\mathrm{H}$. Innervation of the lumbar facet joints. Origins and functions. Spine 1997; 22:477-485.

257. Sameda H, Takahashi Y, Takahashi K, Chiba T, Ohtori S, Moriya H. Primary sensory neurons with dichotomizing axons projecting to the facet joint and the sciatic nerve in rats. Spine 2001; 26:11051109.

258. Yamada H, Honda T, Kikuchi S, Sugiura Y. Direct innervation of sensory fibers from the dorsal root ganglion of the cervical dura mater of rats. Spine 1998; 23:1524-1529.

259. Johnson GM. The sensory and sympathetic nerve supply within the cervical spine: review of recent observations. Man Ther 2004; 9:71-76.

26o. Yoganandan N, Knowles SA, Maiman DJ, 
Pintar FA. Anatomic study of the morphology of human cervical facet joint. Spine 2003; 28:2317-2323.

261. Konnai Y, Honda T, Sekiguchi Y, Kikuchi $S$, Sugiura Y. Sensory innervation of the lumbar dura mater passing through the sympathetic trunk in rats. Spine 2000; 25:776-782.

262. Masini M, Paiva WS, Araujo AS Jr. Anatomical description of the facet joint innervation and its implication in the treatment of recurrent back pain. J Neurosurg Sci 2005; 49:143-146.

263. Ahmed M, Bjurholm A, Kreicbergs A, Schultzberg M. Sensory and autonomic innervation of the facet joint in the rat lumbar spine. Spine 1993; 18:21212126.

264. Cavanaugh JM, Lu Y, Chen C, Kallakuri S. Pain generation in lumbar and cervical facet joints. J Bone Joint Surg Am 2006; 88 Suppl 2:63-67.

265. Inami S, Shiga T, Tsujino A, Yabuki T, Okado N, Ochiai N. Immunohistochemical demonstration of nerve fibers in the synovial fold of the human cervical facet joint. J Orthop Res 2001; 19:593-596.

266. Kallakuri S, Singh A, Chen C, Cavanaugh JM. Demonstration of substance P, calcitonin gene-related peptide, and protein gene product 9.5 containing nerve fibers in human cervical facet joint capsules. Spine 2004; 29:1182-1186.

267. Chen C, Lu Y, Kallakuri S, Patwardhan A, Cavanaugh JM. Distribution of A-delta and $\mathrm{C}$-fiber receptors in the cervical facet joint capsule and their response to stretch. J Bone Joint Surg Am 2006; 88:1807-1816.

268. Ohtori S, Takahashi K, Moriya H. Calcitonin gene-related peptide immunoreactive DRG neurons innervating the cervical facet joints show phenotypic switch in cervical facet injury in rats. Eur Spine J 2003; 12:211-215.

269. Miyagi M, Ohtori S, Ishikawa T, Aoki Y, Ozawa T, Doya H, Saito T, Moriya H, Takahashi K. Up-regulation of TNFalpha in DRG satellite cells following lumbar facet joint injury in rats. Eur Spine J 2006; 15:953-958.

270. Ohtori S, Takahashi K, Chiba T, Yamagata M, Sameda H, Moriya H. Substance P and calcitonin gene-related peptide immunoreactive sensory DRG neurons innervating the lumbar facet joints in rats. Auton Neurosci 2000; 86:13-17.

271. Suseki K, Takahashi Y, Takahashi K, Chiba T, Tanaka K, Moriya H. CGRP-immunoreactive nerve fibers projecting to lumbar facet joints through the paravertebral sympathetic trunk in rats. Neurosci Lett 1996; 221:41-44.
272. Ohtori S, Moriya H, Takahashi K. Calcitonin gene-related peptide immunoreactive sensory DRG neurons innervating the cervical facet joints in rats. $/ \mathrm{Or}$ thop Sci 2002; 7:258-261.

273. Ohtori S, Takahashi K, Chiba T, Yamagata M, Sameda H, Moriya H. Brain-derived neurotrophic factor and vanilloid receptor subtype 1 immunoreactive sensory DRG neurons innervating the lumbar facet joints in rats. Auton Neurosci 2001; 94:132-135.

274. McLain RF, Pickar JG. Mechanoreceptor endings in human thoracic and lumbar facet joints. Spine 1998; 23:168-173.

275. McLain RF. Mechanoreceptors ending in human cervical facets joints. Spine 1994; 5:495-501.

276. Boszczyk BM, Boszczyk AA, Putz R, Buttner A, Benjamin M, Milz S. An immunohistochemical study of the dorsal capsule of the lumbar and thoracic facet joints. Spine 2001; 26:E338-E343.

277. Yamashita T, Cavanaugh JM, Ozaktay AC, Avramov Al, Getchell TV, King Al. Effect of substance $P$ on mechanosensitive units of tissues around and in the lumbar facet joint. J Orthop Res 1993; 11:205-214.

278. Beaman DN, Graziano GP, Glover RA, Wojtys EM, Chang V. Substance P innervation of lumbar spine facet joints. Spine 1993; 18:1044-1049.

279. Ohtori S, Takahashi K, Chiba T, Yamagata M, Sameda H, Moriya H. Phenotypic inflammation switch in rats shown by calcitonin gene-related peptide immunoreactive dorsal root ganglion neurons innervating the lumbar facet joints. Spine 2001; 26:1009-1013.

280. Chen C, Lu Y, Cavanaugh JM, Kallakuri S, Patwardhan A. Recording of neural activity from goat cervical facet joint capsule using custom-designed miniature electrodes. Spine 2005; 30:1367-1372.

281. Lu Y, Chen C, Kallakuri S, Patwardhan A, Cavanaugh JM. Development of an in vivo method to investigate biomechanical and neurophysiological properties of spine facet joint capsules. Eur Spine J 2005; 14:565-572.

282. Lu Y, Chen C, Kallakuri S, Patwardhan A, Cavanaugh JM. Neurophysiological and biomechanical characterization of goat cervical facet joint capsules. J Orthop Res 2005; 23:779-787.

283. Bucknill AT, Coward K, Plumpton C, Tate S, Bountra C, Birch R, Sandison $A$, Hughes SP, Anand P. Nerve fibers in lumbar spine structures and injured spinal roots express the sensory neuronspecific sodium channels SNS/PN3 and
NaN/SNS2. Spine 2002; 27:135-140.

284. Igarashi A, Kikuchi S, Konno S, Olmarker K. Inflammatory cytokines released from the facet joint tissue in degenerative lumbar spinal disorders. Spine 2004; 29:2091-2095.

285. Ozaktay AC, Cavanaugh JM, Blagoev DC, Getchell TV, King Al. Effects of a carrageenan-induced inflammation in rabbit lumbar facet joint capsule and adjacent tissues. Neurosci Res 1994; 20:355364.

286. Ohtori S, Takahashi K, Moriya H. Inflammatory pain mediated by a phenotypic switch in brain-derived neurotrophic factor-immunoreactive dorsal root ganglion neurons innervating the lumbar facet joints in rats. Neurosci Lett 2002; 323:129-132.

287. Mayer TG, Gatchel RJ, Keeley J, McGeary D, Dersh J, Anagnostis C. A randomized clinical trial of treatment for lumbar segmental rigidity. Spine 2004; 29:21992205.

288. Ianuzzi A, Khalsa PS. Comparison of human lumbar facet joint capsule strains during simulated high-velocity, lowamplitude spinal manipulation versus physiological motions. Spine / 2005; 5:277-290.

289. Yang KH, King Al. Mechanism of facet load transmission as a hypothesis for low-back pain. Spine 1984; 9:557 -565.

290. Borchgrevink GE, Smevik O, Nordby A, Rinck PA, Stiles TC, Lereim I. MR imaging and radiography of patients with cervical hypertension-flexion injuries after car accidents. Acta Radiol 1995; 36:425-428.

291. Ronnen HR, de Korte PJ, Brink PR, van der Bijl HJ, Tonino AJ, Franke CL. Acute whiplash injury: is there a role for MR imaging? - a prospective study of 100 patients. Radiology 1996; 201:93-96.

292. Pennie B, Agambar L. Patterns of injury and recovery in whiplash. Injury 1991; 22:57-59.

293. Siegmund GP, Myers BS, Davis MB, Bohnet HF, Winkelstein BA. Mechanical evidence of cervical facet capsule injury during whiplash: a cadaveric study using combined shear, compression, and extension loading. Spine 2001; 26:2095-2101.

294. Winkelstein BA, Nightingale RW, Richardson WJ, Myers BS. Cervical facet joint mechanics: its application to whiplash injury. Stapp Car Crash J. 1999; 43:243252.

295. Onan OA, Heggeness MH, Hipp JA. A motion analysis of the cervical facet joint. Spine 1998; 23:430-439. 
296. Stemper BD, Yoganandan N, Pintar FA. Gender- and region-dependent local facet joint kinematics in rear impact: implications in whiplash injury. Spine 2004; 29:1764-1771.

297. Stemper BD, Yoganandan N, Gennarelli TA, Pintar FA. Localized cervical facet joint kinematics under physiological and whiplash loading. I Neurosurg Spine 2005; 3:471-476.

298. Mayer T, Robinson R, Pegues P, Kohles $S$, Gatchel RJ. Lumbar segmental rigidity: can its identification with facet injections and stretching exercises be useful? Arch Phys Med Rehabil 2000; 81:1143-1150.

299. Merskey H, Bogduk N. Classification of Chronic Pain. Descriptions of Chronic Pain Syndromes and Definition of Pain Terms, 2nd ed. IASP Press, Seattle, 1994.

300. Schwarzer AC, Aprill CN, Derby R, Fortin J, Kine G, Bogduk N. Clinical features of patients with pain stemming from the lumbar zygapophysial joints. Is the lumbar facet syndrome a clinical entity? Spine 1994; 19:1132-1137.

301. Schwarzer AC, Aprill CN, Derby R, Fortin J, Kine G, Bogduk N. The relative contributions of the disc and zygapophyseal joint in chronic low back pain. Spine 1994; 19:801-806.

302. Schwarzer AC, Wang SC, Bogduk N, McNaught PJ, Laurent R. Prevalence and clinical features of lumbar zygapophysial joint pain: A study in an Australian population with chronic low back pain. Am Rheum Dis 1995; 54:100-106.

303. Manchikanti L, Pampati V, Fellows B, Bakhit C. Prevalence of lumbar facet joint pain in chronic low back pain. Pain Physician 1999; 2:59-64.

304. Manchikanti L, Pampati V, Fellows B, Bakhit CE. The diagnostic validity and therapeutic value of medial branch blocks with or without adjuvants agents. Curr Rev Pain 2000; 4:337-344.

305. Manchikanti L, Pampati V, Fellows B, Baha AG. The inability of the clinical picture to characterize pain from facet joints. Pain Physician 2000; 3:158-166.

306. Manchikanti L, Hirsch JA, Pampati V. Chronic low back pain of facet (zygapophysial) joint origin: is there a difference based on involvement of single or multiple spinal regions? Pain Physician 2003; 6:399-405.

307. Manchikanti L, Singh V, Pampati S, Damron K, Beyer C, Barnhill R. Is there correlation of facet joint pain in lumbar and cervical spine? Pain Physician 2002; 5:365-371.
308. Manchikanti L, Manchukonda R, Pampati V, Damron KS, McManus CD. Prevalence of facet joint pain in chronic low back pain in post surgical patients by controlled comparative local anesthetic blocks. Arch Phys Med Rehabil 2007; in press.

309. Barnsley L, Lord SM, Wallis BJ, Bogduk N. The prevalence of chronic cervical zygapophyseal joint pain after whiplash. Spine 1995; 20:20-26.

310. Lord SM, Barnsley L, Wallis BJ, Bogduk N. Chronic cervical zygapophysial joint pain with whiplash: A placebo-controlled prevalence study. Spine 1996; 21:1737-1745.

311. Manchikanti L, Singh V, Rivera J, Pampati V. Prevalence of cervical facet joint pain in chronic neck pain. Pain Physician 2002; 5:243-249.

312. Speldewinde GC, Bashford GM, Davidson IR. Diagnostic cervical zygapophyseal joint blocks for chronic cervical pain. Med J Aust 2001; 174:174-176.

313. Manchikanti L, Singh, V, Pampati V, Beyer C, Damron K. Evaluation of the prevalence of facet joint pain in chronic thoracic pain. Pain Physician 2002; 5:354359.

314. Brisby H. Pathology and possible mechanisms of nervous system response to disc degeneration. J Bone Joint Surg Am 2006; 88 Suppl 2:68-71.

315. Zhang Y, Kerns JM, Anderson DG, Lee YS, Chen EY, Tannoury C, An HS. Sensory neurons and fibers from multiple spinal cord levels innervate the rabbit lumbar disc. Am J Phys Med Rehabil 2006; 85:865-871.

316. Miyamoto K, Masuda K, Kim JG, Inoue $\mathrm{N}$, Akeda K, Andersson GB, An HS. Intradiscal injections of osteogenic protein1 restore the viscoelastic properties of degenerated intervertebral discs. Spine J 2006; 6:692-703.

317. Bogduk N. Nerves of the lumbar spine. Clinical Anatomy of Lumbar Spine and Sacrum. 4th edition. Churchill Livingstone, New York, 2005, pp 123-139.

318. Wiberg G. Back pain in relation to the nerve supply of the intervertebral disc. Acta Orthop Scand 1947; 19:211-221.

319. Ikari C. A study of the mechanism of low-back pain. The neurohistological examination of the disease. J Bone Joint Surg 1954; 36A:195.

320. Jung A, Brunschwig A. Recherches histologiques des articulations des corps vertebraux. Presse Med 193; 40:316317.

321. Anderson J. Pathogenesis of back pain. In: Grahame R, Anderson JAD, eds. Low
Back Pain, Vol. 2. Eden Press, Westmount, 1980, pp 23-32.

322. Lamb DW. The neurology of spinal pain. Phys Ther 1979; 59:971-973.

323. Wyke B. The neurology of low back pain. In: Jayson MIV, ed. The Lumbar Spine and Back Pain, 2nd edn. Tunbridge Wells, Pitman, 1980, pp 265-339.

324. Bogduk N. The anatomy of the lumbar intervertebral disc syndrome. Med J Aust 1976; 1:878-881.

325. Bogduk N, Tynan W, Wilson AS. The nerve supply to the human lumbar intervertebral discs. J Anat 1981; 132:3956.

326. McCarthy PW, Carruthers B, Martin D, Petts P. Immunohistochemical demonstration of sensory nerve fibers and endings in lumbar intervertebral discs of the rat. Spine $1991 ; 16: 653-655$.

327. Cavanaugh JM, Kallakuri S, Ozaktay AC. Innervation of the rabbit lumbar intervertebral disc and posterior longitudinal ligament. Spine 1995; 20:20802085.

328. Jackson HC, Winkelmann RK, Bickel WH. Nerve endings in the human lumbar spinal column and related structures. J Bone Joint Surg 1966; 48A:1272-1281.

329. Ehrenhaft JC. Development of the vertebral column as related to certain congenital and pathological changes. Surg Gynecol Obst 1943; 76:282-292.

330. Roof PG. Innervation of annulus fibrosus and posterior longitudinal ligament. Arch Neurol Psychiatry 1940; 44:100103.

331. Malinsky J. The ontogenetic development of nerve terminations in the intervertebral discs of man. Acta Anat 1959; 38:96-113.

332. Rabischong P, Louis R, Vignaud J, Massare C. The intervertebral disc. Anat Clin 1978; 1:55-64.

333. Yoshizawa H, O'Brien JP, Thomas-Smith W, Trumper M. The neuropathology of intervertebral discs removed for low back pain. J Pathol 1980; 132:95-104.

334. Peng B, Wu W, Hou S, Li P, Zhang C, Yang Y. The pathogenesis of discogenic low back pain. I Bone Joint Surg Br 2005; 87:62-67.

335. Freemont AJ, Peacock TE, Goupille P, Hoyland JA, O'Brien J, Jayson MI. Nerve ingrowth into diseased intervertebral disc in chronic back pain. Lancet 1997; 350:178-181.

336. Coppes MH, Marani E, Thomeer RT, Oudega M, Groen GJ. Innervation of annulus fibrosus in low back pain. Lancet 1990; 336:189-190. 
337. Coppes MH, Marani E, Thomeer RT, Groen GJ. Innervation of "painful” lumbar discs. Spine 1997; 22:2342-2350.

338. Bogduk N, Windsor M, Inglis A. The innervation of the cervical intervertebral discs. Spine 1988; 13:2-8.

339. Mendel T, Wink CS, Zimny ML. Neural elements in human cervical intervertebral discs. Spine 1992; 17:132-135.

340. Nakamura S, Takahashi K, Takahashi Y, Morinaga T, Shimada Y, Moriya H. Origin of nerves supplying the posterior portion of lumbar intervertebral discs in rats. Spine 1996; 21:917-924.

341. Morinaga T, Takahashi K, Yamagata M, Chiba T, Tanaka K, Takahashi Y, Nakamura S, Suseki K, Moriya H. Sensory innervation to the anterior portion of lumbar intervertebral disc. Spine 1996; 21:1848-1851.

342. Ohtori S, Takahashi Y, Takahashi K, Yamagata M, Chiba T, Tanaka K, Hirayama J, Moriya H. Sensory innervation of the dorsal portion of the lumbar intervertebral disc in rats. Spine 1999; 24:2295-2299.

343. Groen G, Baljet B, Drukker J. Nerves and nerve plexuses of the human vertebral column. Am J Anat 1990; 188:282-296.

344. Fagan A, Moore R, Vernon Roberts $B$, Blumbergs $P$, Fraser $R$. The innervation of the intervertebral disc: A quantitative analysis. Spine 2003; 28:2570-2576.

345. Palmgren T, Gronblad M, Virri J, Kaapa E, Karaharju E. An immunohistochemical study of nerve structures in the anulus fibrosus of human normal lumbar intervertebral discs. Spine 1999; 24:20752079.

346. Ashton IK, Roberts S, Jaffray DC, Polak $J M$, Eisenstein SM. Neuropeptides in the human intervertebral disc. J Orthop Res 1994; 12:186-192.

347. Shinohara H. Lumbar disc lesion, with special reference to the histological significane of nerve endings of the lumbar discs. J Jap Orthop Assoc 1970; 44:553570.

348. Roberts S, Eisenstein SM, Menage J, Evans EH, Ashton IK. Mechanoreceptors in intervertebral discs. Spine 1995; 24:2645-2651.

349. Hurri H, Karppinen J. Discogenic pain. Pain 2004; 112:225-228.

350. Aoki Y, Ohtori S, Takahashi K, Ino H, Takahashi Y, Chiba T, Moriya H. Innervation of the lumbar intervertebral disc by nerve growth factor-dependent neurons related to inflammatory pain. Spine 2004; 29:1077-1081.

351. Ohtori S, Takahashi K, Chiba T, Yamagata M, Sameda H, Moriya H. Sensory in- nervation of the dorsal portion of the lumbar intervertebral discs in rats. Spine 2001; 26:946-950.

352. Fernstrom U. A discographical study of ruptured lumbar discs. Acta Chirurg Scand 1960; 258:1-60.

353. Hirsch C. An attempt to diagnose leve of disc lesion clinically by disc puncture. Acta Orthop Scand. 1948; 18:132-140.

354. Lindblom K. Diagnostic puncture of intervertebral disks in sciatica. Acta Orthop Scand 1948; 17:231-239.

355. Palmgren T, Gronblad M, Virri J, Seitsalo S, Ruuskanen M, Karaharju E. Immunohistochemical demonstration of sensory and autonomic nerve terminals in herniated lumbar disc tissue. Spine 1996; 21:1301-1306.

356. Ohtori S, Inoue G, Koshi T, Ito T, Doya $\mathrm{H}$, Moriya H, Takahashi K. Substance P-saporin down-regulates substance $P$ receptor immunoreactive sensory dorsal root ganglion neurons innervating the lumbar intervertebral discs in rats. Spine 2006; 31:2987-2991.

357. Larsson K, Rydevik B, Olmarker K. Disc related cytokines inhibit axonal outgrowth from dorsal root ganglion cells in vitro. Spine 2005; 30:621-624.

358. Kang JD, Georgescu HI, McIntyre-Larkin L, Stefanovic-Racic M, Donaldson WF 3rd, Evans $\mathrm{CH}$. Herniated lumbar intervertebral discs spontaneously produce matrix metalloproteinases, nitric oxide, interleukin-6, and prostaglandin E2. Spine 1996; 21:271-277.

359. Ahmed M, Bjurholm A, Kreicbergs A, Schultzberg M. Neuropeptide Y, tyrosine hydroxylase and vasoactive intestinal polypeptide-immunoreactive nerve fibers in the vertebral bodies, discs, dura mater, and spinal ligaments of the rat lumbar spine. Spine 1993; 18:268273.

360. Ashton IK, Eisenstein SM. The effect of substance $\mathrm{P}$ on proliferation and proteoglycan deposition of cells derived from rabbit intervertebral disc. Spine 1996; 21:421-426.

361. McCarthy PW. Sparse substance Plike immunoreactivity in intervertebral discs. Nerve fibers and endings in the rat. Acta Orthop Scand 1993; 64:664668.

362. O’Neill CW, Kurgansky ME, Derby R, Ryan DP. Disc stimulation and patterns of referred pain. Spine 2002; 27:27762781.

363. Derby R, Eek B, Lee SH, Seo S, Kim BJ. Comparison of intradiscal restorative injections and intradiscal electrothermal treatment (IDET) in the treatment of low back pain. Pain Physician 2004; 7:63-66.

364. Mixter WJ, Barr JS. Rupture of the intervertebral disc with involvement of the spinal canal. N Eng J Med 1934; 211:210215.

365. Rosen S, Falco F. Radiofrequency stimulation of intervertebral discs. Pain Physician 2003; 6:435-438.

366. Slipman CW, Plastaras C, Patel R, Isaac Z, Chow D, Garvan C, Pauza K, Furman M. Provocative cervical discography symptom mapping. Spine / 2005; 5:381388.

367. Schwarzer AC, Aprill CN, Derby R, Fortin J, Kine G, Bogduk N. The prevalence and clinical features of internal disc disruption in patients with chronic low back pain. Spine 1995; 20:1878-1883.

368. Ohnmeiss DD, Vanharanta H, Ekholm J. Relationship of pain drawings to invasive tests assessing intervertebral disc pathology. Eur Spine J 1999; 8:126-131.

369. Schellhas KP, Smith MD, Gundry CR, Pollei SR. Cervical discogenic pain: prospective correlation of magnetic resonance imaging and discography in asymptomatic subjects and pain sufferers. Spine 1996; 21:300-311.

370. Mixter WJ, Ayers JB. Herniation or rupture of the intervertebral disc into the spinal canal. N Engl J Med 1935; 213:385-395.

371. Aoki Y, Takahashi Y, Ohtori S, Moriya H, Takahashi K. Distribution and immunocytochemical characterization of dorsal root ganglion neurons innervating the lumbar intervertebral disc in rats: a review. Life Sci 2004; 74:2627-2642.

372. Freemont AJ, Watkins A, Le Maitre C, Baird P, Jeziorska M, Knight MT, Ross ER, O'Brien JP, Hoyland JA. Nerve growth factor expression and innervation of the painful intervertebral disc. J Pathol 2002; 197:286-292.

373. Burke JG, Watson RW, McCormack D, Dowling FE, Walsh MG, Fitzpatrick JM. Intervertebral discs which cause low back pain secrete high levels of proinflammatory mediators. J Bone Joint Surg Br 2002; 84:196-201.

374. Burke JG, G Watson RW, Conhyea D, McCormack D, Dowling FE, Walsh MG, Fitzpatrick JM. Human nucleus pulposus can respond to a pro-inflammatory stimulus. Spine 2003; 28:2685-2693.

375. Crock HV. A reappraisal of intervertebral disc lesions. Med J Aust 1970; 1:983989.

376. Ohnmeiss DD, Vanharanta H, Ekholm J. Degree of disc disruption and lower extremity pain. Spine 1997; 22:1600-1605. 
377. Wheeler AH, Murrey DB. Chronic lumbar spine and radicular pain: Pathophysiology and treatment. Curr Pain Headache Rep 2002; 6:97-105.

378. Ashton IK, Walsh DA, Polak JM, Eisenstein SM. Substance $P$ in intervertebral discs. Binding sites on vascular endothelium of the human annulus fibrosus. Acta Orthop Scand 1994; 65:635-639.

379. Cervero F. Visceral nociception: peripheral and central aspects of visceral nociceptive systems. Philos Trans $R$ Soc Lond B Biol Sci 1985; 308:325-337.

380. McCarron RF, Wimpee MW, Hudkins PG, Laros GS. The inflammatory effects of nucleus pulposus: A possible element in the pathogenesis of low back pain. Spine 1987; 12:760-764.

381. Olmarker K, Blomquist J, Stromberg J, Nannmark U, Thomsen P, Rydevik B. Inflammatogenic properties of nucleus pulposus. Spine 1995; 20:665-669.

382. Marshall LL, Trethewie ER, Curtain CC. Chemical radiculitis: A clinical, physiological, and immunological study. Clin Orthop Rel Res 1977; 190:61-67.

383. Olmarker K, Nordborg C, Larsson K, Rydevik B. Ultrastructural changes in spinal nerve roots induced by autologous nucleus pulposus. Spine 1996; 27:411-414.

384. Olmarker K, Rydevik B, Nordborg C. Autologous nucleus pulposus induces neurophysiologic and histologic changes in porcine cauda equina nerve roots. Spine 1993; 18:1425-1432.

385. Uchida K, Baba H, Maezawa Y, Kubota C. Progressive changes in neurofilament proteins and growth-associated protein-43 immunoreactivities at the site of cervical spinal cord compression in spinal hyperostotic mice. Spine 2002; 27:480-486.

386. Olmarker K, Rydevik B, Holm S. Edema formation in spinal nerve roots induced by experimental, graded compression: An experimental study on the pig cauda equina with special reference to differences in effects between rapid and slow onset of compression. Spine 1989; 14:569-573.

387. Olmarker K, Rydevik B, Holm S, Bagge $U$. Effects of experimental graded compression on blood flow in spinal nerve roots: A vital microscopic study on the porcine cauda equina. J Orthop Res 1989; 7:817-823.

388. Olmarker K, Holm S, Rydevik B. Importance of compression onset rate for the degree of impairment of impulse propagation in experimental compression injury of the porcine cauda equina. Spine
1990; 35:416-419.

389. Rydevik BL. The effects of compression on the physiology of nerve roots. J Manipul Physiol Ther 1992; 1:62-66.

390. Olmarker K, Holm S, Rosenqvist AL, Rydevik B. Experimental nerve root compression. Presentation of a model for acute, graded compression of the porcine cauda equina, with analysis of neural and vascular anatomy. Spine 1992; 16:61-69.

391. Kawakami M, Tamaki T, Hashizume $\mathrm{H}$, Weinstein JN, Meller ST. The role of phospholipase $\mathrm{A} 2$ and nitric oxide in pain-related behavior produced by an allograft of intervertebral disc material to the sciatic nerve of the rat. Spine 1997; 22:1074-1079.

392. Saal JS, Franson RC, Dobrow R, Saal JA, White AH, Goldthwaite N. High levels of inflammatory phospholipase A2 activity in lumbar disc herniations. Spine 1990; $15: 674-678$.

393. Yabuki S, Kikuchi S, Olmarker K, Myers RR. Acute effects of nucleus pulposus on blood flow and endoneurial fluid pressure in rat dorsal root ganglia. Spine 1998; 23:2517-2523.

394. Yabuki S, Igarashi T, Kikuchi S. Application of nucleus pulposus to the nerve root simultaneously reduces blood flow in dorsal root ganglion and corresponding hindpaw in the rat. Spine 2000; 25:1471-1476.

395. Kang JD, Stefanovic-Racic M, Mclntyre LA, Georgescu HI, Evans CH. Toward a biochemical understanding of human intervertebral disc degeneration and herniation. Contributions of nitric oxide, interleukins, prostaglandin E2, and matrix metalloproteinases. Spine 1997; 22:1065-1073.

396. Takahashi H, Suguro T, Okazima Y, Motegi M, Okada Y, Kakiuchi T. Inflammatory cytokines in the herniated disc of the lumbar spine. Spine 1996; 21:218-224.

397. Olmarker K, Rydevik B. Selective inhibition of tumor necrosis factor-alpha prevents nucleus pulposus-induced thrombus formation, intraneural edema, and reduction of nerve conduction velocity: possible implications for future pharmacologic treatment strategies of sciatica. Spine 2001; 26:863-869.

398. Igarashi T, Kikuchi S, Shubayev V, Myers RR. 2000 Volvo Award winner in basic science studies: Exogenous tumor necrosis factor-alpha mimics nucleus pulposus-induced neuropathology. Molecular, histologic, and behavioral comparisons in rats. Spine 2000; 25:29752980.

399. Homma Y, Brull SJ, Zhang JM. A compar- ison of chronic pain behavior following local application of tumor necrosis factor alpha to the normal and mechanically compressed lumbar ganglia in the rat. Pain 2002; 95:239-246.

400. Miyamoto H, Saura R, Doita M, Kurosaka M, Mizuno K. The role of cyclooxygenase-2 in lumbar disc herniation. Spine 2002; 27:2477-2483.

401. Ishii Y, Thomas AO, Guo XE, Hung CT, Chen $\mathrm{FH}$. Localization and distribution of cartilage oligomeric matrix protein in the rat intervertebral disc. Spine 2006; 31:1539-1546.

402. Haefeli M, Kalberer F, Saegesser D, Nerlich AG, Boos N, Paesold G. The course of macroscopic degeneration in the human lumbar intervertebral disc. Spine 2006; 31:1522-1531.

403. Wang YJ, Shi Q, Lu WW, Cheung KC, Darowish $M$, Li TF, Dong YF, Zhou CJ, Zhou Q, Hu ZJ, Liu M, Bian Q, Li CG, Luk KD, Leong JC. Cervical intervertebral disc degeneration induced by unbalanced dynamic and static forces: a novel in vivo rat model. Spine 2006; 31:15321538.

404. Séguin CA, Pilliar RM, Roughley PJ, Kandel RA. Tumor necrosis factor-alpha modulates matrix production and catabolism in nucleus pulposus tissue. Spine 2005; 30:1940-1948.

405. Ohtori S, Inoue G, Ito T, Koshi T, Ozawa T, Doya H, Saito T, Moriya H, Takahashi K. Tumor necrosis factor-immunoreactive cells and PGP 9.5-immunoreactive nerve fibers in vertebral endplates of patients with discogenic low back pain and modictype 1 or type 2 changes on MRI. Spine 2006; 31:1026-1031.

406. Milette PC, Fontaine S, Lepanto L, Breton G. Radiating pain to the lower extremities caused by lumbar disc rupture without spinal nerve root involvement. Am J Neuroradiol 1995; 16:1605-1615.

407. Crock HV. Isolated lumbar disc resorption as a cause of nerve root canal stenosis. Clin Orthop 1976; 115:109-115.

408. Holm S, Holm AK, Ekstrom L, Karladani A, Hansson T. Experimental disc degeneration due to endplate injury. I Spinal Disord Tech 2004; 17:64-71.

409. Videman T, Nurminen M. The occurrence of anular tears and their relation to lifetime back pain history: a cadaveric study using barium sulfate discography. Spine 2004; 29:2668-2676.

410. Rajasekaran S, Babu JN, Arun R, Armstrong BR, Shetty AP, Murugan S. ISSLS prize winner: A study of diffusion in human lumbar discs: a serial magnetic resonance imaging study documenting the influence of the endplate on diffu- 
sion in normal and degenerate discs. Spine 2004; 29:2654-2667.

411. Boos N, Weissbach S, Rohrbach H, Weiler C, Spratt KF, Nerlich AG. Classification of age-related changes in lumbar intervertebral discs: 2002 Volvo Award in basic science. Spine 2002; 27:26312644 .

412. Roberts S, Urban JP, Evans H, Eisenstein SM. Transport properties of the human cartilage endplate in relation to its composition and calcification. Spine 1996; 21:415-420.

413. Kauppila LI, McAlindon T, Evans S, Wilson PW, Kiel D, Felson DT. Disc degeneration/back pain and calcification of the abdominal aorta. A 25-year followup study in Framingham. Spine 1997; 22:1642-1647.

414. Peng BG, Wu WW, Hou SX, Zhang CL, Yang Y, Wang XH, Fu XB. The pathogenesis of discogenic low back pain. Zhonghua Wai Ke Za Zhi 2004; 42:720-724.

415. Bogduk N, Aprill C. On the nature of neck pain, discography, and cervical zygapophyseal joint blocks. Pain 1993; 54:213-217.

416. Aota Y, Onari K, An HS, Yoshikawa K. Dorsal root ganglia morphologic features in patients with herniation of the nucleus pulposus. Assessment using magnetic resonance myelography and clinical correlation. Spine 2001; 26:2125-2132.

417. Rydevik BL, Myers RR, Powell HC. Pressure increase in the dorsal root ganglion following mechanical compression: Closed compartment syndrome in nerve roots. Spine 1989; 14:574-576.

418. Weinstein J. Mechanisms of spinal pain: The dorsal root ganglion and its role as a pain mediator of low-back pain. Spine 1986; 11:999-1001.

419. Byrod G, Otani K, Brisby H, Rydevik B, Olmarker K. Methylprednisolone reduces the early vascular permeability increase in spinal nerve roots induced by epidural nucleus pulposus application. J Orthop Res 2000; 18:983-987.

420. Harrington JF, Messier AA, Bereiter D, Barnes B, Epstein MH. Herniated lumbar disc material as a source of free glutamate available to affect pain signals through the dorsal root ganglion. Spine 2000; 25:929-936.

421. Cavanaugh JM, Ozaktay AC, Vaidyanathan S. Mechano- and chemosensitivity of lumbar dorsal roots and dorsal root ganglia: An in vitro study. Trans Orthop Res Soc 1994; 19:109.

422. Iwabuchi M, Rydevik B, Kikuchi S, Olmarker K. Effects of anulus fibrosus and experimentally degenerated nucleus pulposus on nerve root conduction velocity: relevance of previous experimental investigations using normal nucleus pulposus. Spine 2001; 26:1651-1655.

423. Takebayashi T, Cavanaugh JM, Cuneyt Ozaktay A, Kallakuri S, Chen C. Effect of nucleus pulposus on the neural activity of dorsal root ganglion. Spine 2001; 26:940-945.

424. Aoki Y, Ohtori S, Ino H, Douya H, Ozawa T, Saito T, Moriya H, Takahashi K. Disc inflammation potentially promotes axonal regeneration of dorsal root ganglion neurons innervating lumbar intervertebral disc in rats. Spine 2004; 29:26212626.

425. Snider WD, McMahon SB. Tackling pain at the source: new ideas about nociceptors. Neuron 1998; 20:629-632.

426. Ohtori S, Inoue G, Koshi T, Ito T, Doya H, Saito T, Moriya H, Takahashi K. Upregulation of acid-sensing ion channel 3 in dorsal root ganglion neurons following application of nucleus pulposus on nerve root in rats. Spine 2006; 31:20482052.

427. Inoue G, Ohtori S, Aoki Y, Ozawa T, Doya $\mathrm{H}$, Saito T, Ito T, Akazawa T, Moriya H, Takahashi K. Exposure of the nucleus pulposus to the outside of the anulus fibrosus induces nerve injury and regeneration of the afferent fibers innervating the lumbar intervertebral discs in rats. Spine 2006; 31:1433-1438.

428. Murata Y, Rydevik B, Takahashi K, Larsson $\mathrm{K}$, Olmarker K. Incision of the intervertebral disc induces disintegration and increases permeability of the dorsal root ganglion capsule. Spine 2005; 30:1712-1716

429. Aoki Y, Ohtori S, Takahashi K, Ino H, Douya H, Ozawa T, Saito T, Moriya H. Expression and co-expression of VR1, CGRP, and IB4-binding glycoprotein in dorsal root ganglion neurons in rats: differences between the disc afferents and the cutaneous afferents. Spine 2005; 30:1496-1500.

430. Onda A, Murata Y, Rydevik B, Larsson K, Kikuchi S, Olmarker K. Nerve growth factor content in dorsal root ganglion as related to changes in pain behavior in a rat model of experimental lumbar disc herniation. Spine 2005; 30:188-193.

431. Hammond DL, Ackerman L, Holdsworth $R$, Elzey $B$. Effects of spinal nerve ligation on immunohistochemically identified neurons in the $\mathrm{L}_{4}$ and $\mathrm{L}_{5}$ dorsal root ganglia of the rat. J Comp Neurol 2004; 475:575-589.

432. Obata K, Yamanaka H, Dai Y, Mizushi- ma T, Fukuoka T, Tokunaga A, Yoshikawa $\mathrm{H}$, Noguchi K. Contribution of degeneration of motor and sensory fibers to pain behavior and the changes in neurotrophic factors in rat dorsal root ganglion. Exp Neurol 2004; 188:149-160.

433. Ohtori S, Takahashi K, Moriya H, Myers RR. TNF-alpha and TNF-alpha receptor type 1 upregulation in glia and neurons after peripheral nerve injury: studies in murine DRG and spinal cord. Spine 2004; 29:1082-1088.

434. Kobayashi S, Kokubo Y, Uchida K, Yayama T, Takeno K, Negoro K, Nakajima H, Baba $\mathrm{H}$, Yoshizawa $\mathrm{H}$. Effect of lumbar nerve root compression on primary sensory neurons and their central branches: changes in the nociceptive neuropeptides substance $P$ and somatostatin. Spine 2005; 30:276-282.

435. Bogduk N. The sacroiliac joint. Clinical Anatomy of Lumbar Spine and Sacrum. 4 th edition. Churchill Livingstone, New York, 2005; pp 173-181.

436. Forst SL, Wheeler MT, Fortin JD, Vilensky JA. The sacroiliac joint: anatomy, physiology and clinical significance. Pain Physician 2006; 9:61-67.

437. Cohen SP. Sacroiliac joint pain: A comprehensive review of anatomy, diagnosis and treatment. Anesth Analg 2005; 101:1440-1453.

438. Zelle BA, Gruen GS, Brown S, George S. Sacroiliac joint dysfunction: Evaluation and management. Clin J Pain 2005; 21:446-455.

439. Hansen HC, Helm S. Sacroiliac joint pain and dysfunction. Pain Physician 2003; 6:179-189.

440. Foley BS, Buschbacher RM. Sacroiliac joint pain: anatomy, biomechanics, diagnosis, and treatment. Am J Phys Med Rehabil 2006; 85:997-1006.

441. Bernard TN, Cassidy JD. The sacroiliac syndrome. Pathophysiology, diagnosis and management. In: Frymoyer JW, ed. The adult spine: principles and practice. Raven, New York, 1991; pp 2107-2130.

442. Grob KR, Neuhuber WL, Kissling RO. Innervation of the sacroiliac joint of the human. Z Rheumatol 1995; 54:117-122.

443. Murata Y, Takahashi K, Yamagata M, Takahashi Y, Shimada Y, Moriya H. Origin and pathway of sensory nerve fibers to the ventral and dorsal sides of the sacroiliac joint in rats. J Orthop Res 2001; 19:379-383.

444. Pitkin HC, Pheasant HC. Sacrarthrogenic telalgia I: a study of referred pain. J Bone Joint Surg 1936; 18:111-133.

445. Solonon K. The sacroiliac joint in light of 
anatomical, roentgenological, and clinical studies. Act Orthop Scand Suppl 1957; 27:1-27.

446. Ikeda R. Innervation of the sacroiliac joint. Macroscopical and histological studies. Nippon Ika Daigaku Zasshi 1991; 58:587-596.

447. Sakamoto N, Yamashita T, Takebayashi T, Sekine M, Ishii S. Mechanoreceptors in the sacroiliac joint. Trans Orthop Res Soc 1999; 24:988.

448. Sakamoto N, Yamashita T, Takebayashi T, Sekine M, Ishii S. An electrophysiologic study of mechanoreceptors in the sacroiliac joint and adjacent tissues. Spine 2001; 26:E468-E471.

449. Yamashita T, Minaki Y, Oota I, Yokogushi $\mathrm{K}$, Ishii S. Mechanosensitive afferent units in the lumbar intervertebral disc and adjacent muscle. Spine 1993; 18:2252-2256.

450. Minaki Y, Yamashita T, Ishii S. An electrophysiological study on the mechanoreceptors in the lumbar spine and adjacent tissues. Neurol Orthop 1996; 20:23-35.

451. Fortin JD, Kissling RO, O’Connor BL, Vilensky JA. Sacroiliac joint innervation and pain. Am J Orthop 1999; 28:687690.

452. Bowen V, Cassidy JD. Macroscopic and microscopic anatomy of the sacroiliac joint from embryonic life until the eighth decade. Spine 1981; 6:620-628.

453. Yin W, Willard F, Carreiro J, Dreyfuss P. Sensory stimulation-guided sacroiliac joint radiofrequency neurotomy: Technique based on neuroanatomy of the dorsal sacral plexus. Spine 2003; 28:2419-2425.

454. Vallejo R, Benyamin RM, Kramer J, Stanton G, Joseph NJ. Pulsed radiofrequency denervation for the treatment of sacroiliac joint syndrome. Pain Med 2006; 7:429-434.

455. Dar G, Peleg S, Masharawi Y, Steinberg N, Rothschild BM, Peled N, Hershkovitz I. Sacroiliac joint bridging: demographical and anatomical aspects. Spine 2005; 30:E429-E432.

456. Fortin JD, Washington WJ, Falco FJ. Three pathways between the sacroiliac joint and neural structures. AJNR Am J Neuroradiol 1999; 20:1429-1434.

457. Fortin JD, Dwyer AP, West S, Pier J. Sacroiliac joint: Pain referral maps upon applying a new injection/arthrography technique. Part I: Asymptomatic volunteers. Spine 1994; 19:1475-1482.

458. Fortin JD, Aprill CN, Ponthieux B, Pier J. Sacroiliac joints: Pain referral maps upon applying a new injection/arthrog- raphy technique. Part II: Clinical evaluation. Spine 1994; 19:1483-1489.

459. Slipman CW, Jackson HB, Lipetz JS, Chan KT, Lenrow D, Vresilovic EJ. Sacroiliac joint pain referral zones. Arch Phys Med Rehabil 2000; 81:334-337.

460. Schwarzer AC, Aprill CN, Bogduk M. The sacroiliac joint in chronic low back pain. Spine 1995; 20:31-37.

461. Maigne JY, Aiviliklis A, Pfefer F. Results of sacroiliac joint double block and value of sacroiliac pain provocation test in 54 patients with low back pain. Spine 1996; 21:1889-1892.

462. Irwin RW, Watson T, Minick RP, Ambrosius WT. Age, body mass index, and gender differences in sacroiliac joint pathology. Am J Phys Med Rehabil 2007; 86:37-44.

463. Ebraheim NA, Elgafy H, Semaan HB. Computed tomographic findings in patients with persistent sacroiliac pain after posterior iliac graft harvesting. Spine 2000; 25:2047-2051.

464. Katz V, Schofferman J, Reynolds J. The sacroiliac joint: a potential cause of pain after lumbar fusion to the sacrum. J Spinal Disord Tech 2003;16:96-99.

465. Maigne JY, Planchon CA. Sacroiliac joint pain after lumbar fusion. A study with anesthetic blocks. Eur Spine J 2005; 14:654-658.

466. Schofferman J, Reynolds J, Herzog R, Covington E, Dreyfuss P, O’Neill C. Failed back surgery: etiology and diagnostic evaluation. Spine J 2003; 3:400-403.

467. Slipman CW, Shin CH, Patel RK, Isaac Z, Huston CW, Lipetz JS, Lenrow DA, Braverman DL, Vresilovic EJ Jr. Etiologies of failed back surgery syndrome. Pain Med 2002; 3:200-214.

468. Waguespack A, Schofferman J, Slosar $P$, Reynolds J. Etiology of long-term failures of lumbar spine surgery. Pain Med 2002; 3:18-22.

469. Sampath P, Bendebba M, Davis JD, Ducker T. Outcome in patients with cervical radiculopathy. Prospective, multicenter study with independent clinical review. Spine 1999; 24:591-597.

470. Waddell G, Kummel EG, Lotto WN, Graham JD, Hall H, McCulloch JA. Failed lumbar disc surgery and repeat surgery following industrial injury. J Bone Joint Surg Am 1979; 61:201-207.

471. Lieberman IH. Disc bulge bubble: Spine economics 101. Spine / 2004; 4:609613.

472. Eisner W. Spinal fusion: CMS says "show us the evidence in November," Orthopedics This Week, July 26, 2006; www. ryortho.com/newsletters/volume2/is- sue24/07-25-06.

473. Deyo RA, Nachemson A, Mirza SK. Spinal fusion surgery - The case for restraint. N Engl J Med 2004; 350:722726.

474. Deyo RA, Mirza SK. Trends and variations in the use of spine surgery. Clin Orthop Relat Res 2006; 443:139-146.

475. McCrory DC, Turner DA, Patwardhan MB, Richardson WL.. Spinal fusion for degenerative disc disease affecting the lumbar spine [draft evidence report/ technology review prepared for the Medicare Coverage Advisory Committee meeting], 2006; as yet unpublished; www.cms.hhs.gov/determinationprocess/downloads/id41ta.pdf.

476. Weinstein JN, Lurie JD, Olson PR, Bronner KK, Fisher ES. United States' trends and regional variations in lumbar spine surgery: 1992-2003. Spine 2006; 31:2707-2714.

477. Logroscino C, Sgrambiglia R. Pointillart V. Intermediate follow-up after treatment of degenerative disc disease with Bryan Cervical Disc Prosthesis: single level and bilevel. Spine 2003; 28:26732678.

478. Edwards $\mathrm{mL}$ 2nd, Karpitskaya Y, Cha C, Heller JG, Lauryssen C, Yoon ST, Riew KD. Accurate identification of adverse outcomes after cervical spine surgery. J Bone Joint Surg Am 2004; 86A:251256.

479. Ross JS, Robertson JT, Frederickson RC, Petrie JL, Obuchowski N, Modic MT, deTribolet N. Association between peridural scar and recurrent radicular pain after lumbar discectomy: Magnetic resonance evaluation. Neurosurgery 1996; 38:855-863.

480. Fritsch EW, Heisel J, Rupp S. The failed back surgery syndrome. Reasons, intraoperative findings, and long-term results: A report of 182 operative treatments. Spine 1996; 21:626-633.

481. North RB, Campbell JN, James CS, Conover-Walker MK, Wang H, Piantadosi S, Rybock JD, Long DM. Failed back surgery syndrome: 5 -year follow-up in 102 patients undergoing repeated operation. Neurosurgery 1991; 28:685-691.

482. Brox JI, Sørensen R, Friis A, Nygaard $\emptyset$, Indahl A, Keller A, Ingebrigtsen T, Eriksen HR, Holm I, Koller AK, Riise R, Reikerås 0 . Randomized clinical trial of lumbar instrumented fusion and cognitive intervention and exercises in patients with chronic low back pain and disc degeneration. Spine 2003; 28:1913-1921.

483. Katz JN. Lumbar spinal fusion. Surgical rates, costs, and complications. Spine 1995; 20:78S-83S. 
484. Hacker RJ, Miller CG. Failed anterior cervical foraminotomy. J Neurosurg Spine 2003; 98:126-130.

485. Osterman H, Sund R, Seitsalo S, Keskimaki I. Risk of multiple reoperations after lumbar discectomy: a populationbased study. Spine 2003; 28:621-627.

486. Bono CM, Lee CK. Critical analysis of trends in fusion for degenerative disc disease over the past 20 years: influence of technique of fusion rate and clinical outcome. Spine 2004; 29:455463.

487. Cherkin DC, Deyo RA, Loeser JD, Bush T, Waddell G. An international comparison of back surgery rates. Spine 1994; 19: 1201-1206.

488. Law JD, Lehman RAW, Kirsch WM. Reoperation after lumbar intervertebral disc surgery. J Neurosurg 1978; 48:259-263.

489. Kuntz KM, Snider RK, Weinstein JN, Pope MH, Katz JN. Cost-effectiveness of fusion with and without instrumentation for patients with degenerative spondylolisthesis and spinal stenosis. Spine 2000; 25:1132-1139.

490. Massie JB, Huang B, Malkmus S, Yaksh TL, Kim CW, Garfin SR, Akeson WH. A preclinical post laminectomy rat model mimics the human post laminectomy syndrome. I Neurosci Methods 2004; 137:283-289.

491. Massie JB, Schimizzi AL, Huang B, Kim CW, Garfin SR, Akeson WH. Topical high molecular weight hyaluronan reduces radicular pain post laminectomy in a rat model. Spine J 2005; 5:494-502.

492. Harrington JF, Messier AA, Hoffman L, Yu E, Dykhuizen M, Barker K. Physiological and behavioral evidence for focal nociception induced by epidural glutamate infusion in rats. Spine 2005; 30:606612.

493. Haq I, Cruz-Almeida Y, Siqueira EB, Norenberg $M$, Green BA, Levi AD. Postoperative fibrosis after surgical treatment of the porcine spinal cord: a comparison of dural substitutes. Invited submission from the Joint Section Meeting on Disorders of the Spine and Peripheral Nerves, March 2004. I Neurosurg Spine 2005; 2:50-54.

494. Buvanendran A, Kroin JS, Kerns JM, Nagalla SN, Tuman KJ. Characterization of a new animal model for evaluation of persistent postthoracotomy pain. Anesth Analg 2004; 99:1453-1460.

495. Faustmann PM. Neuroanatomic basis for discogenic pain. $Z$ Orthop Ihre Grenzgeb 2004; 142:706-708.

496. Kim KD, Wang JC, Robertson DP, Brodke DS, BenDebba M, Block KM, diZere- ga GS. Reduction of leg pain and lower-extremity weakness for 1 year with Oxiplex/SP gel following laminectomy, laminotomy, and discectomy. Neurosurg Focus 2004; 17:ECP1.

497. Manchikanti L, Bakhit CE, Pampati V. Role of epidurography in caudal neuroplasty. Pain Digest 1998; 8:277-281.

498. Manchikanti L, Pampati V, Baha A, Fellows B, Damron K, Barnhill R. Contribution of facet joints to chronic low back pain in postlumbar laminectomy syndrome: A controlled comparative prevalence evaluation. Pain Physician 2001; 4:175-180.

499. Viesca C, Racz G, Day M. Spinal techniques in pain management: lysis of adhesions. Anesthesiol Clin North America 2003; 21:745-766.

500. Manchikanti L, Bakhit CE. Percutaneous lysis of epidural adhesions. Pain Physician 2000; 3:46-64.

501. McCarron RF. Epidural fibrosis: Experimental model and therapeutic alternatives. In Racz GB (ed). Techniques of Neurolysis. Kluwer Academic Publishers, Boston, 1989; pp 87-94.

502. LaRocca H, Macnab I. The laminectomy membrane: Studies in its evolution, characteristics, effects and prophylaxis in dogs. I Bone Joint Surg BR 1974; 56:545-550.

503. Cooper RG, Freemont AJ, Hoyland JA, Jenkins JP, West CG, Illingworth KJ, Jayson MI. Herniated intervertebral discassociated periradicular fibrosis and vascular abnormalities occur without inflammatory cell infiltration. Spine 1995; 20:591-598.

504. Hoyland JA, Freemont AJ, Jayson MI. Intervertebral foramen venous obstruc tion. A cause of periradicular fibrosis? Spine 1989; 14:558-568.

505. Songer M, Ghosh L, Spencer D. Effects of sodium hyaluronate on peridural fibrosis after lumbar laminectomy and discectomy. Spine 1990; 15:550-554.

506. Pawl RP. Arachnoiditis and epidural fibrosis: The relationship to chronic pain. Curr Rev Pain 1998; 2:93-99.

507. Cervellini P, Curri D, Volpin L, Bernardi L, Pinna V, Benedetti A. Computed tomography of epidural fibrosis after discectomy. A comparison between symptomatic and asymptomatic patients. Neurosurgery 1988; 6:710-713.

508. Benoist M, Ficat C, Baraf P, Cauchoix J. Post operative lumbar epiduroarachnoiditis: Diagnostic and therapeutic aspects. Spine 1980; 5:432-436.

509. Key JA, Ford LT. Experimental intervertebral disc lesions. J Bone Joint Surg 1948;
30:621-630,

510. Maliszewski M, Tymowski $M$, Lelek $P$, Bierzynska-Macyszyn G, Majchrzak H. An attempt to use Gore-Tex surgical membrane in lumbar disc surgery. Neurol Neurochir Pol 2004; 38:271-277.

511. Kayaoglu CR, Calikoglu C, Binler S. Reoperation after lumbar disc surgery: results in 85 cases. I Int Med Res 2003; 31:318-323.

512. Anderson SR. A rationale for the treatment algorithm of failed back surgery syndrome. Curr Rev Pain 2000; 4:395406.

513. Zoidl G, Grifka J, Boluki D, Willburger RE, Zoidl C, Kramer J, Dermietzel R, Faustmann PM. Molecular evidence for local denervation of paraspinal muscles in failed-back surgery/post discotomy syndrome. Clin Neuropathol 2003; 22:71-77.

514. Amundsen T, Weber H, Nordal HJ, Magnaes $\mathrm{B}$, Abdelnoor $\mathrm{M}$, Lilleas $\mathrm{F}$. Lumbar spinal stenosis: Conservative or surgical management? Spine 2000; 25:14241436.

515. Morishita Y, Hida S, Naito M, Arimizu J, Matsushima U, Nakamura A. Measurement of the local pressure of the intervertebral foramen and the electrophysiologic values of the spinal nerve roots in the vertebral foramen. Spine 2006; 31:3076-3080.

516. Yuan P, Albert T. Nonsurgical and surgical management of lumbar spinal stenosis. J Bone Joint Surg 2004; 10:23202330.

517. Naderi S, Mertol T. Simultaneous cervical and lumbar surgery for combined symptomatic cervical and lumbar spinal stenoses. I Spin Disord Tech 2002; 15:229-232.

518. Fritz JM, Delitto A, Welch WC, Erhard RE. Lumbar spinal stenosis: A review of current concepts in evaluation, management, and outcome measurements. Arch Phys Med Rehabil 1998; 79:700708.

519. Drew R, Bhandari M, Kulkarni AV, Louw $D$, Reddy K, Dunlop B. Reliability in grading the severity of lumbar spinal stenosis. J Spinal Disord 2000; 13:253-258.

520. Treatment of degenerative lumbar spinal stenosis. Evidence Report/Technology Assessment No. 32 University of North Carolina: Agency for Healthcare Research and Quality. AHRQ Publication No. 01-E048; March 2001.

521. Tong HC, Haig AJ, Geisser ME, Yamakawa KS, Miner JA. Comparing pain severity and functional status of older adults without spinal symptoms, with lumbar 
spinal stenosis, and with axial low back pain. Gerontology 2006; 53:111-115.

522. Fox EJ, Melzack R. Transcutaneous electrical stimulation to acupuncture. Comparison of treatment of low back pain. Pain 1976; 2:141-148.

523. Flower RJ, Blackwell GJ. Anti-inflammatory steroid induced biosynthesis of a phospholipase A2 inhibitor which prevents prostaglandin generation. Nature 1979; 278:456-459.

524. Devor M, Govrin-Lippmann R, Raber P. Corticosteroids suppress ectopic neural discharges originating in experimental neuromas. Pain 1985; 22:127-137.

525. Johansson A, Hao J, Sjolund B. Local corticosteroid application blocks transmission in normal nociceptor C-fibers. Acta Anaesthesiol Scand 1990; 34:335338.

526. Olmarker K, Byrod G, Cornefjord M, Nordborg C, Rydevik B. Effects of methylprednisolone on nucleus pulposus-induced nerve root injury. Spine 1994; 19:1803-1808.

527. Nicol GD, Klingberg DK, Vasko MR. Prostaglandin E2 enhances calcium conductance and stimulates release of substance $\mathrm{P}$ in avian sensory neurons. J Neurosci 1992; 12:1917-1927.

528. Hua SY, Chen YZ. Membrane receptormediated electrophysiological effects of glucocorticoid on mammalian neurons. Endocrinology 1989; 124:687691.

529. Hayashi N, Weinstein JN, Meller ST, Lee HM, Spratt KF, Gebhart GF. The effect of epidural injection of betamethasone or bupivacaine in a rat model of lumbar radiculopathy. Spine 1998; 23:877-885.

530. Lee HM, Weinstein JN, Meller ST, Hayashi N, Spratt KF, Gebhart GF. The role of steroids and their effects on phospholipase A2. An animal model of radiculopathy. Spine 1998; 23:11911196.

531. Minamide A, Tamaki T, Hashizume H, Yoshida M, Kawakami M, Hayashi N. Effects of steroids and lipopolysaccharide on spontaneous resorption of herniated intervertebral discs. An experience study in the rabbit. Spine 1998; 23:870876.

532. Kingery WS, Castellote JM, Maze M. Methylprednisolone prevents the development of autotomy and neuropathic edema in rats, but has no effect on nociceptive thresholds. Pain 1999; 80:555-566.

533. Johansson A, Bennett GJ. Effect of local methylprednisolone on pain in a nerve injury model. A pilot study. Reg Anesth
1997; 22:59-65.

534. Lundin A, Magnuson A, Axelsson K, Nilsson 0 , Samuelsson L. Corticosteroids preoperatively diminishes damage to the C-fibers in microscopic lumbar disc surgery. Spine 2005; 30:2362-2367.

535. McLain RF, Kapural L, Mekhail NA. Epidural steroid therapy for back and leg pain: mechanisms of action and efficacy. Spine J 2005; 5:191-201.

536. Muramoto T, Atsuta Y, Iwahara T, Sato M, Takemitsu Y. The action of prostaglandin E2 and triamcinolone acetonide on the firing activity of lumbar nerve roots. Int Orthop 1997; 21:172-175.

537. Merskey H, Thompson EN. Nerve blocks and cognitive therapy: A beneficial failure. Pain Res Manage 2002; 7:175-176.

538. McCormack K. Signal transduction in neuropathic pain, with special emphasis on the analgesic role of opioids Part I: The basic science of phenotype expression in normal and regenerating nerves. Pain Rev 1999; 6:3-33.

539. McCormack K. Signal transduction in neuropathic pain, with special emphasis on the analgesic role of opioids Part II: Moving basic science towards a new pharmacotherapy. Pain Rev 1999; 6:99-131.

540. Watkins L, Milligan ED, Maier SF. Spinal glia: New players in pain. Pain 2001; 93:201-205.

541. Kim SH, Na HS, Sheen K, Chung JM. Effects of sympathetectomy on a rat model of peripheral neuropathy. Pain 1993; 55:85-92.

542. Bogduk N, McGuirk B. Sources and causes of neck pain. In Management of Acute and Chronic Neck Pain. An Evidence-Based Approach. Elsevier, 2006, pp 9-20.

543. Bogduk N, McGuirk B. Acute neck pain: algorithm for acute neck pain. In Management of Acute and Chronic Neck Pain. An Evidence-Based Approach. Elsevier, 2006, pp 69-77.

544. Bogduk N, Lord S. Cervical zygapophysial joint pain. Neurosurg Q 1998; 8:107117.

545. Schwarzer AC, Derby R, Aprill CN, Fortin J, Kine G, Bogduk N. The value of the provocation response in lumbar zygapophysial joint injections. Clin J Pain 1994; 10:309-313.

546. Bogduk N. Diskography. APS / 1994; 3:149-154.

547. Bonica JJ, Buckley FP. Regional analgesia with local anesthetics. In Bonica J] (ed). The Management of Pain. Lea \& Febiger, Philadelphia, 1990; pp 18831966.
548. Boas RA. Nerve blocks in the diagnosis of low back pain. Neurosurg Clin N Am 1991; 2:806-816.

549. Barnsley L, Lord S, Bogduk N. Comparative local anesthetic blocks in the diagnosis of cervical zygapophysial joints pain. Pain 1993; 55:99-106.

550. Lord SM, Barnsley L, Bogduk N. The utility of comparative local anesthetic blocks versus placebo-controlled blocks for the diagnosis of cervical zygapophysial joint pain. Clin J Pain 1995; 11:208-213.

551. Hogan QH, Abram SE. Neural blockade for diagnosis and prognosis. Anesthesiology 1997; 86:216-241.

552. Hildebrandt J. Relevance of nerve blocks in treating and diagnosing low back pain - is the quality decisive? Schmerz 2001; 15:474-483.

553. Nachemson A, Vingård E. Assessment of patients with neck and back pain: A best-evidence synthesis. In Nachemson A, Jonsson E (eds). Neck and back pain. The Scientific Evidence of Causes, Diagnosis and Treatment. Lippincott Williams \& Wilkins, Philadelphia, 2000; pp 189-236.

554. North RB, Kidd DH, Zahurak M, Piantadosi S. Specificity of diagnostic nerve blocks: a prospective, randomized study of sciatica due to lumbosacral spine disease. Pain 1996; 65:77-85.

555. Jaeschke R, Guyatt G, Lijmer J. Diagnostic tests. In Guyatt G, Rennie D (eds). Users' Guides to the Medical Literature - A Manual for Evidence-Based Clinical Practice. AMA Press, Chicago, 2002; pp 121-140.

556. Cohen SP, Larkin TM, Chang AS, Stojanovic MP. The causes of false-positive medial branch (facet joint) blocks in soldiers and retirees. Mil Med 2004; 169:781-786.

557. Raj PP, Shah RV, Kay AD, Denaro S, Hoover JM. Bleeding risk in interventional pain practice: Assessment, management, and review of the literature. Pain Physician 2004; 6:3-52.

558. Horlocker TT, Wedel DJ, Benzon H, Brown DL, Enneking FK, Heit JA, Mulroy MF, Rosenquist RW, Rowlingson J, Tryba M, Yuan CS. Regional anesthesia in the anticoagulated patient: defining the risks (the second ASRA Consensus Conference on Neuraxial Anesthesia and Anticoagulation). Reg Anesth Pain Med 2003; 28:172-197.

559. Windsor RE, Storm S, Sugar R. Prevention and management of complications resulting from common spinal injections. Pain Physician 2003; 6:473-484. 
560. Revel M, Poiraudeau S, Auleley GR, Payan C, Denke A, Nguyen M, Chevrot A, Fermanian J. Capacity of the clinical picture to characterize low back pain relieved by facet joint anesthesia. Proposed criteria to identify patients with painful facet joints. Spine 1998; 23:1972-1977.

561. Schwarzer AC, Derby R, Aprill CN, Fortin J, Kine G, Bogduk N. Pain from the lumbar zygapophysial joints: A test of two models. J Spinal Disord 1994; 7:331336.

562. Laslett M, Oberg B, Aprill CN, McDonald B. Zygapophysial joint blocks in chronic low back pain; a test of Revel's model as a screening test. BMC Musculoskelet Disord 2004; 5:43.

563. Pneumaticos SG, Chatziioannou SN, Hipp JA, Moore WH, Esses SI. Low back pain: prediction of short-term outcome of facet joint injection with bone scintigraphy. Radiology 2006; 238:693-698.

564. Young S, Aprill C, Laslett M. Correlation of clinical examination characteristics with three sources of chronic low back pain. Spine J 2003; 460-465.

565. Seffinger MA, Najm WI, Mishra SI, Adams A, Dickerson VM, Murphy LS, Reinsch S. Reliability of spinal palpation for diagnosis of back and neck pain: a systematic review of the literature. Spine 2004; 29: E413-E425.

566. Sandmark H, Nisell R. Validity of five common manual neck pain provoking tests. Scand / Rehabil Med 1995; 27:131-136.

567. Schwarzer AC, Scott AM, Wang SC, Hoschl R, Wiseman JC, Copper RA. The role of bone scintigraphy in chronic low back pain: A comparison of SPECT and planar images and zygapophysial joint injection. Aust NZJ Med 1992; 22:185.

568. Haig AJ, Tong HC, Yamakawa KS, Parres C, Quint DJ, Chiodo A, Miner JA, Phalke VC, Hoff JT, Geisser ME. Predictors of pain and function in persons with spinal stenosis, low back pain, and no back pain. Spine 2006; 31:2950-2957.

569. Laslett M, McDonald B, Aprill CN, Tropp $\mathrm{H}$, Oberg B. Clinical predictors of screening lumbar zygapophyseal joint blocks: development of clinical prediction rules. Spine J 2006; 6:370-379.

570. Petersen T, Olsen S, Laslett M, Thorsen $\mathrm{H}$, Manniche C, Ekdahl C, Jacobsen S. Inter-tester reliability of a new diagnostic classification system for patients with non-specific low back pain. Aust J Physiother 2004; 50:85-94

571. Laslett M, McDonald B, Tropp H, Aprill $\mathrm{CN}$, Oberg B. Agreement between diagnoses reached by clinical examination and available reference standards: A prospective study of 216 patients with lumbopelvic pain. BMC Musculoskelet Disord 2005; 6:28

572. Schwarzer AC, Wang SC, O'Driscoll D, Harrington T, Bogduk N, Laurent R. The ability of computed tomography to identify a painful zygapophysial joint in patients with chronic low back pain. Spine 1995; 20:907-912.

573. Binet EF, Moro JJ, Marangola JP, Hodge C). Cervical spine tomography in trauma. Spine 1977; 2:163-172.

574. Abel MS. Occult traumatic lesions of the cervical vertebrae. Critical Rev Clin Ra diol Nuclear Med 1975; 6:469-553.

575. Woodring JH, Goldstein SJ. Fractures of the articular processes of the cervical spine. Am J Roentgenol 1982; 139:341344.

576. Kim KYA, Wang MY. Magnetic resonance image-based morphological predictors of single photon emission computed tomography-positive facet arthropathy in patients with axial back pain. Neurosurgery 2006; 59:147-155.

577. Houseni M, Chamroonrat W, Zhuang $\mathrm{H}$, Alavi A. Facet joint arthropathy demonstrated on FDG-PET. Clin Nucl Med 2006; 31:418-419.

578. Schwarzer AC, Aprill CN, Derby R, Fortin J, Kine G, Bogduk N. The false-positive rate of uncontrolled diagnostic blocks of the lumbar zygapophysial joints. Pain 1994; 58:195-200.

579. Barnsley L, Lord S, Wallis B, Bogduk $N$. False-positive rates of cervical zygapophysial joint blocks. Clin J Pain 1993; 9:124-130.

580. Manchikanti L, Singh V, Pampati V. Are diagnostic lumbar medial branch blocks valid? Results of 2-year follow up. Pain Physician 2003; 6:147-153.

581. Manchikanti L, Damron KS, Rivera J, McManus C, Jackson S, Barnhill R, Martin J. Evaluation of effect of sedation as a confounding factor in the diagnostic validity of lumbar facet joint pain: A prospective, randomized, double-blind, placebo-controlled evaluation. Pain Physician 2004; 7:411-417.

582. Manchikanti L, Pampati V, Damron KS, McManus C, Jackson S, Barnhill R, Martin J. A randomized, prospective, double-blind, placebo-controlled evaluation of the effect of sedation on diagnostic validity of cervical facet joint pain. Pain Physician 2004; 7:301-310.

583. Manchikanti L, Pampati V, Damron KS, McManus CD, Jackson SD, Barnhill RC, Martin JC. The effect of sedation on diagnostic validity of facet joint nerve blocks: An evaluation to assess similarities in population with involvement in cervical and lumbar regions. Pain Physician 2006; 9:47-52.

584. Manchikanti L, Pampati V, Fellows B, Rivera J, Damron K, Beyer C, Cash K. Influence of psychological factors on the ability of diagnose chronic low back pain of facet joint origin. Pain Physician 2001; 4:349-357.

585. Manchikanti L, Singh V, Fellows B, Pampati $V$. Evaluation of influence of gender, occupational injury, and smoking on chronic low back pain of facet joint origin: A subgroup analysis. Pain Physician 2002; 5:30-35.

586. Manchikanti L, Pampati V, Rivera J, Fellows B, Beyer C, Damron K. Role of facet joints in chronic low back pain in the elderly: A controlled comparative prevalence study. Pain Practice 2001; 1:332337.

587. Bogduk N, Holmes S. Controlled zygapophysial joint blocks: The travesty of cost-effectiveness. Pain Med 2000; 1:24-34.

588. Manchikanti L, Singh V. An algorithmic approach to diagnosis and management of low back pain. In Manchikanti L, Slipman CW, Fellows B (eds), Interventional Pain Management: Low Back Pain - Diagnosis and Treatment. ASIPP Publishing, Paducah, KY 2002, 597604.

589. Manchikanti L, Rivera JJ, Pampati V, Beyer C, Damron K, Barnhill R. Effectiveness of clinical guidelines in interventional pain management. Pain Physician 2002; 5:127-132.

590. Heckmann JG, Maihofner C, Lanz S, Rauch C, Neundorfer B. Transient tetraplegia after cervical facet joint injection for chronic neck pain administered without imaging guidance. Clin Neurol Neurosurg 2006; 108:709-711.

591. Orpen NM, Birch NC. Delayed presentation of septic arthritis of a lumbar facet joint after diagnostic facet joint injection. J Spinal Disord Tech 2003; 16:285287.

592. Alcock E, Regaard A, Browne J. Facet joint injection: A rare form cause of epidural abscess formation. Pain 2003; 103:209-210.

593. Dreyfuss P, Kaplan M, Dreyer SJ. Zygapophyseal joint injection techniques in the spinal axis. In Lennard T (ed.) Pain Procedures in Clinical Practice, 2nd ed. Hanley \& Belfus, Inc., Philadelphia, 2000; pp 276-308.

594. Falagas ME, Bliziotis IA, Mavrogenis AF, Papagelopoulos PJ. Spondylodiscitis after facet joint steroid injection: A case report and review of the literature. Scand J Infect Dis 2006; 38:295-299. 
595. Okada F, Takayama H, Doita M, Harada T, Yoshiya S, Kurosaka M. Lumbar facet joint infection associated with epidural and paraspinal abscess: a case report with review of the literature. J Spinal Disord Tech 2005; 18:458-461.

596. Gaul C, Neundorfer B, Winterholler M. latrogenic (para-) spinal abscesses and meningitis following injection therapy for low back pain. Pain 2005; 116:407410.

597. Willburger RE, Knorth H, Haaker R. Side effects and complications of injection therapy for degenerative spinal disorders. Z Orthop Ihre Grenzgeb 2005; 143:170-174.

598. Dizdar O, Alyamac E, Onal IK, Uzun O. Group B streptococcal facet joint arthritis: case report. Spine 2005; 30:E414E416.

599. Ogura T, Mikami Y, Hase H, Mori M, Hayashida T, Kubo T. Septic arthritis of a lumbar facet joint associated with epidural and paraspinal abscess. Orthopedics 2005; 28:173-175.

6oo. Daivajna S, Jones A, O’Malley M, Mehdian $\mathrm{H}$. Unilateral septic arthritis of a lumbar facet joint secondary to acupuncture treatment - A case report. Acupunct Med 2004; 22:152-155.

601. Manchikanti L, Cash KA, Moss TL, Pampati V. Effectiveness of protective measures in reducing risk of radiation exposure in interventional pain management: A prospective evaluation. Pain Physician 2003; 6:301-305.

602. Manchikanti L, Cash KA, Moss TL, Pampati V. Radiation exposure to the physician in interventional pain management. Pain Physician 2002; 5:385-393.

603. Manchikanti L, Cash K, Moss T, Rivera JJ, Pampati V. Risk of whole body radiation exposure and protective measures in fluoroscopically guided interventional techniques: A prospective evaluation. BMC Anesthesiol 2003; 3:2.

604. Magee M, Kannangara S, Dennien B, Lonergan R, Emmett L, van der Wall $H$. Paraspinal abscess complicating facet joint injection. Clin Nucl Med 2000; 25:71-73.

605. Uribe J, Moza K, Jimenez O, Green B, Levi AD. Delayed postoperative spinal epidural hematomas. Spine / 2003; 3:125-129.

606. Doita M, Nishida K, Miyamoto H, Yoshiya S, Kurosaka M, Nabeshima Y. Septic arthritis of bilateral lumbar facet joints: report of a case with MRI findings in the early stage. Spine 2003; 28:E198-E202.

607. Muffolerro AJ, Nader R, Westmark RM, Nauta HJ, Garges KJ, Hadjipavlou AG.
Hematogenous pyogenic facet joint infection of the subaxial cervical spine. A report of two cases and review of the literature. J Neurosurg Spine 2001; 95:135-138.

608. Zhou Y, Singh N, Abdi S, Wu J, Crawford J, Furgang F. Fluoroscopy radiation safety for spine interventional pain procedures in university teaching hospitals. Pain Physician 2005; 8:49-53.

609. Cook NJ, Hanrahan P, Song S. Paraspinal abscess following facet joint injection. Clin Rheumatol 1999; 18:52-53.

610. Coscia MF, Trammell TR. Pyogenic lumbar facet joint arthritis with intradural extension: a case report. J Spinal Disord Tech 2002; 15:526-528.

611. Abdelwahab IF, Gould ES. The role of diskography after negative postmyelography $\mathrm{CT}$ scans: retrospective review. AJNR Am J Neuroradiol 1988; 9:187-190.

612. Wood KB, Schellhas KP, Garvey TA, Aeppli D. Thoracic discography in healthy individuals. A controlled prospective study of magnetic resonance imaging and discography in asymptomatic and symptomatic individuals. Spine 1999; 24:1548-1555.

613. Walsh TR, Weinstein JN, Spratt KF, Lehmann TR, Aprill C, Sayre H. Lumbar discography in normal subjects. J Bone Joint Surg AM 1990; 72:1081-1088.

614. Maigne JY, Lapeyre E, Morvan G, Chatellier G. Pain immediately upon sitting down and relieved by standing up is often associated with radiologic lumbar instability or marked anterior loss of disc space. Spine 2003; 28:1327-1334.

615. Laslett M, Aprill CN, McDonald B, Oberg B. Clinical predictors of lumbar provocation discography: a study of clinical predictors of lumbar provocation discography. Eur Spine J 2006; 15:1473-1484.

616. Laslett M, Oberg B, Aprill CN, McDonald B. Centralization as a predictor of provocation discography results in chronic low back pain, and the influence of disability and distress on diagnostic power. Spine J 2005; 5:370-380.

617. Yrjama M, Tervonen $\mathrm{O}$, Vanharanta $\mathrm{H}$. Ultrasonic imaging of lumbar discs combined with vibration pain provocation compared with discography in the diagnosis of internal anular fissures of the lumbar spine. Spine 1996; 21:571575 .

618. Ohnmeiss DD, Guyer RD, Mason SL. The relation between cervical discographic pain responses and radiographic imag. es. Clin J Pain 2000; 16:1-5.

619. Adams MA, Dolan P, Hutton WC. The stages of disc degeneration as revealed by discograms. J Bone Joint Surg BR 1986; 68:36-41.

620. Yasuma T, Ohno R, Yamauchi Y. Falsenegative lumbar discograms: Correlation of discographic and histologic findings in postmortem and surgical specimens. J Bone Joint Surg AM 1988; 70:1279-1290.

621. Yu SW, Haughton VM, Sether LA, Wagner M. Comparison of MR and discography in detecting radial tears of the annulus: A post-mortem study. AJNR Am J Neuroradiol 1989; 10:1077-1081.

622. Saternus KS, Bornscheuer HH. Comparative radiologic and pathologic-anatomic studies on the value of discography in the diagnosis of acute intravertebral disk injuries in the cervical spine. Fortschr Geb Rontgenstr Nuklearmed 1983; 139:651-657.

623. Viikari-Juntura E, Raininko R, Videman T, Porkka L. Evaluation of cervical disc degeneration with ultralow field MRI and discography. An experimental study on cadavers. Spine 1989; 14:616-619.

624. Agorastides ID, Lam KS, Freeman BJ, Mulholland RC. The Adams classification for cadaveric discograms: Interand intra-observer error in the clinical setting. Eur Spine J 2002; 11:76-79.

625. Antti-Poika I, Soini J, Tallroth K, Yrjonen T, Konttinen YT. Clinical relevance of discography combined with CT scanning. A study of 100 patients. J Bone Joint Surg Br 1990; 72:480-485.

626. Jackson RP, Becker GJ, Jacobs RR, Montesano PX, Cooper BR, McManus GE. The neuroradiographic diagnosis of lumbar herniated nucleus pulposus: I. A comparison of computed tomography (CT), myelography, CT-myelography, discography, and CT-discography. Spine 1989; 14:1356-1361.

627. Gresham JL, Miller R. Evaluation of the lumbar spine by diskography and its use in selection of proper treatment of the herniated disk syndrome. Clin Orthop 1969; 67:29-41.

628. Brodsky AE, Binder WF. Lumbar discography: Its value in diagnosis and treatment of lumbar disc lesions. Spine 1979; 4:110-120.

629. Birney TJ, White JJ Jr, Berens D, Kuhn G. Comparison of MRI and discography in the diagnosis of lumbar degenerative disease. J Spin Disord 1992; 5:417-423.

630. Bernard TN Jr. Repeat lumbar spine surgery: Factors influencing outcome. Spine 1993; 18:2196-2200.

631. Southern EP, Fye MA, Panjabi MM, Patel TC, Cholewicki J. Disc degeneration: A human cadaveric study correlation 
magnetic resonance imaging and quantitative discomanometry. Spine 2000; 25:2171-2175.

632. Simmons JW, Emery SF, McMillin JN, Landa D, Kimmich SJ. Awake discography. A comparison study with magnetic resonance imaging. Spine 1991; 16: S216-S221.

633. Simmons EH, Segil CM. An evaluation of discography in the localization of symptomatic levels in discogenic disease of the spine. Clin Orthop 1975; 108:57-69.

634. Holt EP Jr. Fallacy of cervical discography. Report of 50 cases in normal subjects. JAMA 1964; 188:799-801.

635. Jackson RP, Glah JJ. Foraminal and extraforaminal lumbar disc herniation: Diagnosis and treatment. Spine 1987; 12:577-585.

636. Grubb SA, Lipscomb HJ, Guilford WB. The relative value of lumbar roentgenograms, metrizamide myelography, and discography in the assessment of patients with chronic low back syndrome. Spine 1987; 12:282-286.

637. Winter RB, Schellhas KP. Painful adult thoracic Scheuermann's disease. Diagnosis by discography and treatment by combined arthrodesis. Am J Orthop 1996; 25:783-786.

638. Wiley JJ, Macnab I, Wortzman G. Lumbar discography and its clinical applications. Can J Surg 1968; 11:280-289.

639. Sachs BL, Vanharanta H, Spivey MA, Guyer RD, Videman T, Rashbaum RF, Johnson RG, Hochschuler SH, Mooney V. Dallas discogram description: A new classification of CT/discography in lowback disorders. Spine 1987; 12:287294.

640. Lehmer SM, Dawson MH, O’Brien JP. Delayed pain response after lumbar discography. Eur Spine J 1994; 3:28-31.

641. Milette PC, Raymond J, Fontaine S. Comparison of high-resolution computed tomography with discography in the evaluation of lumbar disc herniations. Spine 1990; 15:525-533.

642. Lim CH, Jee WH, Son BC, Kim DH, Ha KY, Park CK. Discogenic lumbar pain: association with MR imaging and $\mathrm{CT}$ discography. Eur J Radiol 2005; 54:431-437.

643. Gibson MJ, Buckley J, Mawhinney R, Mulholland RC, Worthington BS. Magnetic resonance imaging and discography in the diagnosis of disc degeneration: A comparative study of 50 discs. I Bone Joint Surg BR 1986; 68:369-373.

644. Schneiderman G, Flannigan B, Kingston S, Thomas J, Dillin WH, Watkins RG. Magnetic resonance imaging in the diagnosis of disc degeneration: Corre- lation with discography. Spine 1987; 12:276-282.

645. Whitecloud TS, Seago RA. Cervical discogenic syndrome: results of operative intervention in patients with positive discography. Spine 1987; 12:313-316.

646. Horton WC, Daftari TK. Which disc as visualized by magnetic resonance imaging is actually a source of pain? A correlation between magnetic resonance imaging and discography. Spine 1992; 17: S164-S171.

647. Zucherman J, Derby R, Hsu K, Picetti G, Kaiser J, Schofferman J, Goldthwaite N, White A. Normal magnetic resonance imaging with abnormal discography. Spine 1988; 13:1355-1359.

648. Parfenchuck TA, Janssen ME. A correlation of cervical magnetic resonance imaging and discography/computed tomographic discograms. Spine 1994; 19:2819-2825.

649. Huang TS, Zucherman JF, Hsu KY, Shapiro M, Lentz D, Gartland J. Gadopentetate dimeglumine as an intradiscal contrast agent. Spine 2002; 27:839843.

650. Shin DA, Kim HI, Jung JH, Shin DG, Lee JO. Diagnostic relevance of pressurecontrolled discography. J Korean Med Sci 2006; 21:911-916.

651. Zheng Y, Liew SM, Simmons ED. Value of magnetic resonance imaging and discography in determining the level of cervical discectomy and fusion. Spine 2004; 29:2140-2146.

652. Aprill C, Bogduk N. High-intensity zone: A diagnostic sign of painful lumbar disc on magnetic resonance imaging. $\mathrm{Br} J$ Radiol 1992; 65:361-369.

653. Schellhas KP, Pollei SR, Gundry CR, Heithoff KB. Lumbar disc high-intensity zone. Correlation of magnetic resonance imaging and discography. Spine 1996; 21:79-86.

654. Saifuddin A, Braithwaite I, White J, Taylor BA, Renton P. The value of lumbar spine magnetic resonance imaging in the demonstration of anular tears. Spine 1998; 23:453-457.

655. Smith BM, Hurwitz EL, Solsberg D, Rubinstein D, Corenman DS, Dwyer AP, Kleiner J. Interobserver reliability of detecting lumbar intervertebral disc highintensity zone on magnetic resonance imaging and association of high-intensity zone with pain and anular disruption. Spine 1998; 23:2074-2080.

656. Lappalainen AK, Kääpä E, Lamminen A, Laitinen OM, Gronblad M. The diagnostic value of contrast-enhanced magnetic resonance imaging in the detection of experimentally induced anular teras in sheep. Spine 2002; 27:2806-2810.

657. Ricketson R, Simmons JW, Hauser BO. The prolapsed intervertebral disc. The high-intensity zone with discography correlation. Spine 1996; 21:2758-2762.

658. Peng B, Hou S, Wu W, Zhang C, Yang Y. The pathogenesis and clinical significance of a high-intensity zone (HIZ) of lumbar intervertebral disc on MR imaging in the patient with discogenic low back pain. Eur Spine J 2006; 15:583587.

659. Carragee EJ, Paragiodakis SJ, Khurana S. Lumbar high-intensity zone and discography in subjects without low back problems. Spine 2000; 25:2987-2992.

660. Lam KS, Carlin D, Mulholland RC. Lumbar disc high-intensity zone: The value and significance of provocative discography in the determination of the discogenic pain source. Eur Spine J 2000; 9:36-41.

661. Bogduk N. Cervical disc stimulation (provocation discography). In Practice Guidelines for Spinal Diagnostic and Treatment Procedures, 1st edition. International Spine Intervention Society, 2004, pp 95-111.

662. Bogduk N. Thoracic provocation discography. In Practice Guidelines for Spinal Diagnostic and Treatment Procedures, 1st edition. International Spine Intervention Society, 2004, pp 287-294.

663. Bogduk N. Lumbar disc stimulation (provocation discography). In Practice Guidelines for Spinal Diagnostic and Treatment Procedures, 1st edition. International Spine Intervention Society, 2004, pp 20-46.

664. Grubb SA, Kelly CK. Cervical discography: Clinical implications from 12 years of experience. Spine 2000; 25:13821389.

665. Connor PM, Darden BV II. Cervical discography complications and clinical efficacy. Spine 1993; 18:2035-2038.

666. Holt EP Jr. The question of lumbar discography. J Bone Joint Surg Am 1968; 50:720-726.

667. Simmons JW, Aprill CN, Dwyer AP, Brodsky $A E$. A reassessment of Holt's data on: "The question of lumbar discography." Clin Orthop 1988; 237:120-124.

668. Milette PC, Fontaine S, Lepanto L, Cardinal E, Breton G. Differentiating lumbar disc protrusions, disc bulges, and discs with normal contour but abnormal signal intensity: Magnetic resonance imaging with discographic correlations. Spine 1999; 24:44-53.

669. Ito M, Incorvaia KM, Yu SF, Fredrickson BE, Yuan HA, Rosenbaum AE. Predictive signs of discogenic lumbar pain on mag- 
netic resonance imaging with discography correlation. Spine 1998; 23:12521260.

670. Osti OL, Fraser RD. MRI and discography of anular tears and intervertebral disc degeneration. A prospective clinical comparison. J Bone Joint Surg BR 1992; 74:431-435.

671. Greenspan A, Amparo EG, Gorczyca DP, Montesano PX. Is there a role of discography in the era of magnetic resonance imaging? Prospective correlation and quantitative analysis of computed tomography-diskography, magnetic resonance imaging, and surgical findings. I Spinal Disord 1992; 5:26-31.

672. Buirski G, Silberstein M. The symptomatic lumbar disc in patients with lowback pain: Magnetic resonance imaging appearances in both a symptomatic and control population. Spine 1993; 18:1808-1811.

673. Gill K, Blumenthal SL. Functional results after anterior lumbar fusion at $L_{5} / S_{1}$ in patients with normal fusion at $\mathrm{L}_{5} / \mathrm{S}_{1}$ in patients with normal and abnormal MRI scans. Spine 1992; 17:940-942.

674. Carragee EJ, Tanner CM, Khurana S, Hayward C, Welsh J, Date E, Truong T, Rossi M, Hagle C. The rates of falsepositive lumbar discography in select patients without low back symptoms. Spine 2000; 25:1373-1380.

675. Carragee EJ, Chen Y, Tanner CM, Hayward C, Rossi M, Hagle C. Can discography cause long-term back symptoms in previously asymptomatic subjects? Spine 2000; 25:1803-1808.

676. Carragee EJ, Barcohana B, Alamin T, van den Haak E. Prospective controlled study of the development of lower back pain in previously asymptomatic subjects undergoing experimental discography. Spine 2004; 29:1112-1117.

677. Carragee EJ, Alamin TF, Miller J, Grafe M. Provocative discography in volunteer subjects with mild persistent low back pain. Spine / 2002; 2:25-34.

678. Carragee EJ, Chen Y, Tanner CM, Truong T, Lau E, Brito JL. Provocative discography in patients after limited lumbar discectomy: A controlled, randomized study of pain response in symptomatic and asymptomatic subjects. Spine 2000; 25:3065-3071.

679. Carragee EJ, Tanner CM, Yang B, Brito JL, Truong T. False-positive findings on lumbar discography. Reliability of subjective concordance assessment during provocative disc injection. Spine 1999; 24:2542-2547.

680. Carragee EJ, Alamin TF, Miller JL, Carra- gee JM. Discographic, MRI, and psychosocial determinants of low back pain disability and remission: a prospective study in subjects with benign persistent back pain. Spine J 2005; 5:24-35.

681. Carragee EJ, Alamin TF, Carragee JM. Low-pressure positive discography in subjects asymptomatic of significant low back pain illness. Spine 2006; 31:505-509.

682. Carragee EJ, Lincoln T, Parmar VS, Alamin T. A gold standard evaluation of the "discogenic pain" diagnosis as determined by provocative discography. Spine 2006; 31:2115-2123.

683. Carragee EJ, Paragioudakis SJ, Khurana S. 2000 Volvo Award winner in clinical studies: Lumbar high-intensity zone and discography in subjects without low back problems. Spine 2000; 25:29872992.

684. Derby R, Howard MW, Grant JM, Lettice JJ, Van Peteghem PK, Ryan DP. The ability of pressure-controlled discography to predict surgical and nonsurgical outcomes. Spine 1999; 24:364-371.

685. O'Neill C, Kurgansky M. Subgroups of positive discs on discography. Spine 2004; 29:2134-2139.

686. Derby R, Lee SH, Kim BJ, Chen Y, Aprill C, Bogduk N. Pressure-controlled lumbar discography in volunteers with low back pain symptoms. Pain Med 2005; 6:213-221.

687. Derby R, Kim BJ, Lee SH, Chen Y, Seo KS, Aprill C. Comparison of discographic findings in asymptomatic subject discs and negative discs of chronic LBP patients: Can discography distinguish asymptomatic discs among morphologically abnormal discs? Spine J 2005; 5:389-394.

688. Derby R, Kim BJ, Chen Y, Seo KS, Lee SH. The relation between annular disruption on computed tomography scan and pressure-controlled diskography. Arch Phys Med Rehabil 2005; 86:1534-1538.

689. Manchikanti L, Singh V, Pampati V, Fellows B, Beyer C, Damron K, Cash K. Provocative discography in low back pain patients with or without somatization disorder: A randomized prospective evaluation. Pain Physician 2001; 4:227239.

690. Cohen SP, Larkin T, Fant GV, Oberfoell $R$, Stojanovic M. Does needle insertion site affect diskography results? A retrospective analysis. Spine 2002; 27:22792283.

691. Colhoun E, McCall IW, Williams L, Cassar Pullicino VN. Provocation discography as a guide to planning operations on the spine. J Bone Joint Surg Br 1988;
70:267-271

692. Zeidman SM, Thompson K, Ducker TB. Complications of cervical discography: Analysis of 4400 diagnostic disc injections. Neurosurgery 1995; 37:414-417.

693. Fraser RD, Osti OL, Vernon-Roberts B. Discitis after discography. J Bone Joint Surg 1987; 69-B:26-35.

694. Lownie SP, Ferguson GG. Spinal subdural empyema complicating cervical discography. Spine 1989; 14:1415-1417.

695. Schreck RI, Manion WL, Kambin P, Sohn M. Nucleus pulposus pulmonary embolism. A case report. Spine 1997; 22:927928.

696. Laun A, Lorenz R, Agnoli NL. Complications of cervical discography. I Neurosurg Sci 1981; 25:17-20.

697. Tsuji N, Igarashi S, Koyama T. Spinal epidural abscess. No Shinkei Geka 1987; 15:1079-1085.

698. Junila J, Niinimäki T, Tervonen O. Epidural abscess after lumbar discography. Spine 1997; 22:2191-2193.

699. Weingarten TN, Hooten WM, Huntoon MA. Septic facet joint arthritis after a corticosteroid facet injection. Pain Med 2006; 7:52-56.

700. Johnson RG. Does discography injure normal discs? An analysis of repeat discograms. Spine 1989; 14:424-426.

701. Heggeness MH, Doherty BJ. Discography causes end plate deflection. Spine 1993; 18:1050-1053.

702. Reitman CA, Hipp JA, Kirking BC, Haas S, Esses SI. Posterior annular strains during discography. I Spinal Disord 2001; 14:347-352.

703. Willems PC, Jacobs W, Duinkerke ES, De Kleuver M. Lumbar discography: should we use prophylactic antibiotics? A study of 435 consecutive discograms and a systematic review of the literature. J Spinal Disord Tech 2004; 17:243247.

704. Guiboux JP, Cantor JB, Small SD, Zervos $M$, Herkowitz HN. The effect of prophylactic antibiotics on iatrogenic intervertebral disc infections. A rabbit model. Spine 1995; 20:685-688.

705. Koroglu A, Acar O, Ustun ME, Tiras B, Eser 0 . The penetration of cefoperazone and sulbactam into the lumbar intervertebral discs. J Spinal Disord 2001; 14:453-454.

706. Boswell M, Wolfe J. Intrathecal cefazolin-induced seizures following attempted discography. Pain Physician 2004; 7:103-106.

707. Steindler A. Luck JV. Differential diagnosis of pain in the low back: Allocation of the source of the pain by the procaine 
hydrochloride method. JAMA 1938; 110:106-113.

708. MacNab I. Negative disc exploration: An analysis of the causes of nerve root involvement in sixty-eight patient. J Bone Joint Surg AM 1971; 53:5891-5903.

709. Bogduk N. Lumbar medial branch blocks. In Practice Guidelines for Spinal Diagnostic and Treatment Procedures, 1st edition. International Spine Intervention Society, 2004, pp 47-65.

710. Schutz H, Lougheed WM, Wortzman G, Awerbuck BG. Intervertebral nerve-root in the investigation of chronic lumbar disc disease. Can J Surg 1973; 16:217221.

711. Krempen JF, Smith BS. Nerve root injection: A method for evaluating the etiology of sciatica. J Bone Joint Surg AM 1974; 56:1435-1444.

712. Haueisen DC, Smith BS, Myers SR, Pryce ML. The diagnostic accuracy of spinal nerve injection studies. Clin Orthop 1985; 198:179-183.

713. Dooley JF, McBroom RJ, Taguchi T, Macnab I. Nerve root infiltration in the diagnosis of radicular pain. Spine 1988; 13:79-83.

714. Stanley D, McLaren MI, Euinton HA, Getty CJ. A prospective study of nerve root infiltration in the diagnosis of sciatica: A comparison with radiculography, computed tomography, and operative findings. Spine 1990; 6:540-543.

715. Derby R, Kine G, Saal JA, Reynolds J, Goldthwaite N, White AH, Hsu K, Zucherman J. Response to steroid and duration of radicular pain as predictors of surgical outcome. Spine 1992; 17 (Suppl):176-183.

716. Castro WH, van Akkerveeken PF. Der diagn ostische Wert der selektiven lumbalen Nervenwurzelblockde. Z orthop Ihre Grenzgeb 1991; 129:374-379.

717. Kikuchi S, Hasue M, Nishiyama K. Anatomic and clinical studies of radicular symptoms. Spine 1984; 9:23-30.

718. Van Akkerveeken PF. The diagnostic value of nerve root sheath infiltration. Acta Orthop Scand 1993; 251:61-63.

719. Herron LD. Selective nerve root block in patient selection for lumbar surgery: Surgical results. J Spinal Disord 1989; 2:75-79.

720. Hoppenstein R. A new approach to the failed back syndrome. Spine 1980; 5:371-379.

721. Strobel K, Pfirrmann CW, Schmid $M$, Hodler J, Boos N, Zanetti M. Cervical nerve root blocks: indications and role of MR imaging. Radiology 2004; 233:87-92.
722. Wolff AP, Groen GJ, Crul BJ. Diagnostic lumbosacral segmental nerve blocks with local anesthetics: A prospective double-blind study on the variability and interpretation of segmental effects. Reg Anesth Pain Med 2001; 26:147155 .

723. Pfirrmann CW, Oberholzer PA, Zanetti M, Boos N, Trudell DJ, Resnick D, Hodler J. Selective nerve root blocks for the treatment of sciatica: Evaluation of injection site and effectiveness - a study with patients and cadavers. Radiology 2001; 221:704-711.

724. Slipman CW, Plastaras CT, Palmitier RA, Huston CW, Sterenfeld EB. Symptom provocation of fluoroscopically guided cervical nerve root stimulation. Are dynatomal maps identical to dermatomal maps? Spine 1998; 23:2235-2242.

725. Anderberg L, Annertz M, Brandt L, Saveland $H$. Selective diagnostic cervical nerve root block - correlation with clinical symptoms and MRI pathology. Acta Neurochir 2004; 146:559-565.

726. Nachemson A. Newest knowledge of low back pain: A critical look. Clin Orthop Rel Res 1992; 279:8-20.

727. Anderberg L, Saveland H, Annertz M. Distribution patterns of transforaminal injections in the cervical spine evaluated by multi-slice computed tomography. Eur Spine J 2006; 15:1465-1471.

728. Faraj AA, Mulholland RC. The value of nerve root infiltration for leg pain when used with a nerve stimulator. Eur Spine J 2006; 15:1495-1499.

729. Wolff AP, Groen GJ, Wilder-Smith $\mathrm{OH}$, Richardson J, van Edmond J, Crul BJ. Do diagnostic segmental nerve root blocks in chronic low back pain patients with radiation to the leg lack distinct sensory effects? A preliminary study. $\mathrm{Br} / \mathrm{An}$ aesth 2006; 96:253-258.

730. Wolff AP, Groen GJ, Wilder-Smith $\mathrm{OH}$. Influence of needle position on lumbar segmental nerve root block selectivity. Reg Anesth Pain Med 2006; 31:523530.

731. Koning HM, Koning AJ. Prolonged pain relief following selective nerve root infiltration. Pain Clinic 2003; 14:225-233.

732. White A. Injection techniques for the diagnosis and treatment of low back pain. Orthop Clin N Am 1983; 14:553-567.

733. Elias M. A rare cause of radiculopathy following transforaminal epidural steroid injection. Pain Clinic 1998; 11:159160.

734. Houten JK, Errico TJ. Paraplegia after lumbosacral nerve root block: Report of three cases. Spine J 2002; 2:70-75.
735. Tajima T, Furukawa K, Kuramochi E. Selective lumbosacral radiculography and block. Spine 1980; 1:68-77.

736. Brouwers PJ, Kottink EJ, Simon MA, Prevo RL. A cervical anterior spinal artery syndrome after diagnostic blockade of the right C6-nerve root. Pain 2001; 91:397-399.

737. Nash TP. Comment on A cervical anterior spinal artery syndrome after diagnostic blockade of the right C6-nerve root. Pain 2002; 91:217-218.

738. Stohr M, Mayer K. Nerve-root damage from local injections. Dtsch Med Wochenschr 1976; 101:1218-1220.

739. Schultz D. Risk of transforaminal epidural injections. Pain Physician 2004; 7:289-290.

740. Helm S, Jasper J, Racz G. Complications of transforaminal epidural injections. Pain Physician 2003; 6:389-390.

741. Baker R, Dreyfuss P, Mercer S, Bogduk N. Cervical transforaminal injection or corticosteroids into a radicular artery: $A$ possible mechanism for spinal cord injury. Pain 2003; 109:211-215.

742. Rozin L, Rozin R, Koehler SA, Shakir A, Ladham S, Barmada M, Dominick J, Wecht $\mathrm{CH}$. Death during transforaminal epidural steroid nerve root block ( $\left.C_{7}\right)$ due to perforation of the left vertebral artery. Am J Forensic Med Pathol 2003; 24:351-355.

743. Glaser SE, Falco F. Paraplegia following a thoracolumbar transforaminal epidural Steroid injection. Pain Physician 2005; 8:309-314.

744. Beckman WA, Mendez RJ, Paine GF, Mazzilli MA. Cerebellar herniation after cervical transforaminal epidural injection. Reg Anesth Pain Med 2006; 31:282-285.

745. Ludwig MA, Burns SP. Spinal cord infarction following cervical transforaminal epidural injection: a case report. Spine 2005; 30:E266-E268.

746. Karasek M, Bogduk N. Temporary neurologic deficit after cervical transforaminal injection of local anesthetic. Pain Med 2004; 5:202-205.

747. Huntoon MA. Anatomy of the cervical intervertebral foramina: vulnerable arteries and ischemic neurologic injuries after transforaminal epidural injections. Pain 2005; 117:104-111.

748. Hoeft MA, Rathmell JP, Monsey RD, Fonda BJ. Cervical transforaminal injection and the radicular artery: variation in anatomical location within the cervical intervertebral foramina. Reg Anesth Pain Med 2006; 31:270-274.

749. Ma DJ, Gilula LA, Riew KD. Complica- 
tions of fluoroscopically guided extraforaminal cervical nerve blocks. An analysis of 1036 injections. J Bone Joint Surg Am 2005; 87:1025-1030.

750. Derby R, Lee SH, Kim BJ, Chen Y, Seo KS. Complications following cervical epidural steroid injections by expert interventionalists in 2003. Pain Physician 2004; 7:445-449.

751. Huston CW, Slipman CW, Garvin C. Complications and side effects of cervical and lumbosacral selective nerve root injections. Arch Phys Med Rehabil 2005; 86:277-283.

752. Dietrich CL, Smith CE. Epidural granuloma and intracranial hypotension resulting from cervical epidural steroid injection. Anesthesiology 2004; 100:445447.

753. Saigal G, Donovan Post MJ, Kozic D. Thoracic intradural Aspergillus abscess formation following epidural steroid injection. AJNR Am J Neuroradiol 2004; 25:642-644.

754. Bose B. Quadriparesis following cervical epidural steroid injections: case report and review of the literature. Spine J 2005; 5:558-563.

755. Bilir A, Gulec S. Cauda equina syndrome after epidural steroid injection: A case report. I Manipulative Physiol Ther 2006; 29:492-494.

756. Tripathi M, Nath SS, Gupta RK. Paraplegia after intracord injection during attempted epidural steroid injection in an awake-patient. Anesth Analg 2005; 101:1209-1211.

757. Finn KP, Case JL. Disk entry: a complication of transforaminal epidural injection-a case report. Arch Phys Med Rehabil 2005; 86:1489-1491.

758. Hooten WM, Mizerak A, Carns PE, Huntoon MA. Discitis after lumbar epidural corticosteroid injection: a case report and analysis of the case report literature. Pain Med 2006; 7:46-51.

759. Kabbara A, Rosenberg SK, Untal C. Methicillin-resistant Staphylococcus aureus epidural abscess after transforaminal epidural steroid injection. Pain Physician 2004; 7:269-272.

760. Browning DJ. Acute retinal necrosis following epidural steroid injections. Am J Ophthalmol 2003; 36:192-194.

761. Dreyfuss P, Michaelsen M, Pauza K, McLarty J, Bogduk N. The value of medical history and physical examination in diagnosing sacroiliac joint pain. Spine 1996; 21:2594-2602.

762. Dreyfuss P, Dryer S, Griffin J, Hoffman J, Walsh N. Positive sacroiliac screening tests in asymptomatic adults. Spine
1994; 19:1138-1143.

763. Slipman CW, Sterenfeld EB, Chou LH, Herzog R, Vresilovic E. The predictive value of provocative sacroiliac joint stress maneuvers in the diagnosis of sacroiliac joint syndrome. Arch Phys Med Rehab 1998; 79:288-292.

764. Broadhurst NA, Bond MJ. Pain provocation tests for the assessment of sacroiliac joint dysfunction. J Spin Disord 1998; 11:341-345.

765. Meijne W, van Neerbos K, Aufdemkampe $G$, van der Wurff P. Intraexaminer and interexaminer reliability of the Gillet test. J Man Phys Ther 1999; 22:4-9.

766. Ebraheim NA, Mekhail AO, Wiley WF, Jackson WT, Yeasting RA. Radiology of the sacroiliac joint. Spine 1997; 22: 869-876.

767. Vogler JB 3rd, Brown WH, Helms CA, Genant HK. The normal sacroiliac joint: A CT study of asymptomatic patients. Radiology 1984; 151:433-437.

768. Resnik CS, Resnick D. Radiology of disorders of the sacroiliac joints. JAMA $1985 ; 253: 2863-2866$.

769. Slipman CW, Sterenfeld EB, Chou LH, Herzog R, Vresilovic E. The value of radionuclide imaging in the diagnosis of sacroiliac joint syndrome. Spine 1996; 21:2251-2254.

770. Maigne JY, Boulahdour H, Charellier G. Value of quantitative radionuclide bone scanning in the diagnosis of sacroiliac joint syndrome in 32 patients with low back pain. Eur Spine J 1998; 7:328-331.

771. Goldberg RP, Genant HK, Shimshak R, Shames D. Applications and limitations of quantitative sacroiliac joint scintigraphy. Radiology 1978; 128:683-686.

772. Lantto T. The scintigraphy of sacroiliac joints: A comparison of 99-mTc-VPB and 99mTc-MDP. Eur J Nucl Med 1990; 16:677-681.

773. Lentle BC, Russell AS, Percy JS, Jackson Fl. The scintigraphic investigation of sacroiliac disease. J Nucl Med 1977; 6:529-533.

774. Verlooy H, Mortelmans L, Vleugels S, De Roo M. Quantitative scintigraphy of the sacroiliac joints. Clin Imaging 1992; 16:230-233.

775. Hanly JG, Mitchell MJ, Barnes DC, MacMillan L. Early recognition of sacroiliitis by magnetic resonance imaging and single photon emission computed tomog raphy. J Rheum 1994; 21:2088-2095.

776. Bredella MA, Steinbach LS, Morgan S, Ward M, Davis JC. MRI of the sacroiliac joints in patients with moderate to severe ankylosing spondylitis. $A J R A m$ J Roentgenol 2006; 187:1420-1426.
777. Laslett M, Young SB, Aprill CN, McDonald B. Diagnosing painful sacroiliac joints: A validity study of a McKenzie evaluation and sacroiliac provocation tests. Aust / Physiother 2003; 49:8997.

778. Laslett M, Aprill CN, McDonald B, Young SB. Diagnosis of sacroiliac joint pain: validity of individual provocation tests and composites of tests. Man Ther 2005; 10:207-218.

779. Kokmeyer DJ, van der Wurff P, Aufdemkampe G, Fickenscher TC. The reliability of multitest regimens with sacroiliac pain provocation tests. I Manipulative Physiol Ther 2002; 25:42-48.

780. Levin U, Stenstrom CH. Force and time recording for validating the sacroiliac distraction test. Clin Biomech 2003; 18:821-826.

781. van der Wurff P, Buijs EJ, Groen GJ. Intensity mapping of pain referral areas in sacroiliac joint pain patients. J Manipulative Physiol Ther 2006; 29:190-195.

782. van der Wurff P, Meyne W, Hagmeijer $\mathrm{RH}$. Clinical tests of the sacroiliac joint. Man Ther 2000; 5:89-96.

783. van der Wurff P, Buijs EJ, Groen GJ. A multitest regimen of pain provocation tests as an aid to reduce unnecessarily minimally invasive sacroilac joint procedures. Arch Phys Med Rehabil 2006; 87:10-14.

784. McGrath MC. Palpation of the sacroiliac joint: An anatomical and sensory challenge. Int J Osteopath Med 2006; 9:103107.

785. Berthelot JM, Labat JJ, Le Goff B, Gouin F, Maugars Y. Provocative sacroiliac joint maneuvers and sacroiliac joint block are unreliable for diagnosing sacroiliac joint pain. Joint Bone Spine 2006; 73:17-23.

786. Malanga GA, Nadler SF. Physical examination of the sacroiliac joint. In Musculoskeletal Physical Examination: An Evidence-Based Approach. Elsevier, Philadelphia, 2006; pp 227-250.

787. Simpson R, Gemmell H. Accuracy of spinal orthopaedic tests: A systematic review. Chiropr Osteopat 2006; 14:26.

788. Rosenberg JM, Quint TJ, de Rosayro AM. Computerized tomographic localization of clinically-guided sacroiliac joint injections. Clin J Pain 2000; 16:18-21.

789. Hansen H. Is fluoroscopy necessary for sacroiliac joint injections? Pain Physician 2003; 6:155-158.

790. Fortin J, Tolchin R. Sacroiliac arthrograms and post-arthrography computerized tomography. Pain Physician 2003; 6:287-290. 
791. Fortin JD, Vilensky JA, Merkel GF. Can the sacroiliac joint cause sciatica? Pain Physician 2003; 6:269-271.

792. Weinstein JN, Tosteson TD, Lurie JD, Tosteson AN, Hanscom B, Skinner JS, Abdu WA, Hilibrand AS, Boden SD, Deyo RA. Surgical vs nonoperative treatment for lumbar disk herniation: the Spine Patient Outcomes Research Trial (SPORT): A randomized trial. JAMA 2006; 296:2441-2450.

793. Weinstein JN, Tosteson TD, Lurie JD, Tosteson AN, Hanscom B, Skinner JS, Abdu WA, Hilibrand AS, Boden SD, Deyo RA. Surgical and nonsurgical management of sciatica secondary to a lumbar disc herniation: 10 year results from the maine lumbar spine study. Spine 2005; 30:927-935.

794. Carragee E. Surgical treatment of lumbar disk disorders. JAMA 2006; 296:24852487.

795. Weinstein JN, Lurie JD, Tosteson TD, Skinner JS, Hanscom B, Tosteson AN, Herkowitz H, Fischgrund J, Cammisa FP, Albert T, Deyo RA. Surgical vs nonoperative treatment for lumbar disk herniation: the Spine Patient Outcomes Research Trial (SPORT) observational cohort. JAMA 2006; 296:2451-2459.

796. Boden SD, McCowin PR, Davis DO, Dina TS, Wiesel S. Abnormal magnetic-resonance scans of the cervical spine in asymptomatic subjects. A prospective investigation. J Bone Joint Surg Am 1990; 72:1178-1184.

797. Boden SD, Davis DO, Dina TS, Patronas NJ, Wiesel SW. Abnormal magnetic-resonance scans of the lumbar spine in asymptomatic subjects. A prospective investigation. J Bone Joint Surg Am 1990; 72:403-408.

798. Borenstein DG, O’Mara JW Jr., Boden SD, Lauerman WC, Jacobson A, Platenberg C, Schellinger D, Wiesel SW. The value of magnetic resonance imaging of the lumbar spine to predict low-back pain in asymptomatic subjects: A seven-year follow-up study. J Bone Joint Surg Am 2001; 83-A:1306-1311.

799. Wood KB, Garvey TA, Gundry C, Heithoff $K B$. Magnetic resonance imaging of the thoracic spine. Evaluation of asymptomatic individuals. J Bone Joint Surg Am 1995; 77:1631-1638.

80o. Matsumoto M, Fujimura Y, Suzuki N, Nishi Y, Nakamura M, Yabe Y, Shiga H. MRI of cervical intervertebral discs in asymptomatic subjects. J Bone Joint Surg Br 1998; 80:19-24.

801. Jensen MC, Brant-Zawadzki MN, Obuchowski N, Modic MT, Malkasian D,
Ross JS. Magnetic resonance imaging of the lumbar spine in people without back pain. N Engl J Med 1994; 331:6973.

802. Magora A, Bigos SJ, Stolov WC, Tomsli MA, Magora F, Vatine JJ. The significance of medical imaging findings in low back pain. Pain Clinic 1994; 7:99-105.

803. Murtagh FR. Computed tomography and fluoroscopy guided anesthesia and steroid injection in facet syndrome. Spine 1988; 13:686-689.

804. Videman T, Battie MC, Gibbons LE, Maravilla K, Manninen H, Kaprio J. Associations between back pain history and lumbar MRI findings. Spine 2003; 28:582-588.

805. Kleinstuck F, Dvorak J, Mannion AF. Are "structural abnormalities" on magnetic resonance imaging a contraindication to the successful conservative treatment of chronic nonspecific low back pain? Spine 2006; 31:2250-2257.

806. Haig AJ, Tong HC, Yamakawa KS, Quint DJ, Hoff JT, Chiodo A, Miner JA, Choksi VR, Geisser ME, Parres CM. Spinal stenosis, back pain, or no symptoms at all? A masked study comparing radiologic and electrodiagnostic diagnoses to the clinical impression. Arch Phys Med Re habil 2006; 87:897-903.

807. Kwan 0, Friel J. Critical appraisal of facet joints injections for chronic whiplash. Med Sci Monit 2002; 8:RA191-195.

808. Yang SC, Yang PH. Significance of the bright facet sign on T2W MRI of the lum bar facet joint. Mid-Taiwan J Med 2005; 10:150-154.

809. Manchikanti L, Pampati V, Singh V, Beyer C, Damron K, Fellows B. Evaluation of role of facet joints in persistent low back pain in obesity: A controlled, perspective, comparative evaluation. Pain Physician 2001; 4:266-272.

810. Kim TK, Kim KH, Kim CH, Shin SW, Kwon JY, Kim HK, Baik SW. Percutaneous vertebroplasty and facet joint block. J Korean Med Sci 2005; 20:1023-1028.

811. Ackerman WE, Munir MA, Zhang JM, Ghaleb A. Are diagnostic lumbar facet injections influenced by pain of muscular origin? Pain Pract 2004; 4:286-291.

812. Bogduk N. Diagnosing lumbar zygapophysial joint pain. Pain Med 2005; 6:139-142.

813. Yamashita T, Cavanaugh JM, el-Bohy AA, Getchell TV, King Al. Mechanosensitive afferent units in the lumbar facet joint. $J$ Bone Joint Surg Am 1990; 72:865-870.

814. Özaktay AC, Yamashita T, Cavanaugh JM, King Al. Fine nerve fibers and endings in the fibrous capsule of the lum- bar facet joint. Trans Orthop Res Soc 1991; 16:353.

815. Bogduk N, Marsland A. The cervical zygapophysial joints as a source of neck pain. Spine 1988; 13:610-617.

816. Revel ME, Listrat VM, Chevalier XJ, Dougados M, N'guyen MP, Vallee C, Wybier M, Gires F, Amor B. Facet joint block for low back pain: Identifying predictors of a good response. Arch Phys Med Rehabil 1992; 73:824-829

817. Bogduk N. Management of chronic low back pain. Med J Aust 2004; 180:79-83.

818. Bogduk N. Diagnostic nerve blocks in chronic pain. Best Pract Res Clin Anaesthesiol 2002; 16:565-578.

819. Dreyfuss P, Dreyer SJ, NASS. Lumbar zygapophysial (facet) joint injections. Spine J 2003; 3:50S-59S.

820. Dreyfuss PH, Dreyer SJ, Herring SA. Lumbar zygapophysial (facet) joint injections. Spine 1995; 20:2040-2047.

821. Jackson RP. The facet syndrome: Myth or reality? Clin Orthop 1992; 279:110121.

822. Jackson RP, Jacobs RR, Montesano PX. Facet joint injection in low back pain. A prospective statistical study. Spine 1988; 13:966-971.

823. Bogduk N. A narrative review of intraarticular corticosteroid injections for low back pain. Pain Med 2005; 6:287296.

824. Bogduk N. Diagnostic blocks: A truth serum for malingering. Clin J Pain 2004; 20:409-414.

825. Hooten WM, Martin DP, Huntoon MA. Radiofrequency neurotomy for low back pain: evidence-based procedural guidelines. Pain Med 2005; 6:129-138.

826. Carette S, Marcoux S, Truchon R, Grondin C, Gagnon J, Allard Y, Latulippe M. A controlled trial of corticosteroid injections into facet joints for chronic low back pain. N Engl J Med 1991; 325:10021007.

827. Barnsley L, Lord SM, Wallis BJ, Bogduk N. Lack of effect of intra-articular corticosteroids for chronic pain in the cervical zygapophyseal joints. $N$ Engl I Med 1994; 330:1047-1050.

828. Marks RC, Houston T, Thulbourne T. Facet joint injection and facet nerve block. A randomized comparison in 86 patients with chronic low back pain. Pain 1992; 49:325-328.

829. Nash TP. Facet joints. Intra-articular steroids or nerve blocks? Pain Clinic 1990; 3:77-82.

830. Lilius G, Laasonen EM, Myllynen P, Harilainen A, Gronlund G. Lumbar facet 
joint syndrome. A randomized clinical trial. J Bone Joint Surg Br 1989; 71:681684 .

831. Fuchs S, Erbe T, Fischer HL, Tibesku CO. Intraarticular hyaluronic acid versus glucocorticoid injections for nonradicular pain in the lumbar spine. J Vasc Interv Radiol 2005; 16:1493-1498.

832. Shih C, Lin GY, Yueh KC, Lin JJ. Lumbar zygapophyseal joint injections in patients with chronic lower back pain. J Chin Med Assoc 2005; 68:59-64.

833. Gorbach C, Schmid MR, Elfering A, Hodler J, Boos N. Therapeutic efficacy of facet joint blocks. AJR Am J Roentgenol 2006; 186:1228-1233.

834. Schulte TL, Pietila TA, Heidenreich J, Brock M, Stendel R. Injection therapy of lumbar facet syndrome: A prospective study. Acta Neurochir (Wien) 2006; 148:1165-1172.

835. Kim KH, Choi SH, Kim TK, Shin SW, Kim $\mathrm{CH}$, Kim JI. Cervical facet joint injections in the neck and shoulder pain. J Korean Med Sci 2005; 20:659-662.

836. Folman Y, Livshitz A, Shabat S, Gepstein R. Relief of chronic cervical pain after selective blockade of zygapophyseal joint. Harefuah 2004; 143:339-341, 391.

837. Destouet JM, Gilula LA, Murphy WA, Monsees B. Lumbar facet joint injection: Indication, technique, clinical correlation, and preliminary results. Radiology 1982; 145:321-325.

838. Lynch MC, Taylor JF. Facet joint injection for low back pain. A clinical study. J Bone Joint Surg Br 1986; 68:138-141.

839. Lippitt AB. The facet joint and its role in spine pain. Management with facet joint injections. Spine 1984; 9:746-750.

840. Lau LS, Littlejohn GO, Miller MH. Clinical evaluation of intra-articular injections for lumbar facet joint pain. Med J Aust 1985; 143:563-565.

841. Manchikanti L, Pampati V, Bakhit C, Rivera J, Beyer C, Damron K, Barnhill R. Effectiveness of lumbar facet joint nerve blocks in chronic low back pain: A randomized clinical trial. Pain Physician 2001; 4: 101-117.

842. Manchikanti KN, Pampati V, Damron KS, McManus C. A double-blind, controlled evaluation of the value of Sarapin in neural blockade. Pain Physician 2004; 7:59-62.

843. Manchikanti L, Damron KS, Cash KA, Manchukonda R, Pampati V. Therapeutic medial branch blocks in managing chronic neck pain: A preliminary report of a randomized, double-blind, controlled trial: Clinical Trial NCTo033272. Pain Physician 2006; 9:333-346.
844. Manchikanti L, Damron KS, Cash KA, Manchukonda R, Pampati V. Evaluation of lumbar facet joint nerve blocks in the management of chronic low back pain: a preliminary report of a randomized, double-blind controlled trial. Clinical Trial NCTo0355914. 2007; in press.

845. Manchikanti L, Manchikanti KN, Damron KS, Pampati V. Effectiveness of cervical medial branch blocks in chronic neck pain: A prospective outcome study. Pain Physician 2004; 7:195-202.

846. Manchikanti L, Manchikanti KN, Manchukonda R, Pampati V, Cash KA. Evaluation of therapeutic thoracic medial branch block effectiveness in chronic thoracic pain: A prospective outcome study with minimum 1-year follow up. Pain Physician 2006; 9:97-105.

847. Lord SM, Barnsley L, Wallis BJ, McDonald GJ, Bogduk N. Percutaneous radiofrequency neurotomy for chronic cervical zygapophyseal joint pain. $N$ Engl J Med 1996; 335:1721-1726.

848. van Kleef M, Barendse GA, Kessels A, Voets HM, Weber WE, de Lange S. Randomized trial of radiofrequency lumbar facet denervation for chronic low back pain. Spine 1999; 24:1937-1942.

849. Gallagher J, Vadi PLP, Wesley JR. Radiofrequency facet joint denervation in the treatment of low back pain - A prospective controlled double-blind study to assess efficacy. Pain Clinic 1994; 7:193198.

850. Sanders M, Zuurmond WWA. Percutaneous intraarticular lumbar facet joint denervation in the treatment of low back pain: A comparison with percutaneous extra-articular lumbar facet denervation. Pain Clinic 1999; 11:329-335.

851. Leclaire R, Fortin L, Lambert R, Bergeron YM, Rossignol M. Radiofrequency facet joint denervation in the treatment of low back pain: a placebo-controlled clinical trial to assess efficacy. Spine 2001; 26:1411-1416.

852. Buijs EJ, van Wijk RM, Geurts JW, Weeseman RR, Stolker RJ, Groen GG. Radiofrequency lumbar facet denervation: a comparative study of the reproducibility of lesion size after 2 current radiofrequency techniques. Reg Anesth Pain Med 2004; 9:400-407.

853. Haspeslagh SR, Van Suijlekom HA, Lame IE, Kessels AG, van Kleef M, Weber WE. Randomised controlled trial of cervical radiofrequency lesions as a treatment for cervicogenic headache [ISRCTNo7444684]. BMC Anesthesiol 2006; 6:1.

854. Van Wijk RM, Geurts JW, Wynne HJ, Hammink E, Buskens E, Lousberg R,
Knape JT, Groen GJ. Radiofrequency denervation of lumbar facet joints in the treatment of chronic low back pain: a randomized, double-blind, sham lesion-controlled trial. Clin J Pain 2005; 21:335-344.

855. Barnsley L. Percutaneous radiofrequency neurotomy for chronic neck pain: outcomes in a series of consecutive patients. Pain Med 2005; 6:282-286.

856. Shin WR, Kim HI, Shin DG, Shin DA. Radiofrequency neurotomy of cervical medial branches for chronic cervicobrachialgia. J Korean Med Sci 2006; 21:119-125.

857. Birkenmaier C, Veihelmann A, Trouillier H, Hausdorf J, Devens C, Wegener $B$, Jansson V, von Schulze Pellengahr C. Percutaneous cryodenervation of lumbar facet joints: a prospective clinical trial. Int Orthop 2006; Aug 23. [Epub ahead of print].

858. Staender M, Maerz U, Tonn JC, Steude U. Computerized tomography-guided kryorhizotomy in 76 patients with lumbar facet joint syndrome. I Neurosurg Spine 2005; 3:444-449.

859. Mogalles AA, Dreval' ON, Akatov OV, Kuznetsov AV, Rynkov IP, Plotnikov VM, Minaev VP. Percutaneous laser denervation of the zygapophyseal joints in the pain facet syndrome. Zh Vopr Neirokhir Im N N Burdenko 2004; 1:20-25.

860. Martinez-Suarez JE, Camblor L, Salva $\mathrm{S}$, De Jongh WA. Thermocoagulation of lumbar facet joints. Experience in 252 patients. Revista de la Sociedad Espanola del Dolor 2005; 12:425-428.

861. Sapir D, Gorup JM. Radiofrequency medial branch neurotomy in litigant and nonlitigant patients with cervical whiplash. Spine 2001; 26:E268-E273.

862. McDonald GJ, Lord SM, Bogduk N. Longterm follow-up of patients treated with cervical radiofrequency neurotomy for chronic neck pain. Neurosurgery 1999; 45:61-68.

863. Tzaan WC, Tasker RR. Percutaneous radiofrequency facet rhizotomy - experience with 118 procedures and reappraisal of its value. Can J Neurol Sci 2000; 27:125-130.

864. Schaerer JP. Radiofrequency facet rhizotomy in the treatment of chronic neck and low back pain. Int Surg 1978; 63:5359.

865. Dreyfuss P, Halbrook B, Pauza K, Joshi A, McLarty J, Bogduk N. Efficacy and validity of radiofrequency neurotomy for chronic lumbar zygapophysial joint pain. Spine 2000; 25:1270-1277.

866. Schofferman J, Kine G. Effectiveness of repeated radiofrequency neurotomy for 
lumbar facet pain. Spine 2004; 29:24712473.

867. Vad V, Cano W, Basrai D, Lutz G, Bhat A. Role of radiofrequency denervation in lumbar zygapophyseal joint synovitis in baseball pitchers: A clinical experience. Pain Physician 2003; 6:307-312.

868. North RB, Han M, Zahurak M, Kidd DH. Radiofrequency lumbar facet denervation: analysis of prognostic factors. Pain 1994; 57:77-83.

869. Stolker RJ, Vervest AC, Groen GJ. Percutaneous facet denervation in chronic thoracic spinal pain. Acta Neurochir (Wien) 1993; 122:82-90.

870. Mikeladze G, Espinal R, Finnegan R, Routon J, Martin D. Pulsed radiofrequency application in treatment of chronic zygapophyseal joint pain. Spine J 2003; 3:360-362.

871. Lindner R, Sluijter ME, Schleinzer W. Pulsed radiofrequency treatment of the lumbar medial branch for facet pain: a retrospective analysis. Pain Med 2006; 7:435-439.

872. Jerosch J. Facet syndrome. 2. Percutaneous facet coagulation. Chirurgische Praxis 2005; 65:43-55.

873. Bogduk N. Lumbar radiofrequency neurotomy. Clin J Pain 2006; 22:409.

874. Gofeld M. Radiofrequency facet denervation: a randomized control placebo versus sham procedure. Clin J Pain 2006; 22:410-411.

875. van Kleef M, Weber WE, Kessels A, Dreyfuss P, Pauza K, Bogduk N. Re: Efficacy and validity of radiofrequency neurotomy for chroniclumbar zygapophysial joint pain (Spine 2000; 25:1270-1277). Spine 2001; 26:E163-E164.

876. Dreyfuss P, Baker R, Leclaire R, Fortin L, Lambert R, Bergeron Y, Rossignol M. Radiofrequency facet joint denervation in the treatment of low back pain: a placebo-controlled clinical trial to assess efficacy. Spine 2002; 27:556-567.

877 . Bogduk N. Percutaneous radiofrequency cervical medial branch neurotomy. In Practice Guidelines for Spinal Diagnostic and Treatment Procedures, 1st edition, International Spine Intervention Society, 2004, pp 249-284.

878. Smith M, Ferretti G, Mortazavi S. Radiographic changes induced after cervical facet radiofrequency denervation. Spine J 2005; 5:668-671.

879. Manchikanti L. Role of neuraxial steroids in interventional pain management. Pain Physician 2002; 5:182-199.

880. Kornick CA, Kramarich SS, Sitzman BT, Marshall KA, Santiago-Palma J, Lamer TJ. Complication rate associated with facet joint radiofrequency denervation procedures. Pain Med 2002; 3:175-176.

881. Kornick CA, Kramarich SS, Lamer TJ, Sitzman BT. Complications of lumbar facet radiofrequency denervation. Spine 2004; 29:1352-1354.

882. Manchikanti L, Pampati V, Beyer C, Damron KS, Cash KA, Moss TL. The effect of neuraxial steroids on weight and bone mass density: A prospective evaluation. Pain Physician 2000; 3:357-366.

883. Thomson SJ, Lomax DM, Collett BJ. Chemical meningism after lumbar facet joint nerve block with local anesthetic and steroids. Anesthesia 1993; 46:563564 .

884. Nelson DA, Landau WM. Intraspinal steroids: History, efficacy, accidentality, and controversy with review of United States Food and Drug Administration reports. J Neurol Neurosurg Psychiatry 2001; 70:433-443.

885. Berrigan T. Chemical meningism after lumbar facet joint block. Anesthesia 1992; 7:905-906.

886. Bogduk N, Christophidis N, Cherry D. Epidural use of steroids in the management of back pain. Report of working party on epidural use of steroids in the management of back pain. National Health and Medical Research Council. Canberra, Commonwealth of Australia, 1994; pp 1-76.

887. Rozenberg S. Glucocorticoid therapy in common lumbar spinal disorders. Rev Rhum Engl Ed 1998; 65:649-655.

888. Watts RW, Silagy CA. A meta-analysis on the efficacy of epidural corticosteroids in the treatment of sciatica. Anaesth In tensive Care 1995; 23:564-569.

889. Dashfield AK, Taylor MB, Cleaver JS, Farrow D. Comparison of caudal steroid epidural with targeted steroid placement during spinal endoscopy for chronic sciatica: a prospective, randomized, double-blind trial. $\mathrm{Br} /$ Anaesth 2005; 94:514-519.

890. Anwar A, Zaidah I, Rozita R. Prospective randomized single blind study of epidural steroid injection comparing triamcinalone acetonide with methylprednisolone acetate. APLAR / Rheumatology 2005; 8:1-53.

891. McGregor AH, Anjarwalla NK, Stambach T. Does the method of injection alter the outcome of epidural injections? J Spinal Disord 2001; 14:507-510.

892. Revel M, Auleley GR, Alaoui S, Nguyen M, Duruoz T, Eck-Michaud S, Roux C, Amor B. Forceful epidural injections for the treatment of lumbosciatic pain with post-operative lumbar spinal fibrosis. Rev Rhum Engl Ed 1996; 63:270-277.
893. Meadeb J, Rozenberg S, Duquesnoy B, Kuntz JL, Le Loet X, Sebert JL, Le Goff P, Fallut M, Marty M, Blevin S, Guggenbuhl P, Chales G, Duvauferrier R. Forceful sacrococcygeal injections in the treatment of postdiscectomy sciatica. A controlled study versus glucocorticoid injections. Joint Bone Spine 2001; 68:43-49.

894. Breivik H, Hesla PE, Molnar I, Lind B. Treatment of chronic low back pain and sciatica. Comparison of caudal epidural injections of bupivacaine and methylprednisolone with bupivacaine followed by saline. In Bonica JJ, Albe-Fesard D (eds). Advances in Pain Research and Therapy. Raven Press, New York, 1976; pp 927-932.

895. Bush K, Hillier S. A controlled study of caudal epidural injections of triamcinolone plus procaine for the management of intractable sciatica. Spine 1991; 16:572-575.

896. Mathews JA, Mills SB, Jenkins VM, Grimes SM, Morkel MJ, Mathews W, Scott CM, Sittampalam Y. Back pain and sciatica: Controlled trials of manipulation, traction, sclerosant and epidural injections. Brit J Rheumatol 1987; 26:416-423.

897. Beliveau P. A comparison between epidural anesthesia with and without corticosteroids in the treatment of sciatica. Rheum Phys Med 1971; 11:40-43.

898. Czarski Z. Leczenie rwy kulszowej wstrzykiwaniem hydrokortyzonu inowokainy do rozworu kryzowego. Przeglad Kekarski 1965; 21:511-513.

899. Hesla PE, Breivik H. Epidural analgesia and epidural steroid injection for treatment of chronic low back pain and sciatica. Tidsskr Nor Laegeforen 1979; 99:936-939.

900. Manchikanti L, Pampati V, Rivera JJ, Beyer C, Damron K, Barnhill R. Caudal epidural injections with Sarapin or steroids in chronic low back pain. Pain Physician 2001; 4:322-335.

901. Manchikanti L, Singh V, Rivera J, Pampati V, Beyer C, Damron K, Barnhill R. Effectiveness of caudal epidural injections in discogram positive and negative chronic low back pain. Pain Physician 2002; 5:18-29.

902. Yates DW. A comparison of the types of epidural injection commonly used in the treatment of low back pain and sciatica. Rheum Rehab 1978; 17:181-186.

903. Waldman SD. The caudal epidural administration of steroids in combination with local anesthetics in the palliation of pain secondary to radiographically documented lumbar herniated disc: A prospective outcome study with 
6-months follow-up. Pain Clinic 1998; 11:43-49.

904. Ciocon JO, Galindo-Ciocon D, Amaranath L, Galindo D. Caudal epidural blocks for elderly patients with lumbar canal stenosis. J Am Geriatr Soc 1994; 42:593-596.

905. Manchikanti L, Pakanati RR, Pampati V. Comparison of three routes of epidural steroid injections in low back pain. Pain Digest 1999; 9:277-285.

906. Barre L, Lutz GE, Southern D, Cooper G. Fluoroscopically guided caudal epidural steroid injections for lumbar spinal stenosis: A retrospective evaluation of long-term efficacy. Pain Physician 2004; 7:187-193.

907. Banaszkiewicz PA, Kader D, Wardlaw D. The role of caudal epidural injections in the management of low back pain. Bull Hosp Jt Dis 2003; 61:127-131.

908. Bronfort G, Evans RL, Maiers M, Anderson AV. Spinal manipulation, epidural injections, and self-care for sciatica: a pilot study for a randomized clinical trial. J Manipulative Physiol Ther 2004; 278:503-508.

909. Wilson-MacDonald J, Burt G, Griffin D, Glynn C. Epidural steroid injection for nerve root compression. A randomised, controlled trial. J Bone Joint Surg $\mathrm{Br}$ 2005; 87:352-355.

910. Arden NK, Price C, Reading I, Stubbing J, Hazelgrove J, Dunne C, Michel M, Rogers P, Cooper C, WEST Study Group. A multicentre randomized controlled trial of epidural corticosteroid injections for sciatica: the WEST study. Rheumatology (Oxford) 2005; 44:1399-1406.

911. Price C, Arden N, Coglan L, Rogers P. Cost-effectiveness and safety of epidural steroids in the management of sciatica. Health Technol Assess 2005; 9:1-58, iii.

912. Pirbudak L, Karakurum G, Oner U, Gulec A, Karadasli H. Epidural corticosteroid injection and amitriptyline for the treatment of chronic low back pain associated with radiculopathy. Pain Clinic 2003; 15:247-253.

913. Carette S, Leclaire R, Marcoux S, Morin F, Blaise GA, St-Pierre A, Truchon R, Parent $F$, Levesque J, Bergeron V, Montminy P, Blanchette C. Epidural corticosteroid injections for sciatica due to herniated nucleus pulposus. N Engl J Med 1997; 336:1634-1640.

914. Snoek W, Weber H, Jorgensen B. Double-blind evaluation of extradural methylprednisolone for herniated lumbar disc. Acta Orthop Scand 1977; 48:635641.

915. Cuckler JM, Bernini PA, Wiesel SW,
Booth RE Jr, Rothman RH, Pickens GT. The use of epidural steroid in the treatment of radicular pain. J Bone Joint Surg AM 1985; 67:63-66.

916. Dilke TFW, Burry HC, Grahame R. Extradural corticosteroid injection in the management of lumbar nerve root compression. Br Med J 1973; 2:635-637.

917. Serrao JM, Marks RL, Morley SJ, Goodchild CS. Intrathecal midazolam for the treatment of chronic mechanical low back pain: A controlled comparison with epidural steroid in a pilot study. Pain 1992; 48:5-12.

918. Klenerman L, Greenwood R, Davenport HT, White DC, Peskett S. Lumbar epidural injections in the treatment of sciatica. BrJ Rheumatol 1984; 23:35-38.

919. Rocco AG, Frank E, Kaul AF, Lipson SJ, Gallo JP. Epidural steroids, epidural morphine and epidural steroids combined with morphine in the treatment of postlaminectomy syndrome. Pain 1989; 36:297-303.

920. Ridley MG, Kingsley GH, Gibson T, Grahame R. Outpatient lumbar epidural corticosteroid injection in the management of sciatica. Br J Rheumatol 1988; 27:295-299.

921. Rogers P, Nash T, Schiller D, Norman J. Epidural steroids for sciatica. Pain Clinic 1992; 5:67-72.

922. Castagnera L, Maurette P, Pointillart V, Vital JM, Erny P, Senegas J. Long-term results of cervical epidural steroid injection with and without morphine in chronic cervical radicular pain. Pain 1994; 58:239-243.

923. Hernandez R, Lopez F. Assessment of pain intensity in patients with diabetic polyneuropathy treated with peridural $2 \%$ lidocaine methylprednisolone acetate vs peridural $2 \%$ lidocaine. Anestesia en Mexico 1999; 11:65-69.

924. Kikuchi A, Kotani N, Sato T, Takamura K, Sakai I, Matsuki A. Comparative therapeutic evaluation of intrathecal versus epidural methylprednisolone for longterm analgesia in patients with intractable postherpetic neuralgia. Reg Anesth Pain Med 1999; 24:287-293.

925. Helliwell M, Robertson JC, Ellia RM. Outpatient treatment of low back pain and sciatica by a single extradural corticosteroid injection. Br J Clin Pract 1985; 39:228-231.

926. Stav A, Ovadia L, Sternberg A, Kaadan M, Weksler N. Cervical epidural steroid injection for cervicobrachialgia. Acta Anaesthesiol Scand 1993; 37:562-566.

927. Buchner M, Zeifang F, Brocai DR, Schiltenwolf M. Epidural corticosteroid in- jection in the conservative management of sciatica. Clin Orth Rel Res 2000; 375:149-156.

928. Valat JP, Giraudeau B, Rozenberg S, Goupille P, Bourgeois P, Micheau-Beaugendre V, Soubrier M, Richard S, Thomas E. Epidural corticosteroid injections for sciatica: a randomised, double blind, controlled clinical trial. Ann Rheum Dis 2003; 62:639-643.

929. Kraemer J, Ludwig J, Bickert U, Owczarek V, Traupe M. Lumbar epidural perineural injection: A new technique. Eur Spine J 1997; 6:357-361.

930. Bush K, Hillier S. Outcome of cervical radiculopathy treated with periradicular/epidural corticosteroid injections: A prospective study with independent clinical review. Eur Spine J 1996; 5:319325.

931. Caglar S, Erdine S, Aldemir T. The results of the epidural steroid injections in patients with radiculopathies due to lumbar disc herniations. Fiz Tedavi Rehabil Derg 1995; 19:186-190.

932. Dallas TL, Lin RL, Wu WH, Wolskee P. Epidural morphine and methylprednisolone for low-back pain. Anesthesiology 1987; 67:408-411.

933. Rivest C, Katz JN, Ferrante FM, Jamison $R N$. Effects of epidural steroid injection on pain due to lumbar spinal stenosis or herniated discs: A prospective study. Arthritis Care Res 1998; 11:291-297.

934. Koning HM, Koning AJ, Bruinen TCM; Koster HG; Heybroek E. The period of pain relief following a successful epidural steroid injection for low back pain. Pain Clinic 2002; 13:331-338.

935. Andersen KH, Mosdal C. Epidural application of corticosteroids in low-back pain and sciatica. Acta Neurochir 1987; 87:52-53.

936. Warfield CA, Crews DA. Epidural steroid injection as a predictor of surgical outcome. Surg Gyn Obstet 1987; 164:457458.

937. Fukusaki M, Kobayashi I, Hara T, Sumikawa K. Symptoms of spinal stenosis do not improve after epidural steroid injection. Clin J Pain 1998; 14:148-151.

938. Ferrante FM, Wilson SP, lacobo C, Orav EJ, Rocco AG, Lipson S. Clinical classification as a predictor of therapeutic outcome after cervical epidural steroid injection. Spine 1993; 18:730-736.

939. Stav A, Ovadia L, Landau M, Weksler N, Berman $M$. Epidural steroid injection in the treatment of lumbar and cervical pain syndromes. A preliminary retrospective comparison. Pain Clinic 1991; 4:95-112. 
940. Shulman M. Treatment of neck pain with cervical epidural steroid injection. Reg Anesth Pain Med 1986; 11:92-94.

941. Catchlove RFH, Braha R. The use of cervical epidural nerve blocks in the management of chronic head and neck pain. Can Anaesth Soc J 1984; 31:188-191.

942. Purkis IE. Cervical epidural steroids. Pain Clinic 1986; 1:3-7.

943. Rowlingson JC, Kirschenbaum LP. Epidural analgesic techniques in the management of cervical pain. Anesth Analg 1986; 65:938-942.

944. Warfield CA, Biber MP, Crews DA, Dwarakanath, GK. Epidural steroid injection as a treatment for cervical radiculitis. Clin J Pain 1988; 4:201-204.

945. Cicala RS, Thoni K, Angel JJ. Long-term results of cervical epidural steroid injections. Clin J Pain 1989; 5:143-145.

946. Pawl RP, Anderson W, Shulman M. Effect of epidural steroids in the cervical and lumbar region on surgical intervention for discogenic spondylosis. Clin J Pain 1985; 1:181-185.

947. Ozyalcin S, Yucel A, Erdine S. Epidural steroid injection in the treatment of cervical pain syndromes: $A$ retrospective follow up study. Angri Dergisi 1996; 8:914 .

948. Schaufele MK, Hatch L, Jones W. Interlaminar versus transforaminal epidural injections for the treatment of symptomatic lumbar intervertebral disc herniations. Pain Physician 2006; 9:361366.

949. Lin EL, Lieu V, Halevi L, Shamie AN, Wang JC. Cervical epidural steroid injections for symptomatic disc herniations. J Spinal Disord Tech 2006; 19:183-186.

950. Riew KD, Yin Y, Gilula L, Bridwell KH, Lenke LG, Lauryssen C, Goette K. The effect of nerve-root injections on the need for operative treatment of lumbar radicular pain. I Bone Joint Surg AM 2000; 82: 1589-1593.

951. Karppinen J, Malmivaara A, Kurunlahti M, Kyllonen E, Pienimaki T, Nieminen P, Ohinmaa A, Tervonen O, Vanharanta $\mathrm{H}$. Periradicular infiltration for sciatica. Spine 2001; 26:1059-1067.

952. Karppinen J, Ohinmaa A, Malmivaara A, Kurunlahti M, Kyllonen E, Pienimaki $T$, Nieminen P, Tervonen O, Vanharanta $\mathrm{H}$. Cost effectiveness of periradicular infiltration for sciatica. Spine 2001; 26:2587-2595.

953. Devulder J, Deene P, De Laat M, Van Bastelaere M, Brusselmans G, Rolly G. Nerve root sleeve injections in patients with failed back surgery syndrome: A comparison of three solutions. Clin J
Pain 1999; 15:132-135.

954. Kolsi I, Delecrin J, Berthelot JM, Thomas L, Prost A, Maugars Y. Efficacy of nerve root versus interspinous injections of glucocorticoids in the treatment of discrelated sciatica. A pilot, prospective, randomized, double-blind study. Joint Bone Spine 2000; 67:113-118.

955. Vad VB, Bhat AL, Lutz GE, Cammisa F. Transforaminal epidural steroid injections in lumbosacral radiculopathy; $A$ prospective randomized study. Spine 2002; 27:11-16.

956. Thomas E, Cyteval C, Abiad L, Picot MC, Taourel P, Blotman F. Efficacy of transforaminal versus interspinous corticosteroid injection in discal radiculalgia - $\mathrm{A}$ prospective, randomised, double-blind study. Clin Rheumatol 2003; 22:299304.

957. Anderberg L, Annertz M, Persson L, Brandt L, Saveland H. Transforaminal steroid injections for the treatment of cervical radiculopathy: a prospective and randomised study. Eur Spine 2006; Epub ahead of print.

958. Ng L, Chaudhary N, Sell P. The efficacy of corticosteroids in periradicular infiltration for chronic radicular pain: a randomized, double-blind, controlled trial. Spine 2005; 30:857-862.

959. Kolstad F, Leivseth G, Nygaard OP. Transforaminal steroid injections in the treatment of cervical radiculopathy. A prospective outcome study. Acta Neurochir (Wien) 2005; 147:1065-1070.

960. Yang SC, Fu TS, Lai PL, Niu CC, Chen LH, Chen WJ. Transforaminal epidural steroid injection for discectomy candidates: an outcome study with a minimum of two-year follow-up. Chang Gung Med J 2006; 29:93-99.

961. Riew KD, Park JB, Cho YS, Gilula L, Patel A, Lenke LG, Bridwell KH. Nerve root blocks in the treatment of lumbar radicular pain. A minimum five-year followup. J Bone Joint Surg Am 2006; 88:17221725.

962. Ng LC, Sell P. Outcomes of a prospective cohort study on peri-radicular infiltration for radicular pain in patients with lumbar disc herniation and spinal stenosis. Eur Spine J 2004; 13:325-329.

963. Karaeminogullari O, Sahin O, Boyvat F, Akgun RC, Gurun U, Demirors H, Tuncay IC, Tandogan RN. Transforaminal epidural steroid injection under computed tomography guidance in relieving lumbosacral radicular pain. Acta Orthop Traumatol Turc 2005; 39:416-420.

964. Michel JL, Lemaire S, Bourbon H, Reynier C, Lhoste A, Soubrier S, Dubost JJ, Ris- tori JM. Fluoroscopy guided $\mathrm{L}_{5}-\mathrm{S}_{1}$ transforaminal injection as a treatment for $\mathrm{S1}$ radiculopathy. J Radiol 2004; 85:19371941.

965. Lutz GE, Vad VB, Wisneski RJ. Fluoroscopic transforaminal lumbar epidural steroids: An outcome study. Arch Phys Med Rehabil 1998; 79:1362-1366.

966. Dreyfuss P, Baker R, Bogduk N. Comparative effectiveness of cervical transforaminal injections with particulate and nonparticulate corticosteroid preparations for cervical radicular pain. Pain Med 2006; 7:237-242.

967. Rull BM, Miralles M, Aure S. Therapeutic epidural infiltrations in the lumbar nerve roots. Rev Orthop Traumatol 1996; 40:209-217.

968. Berger O, Dousset V, Delmer O, Pointillart V, Vital JM, Caille JM. Evaluation of the efficacy of foraminal infusions of corticosteroids guided by computed tomography in the treatment of radicular pain by foraminal injection. J Radiol 1999; 80:917-925.

969. Melzer A, Seibel RM. Magnetic resonance (MR)-guided percutaneous pain therapy of degenerative spinal diseases. Semin Interv Radiol 1999; 16:143150.

970. Sequeiros RB, Ojala RO, Klemola R, Vaara TJ, Jyrkinen L, Tervonen OA. MRIguided periradicular nerve root infiltration therapy in low-field (0.23-T) MRI system using optical instrument tracking. Eur Radiol 2002; 12:1331-1337.

971. Zennaro H, Dousset V, Viaud B, Allard M, Dehais J, Senegas J, Caille JM. Periganglionic foraminal steroid injections performed under CT control. Am J Neuroradiol 1998; 19:349-352.

972. Groenemeyer DH, Gevargez A, Schindler O, Schirp S, Braun M. CT-guided periradicular injections of corticosteroids in the management of lumbar radiculopathy associated with disk herniation. J Radiol 2002; 1-12.

973. Buttermann GR. The effect of spinal steroid injections for degenerative disc disease. Spine J 2004; 4:495-505.

974. Buttermann GR. Treatment of lumbar disc herniation: epidural steroid injection compared with discectomy. A prospective, randomized study. J Bone Joint Surg Am 2004; 86-A:670-679.

975. Cyteval C, Thomas E, Decoux E, Sarrabere MP, Cottin A, Blotman F, Taourel P. Cervical radiculopathy: Open study on percutaneous periradicular foraminal steroid infiltration performed under CT control in 30 patients. AJNR Am J Neuroradiol 2004; 25:441-445. 
976. Tong HC, Williams JC, Haig AJ, Geisser ME, Chiodo A. Predicting outcomes of transforaminal epidural injections for sciatica. Spine J 2003; 3:430-434.

977. Botwin KP, Gruber RD, Bouchlas CG, Torres-Ramos FM, Sanelli JT, Freeman ED, Slaten WK, Rao S. Fluoroscopically guided lumbar transformational epidural steroid injections in degenerative lumbar stenosis: an outcome study. Am J Phys Med Rehabil 2002; 81:898-905.

978. Slipman CW, Lipetz JS, Jackson HB, Rogers DP, Vresilovic EJ. Therapeutic selective nerve root block in the nonsurgical treatment of atraumatic cervical spondylotic radicular pain: A retrospective analysis with independent clinical review. Arch Phys Med Rehabil 2000; 81:741-746.

979. Slipman CW, Lipetz JS, DePalma MJ, Jackson HB. Therapeutic selective nerve root block in the nonsurgical treatment of traumatically induced cervical spondylotic radicular pain. Am J Phys Med Rehabil 2004; 83:446-454.

980. Slipman CW, Lipetz JS, Jackson HB, Plastaras CT, Vresilovic EJ. Outcomes of therapeutic selective nerve root blocks for whiplash induced cervical radicular pain. Pain Physician 2001; 4:167-174.

981. Lutze M, Stendel R, Vesper J, Brock M. Periradicular therapy in lumbar radicular syndromes: Methodology and results. Acta Neurochir 1997; 139:719724.

982. Uhlenbrock D, Arlinghaus J. Results of CT-guided periradicular pain therapy. Rofo Fortschr Geb Rontgenstr Neuen Bildgeb Verfahr 1997; 166:528-534.

983. Le Chevallier PL, Videgrain M, Roulleau P, Delvert JC, Valat JP, Castaing J. Injection of the sacrolumbar roots: A complementary method of staging sciatica. 18 cases. Rev Rhum Mal Osteoartic 1978; 45:473-477.

984. Devulder J. Transforaminal nerve root sleeve injection with corticosteroids, hyaluronidase, and local anesthetic in the failed back surgery syndrome. J Spinal Disord 1998; 11:151-154.

985. Weiner BK, Fraser RD. Foraminal injection for lateral lumbar disc herniation. J Bone Joint Surg 1997; 79-B:804-807.

986. Narozny M, Zanetti M, Boos N. Therapeutic efficacy of selective nerve root blocks in the treatment of lumbar radicular leg pain. Swiss Med Wkly 2001; 131:75-80.

987. Friedman R, Li V, Mehrotra D, Mosuro $Y$, Atkinson G. Foraminal injection of a painful sacral nerve root using an epidural catheter: Case report. Reg Anesth
Pain Med 2002; 27:214-216.

988. Rosenberg SK, Grabinsky A, Kooser C, Boswell M. Effectiveness of transforaminal epidural steroid injections in low back pain: A one year experience. Pain Physician 2002; 5:266-270.

989. Wang JC, Lin E, Brodke DS, Youssef JA. Epidural injections for the treatment of symptomatic lumbar herniated discs. I Spinal Disord Tech 2002; 15:269-272.

990. Botwin KP, Sakalkale DP. Epidural steroid injections in the treatment of symptomatic lumbar spinal stenosis associated with epidural lipomatosis. Am J Phys Med Rehabil 2004; 83:926-930.

991. Schmid G, Vetter S, Gottmann D, Strecker EP. CT-guided epidural/perineural injections in painful disorders of the lumbar spine: Short- and extended-term results. Cardiovasc Intervent Radiol 1999; 22:493-498.

992. Groenmeyer DH, Seibel R, Schindler O, Schattauer K, Lange S, Schmidt A. Microinvasive CT guided periradicular therapy for treatment of chronical functional disorders of the spine. Weiner Medizinische Wochenschrift 1995; 145:129-139.

993. Cooper G, Lutz GE, Boachie-Adjei O, Lin J. Effectiveness of transforaminal epidural steroid injections in patients with degenerative lumbar scoliotic stenosis and radiculopathy. Pain Physician 2004; 7:311-317.

994. Lee JW, Kim SH, Choi JY, Yeom JS, Kim KJ, Chung SK, Kim HJ, Kim C, Kwack KS, Kwon JW, Moon SG, Jun WS, Kang HS. Transforaminal epidural steroid injection for lumbosacral radiculopathy: preganglionic versus conventional approach. Korean J Radiol 2006; 7:139144 .

995. Lee JW, Kim SH, Lee IS, Choi JA, Choi JY, Hong SH, Kang HS. Therapeutic effect and outcome predictors of sciatica treated using transforaminal epidural steroid injection. AJR Am J Roentgenol 2006; 187:1427-1431.

996. Lee KS, Lin CL, Hwang SL, Howng SL, Wang CK. Transforaminal periradicular infiltration guided by $\mathrm{CT}$ for unilateral sciatica-an outcome study. Clin Imaging 2005; 29:211-214.

997. Sasso RC, Macadaeg K, Nordmann D, Smith M. Selective nerve root injections can predict surgical outcome for lumbar and cervical radiculopathy: comparison to magnetic resonance imaging. I Spinal Disord Tech 2005;18:471-478.

998. Blankenbaker DG, De Smet AA, Stanczak JD, Fine JP. Lumbar radiculopathy: treatment with selective lumbar nerve blocks-comparison of effectiveness of triamcinolone and betamethasone injectable suspensions. Radiology 2005; 237:738-741.

999. Waldman SD. Complications of cervical epidural nerve blocks with steroids: A prospective study of 790 consecutive blocks. Reg Anesth 1989; 14:149-151.

1000. Furman MB, Giovanniello MT, O’Brien $E M$. Incidence of intravascular penetration in transforaminal cervical epidural steroid injections. Spine 2003; 28:2125.

1001. Furman MB, O’Brien EM, Zgleszewski $T M$. Incidence of intravascular penetration in transforaminal lumbosacral epidural steroid injections. Spine 2000; 25:2628-2632.

1002. Botwin KP, Gruber RD, Bouchlas CG, Torres-Ramos FM, Freeman TL, Slaten WK. Complications of fluoroscopically guided transforaminal lumbar epidural injections. Arch Phys Med Rehabil 2000; 81:1045-1050.

1003. Botwin KP, Castellanos R, Rao S, Hanna AF, Torres-Ramos FM, Gruber RD, Bouchlas CG, Fuoco GS. Complications of fluoroscopically guided interlaminar cervical epidural injections. Arch Phys Med Rehabil 2003; 84:627-633.

1004. Huang RC, Shapiro GS, Lim M, Sandhu HS, Lutz GE, Herzog RJ. Cervical epidural abscess after epidural steroid injection. Spine 2004; 29:E7-E9.

1005. Hooten WM, Kinney MO, Huntoon MA. Epidural abscess and meningitis after epidural corticosteroid injection. Mayo Clin Proc 2004; 79:682-686.

1006. Stitz MY, Sommer HM. Accuracy of blind versus fluoroscopically guided caudal epidural injection. Spine 1999; 24:1371-1376.

1007. Williams KN, Jackowski A, Evans PJ. Epidural hematoma requiring surgical decompression following repeated cervical epidural steroid injections for chronic pain. Pain 1990; 42:197-199.

1008. Reitman CA, Watters W. Subdural hematoma after cervical epidural steroid injection. Spine 2002; 27:E174-E176.

1009. Bromage RP, Benumof JL. Paraplegia following intracord injection during attempted epidural anesthesia under general anesthesia. Reg Anesth Pain Med 1998; 23:104-107.

1010. MacLean CA, Bachman DT. Documented arterial gas embolism after spinal epidural injection. Ann Emerg Med 2001; 38:592-595.

1011. Yue WM, Tan SB. Distant skip level discitis and vertebral osteomyelitis after caudal epidural injection: A case report 
of a rare complication of epidural injections. Spine 2003; 28:E209-E211.

1012. McMillan MR, Crumpton C. Cortical blindness and neurologic injury complicating cervical transforaminal injection for cervical radiculopathy. Anesthesiology 2003; 99:509-511.

1013. Hodges SD, Castleberg RL, Miller T, Ward R, Thornburg C. Cervical epidural steroid injection with intrinsic spinal cord damage. Two case reports. Spine 1998; 23:2137-2142.

1014. Mateo E, Lopez-Alarcon MD, Moliner S, Calabuig E, Vivo M, De Andres J, Grau F. Epidural and subarachnoid pneumocephalus after epidural technique. Eur J Anesthesiol 1999; 16:413-417.

1015. Katz JA, Lukin R, Bridenbaugh PO, Gunzenhauser L. Subdural intracranial air: An unusual cause of headache after epidural steroid injection. Anesthesiology 1991; 74:615-618.

1016. Benzon HT, Wong HY, Siddiqui T, Ondra S. Caution in performing epidural injections in patients on several antiplatelet drugs. Anesthesiology 1999; 91:15581559.

1017. Waldman SD. Cervical epidural abscess after cervical epidural nerve block with steroids (Letter). Anesth Anal 1991; 72:717.

1018. Mamourian AC, Dickman CA, Drayer BP, Sonntag VK. Spinal epidural abscess: Three cases following spinal epidural injection demonstrated with magnetic resonance imaging. Anesthesiology 1993; 78:204-207.

1019. Knight JW, Cordingley JJ, Palazzo MG. Epidural abscess following epidural steroid and local anesthetic injection. Anaesthesia 1997; 52:576-578.

1020. Kaul S, Meena AK, Sundaram C, Reddy JM, Naik RT, Murthy JM. Spinal extradural abscess following local steroid injection. Neurol India 2000; 48:181-183.

1021. Tekkok IH, Carter DA, Brinker R. Spinal subdural hematoma as a complication of immediate epidural blood patch. Can J Anaesth 1996; 43:306-309.

1022. Sabel M, Felsberg J, Neuen-Jacob E, Lichota A, Schnitzler A, Herdmann J. Enlargement of a chronic aseptic lumbar epidural abscess by intraspinal injections $-a$ rare cause of progressive paraparesis. Zentralbl Neurochir 2000; 61:111-114.

1023. Gutknecht DR. Chemical meningitis following epidural injections of corticosteroids (Letter). Am J Med 1987; 82:570.

1024. Kusher FH, Olson JC. Retinal hemorrhage as a consequence of epidural steroid injection. Arch Opthalmol 1995;
113:309-313.

1025. Tiso RL, Cutler T, Catania JA, Whalen $\mathrm{K}$. Adverse central nervous system sequelae after selective transforaminal block: the role of corticosteroids. Spine J 2004; 4:468-474.

1026. Huntoon MA, Martin DP. Paralysis after transforaminal epidural injection and previous spinal surgery. Reg Anesth Pain Med 2004; 29:494-495.

1027. Huntoon MA. The ascending and deep cervical arteries are vulnerable to injury during cervical transforaminal epidural injections: An anatomic study. Presented at the ASA Annual Meeting, October 23-27, 2004, Las Vegas, Nevada.

1028. Nishimura H, Uemura Y, Fukuda S, Kamada Y, Moriwaki T. Two cases of pyogenic cervical discitis presenting tetraparesis. No Shinkei Geka 2000; 28:631637.

1029. McHaourab AS. Cervical epidural steroid injection: impact of cervical epidural anatomy. Anesthesiology 2004; 101:1238-1239.

1030. Botwin KP, Baskin M, Rao S. Adverse effects of fluoroscopically guided interlaminar thoracic epidural steroid injections. Am J Phys Med Rehabil 2006; $85: 14-23$.

1031. Ziai WC, Ardelt AA, Llinas RH. Brainstem stroke following uncomplicated cervical epidural steroid injection. Arch Neurol 2006; 63:1643-1646.

1032. Pizzimenti JJ, Daniel KP. Central serous chorioretinopathy after epidural steroid injection. Pharmacotherapy 2005; 25:1141-1146.

1033. Botwin KP, Gruber RD, Bouchlas CG, Torres-Ramos FM, Hanna A, Rittenberg J, Thomas SA. Complications of fluoroscopically guided caudal epidural injections. Am J Phys Med Rehabil 2001; 80:416-424.

1034. Quintero N, Laffont I, Bouhmidi L, Rech C, Schneider AE, Gavardin T, Dizien 0. Transforaminal epidural steroid injection and paraplegia: case report and bibliographic review. Ann Readapt Med Phys 2006; 49:242-247.

1035. Chiang HL, Chia YY, Chen YS, Hung CC, Liu K, Lo Y. Epidural abscess in an obstetric patient with patient-controlled epidural analgesia-a case report. Int $J$ Obstet Anesth 2005; 14:242-245.

1036. Manchikanti L, Saini B, Singh V. Lumbar epidural adhesiolysis. In Manchikanti L, Slipman CW, Fellows B (eds), Interventional Pain Management: Low Back Pain - Diagnosis and Treatment. ASIPP Publishing, Paducah KY 2002; 353-390. 1037. Heavner JE, Racz GB, Raj P. Percutane- ous epidural neuroplasty. Prospective evaluation of $0.9 \% \mathrm{NaCl}$ versus $10 \%$ $\mathrm{NaCl}$ with or without hyaluronidase. Reg Anesth Pain Med 1999; 24:202207.

1038. Racz GB, Heavner JE, Raj PP. Percutaneous epidural neuroplasty. Prospective one-year follow up. Pain Digest 1999; 9:97-102.

1039. Manchikanti L, Rivera JJ, Pampati V, Damron KS, MCManus CD, Brandon DE, Wilson SR. One day lumbar epidural adhesiolysis and hypertonic saline neurolysis in treatment of chronic low back pain: A randomized, double-blind trial. Pain Physician 2004; 7:177-186

1040. Manchikanti L, Pampati V, Fellows B, Rivera JJ, Beyer CD, Damron KS. Role of one day epidural adhesiolysis in management of chronic low back pain: A randomized clinical trial. Pain Physician 2001; 4:153-166.

1041. Veihelmann A, Devens C, Trouiller H, Birkenmaier C, Gerdesmeyer L, Refior HJ. Epidural neuroplasty versus physiotherapy to relieve pain pain in patients with sciatica: a prospective randomized blinded clinical trial. J Orthop Science 2006; 11:365-369.

1042. Gerdesmeyer L, Rechl H, Wagenpfeil S, Ulmer M, Lampe R, Wagner K. Minimally invasive epidural neurolysis in chronic radiculopathy. A prospective controlled study to prove effectiveness. Der Orhopade 2003; 32:869-876.

1043. Gerdesmeyer L, Lampe R, Veihelmann A, Burgkart R, Gobel M, Gollwitzer H, Wagner K. Chronic radiculopathy. Use of minimally invasive percutaneous epidural neurolysis according to Racz. Der Schmerz 2005; 19:285-295.

1044. Manchikanti L, Pakanati R, Bakhit CE, Pampati V. Role of adhesiolysis and hypertonic saline neurolysis in management of low back pain. Evaluation of modification of Racz protocol. Pain Digest 1999; 9:91-96.

1045. Manchikanti L, Pampati V, Bakhit CE, Pakanati RR. Non-endoscopic and endoscopic adhesiolysis in post lumbar laminectomy syndrome. A one-year outcome study and cost effective analysis. Pain Physician 1999; 2:52-58.

1046. Manchikanti L, Pampati V, Rivera J, Fellows B, Beyer CD, Damron KS, Cash KA. Effectiveness of percutaneous adhesiolysis and hypertonic saline neurolysis in refractory spinal stenosis. Pain Physician 2001; 4:366-373.

1047. Racz GB, Holubec JT. Lysis of adhesions in the epidural space. In Racz GB (ed). Techniques of Neurolysis. Kluwer 
Academic Press, Boston, 1989; pp 5772.

1048. Hammer M, Doleys D, Chung O. Transforaminal ventral epidural adhesiolysis. Pain Physician 2001; 4: 273-279.

1049. Devulder J, Bogaert L, Castille F, Moerman A, Rolly G. Relevance of epidurography and epidural adhesiolysis in chronic failed back surgery patients. Clin J Pain 1995; 11:147-150.

1050. Arthur J, Racz GB, Heinrich R, Diede JH, McCann M, Wilson E, Heavner J C., Noe C. Epidural space. Identification of filling defects in lysis of adhesions in the treatment of chronic painful conditions. In: Abstracts, 7th World Congress of Pain. Paris, IASP Publications, 1993, pp 557.

1051. Manchikanti L, Singh V. Epidural lysis of adhesions and myeloscopy. Curr Pain Headache Rep 2002; 6:427-435.

1052. Manchikanti L, Rivera JJ, Pampati V, Damron KS, Beyer CD, Brandon DE, Wilson SR. Spinal endoscopic adhesiolysis in the management of chronic low back pain: A preliminary report of a randomized, double-blind trial. Pain Physician 2003; 6:259-268.

1053. Manchikanti L, Boswell MV, Rivera JJ, Pampati V, Damron KS, McManus CD, Brandon DE, Wilson SR. A randomized, controlled trial of spinal endoscopic adhesiolysis in chronic refractory low back and lower extremity pain. BMC Anesthesiol 2005; 5:10

1054. Geurts JW, Kallewaard JW, Richardson J, Groen. Targeted methylprednisolone acetate/hyaluronidase/clonidine injection after diagnostic epiduroscopy for chronic sciatica: a prospective, 1-year follow-up study. Reg Anesth Pain Med 2002; 27:343-352.

1055. Igarashi T, Hirabayashi Y, Seo N, Saitoh $\mathrm{K}$, Fukuda H, Suzuki H. Lysis of adhesions and epidural injection of steroid/local anesthetic during epiduroscopy potentially alleviate low back and leg pain in elderly patients with lumbar spine stenosis. Br J Anaesth 2004; 93:181-187.

1056. Richardson J, McGurgan P, Cheema S, Prasad R, Gupta S. Spinal endoscopy in chronic low back pain with radiculopathy: A prospective case series. Anaesthesia 2001; 56:454-460.

1057. Manchikanti L, Pakanati RR, Pampati V. The value and safety of epidural endoscopic adhesiolysis. Am J Anesthesiol 2000; 27:275-279.

1058. Saberski L. A retrospective analysis of spinal canal endoscopy and laminectomy outcomes data. Pain Physician 2000; 3:193-196.
1059. Lewandowski EM. The efficacy of solutions used in caudal neuroplasty. Pain Digest 1997; 7:323-330.

1060. Aldrete JA, Zapata JC, Ghaly R. Arachnoiditis following epidural adhesiolysis with hypertonic saline report of two cases. Pain Digest 1996; 6:368-370.

1061. Hitchcock ER, Prandini MN. Hypertonic saline in management of intractable pain. Lancet 1973; 1:310-312.

1062. Lucas JT, Ducker TB, Perot PL. Adverse reactions to intrathecal saline injections for control of pain. I Neurosurg 1975; 42:557-561.

1063. Dagi TF. Comments on myelopathy after the intrathecal administration of hypertonic saline. Neurosurgery 1988; 22:944-945.

1064. Lundy JS, Essex HE, Kernohan JW. Experiments with anesthetics. IV. Lesions produced in the spinal cord of dogs by a dose of procaine hydrochloride sufficient to cause permanent and fatal paralysis. JAMA 1936; 101: 1546-1550.

1065. Gentili ME, Samii K. Accidental epidural injection of hypertonic sodium chloride solution. Ann Fr Anesth Reanim 1991; 10:401-403.

1066. Manchikanti L, Bakhit CE. Removal of torn Racz catheter from lumbar epidural space. Reg Anesth Pain Med 1997; 22:579-581.

1067. Tabandeh H. Intraocular hemorrhages associated with endoscopic spinal surgery. Am J Ophthalmol 2000; 129:688690.

1068. Hammer M. Safety of spinal endoscopy is contingent on basic image interpretation. Letter to the editor. Reg Anesth Pain Med 2002; 27:621.

1069. Talu GK, Erdine S. Complications of epidural neuroplasty: a retrospective evaluation. Neuromodulation 2003; 6:237347.

1070. Perkins WJ, Davis DH, Huntoon MA, Horlocker TT. A retained Racz catheter fragment after epidural neurolysis: implications during magnetic resonance imaging. Anesth Analg 2003; 96:17171719.

1071. Richter HP. Is the so-called epidural neuroplasty (Racz catheter) a harmless procedure? Meeting abstract. Deutsche Gesellschaft für Neurochirurgie, Strasbourg, Germany May 2005.

1072. Wagner KJ, Sprenger T, Pecho C, Kochs EF, Tölle TR, Berthele A, Gerdesmeyer L. Risks and complications of epidural neurolysis - a review with case report. Anasthesiol Intensmed Notfallmed Schmerzther 2006; 41:213-222.

1073. Akbas M, Karsli B. Caudal epidural neuroplasty. Agri 2005; 17:40-43.

1074. Luukkainen RK, Wennerstrand PV, Kautiainen HH, Sanila MT, Asikainen EL. Efficacy of periarticular corticosteroid treatment of the sacroiliac joint in non-spondylarthropathic patients with chronic low back pain in the region of the sacroiliac joint. Clin Exp Rheumatol 2002; 20:52-54.

1075. Maugars Y, Mathis C, Berthelot JM, Charlier C, Prost A. Assessment of the efficacy of sacroiliac corticosteroid injections spondyloarthropathies: a double blind study. $\mathrm{Br} /$ Rheumatol 1996; 35:767-770.

1076. Fischer T, Biedermann T, Hermann KG, Diekmann F, Braun J, Hamm B, Bollow $M$. Sacroiliitis in children with spondyloarthropathy: therapeutic effect of CTguided intra-articular corticosteroid injection. Rofo 2003; 175:814-821.

1077. Luukkainen R, Nissila M, Asikainen E, Sanila M, Lehtinen K, Alanaatu A, Kautianen H. Periarticular corticosteroid treatment of the sacroiliac joint in patients with seronegative spondyloarthropathy. Clin Exp Rheumatol 1999; 17:88-90.

1078. Karabacakoglu A, Karakose S, Ozerbil OM, Odev K. Fluoroscopy-guided intraarticular corticosteroid injection into the sacroiliac joints in patients with ankylosing spondylitis. Acta Radiol 2002; 43:425-427.

1079. Hanly JG, Mitchell M, MacMillan L, Mosher D, Sutton E. Efficacy of sacroiliac corticosteroid injections in patients with inflammatory spondyloarthropathy: Results of a 5-month controlled study. J Rheum 2000; 27:719-722.

1080. Maugars Y, Mathis C, Vilon P, Prost A. Corticosteroid injection of the sacroiliac joint in patients with seronegative spondylarthropathy. Arthritis Rheum 1992; 35:564-568.

1081. Bollow M, Braun J, Taupitz M, Haberle J, Reibhauer BH, Paris S, Mutze S, Seyrekbasan F, Wolf KJ, Hamm B. CT-guided intraarticular corticosteroid injection into the sacroiliac joints in patients with spondyloarthropathy: indication and follow-up with contrast-enhanced MRI. J Comput Assist Tomogr 1996; 20:512521.

1082. Braun J, Bollow M, Seyrekbasan F, Haberle HJ, Eggens U, Mertz A, Distler A, Sieper J. Computed tomography guided corticosteroid injection of the sacroiliac joint in patients with spondyloarthropathy with sacroiliitis: clinical outcome and follow-up by dynamic magnetic resonance imaging. J Rheumatol 1996; 23:659-664. 
1083. Gunaydin I, Pereira PL, Daikeler T, Mohren M, Trubenbach J, Schick F, Kanz L, Kotter I. Magnetic resonance imaging guided corticosteroid injection of the sacroiliac joints in patients with therapy resistant spondyloarthropathy: A pilot study. J Rheumatol 2000; 27:424-428.

1084. Pereira PL, Gunaydin I, Duda SH, Trubenbach J, Remy CT, Kotter I, Kastler $B$, Claussen CD. Corticosteroid injections of the sacroiliac joint during magnetic resonance: preliminary results [in French]. J Radiol 2000; 81:223-226.

1085. Pereira PL, Gunaydin I, Trubenbach J,Dammann F, Remy CT, Kotter I, Schick F, Koenig CW, Claussen CD. Interventional MR imaging for injection of sacroiliac joints in patients with sacroiliitis. AJR Am / Roentgenol 2000; 175:265266.

1086. Ojala R, Klemola R, Karppinen J, Sequeiros RB, Tervonen O. Sacro-iliac joint arthrography in low back pain: feasibility of MRI guidance. Eur J Radiol 2001; 40:236-239.

1087. Dussault RG, Kaplan PA, Anderson MW. Fluoroscopy-guided sacroiliac joint injections. Radiology 2000;214:273-277.

1088. Slipman CW, Lipetz JS, Plastaras CT, Jackson HB, Vresilovic EJ, Lenrow DA, Braverman DL. Fluoroscopically guided therapeutic sacroiliac joint injections for sacroiliac joint syndrome. Am J Phys Med Rehabil 2001; 80:425-432.

1089. Chakraverty R, Dias R. Audit of conservative management of chronic low back pain in a secondary care setting-part I: facet joint and sacroiliac joint interventions. Acupunct Med 2004; 22:207-213.

1090. Ferrante FM, King LF, Roche EA, Kim PS, Aranda M, Delaney LR, Mardini IA, Mannes AJ. Radiofrequency sacroiliac joint denervation for sacroiliac syndrome. Reg Anesth Pain Med 2001; 26:137-142.

1091. Gevargez A, Groenemeyer D, Schirp S, Braun M. CT-guided percutaneous radiofrequency denervation of the sacroiliac joint. Eur Radiol 2002; 12:13601365.

1092. Cohen SP, Abdi S. Lateral branch blocks as a treatment for sacroiliac joint pain: a pilot study. Reg Anesth Pain Med 2003; 28:113-119.

1093. Buijs EJ, Kamphuis ET, Groen GJ. Radiofrequency treatment of sacroiliac jointrelated pain aimed at the first three sacral dorsal rami: a minimal approach. Pain Clinic 2004; 16:139-146.

1094. Burnham RS, Yasui Y. An alternate method of radiofrequency neurotomy of the sacroiliac joint: A pilot study of the effect of pain, function, and satis- faction. Reg Anesth Pain Med 2007; 32:12-19.

1095. Crock HV. Abnormal disc disruption. A challenge to disc prolapse fifty years on. Spine 1986; 11:650-653.

1096. Kapural L, Hayek S, Malak O, Arrigain $\mathrm{S}$, Mekhail N. Intradiscal thermal annuloplasty versus intradiscal radiofrequency ablation for the treatment of discogenic pain: a prospective matched control trial. Pain Med 2005; 6:425431.

1097. Saal JA, Saal JS. Intradiscal electrothermal treatment for chronic discogenic low back pain: a prospective outcome study with minimum 1-year follow-up. Spine 2000; 25:2622-2627.

1098. Bogduk N, Lau P, Govind J, Karasek M. Intradiscal electrothermal therapy. Tech Reg Anesth Pain Manag 2005; 9: 2534 .

1099. Pauza KJ, Howell S, Dreyfuss P. A randomized, placebo-controlled trial of intradiscal electrothermal therapy for the treatment of discogenic low back pain. Spine J 2004; 4:27-35.

1100. Freeman BJ, Fraser RD, Cain CM, Hall DJ, Chapple DC. A randomized, doubleblind, controlled trial: intradiscal electrothermal therapy versus placebo for the treatment of chronic discogenic low back pain. Spine 2005; 30:2369-2377.

1101. Karasek M, Bogduk N. Twelve-month follow-up of a controlled trial of intradiscal thermal annuloplasty for back pain due to internal disc disruption. Spine 2000; 25:2601-2607.

1102. Bogduk N, Karasek M. Two-year followup of a controlled trial of intradiscal electrothermal anuloplasty for chronic low back pain resulting from internal disc disruption. Spine J 2002; 2:343350.

1103. Derby R, Eek B, Chen Y, O'Neill C, Ryan D. Intradiscal electrothermal annuloplasty (IDET): A novel approach for treating chronic discogenic back pain. Neuromodulation 2000; 3:82-88.

1104. Saal JS, Saal JA. Management of chronic discogenic low back pain with a thermal intradiscal catheter. A preliminary report. Spine 2000; 25:382-388.

1105. Welch WC, Gerszten PC, McGrath P. Intradiscal electrothermy: Indications, techniques, and clinical results. Clin Neurosurg 2001; 48:219-225.

1106. Singh V. Intradiscal electrothermal therapy: A preliminary report. Pain Physician 2000; 3:367-373.

1107. Gerszten PC, Welch WC, McGrath PM, Willis SL. A prospective outcome study of patients undergoing intradiscal elec- trothermy (IDET) for chronic low back pain. Pain Physician 2002; 5:360-364.

1108. Saal JA, Saal JS. Intradiscal electrothermal treatment for chronic discogenic low back pain: prospective outcome study with a minimum 2-year follow-up. Spine 2002; 27:966-973.

1109. Spruit M, Jacobs WC. Pain and function after intradiscal electrothermal treatment (IDET) for symptomatic lumbar disc degeneration. Eur Spine J 2002; 11:589-593.

1110. Lutz C, Lutz GE, Cooke PM. Treatment of chronic lumbar diskogenic pain with intradiscal electrothermal therapy: A prospective outcome study. Arch Phys Med Rehabil 2003; 84:23-28.

1111. Kapural L, Mekhail N, Korunda Z, Basali A. Intradiscal thermal annuloplasty for the treatment of lumbar discogenic pain in patients with multilevel degenerative disc disease. Anesth Analg 2004; 99:472-476.

1112. Mekhail N, Kapural L. Intradiscal thermal annuloplasty for discogenic pain: An outcome study. Pain Practice 2004; 4:84-90.

1113. Bryce DA, Nelson J, Glurich I, Berq RL. Intradiscal electrothermal annuloplasty therapy: A case series study leading to new considerations. WMJ 2005; 104:3946.

1114. Endres SM, Fiedler GA, Larson KL. Effectiveness of intradiscal electrothermal therapy in increasing function and reducing chronic low back pain in selected patients. WMJ 2002; 101:31-34.

1115. Cohen SP, Larkin T, Abdi S, Chang A, Stojanovic M. Risk factors for failure and complications of intradiscal electrothermal therapy: A pilot study. Spine 2003; 28:1142-1147.

1116. Freedman BA, Cohen SP, Kuklo TR, Lehman RA, Larkin P, Giuliani JR. Intradiscal electrothermal therapy (IDET) for chronic low back pain in active duty soldiers: 2-year follow-up. Spine J 2003; 3:502-509.

1117. Lee MS, Cooper G, Lutz GE, Lutz C, Hong HM. Intradiscal electrothermal therapy (IDET) for treatment of chronic lumbar discogenic pain: A minimum 2-year clinical outcome study. Pain Physician 2003; 6:443-448.

1118. Webster BS, Verma S, Pranksy GS. Outcomes of workers' compensation claimants with low back pain undergoing intradiscal electrothermal therapy. Spine 2004; 29:435-441.

1119. Davis TT, Delamarter RB, Sra P, Goldstein TB. The IDET procedure for chronic discogenic low back pain. Spine 2004; 
29:752-756.

1120. Derby R, Seo KS, Kazala K, Chen YC, Lee $\mathrm{SH}$, Kim BJ. A factor analysis of lumbar intradiscal electrothermal annuloplasty outcomes. Spine J 2005; 5:256-261.

1121. Hsia AW, Isaac K, Katz JS. Cauda equina syndrome from intradiscal electrothermal therapy. Neurology 2000; 55:320.

1122. Saal JA. Complications related to intradiscal electrothermal therapy: Technical considerations and prevention. Semin Spine Surg 2002; 14:163-165.

1123. Lee J, Lutz GE, Campbell D, Rodeo SA, Wright T. Stability of the lumbar spine after intradiscal electrothermal therapy. Arch Phys Med Rehabil 2001; 82:120122.

1124. Ackerman WE. Cauda equina syndrome after intradiscal electrothermal therapy. Reg Anaesth Pain Med 2002; 27:622.

1125. Eckel TS, Ortiz AO. Intradiscal electrothermal therapy in the treatment of discogenic low back pain. Tech Vasc Interv Radiol 2002; 5:217-222.

1126. Djurasovic M, Glassman SD, Dimar JR 2nd, Johnson JR. Vertebral osteonecrosis associated with the use of intradiscal electrothermal therapy. A case report. Spine 2002; 27:E325-E328

1127. Scholl BM, Theiss SM, Lopez-Ben R, Kraft M. Vertebral osteonecrosis related to intradiscal electrothermal therapy: $A$ case report. Spine 2003; 28: E161-E164.

1128. Wetzel FT. Cauda equina syndrome from intradiscal electrothermal therapy. $\mathrm{Neu}$ rology 2001; 56:1607.

1129. Orr RD, Thomas S. Intradural migration of broken IDET catheter causing a radiculopathy. J Spinal Disord Tech 2005; 18:185-187.

1130. Cohen SP, Larkin T, Polly DW Jr. A giant herniated disc following intradiscal electrothermal therapy. J Spinal Disord Tech 2002; 15:537-541.

1131. Finch PM, Price LM, Drummond PD. Radiofrequency heating of painful annular disruptions: one-year outcomes. J Spinal Disord Tech 2005; 18:6-13.

1132. Delamarter RB, Howard MW, Goldstein T, Deutsch AL, Mink JH, Dawson EG. Percutaneous lumbar discectomy. Preoperative and postoperative magnetic resonance imaging. J Bone Joint Surg Am 1995; 77:578-584.

1133. Revel M, Payan C, Vallee C, Laredo JD, Lassale B, Roux C, Carter H, Salomon C, Delmas E, Roucoules J. Automated percutaneous lumbar discectomy versus chemonucleolysis in the treatment of sciatica. A randomized multicenter trial. Spine 1993; 18:1-7

1134. Sakou T, Masuda A. Percutaneous dis- kectomy for lumbar disk herniation. A preliminary report. Clin Orthop Relat Res 1993; 286:174-179.

1135. Waddell G, Gibson A, Grant I. Surgical treatment of lumbar disc prolapse and degenerative lumbar disc disease. In Nachemson AL, Jonsson E (eds). Neck and Back Pain: The Scientific Evidence of Causes, Diagnosis and Treatment, Lippincott Williams \& Wilkins, 2000; pp 305-326.

1136. Krugluger J, Knahr K. Chemonucleolysis and automated percutaneous discectomy-a prospective randomized comparison. Int Orthop 2000; 24:167-169.

1137. Chatterjee S, Foy PM, Findlay GF. Report of a controlled clinical trial comparing automated percutaneous lumbar discectomy and microdiscectomy in the treatment of contained lumbar disc herniation. Spine 1995; 20:734-738.

1138. Haines SJ, Jordan N, Boen JR, Nyman JA, Oldridge NB, Lindgren BR; LAPDOG/ LEAPDOG Investigators. Discectomy strategies for lumbar disc herniation: results of the LAPDOG trial. J Clin Neurosci 2002; 9:411-417.

1139. Haines SJ, Jordan N, Boen JR, Nyman JA, Oldridge NB, Lindgren BR; LAPDOG/LEAPDOG Investigators. Discectomy strategies for lumbar disc herniation: study design and implications for clinical research. J Clin Neurosci 2002; 9:440-446.

1140. Teng GJ, Jeffery RF, Guo JH, He SC, Zhu $H Z$, Wang $X H, W u Y Z$, Lu JM, Ling $X L$, Qian Y, Zhang YM, Zhu MJ, Guan L, He $X M$. Automated percutaneous lumbar discectomy: a prospective multi-institutional study. J Vasc Interv Radiol 1997; 8:457-463.

1141. Onik G, Mooney V, Maroon JC, Wiltse L, Helms C, Schweigel J, Watkins R, Kahanovitz N, Day A, Morris J. Automated percutaneous discectomy: A prospective multi-institutional study. Neurosurgery 1990; 26:228-232.

1142. Bernd L, Schiltenwolf M, Mau H, Schindele S. No indications for percutaneous lumbar discectomy? Int Orthop 1997; 21:164-168.

1143. Sortland O, Kleppe H, Aandahl M, Blikra G. Percutaneous lumbar discectomy. Technique and clinical result. Acta Radiol 1996; 37:85-90.

1144. Negri V, Belledi G. Percutaneous nucleotomy according to Onik: indications and results in 76 cases. Chir Organi Mov 1996; 81:49-54.

1145. Shapiro S. Long-term follow up of 57 patients undergoing automated percutaneous discectomy. I Neurosurg 1995;
83:31-33.

1146. Grevitt MP, McLaren A, Shackleford IM, Mulholland RC. Automated percutaneous lumbar discectomy. An outcome study. J Bone Joint Surg Br 1995; 77:626-629.

1147. Fiume D, Parziale G, Rinaldi A, Sherkat S. Automated percutaneous discectomy in herniated lumbar discs treatment: experience after the first 200 cases. J Neurosurg Sci 1994; 38:235-237.

1148. Choy DS. Percutaneous laser disc decompression (PLDD) update: Focus on device and procedure advances. J Clin Laser Med Surg 1993; 11:181-183.

1149. Dullerud R, Amundsen T, Lie H, Juel NG, Abdelnoor M, Magnaes B. Clinical results after percutaneous automated lumbar nucleotomy. A follow-up study. Acta Radiol 1995; 36:418-424.

1150.Gill K. New-onset sciatica after automated percutaneous discectomy. Spine 1994; 19:466-467.

1151. Schaffer JL, Kambin P. A multicenter analysis of percutaneous discectomy. Spine 1991; 16:854-855.

1152. Stevenson RC, McCabe CJ, Findlay AM. An economic evaluation of a clinical trial to compare automated percutaneous lumbar discectomy with microdiscectomy in the treatment of contained lumbar disc herniation. Spine 1995; 20:739742.

1153. Casper GD, Hartman VL, Mullins LL. Percutaneous laser disc decompression with the holmium: YAG laser. J Clin Laser Med Surg 1995; 13:195-203.

1154. Bosacco SJ, Bosacco DN, Berman AT, Cordover A, Levenberg RJ, Stellabotte J. Functional results of percutaneous laser discectomy. Am J Orthop 1996; 25:825828.

1155. Choy DS. Percutaneous laser disc decompression (PLDD): Twelve years' experience with 752 procedures in 518 patients. J Clin Laser Med Surg 1998; 16:325-331.

1156. Siebert WE, Berendsen BT, Tollgaard J. Percutaneous laser disk decompression. Experience since 1989. Orthopade 1996; 25:42-48.

1157. Ohnmeiss DD, Guyer RD, Hochschuler $\mathrm{SH}$. Laser disc decompression. The importance of proper patient selection. Spine 1994; 19:2054-2058.

1158. Liebler WA. Percutaneous laser disc nucleotomy. Clin Orthop Relat Res 1995; 310:58-66.

1159. Botsford JA. Radiological considerations: patient selection for percutaneous laser disc decompression. J Clin La- 
ser Med Surg 1994; 12:255-259.

116o. Senel A, Gokyar A, Iyigun O, Cokluk C, Rakunt, C; Celik, F. Percutaneous lumbar disc decompression with NdYAG laser. Ondokuz Mayis Universitesi Tip ergisi 1998; 15:221-226.

1161. Knight M, Goswami A. Lumbar percutaneous KTP532 wavelength laser disc decompression and disc ablation in the management of discogenic pain. J Clin Laser Med Surg 2002; 20:9-13.

1162. Groenmeyer DH, Buschkamp H, Braun M, Schirp S, Weinsheimer PA, Gevargez A. Image-guided percutaneous laser disk decompression for herniated lumbar disks: a 4-year follow-up in 200 patients. J Clin Laser Med Surg 2003; 21:131-138.

1163. Tassi GP. Preliminary Italian experience of lumbar spine percutaneous laser disc decompression according to Choy's method. Photomed Laser Surg 2004; 22:439-441.

1164. Zhao D, Du F, Yang J, Zheng YB. Cohortcontrolled study on percutaneous laser decompression in treating lumbar disc herniation. Chin J Clin Rehabil 2005; 9:202-203.

1165. Lee SH, Chung SE, Ahn Y, Kim TH, Park JY, Shin SW. Comparative radiologic evaluation of percutaneous endoscopic lumbar discectomy and open microdiscectomy: a matched cohort analysis. $M t$ Sinai J Med 2006; 73:795-801.

1166. Tonami H, Yokota H, Nakagawa T, Higashi K, Okimura T, Yamamoto I, Nishijima Y. Percutaneous laser discectomy: MR findings within the first 24 hours after treatment and their relationship to clinical outcome. Clin Radiol 1997; 52:938-944.

1167. Nerubay J, Caspi I, Levinkopf M. Percutaneous carbon dioxide laser nucleolysis with 2- to 5-year followup. Clin Orthop Relat Res 1997; 337:45-48.

1168. Simons P, Lensker E, von Wild K. Percutaneous nucleus pulposus denaturation in treatment of lumbar disc protrusions-a prospective study of 50 neurosurgical patients. Eur Spine J 1994; 3:219-221.

1169. Mayer HM, Brock M, Stern E. Percutaneous endoscopic laser discectomy: Experimental results. In Percutaneous Lumbar Discectomy. Springer-Verlag, Heidelberg, 1989.

1170. Epstein NE. Nerve root complications of percutaneous laser-assisted diskectomy performed at outside institutions: A technical note. J Spinal Disord 1994; 7:510-512.

1171. Epstein NE. Laser-assisted diskectomy performed by an internist resulting in cauda equina syndrome. J Spinal Disord 1999; 12:77-79.

1172. Chen YC, Lee SH, Chen D. Intradiscal pressure study of percutaneous disc decompression with nucleoplasty in human cadavers. Spine 2003; 28:661665.

1173. Chen YC, Lee SH, Saenz Y, Lehman NL. Histologic findings of disc, end plate and neural elements after coblation of nucleus pulposus: An experimental nucleoplasty study. Spine / 2003; 3:466470.

1174. Singh V, Piryani C, Liao K, Nieschultz S. Percutaneous disc decompression using coblation (nucleoplasty ) in the treatment of chronic discogenic pain. Pain Physician 2002; 5:250-259.

1175. Sharps LS, Isaac Z. Percutaneous disc decompression using Nucleoplasty. Pain Physician 2002; 5:121-126.

1176. Welch WC, Gerszten PC. Alternative strategies for lumbar discectomy: intradiscal electrothermy and nucleoplasty. Neurosurg Focus 2002; 13:E7.

1177. Singh V, Piryani C, Liao K. Role of percutaneous disc decompression using coblation in managing chronic discogenic low back pain: A prospective, observational study. Pain Physician 2004; 7:419-425.

1178. Singh V, Piryani C, Liao K. Evaluation of percutaneous disc decompression using coblation in chronic back pain with or without leg pain. Pain Physician 2003; 6:273-280.

1179. Marin FZ. CAM versus nucleoplasty. Acta Neurochir Suppl 2005; 92:111-114.

1180. Gerszten PC, Welch WC, King JT. Quality of life assessment in patients undergoing nucleoplasty-based percutaneous discectomy. I Neurosurg Spine 2006; 4:36-42.

1181. Bhagia SM, Slipman CW, Nirschl $M$, Isaac Z, El-Abd O, Sharps LS, Garvin C. Side effects and complications after percutaneous disc decompression using coblation technology. Am J Phys Med Rehabil 2006; 85:6-13.

1182. Alo KM, Wright RE, Sutcliffe J, Brandt SA. Percutaneous lumbar discectomy: Clinical response in an initial cohort of fifty consecutive patients with chronic radicular pain. Pain Pract 2004; 4:1929.

1183. Alo KM, Wright RE, Sutcliffe J, Brandt SA. Percutaneous lumbar discectomy: oneyear follow-up in an initial cohort of fifty consecutive patients with chronic radicular pain. Pain Pract 2005; 5:116-124.

1184. Amoretti N, David P, Grimaud A, Flory P,
Hovorka I, Roux C, Chevallier P, Bruneton JN. Clinical follow-up of 50 patients treated by percutaneous lumbar discectomy. Clin Imaging 2006; 30:242-244.

1185. Domsky R, Goldberg M, Hirsh RA, Scaringe $\mathrm{D}$, Torjman MC. Critical failure of a percutaneous discectomy probe requiring surgical removal during disc decompression. Reg Anesth Pain Med 2006; 31:177-179.

1186. Old J, Calvert M. Vertebral compression fractures in the elderly. Am Fam Physician 2004; 69:111-1116.

1187. Hall SE, Criddle RA, Comito TL, Prince RL. A case-control study of quality of life and functional impairment in women with long-standing vertebral osteoporotic fractures. Osteoporos Int 1999; 9:508.

1188. Report on Osteoporosis in the European Commission. European Commission, DG Employment, Industrial Relations and Social Affairs, 1998.

1189. Silverman SL. The clinical consequences of vertebral compression fracture. Bone 1992; 13(suppl 2):S27-S31.

1190. Rapado A. General management of vertebral fractures. Bone 1996; 18(suppl 3):191-196.

1191. Reginster J, Minne HW, Sorensen $\mathrm{OH}$, Hooper M, Roux C, Brandi ML, Lund B, Ethgen D, Pack S, Roumagnac I, Eastell R. Randomized controlled trial of risedronate on vertebral fractures in women with established postmenopausal osteoporosis. Osteoporos Int 2000; 11:83-91.

1192. Philips FM. Minimally invasive treatments of osteoporotic vertebral compression fractures. Spine 2003; 28(suppl):45-52.

1193. Hu SS. Internal fixation in osteoporotic spine Spine 1997; 22 (suppl):42-45.

1194. Dickman C, Fessler RG, MacMillan M, Haid RW. Transpedicular screw-rod fixation of the lumbar spine: operative technique and outcome in 104 cases. J Neurosurg 1992; 77:860-870.

1195. Essens S, Sacs BL, Drezyin V. Complications associated with the technique of pedicle screw fixation: A selected survey of ABC members. Spine 1993; 18:2231-2239.

1196. Galibert P, Deramond H, Rosat P, Le Gars D. Preliminary note on the treatment of vertebral angioma by percutaneous acrylic vertebroplasty [in French]. Neurochirurgie 1987; 33:166-168.

1197. Coumans JV, Reinhardt MK, Lieberman IH. Kyphoplasty for vertebral compression fractures: 1-year clinical outcomes from a prospective study. J Neurosurg 
2003; 99:44-50.

1198. Heini PF, Orler R. Kyphoplasty for treatment of osteoporotic vertebral fractures. Eur Spine J 2004; 13:184-192.

1199. McGraw JK, Lippert JA, Minkus KD, Rami PM, Davis TM, Budzik RF. Prospective evaluation of pain relief in 100 patients undergoing percutaneous vertebroplasty: Results and follow-up. J Vasc Interv Radiol 2002; 13:883-886.

1200. Lieberman I, Reinhardt MK. Vertebroplasty and kyphoplasty for osteolytic vertebral collapse. Clin Orthop Relat Res 2003; 415S:S176-S186.

1201. Truumees E. The roles of vertebroplasty and kyphoplasty as parts of a treatment strategy. Curr Opin Orthop 2002; 13:193-199.

1202. Gross KA. Vertebroplasty: A new therapeutic option. Orthop Nurs 2002; 21:2329.

1203. Levine SA, Perin LA, Hayes D, Hayes WS. An evidence-based evaluation of percutaneous vertebroplasty. Manag Care 2000; 9:56-63.

1204. Truumees E, Hilibrand A, Vaccaro AR. Percutaneous vertebral augmentation. Spine J 2004; 4:218-229.

1205. Gangi A, Guth S, Imbert JP, Marin H, Dietemann JL. Percutaneous vertebroplasty: Indications, technique, and results. Radiographics 2003; 23:e10.

1206. Garfin SR, Yuan HA, Reiley MA. New technologies in spine: Kyphoplasty and vertebroplasty for the treatment of painful osteoporotic compression fractures. Spine 2001; 26:1511-1515.

1207. Moreland DB, Landi MK, Grand W. Vertebroplasty: Techniques to avoid complications. Spine J 2001; 1:66-71.

1208. Wong W, Riley MA, Garfin S. Vertebroplasty/kyphoplasty. J Womens Imaging 2000; 2:117-124.

1209. Watts NB, Harris ST, Genant HK. Treatment of painful osteoporotic vertebral fractures with percutaneous vertebroplasty or kyphoplasty. Osteoporos Int 2001; 12:429-437.

1210. Kallmes DF, Jensen ME. Percutaneous vertebroplasty. Radiology 2003; 229:27-36.

1211. Fourney DR, Schomer DF, Nader R, Chlan-Fourney J, Suki D, Ahrar K, Rhines LD, Gokaslan ZL. Percutaneous vertebroplasty and kyphoplasty for painful vertebral body fractures in cancer patients. J Neurosurg (Spine 1) 2003; 98:21-30.

1212. Diamond TH, Champion B, Clark WA. Management of acute osteoporotic vertebral fractures: A nonrandomized trial comparing percutaneous vertebroplasty with conservative therapy. American Journal Medicine 2003; 114:257-265.

1213. Amar AP, Larsen DW, Esnaashari N, Albuquerque FC, Lavine SD, Teitelbaum GP. Percutaneous transpedicular polymethylmethacrylate vertebroplasty for the treatment of spinal compression fractures. Neurosurgery 2001; 49:11051114.

1214. Brown DB, Glaiberman CB, Gilula LA, Shimony JS. Correlation between preprocedural MRI findings and clinical outcomes in the treatment of chronic symptomatic vertebral compression fractures with percutaneous vertebroplasty. AJR Am J Roentgenol 2005; 184:1951-1955.

1215. Gaughen JR Jr, Jensen ME, Schweickert PA, Kaufmann TJ, Marx WF, Kallmes DF. Relevance of antecedent venography in percutaneous vertebroplasty for the treatment of osteoporotic compression fractures. AJNR Am J Neuroradiol 2002; 23:594-600.

1216. Hodler J, Peck D, Gilula LA. Midterm outcome after vertebroplasty: Predictive value of technical and patient-related factors. Radiology 2003; 227:662668.

1217. Lane JM, Johnson CE, Khan SN, Girardi FP, Cammisa FP Jr. Minimally invasive options for the treatment of osteoporotic vertebral compression fractures. Orthop Clin North Am 2002; 33:431-438.

1218. McKiernan F, Jensen R, Faciszewski T. The dynamic mobility of vertebral compression fractures. J Bone Miner Res 2003; 18:24-29.

1219. Evans AJ, Jensen ME, Kip KE, DeNardo AJ, Lawler GJ, Negin GA, Remley KB, Boutin SM, Dunnagan SA. Vertebral compression fractures: Pain reduction and improvement in functional mobility after percutaneous polymethylmethacrylate vertebroplasty retrospective report of 245 cases. Radiology 2003; 226:366-72.

1220. Gaughen JR Jr, Jensen ME, Schweickert PA, Kaufmann TJ, Marx WF, Kallmes DF. Lack of preoperative spinous process tenderness does not affect clinical suc cess of percutaneous vertebroplasty. $J$ Vasc Interv Radiol 2002; 13:1135-1138.

1221. Gaughen JR Jr, Jensen ME, Schweickert PA, Marx WF, Kallmes DF. The therapeutic benefit of repeat percutaneous vertebroplasty at previously treated vertebral levels. AJNR Am J Neuroradiol 2002; 23:1657-1661.

1222. Kallmes DF, Schweickert PA, Marx WF, Jensen ME. Vertebroplasty in the midand upper thoracic spine. AJNR Am J
Neuroradiol 2002; 23:1117-1120.

1223. Kaufmann TJ, Jensen ME, Schweickert PA, Marx WF. Age of fracture and clinical outcomes of percutaneous vertebroplasty. AJNR Am J Neuroradiol 2001; 22:1860-1863.

1224. O’Brien JP, Sims JT, Evans AJ. Vertebroplasty in patients with severe vertebral compression fractures: A technical report. AJNR Am J Neuroradiol 2000; 21:1555-1558.

1225. Brown DB, Gilula LA, Sehgal M, Shimony JS. Treatment of chronic symptomatic vertebral compression fractures with percutaneous vertebroplasty. AJR Am J Roentgenol 2004; 182:319-322.

1226. Legroux-Gérot I, Lormeau C, Boutry N, Cotton A, Duquesnoy B, Cortet B. Longterm follow-up of vertebral osteoporotic fractures treated by percutaneous vertebroplasty. Clin Rheumatol 2004; 23:310-317.

1227. Cortet B, Cotten A, Boutry N, Flipo RM, Duquesnoy B, Chastanet P, Delcambre B. Percutaneous vertebroplasty in the treatment of osteoporotic vertebral compression fractures: An open prospective study. J Rheumatol 1999; 26:2222-2228.

1228. Grohs JG, Matzner M, Trieb K, Krepler P. Minimal invasive stabilization of osteoporotic vertebral fractures: A prospective nonrandomized comparison of vertebroplasty and balloon kyphoplasty. J Spinal Disord Tech 2005; 18:238-242.

1229. Yeom JS, Kim WJ, Choy W, Lee CK, Chang BS, Kang JW. Leakage of cement in percutaneous transpedicular veterbroplasty for painful osteoporotic compression fractures. J Bone Joint Surg 2003; 85:83-89.

1230. Cotten A, Deramond $H$, Cortet B, Lejeune JP, Leclerc X, Chastanet P, Clarisse J. Preoperative percutaneous injection of methyl methcrylate and $\mathrm{N}$ butyl cyanoacrylate in vertebral hemangiomas. Am Soc Neuroradiology 1996;17:137-142

1231. Alvarez L, Perez-Higueras A, Quinones D, Quinones D, Calvo E, Rossi RE. Vertebroplasty in the treatment of vertebral tumors: postprocedural outcome and quality of life. Eur Spine J 2003; 12:356360.

1232. Jang JS, Lee SH, Jung SK. Pulmonary embolism of polymethylmethacrylate after percutaneous vertebroplasty: A report of three cases. Spine 2002; 27: E416-E418.

1233. Tsou IY, Goh PYT, Peh WCG, Goh LA, Chee TS. Percutaneous vertebroplasty in the management of osteoporotic ver- 
tebral compression fractures: initial experience. Annals Acad Medicine, Singapore 2002;31:15-20.

1234. Kasperk C, Hillmeier J, Noldge G, Grafe IA, Dafonseca K, Raupp D, Bardenheuer H, Libicher M, Liegibel UM, Sommer U, Hilscher U, Pyerin W, Vetter M, Meinzer HP, Meeder PJ, Taylor RS, Nawroth P. Treatment of painful osteoporotic vertebral fractures by kyphoplasty in patients with primary osteoporosis. J Bone \& Mineral Res 2004 [in press].

1235. Komp M, Ruetten S, Godolias G. Minimally invasive therapy for functionally unstable osteoporotic vertebral fracture by means of kyphoplasty: prospective comparative study of 19 surgically and 17 conservatively treated patients. J Miner Stoffwechs 2004:11(suppl 1):1315

1236. Darius T, Vanderschot P, Broos P. Balloon kyphoplasty: A new treatment option for painful osteoporotic vertebral body compression fractures. Tijdschrift voor Geneekuunde 2003; 59:1141-1152.

1237. Dudeney S, Lieberman IH, Reinhardt MK, Hussein M. Kyphoplasty in the treatment of osteolytic vertebral compression fractures as a result of multiple myeloma. J Clin Oncol 2002; 20:23822387.

1238. Garfin SR. A Multi-center Post-Marketing Registry To Assess Outcomes of Treatment of Vertebral Body Compression Fractures with an Inflatable Bone Tamp. Final Report 2003 [Kyphon Registry Report - unpublished].

1239. Hillmeier J, Meeder PJ, Noldge G. Minimal invasive reduction and internal stabilisation of osteoporotic vertebral body fracture. Operat Orthop und Traumatologie 2003, 4:343-362.

1240. Kasperk C. Kyphoplastie Konzept zur behandlung schmerzhafter wirbelkorperbruch. Deutsches Afzteblatt 2003; 100:1748-1753.

1241. Kumar S, Ferrari R, Narayan Y, Jones T. The effect of a 3-point harness restraint and car seat in whiplash-type lateral impacts. Spine 2006; 31:E11-18.

1242. Phillips FM, Wetzel TF, Lieberman I, Campbell-Hupp M. An in vivo comparison of the potential for extravertebral cement leak after vertebroplasty and kyphoplasty. Spine 2002; 27:21732178.

1243. Phillips FM, Ho E, Campbell-Hupp M, McNally T, Todd Wetzel F, Gupta P. Early radiographic and clinical results of balloon kyphoplasty for the treatment of osteoporotic vertebral compression fractures. Spine 2003; 28:2260-2265.
1244. Gaitanis IN, Hadjipavlou AG, Katonis PG, Tzermiadianos MN, Pasku DS, Patwardhan AG. Balloon kyphoplasty for the treatment of pathological vertebral compressive fractures. Eur Spine J 2005; 14:250-260.

1245. Barr JD, Barr MS, Lemley TJ, McCann RM. Percutaneous vertebroplasty for pain relief and spinal stabilization. Spine 2000; 25:923-928.

1246. Yu SW, Lee PC, Ma CH, Chuang TY, Chen YG. Vertebroplasty for the treatment of osteoporotic compression spinal fracture: Comparison of remedial action at different stages of injury. J Trauma 2004; 56:629-632.

1247. Jensen ME, Evans AJ, Mathis JM, Kallmes DF, Cloft HJ, Dion JE. Percutaneous polymethylmethacrylate vertebroplasty in the treatment of osteoporotic vertebral body compression fractures: Technical aspects. AJNR Am J Neuroradiol 1997; 18:1897-1904.

1248. Martin JB, Jean B, Sugiu K, San Millan Ruiz D, Piotin M, Murphy K, Rufenacht $B$, Muster M, Rufenacht DA. Vertebroplasty: Clinical experience and followup results. Bone 1999; 25:11S-15S.

1249. Oakley J, Prager J. Spinal cord stimulation: Mechanism of action. Spine 2002; 22:2574-2583.

1250. Turner JA, Loeser JD, Bell KG. Spinal cord stimulation for chronic low back pain. A systematic literature synthesis. Neurosurgery 1995; 37:1088-1096.

1251. Taylor RS. Spinal cord stimulation in complex regional pain syndrome and refractory neuropathic back and leg pain/ failed back surgery syndrome: results of a systematic review and meta-analysis. J Pain Symptom Manage 2006; 31: S13-S19.

1252. Taylor RS, Van Buyten JP, Buchser E. Spinal cord stimulation for complex regional pain syndrome: a systematic review of the clinical and cost-effectiveness literature and assessment of prog. nostic factors. Eur J Pain 2006; 10:91101.

1253. Cameron T. Safety and efficacy of spinal cord stimulation for the treatment of chronic pain: A 20-year literature review. J Neurosurg 2004; 100:S254-S67.

1254. Taylor RS, Taylor RJ, Van Buyten JP, Buchser E, North R, Bayliss S. The cost effectiveness of spinal cord stimulation in the treatment of pain: a systematic review of the literature. I Pain Symptom Manage 2004; 27:370-378.

1255. North RB, Kidd DH, Lee MS, Piantadosi S. Spinal cord stimulation versus reoperation for the failed back surgery syndrome: A prospective, randomized study design. Stereotact Funct Neurosurg 1994; 62:267-272.

1256. Raphael JH, Southall JL, Gnanadurai TV, Treharne GJ, Kitas GD. Multiple lead spinal cord stimulation for chronic mechanical low back pain: a comparative study with intrathecal opioid drug delivery. Neuromodulation 2004; 7:260266.

1257. Kemler MA, Barendse GA, van Kleef $M$, de Vet HC, Rijks CP, Furnee CA, van den Wildenberg FA. Spinal cord stimulation in patients with chronic reflex sympathetic dystrophy. N Engl J Med 2000; 343:618-624.

1258. Kemler M, Furnee C. Economic evaluation of spinal cord stimulation for chronic reflex sympathetic dystrophy. Neurology 2002; 59:1203-1209.

1259. North RB, Kidd DH, Farrokhi F, Piantadosi SA. Spinal cord stimulation versus repeated lumbosacral spine surgery for chronic pain: A randomized, controlled trial. Neurosurgery 2005; 56:98-107.

1260. Burchiel KJ, Anderson VC, Brown FD, Fessler RG, Friedman WA, Pelofsky S, Weiner RL, Oakley J, Shatin D. Prospective: Multicenter study of spinal cord stimulation for relief of chronic back and extremity pain. Spine 1996; 21:2786-2794.

1261. Barolat G, Oakley JC, Law JD, North RB, Ketcik B, Sharan A. Epidural spinal cord stimulation with a multiple electrode paddle lead is effective in treating low back pain. Neuromodulation 2001; 4:59-66.

1262. Oakley JC, Espinoso F, Bothe H, McKean J, Allen P, Burchiel K, Quartery G, Spincemaille G, Nuttin B, Gielen F, King G, Holsheimer J. Transvere tripolar spinal cord stimulation: Results of an international multi-center study. Neuromodulation 2006; 9:192-203.

1263. Harke H, Gretenkort P, Ladleif HU, Rahman S. Spinal cord stimulation in sympathetically maintained complex regional pain syndrome type I with severe disability. A prospective clinical study. Eur J Pain 2005; 9:363-373.

1264. Harke H, Gretenkort P, Ladleif HU, Koester P, Rahman S. Spinal cord stimulation in postherpetic neuralgia and in acute herpes zoster pain. Anesth Analg 2002; 94:694-700.

1265. Comiter CV. Sacral neuromodulation for the symptomatic treatment of refractory interstitial cystitis: A prospective study. J Urol 2003; 169:1369-1373.

1266. Kemler MA, Barendse GA, Van Kleef M, Van Den Wildenberg FA, Weber WE. 
Electrical spinal cord stimulation in reflex sympathetic dystrophy: retrospective analysis of 23 patients. J Neurosurg 1999; 90(1 Suppl):79-83.

1267. Bennett DS, Alo KM, Oakley J, Feler CA. Spinal cord stimulation for complex regional pain syndrome I (RSD): A retrospective multi-center experience from 1995-1998 of 101 patients. Neuromodulation 1999; 2:202-210.

1268. Calvillo O, Racz G, Didie J, Smith K. Neuroaugmentation in the treatment of complex regional pain syndrome of the upper extremity. Acta Orthop Belg 1998; 64:57-63.

1269. Dario A, Fortini G, Bertoloo D, Bacuzzi A, Girzzetti C, Cuffari S. Treatment of failed back surgery syndrome. Neuromodulation 2001; 4:105-110.

1270. North RB, Ewend MG, Lawton MT, Kidd $\mathrm{DH}$, Piantadosi S. Failed back surgery syndrome: 5-year follow-up after spinal cord stimulator implantation. Neurosurgery 1991; 28:692-699.

1271. Villavicencio AT, Leveque JC, Rubin L, Bulsara K, Gorecki JP. Laminectomy versus percutaneous electrode placement for spinal cord stimulation. Neurosurgery 2000; 46:399-405.

1272. Quigley DG, Arnold J, Eldridge PR. Longterm outcome of spinal cord stimulation and hardware complications. Stereotact Funct Neurosurg 2003; 81:50-56.

1273. Chandler GS III, Nixon B, Stewart LT, Love J. Dorsal column stimulation for lumbar spinal stenosis. Pain Physician 2003; 6:113-118.

1274. Alo KM, Redko V, Charnov J. Four year follow up of dual electrode spinal cord stimulation for chronic pain. Neuromodulation 2002; 5:79-88.

1275. North RB, Kidd DH, Zahurak M, James CS, Long DM. Spinal cord stimulation for chronic, intractable pain: experience over two decades. Neurosurgery 1993; 32:384-394.

1276. Kumar K, Hunter G, Demeria D. Spinal cord stimulation in treatment of chronic benign pain: challenges in treatment planning and present status, a 22year experience. Neurosurgery 2006; 58:481-496.

1277. Heidecke V, Rainov NG, Burkert W. Hardware failures in spinal cord stimulation for failed back surgery syndrome. Neuromodulation 2000; 3:27-30.

1278. Bennett G, Burchiel K, Buchser E, Classen A, Deer T, Du Pen S, Ferrante FM, Hassenbusch SJ, Lou L, Maeyaert J, Penn R, Portenoy RK, Rauck R, Serafini M, Willis KD, Yaksh T. Clinical guide- lines for intraspinal infusion: Report of an expert panel. J Pain Symptom Manage 2000; 20:S37-S43.

1279. Walker SM, Goudas LC, Cousins MJ, Carr DB. Combination spinal analgesic chemotherapy: A systematic review. Anesth Analg 2002; 95:674-715.

1280. Anderson VC, Burchiel KJ. A prospective study of long-term intrathecal morphine in the management of chronic nonmalignant pain. Neurosurgery 1999; 44:289-301.

1281. Kumar K, Kelly M, Pirlot T. Continuous intrathecal morphine treatment for chronic pain of nonmalignant etiology: Long-term benefits and efficacy. Surg Neurol 2001; 55:79-88.

1282. Rainov NG, Heidecke V, Burkert W. Long-term intrathecal infusion of drug combinations for chronic back and leg pain. J Pain Symptom Manage 2001; 22:862-871.

1283. Kumar K, Hunter G, Demeria DD. Treat ment of chronic pain by using intrathecal drug therapy compared with conventional pain therapies: A cost effectiveness analysis. J Neurosurg 2002; 97:803-810.

1284. Anderson VC, Burchiel KJ, Cooke B. A prospective, randomized trial of intrathecal injection vs. epidural infusion in the selection of patients for continuous intrathecal opioid therapy. Neuromodulation 2003; 6:142-152.

1285. Deer T, Chapple I, Classen A, Javery K, Stoker V, Tonder L, Burchiel K. Intrathecal drug delivery for treatment of chronic low back pain: Report from the $\mathrm{Na}$ tional Outcomes Registry for Low Back Pain. Pain Med 2004; 5:6-13

1286. Hassenbusch SJ, Portenoy RK, Cousins $M$, Buchser E, Deer TR, Du Pen SL, Eisenach J, Follett KA, Hildebrand KR, Krames ES, Levy RM, Palmer PP, Rathmell JP, Rauck RL, Staats PS, Stearns L, Willis KD. Polyanalgesic consensus conference 2003: an update on the management of pain by intraspinal drug delivery - report of an expert panel. J Pain Symptom Manage 2004; 27:540-563.

1287. Siddall PJ, Molloy AR, Walker S, Mather LE, Rutkowski SB, Cousins MJ The efficacy of intrathecal morphine and clonidine in the treatment of pain after spinal cord injury. Anesth Analg 2000; 91:1493-1498.

1288. van Hilten BJ, van de Beek WJ, Hoff JI, Voormolen JH, Delhaas EM. Intrathecal baclofen for the treatment of dystonia in patients with reflex sympathetic dystrophy. N Engl J Med 2000; 343:654656.
1289. Smith TJ, Staats PS, Deer T, Stearns LJ, Rauck RL, Boortz-Marx RL, Buchser E, Catala E, Bryce DA, Coyne PJ, Pool GE; Implantable Drug Delivery Systems Study Group. Randomized clinical trial of an implantable drug delivery system compared with comprehensive medical management for refractory cancer pain: impact on pain, drug-related toxicity, and survival. J Clin Oncol 2002; 20:4040-4049.

1290. Staats PS, Yearwood T, Charapata SG, Presley RW, Wallace MS, Byas-Smith M, Fisher R, Bryce DA, Mangieri EA, Luther RR, Mayo M, McGuire D, Ellis D. Intrathecal ziconotide in the treatment of refractory pain in patients with cancer or AIDS: A randomized controlled trial. JAMA 2004; 291:63-70.

1291. Hassenbusch SJ, Stanton-Hicks M, Covington EC, Walsh JG, Guthrey DS. Longterm intraspinal infusions in the treatment of neuropathic pain. J Pain Symptom Manage 1995; 10:527-543.

1292. Angel IF, Gould HJ Jr., Carey ME. Intrathecal morphine pump as a treatment option in chronic pain of nonmalignant origin. Surg Neurol 1998; 49:92-99.

1293. Corrado P, Gottlieb H, Varga CA. The effect of intrathecal morphine infusion on pain level and disability in pain patients with chronic intractable low back pain. AJPM 2000; 10:160-166.

1294. Onofrio BM, Yaksh TL. Long-term pain relief produced by intrathecal infusion in 53 patients. J Neurosurg 1990; 72:200-209.

1295. Paice JA, Penn RD, Shott S. Intraspinal morphine for chronic pain: A retrospective, multicenter study. J Pain Symptom Manage 1996; 11:71-80.

1296. Winkelmüller $M$, Winkelmüller W. Long-term effects of continuous intrathecal opioid treatment in chronic pain of nonmalignant etiology. I Neurosurg 1996; 85:458-467.

1297. Roberts LJ, Finch PM, Goucke CR, Price LM. Outcome of intrathecal opioids in chronic non-cancer pain. Eur J Pain 2001; 5:353-361.

1298. Burton AW, Rajagopal A, Shah HN, Mendoza T, Cleeland C, Hassenbusch SJ 3rd, Arens JF. Epidural and intrathecal analgesia is effective in treating refractory cancer pain. Pain Med 2004; 5:239247.

1299. Mueller-Schwefe G, Hassenbusch SJ, Reig E. Cost-effectiveness of intrathecal therapy for pain. Neuromodulation 1999; 2:77-84.

1300. Tutak U, Doleys DM. Intrathecal infu- 
sion systems for treatment of chronic low back and leg pain of noncancer origin. South Med J 1996; 89: 295-300.

1301. Willis KD, Doleys DM. The effects of long-term intraspinal infusion therapy with noncancer pain patients: Evaluation of patient, significant-other, and clinic staff appraisals. Neuromodulation 1999; 2: 241-253.

1302. Manchikanti L. Documentation for evaluation and management services. Principles of Documentation, Billing, Coding \& Practice Management for the Interventional Pain Professional. ASIPP Publishing, Paducah KY 2004; pp 3146.

1303. 1995 Documentation Guidelines for Evaluation and Management Services. Centers for Medicare \& Medicaid Services. http://www.cms.hhs.gov/MLNProducts/Downloads/1995dg.pdf

1304. 1997 Documentation Guidelines for Evaluation and Management Services. Centers for Medicare \& Medicaid Services. http://www.cms.hhs.gov/MLNProducts/Downloads/MASTER1.pdf

1305. Evaluation \& Management Services Guide, Revised July 2006. Centers for Medicare \& Medicaid Services. http:// www.cms.hhs.gov/MLNProducts/ downloads/eval_mgmt_serv_guide.pdf

1306. Consultations in Medicare: Coding and Reimbursement. March 2006. Centers for Medicare \& Medicaid Services. http://www.oig.hhs.gov/oei/reports/ oei-09-02-00030.pdf

1307. Current Procedural Terminology. CPT 2007, American Medical Association, Chicago, 2006.

1308. Mikhail GR, Sweet LC, Mellinger RC. Parenteral long-acting corticosteroid effect on hypothalamic pituitary adrenal function. Ann Allergy 1973; 31:337343.

1309. Mikhail GR, Livingood CS, Mellinger RC, Paige TN, Salyer HL. Effect of longacting parenteral corticosteroids on adrenal function. Arch Dermatol 1969; 100:263-268.

1310. Melby JC. Drug spotlight program: Systemic corticosteroid therapy; pharmacologic and endocrinologic considerations. Ann Intern Med 1974; 81:505512.
1311. Schimmer BP, Parker KL. Adrenocorticotropic hormone; adrenocortical steroids and their synthetic analogs; inhibitors of the synthesis and actions of adrenocortical hormones. In Harman JG, Molinoff PB, Ruddon RW (eds). Goodman's \& Gilman's, The Pharmacological Basis of Therapeutics, Ninth Edition, McGrawHill, New York, 1996; pp 1459-1485.

1312. McEvoy GK, Litvak K, Welsh OH. Adrenals. AHFS 99 drug information. American Society of Health-System Pharmacists, Bethesda, 1999; pp 2636-2662.

1313. Boonen S, Van Distel G, Westhovens R, Dequeker J. Steroid myopathy induced by epidural triamcinolone injection. Brit J Rheumatol 1995; 34:385-386.

1314. Maillefert JF, Aho S, Huguenin MC, Chatard C, Peere T, Marquignon MF, Lucas $B$, Tavernier C. Systemic effects of epidural dexamethasone injections. Revue du Rhumatisme 1995; 62:429-432.

1315. Ward A, Watson J, Wood P, Dunne C, Kerr D. Glucocorticoid epidural for sciatica: Metabolic and endocrine sequelae. Rheumatology 2002; 41:68-71.

1316. Shishido H, Kikuchi S, Heckman H, Myers RR. Dexamethasone decreases blood flow in normal nerves and dorsal root ganglia. Spine 2002; 27:581-586.

1317. Mace S, Vadas P, Pruzanski W. Anaphylactic shock induced by intraarticular injection of methylprednisolone acetate. J Rheumatol 1997; 24:1191-1194.

1318. Weissman DE, Dufer D, Vogel V, Abeloff MD. Corticosteroid toxicity in neurooncology patients. J Neurooncol 1987; 5:125-128.

1319. Delaney TJ, Rowlingson JC, Carron H, Butler A. Epidural steroid effects on nerves and meninges. Anesth Analg 1980; 58:610-614.

1320. Mackinnon SE, Hudson AR, Gentili F, Kline DG, Hunter D. Peripheral nerve injection injury with steroid agents. Plast Reconstr Surg 1982; 69:482-489.

1321. Chino N, Awad EA, Kottke FJ. Pathology of propylene glycol administered by perineural and intramuscular injection in rats. Arch Phys Med Rehab 1974; 55:33-38.

1322. Benzon HT, Gissen AJ, Strichartz GR, Avram MJ, Covino BG. The effect of polyethylene glycol on mammalian nerve impulses. Anesth Analg 1987; 66:553559.

1323. Abram SE, Marsala M, Yaksh TL. Analgesic and neurotoxic effects of intrathecal corticosteroids in rats. Anesthesiology 1994; 81:1198-1205.

1324. Latham JM, Fraser RD, Moore RJ, Blumbergs PC, Bogduk N. The pathologic effects of intrathecal betamethasone. Spine 1997; 22:1558-1562.

1325. Robustelli della Cuna FS, Mella M, Magistrali $G$, Ricci $M$, Losurdo A, Goglio AM. Stability and compatibility of methylprednisolone acetate and ropivacaine hydrochloride in polypropylene syringes for epidural administration. Am J Health Syst Pharm 2001; 58:1753-1756.

1326. Swai EA, Rosen M. An attempt to develop a model to study the effects of intrathecal steroids. Eur J Anaesthesiol 1986; 3:127-136.

1327. Dunbar SA, Manikantan P, Philip J. Epidural infusion pressure in degenerative spinal disease before and after epidural steroid therapy. Anesth Analg 2002; 94:417-420.

1328. Slucky AV, Sacks MS, Pallares VS, Malinin TI, Eismont FJ. Effects of epidural steroids on lumbar dura material properties. J Spin Disord 1999; 12:331-340.

1329. Stanczak J, Blankenbaker DG, De Smet AA, Fine J. Efficacy of epidural injections of Kenalog and Celestone in the treatment of lower back pain. AJR Am J Roentgenol 2003; 181:1255-1258.

1330. Noe CE, Haynsworth RF Jr. Comparison of epidural depo-medrol vs. aqueous betamethasone in patients with low back pain. Pain Pract 2003; 3:222-225.

1331. Adminastar Federal Paravertebral Facet Joint Nerve Block (Diagnostic or Therapeutic) Policy. LCD Database ID Number L7848. Effective Date 09/20/2005.

1332. Adminastar Federal Paravertebral Facet Nerve Denervation Policy. LCD Database ID Number L8527. Effective Date 09/20/2005.

1333. Adminastar Federal Epidural Injections: Transforaminal Policy. LCD Database ID Number L17911.

1334. Adminastar Federal Epidural and Intrathecal Injections: Interlaminar or Caudal Policy. LCD Database ID Number L17912. Effective Date 09/20/2004. 